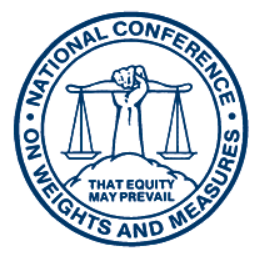

\title{
NGT
}

National Institute of

Standards and Technology

U.S. Department of Commerce

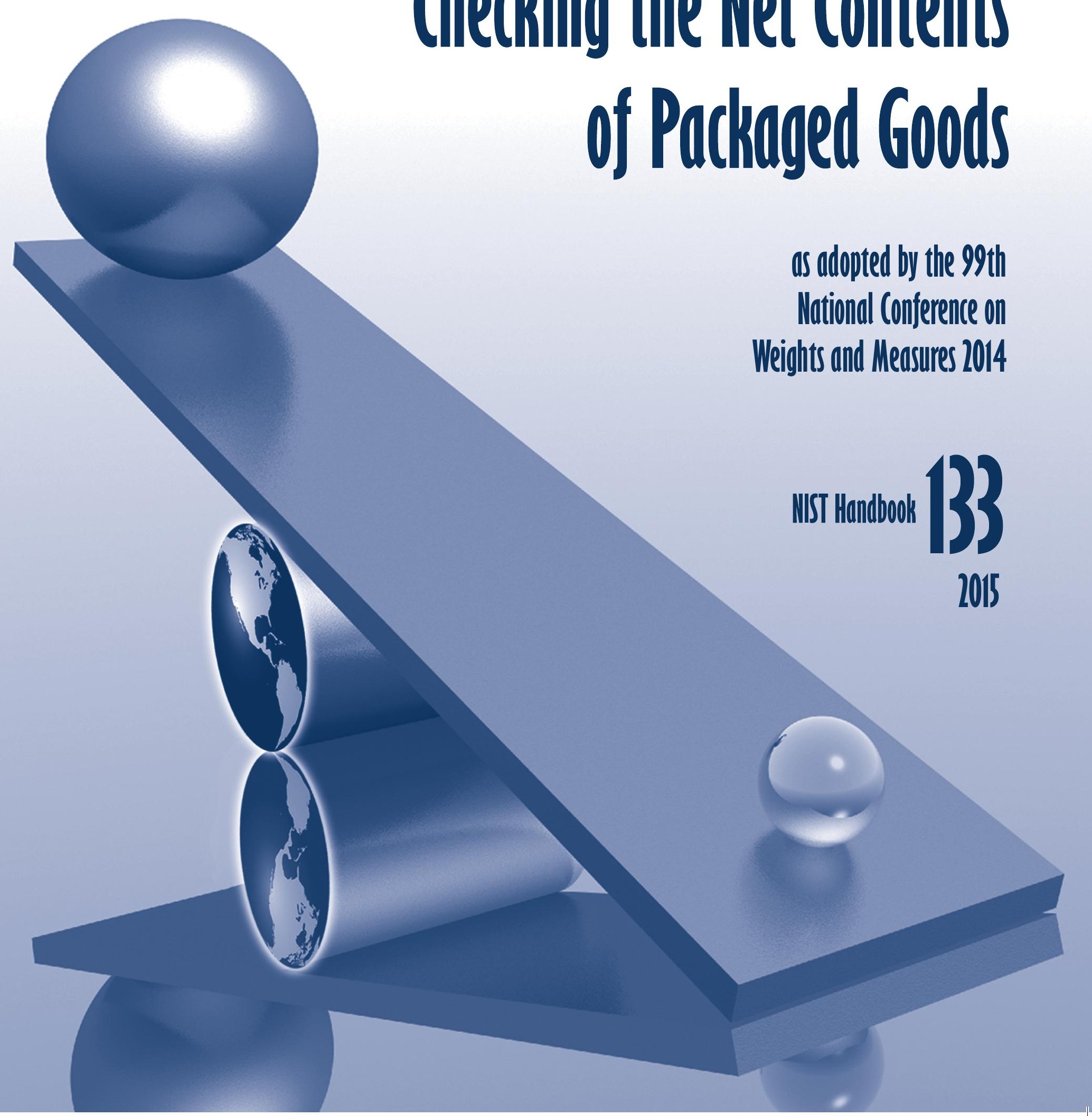

Checking the Net Contents of Packaged Goods

as adopted by the 99th National Conference on Weights and Measures 2014

2015 
INSIDE FRONT COVER -INTENTIONALLY LEFT BLANK 


\section{Checking the Net Contents of Packaged Goods}

as adopted by the 99 $9^{\text {th }}$ National Conference on Weights and Measures 2014

Editors:

Linda Crown

David Sefcik

Lisa Warfield

Carol Hockert, Chief Office of Weights and Measures Physical Measurement Laboratory

http:/ / dx.doi.org/10.6028.NIST.HB.133

November 2014

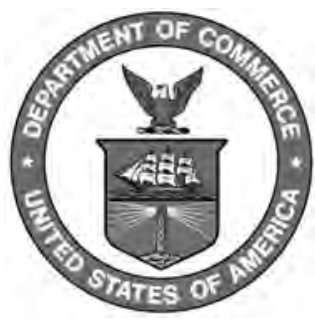

U.S. Department of Commerce Penny Pritzker, Secretary

National Institute of Standards and Technology

Willie May, Acting Under Secretary of Commerce for Standards and Technology and Acting Director

NIST Handbook 133

2015 Edition

Supersedes NIST Handbook 133, 2014 Edition 
Certain commercial entities, equipment, or materials may be identified in this document in order to describe an experimental procedure or concept adequately. Such identification is not intended to imply recommendation or endorsement by the National Institute of Standards and Technology, nor is it intended to imply that the entities, materials, or equipment are necessarily the best available for the purpose.

National Institute of Standards and Technology Handbook 133, 2015 Edition Natl. Inst. Stand.

Technol. Handb. 133, 2015 Ed. 190 Pages (Nov. 2014)

CODEN: NIHAE2

\section{U.S. GOVERNMENT PRINTING OFFICE WASHINGTON: 2014}

Internet: bookstore.gpo.gov Phone: toll free (866) 512-1800; DC area (202) 512-1800 Fax: (202) 512-2250 Mail: Stop SSOP, Washington, DC 20402-0001 ISBN 0-16-051249-2 


\section{Foreword}

This handbook has been prepared as a procedural guide for the compliance testing of net content statements on packaged goods. Compliance testing of packaged goods is the determination of the conformance of the results of the packaging, distribution, and retailing process (the packages) to specific legal requirements for net content declarations. This handbook has been developed primarily for the use of government officials. However, it should also be useful to commercial and industrial establishments in the areas of packaging, distribution, and sale of commodities.

In conducting compliance testing, the conversion of quantity values from one measurement system to another (e.g., from the metric system to the avoirdupois system) should be handled with careful regard to the implied correspondence between the accuracy of the data and the number of digits displayed. In all conversions, the number of significant digits retained should ensure that accuracy is neither sacrificed nor exaggerated. For this 2015 edition of Handbook 133 all dimensions for test procedures, devices, or environments have been rounded to two significant digits (e.g., $2.5 \mathrm{~cm}$ to $1.0 \mathrm{in}$ ) or to a precision level applicable to the test equipment (e.g., $200 \mathrm{kPa}$ for $25 \mathrm{psi}$ and $35 \mathrm{MPa}$ for 5,000 psi).

You are invited to provide online feedback regarding this document at: https://www.surveymonkey.com/s/customer-satisfaction-pub or by e-mail to: owm@nist.gov. 


\title{
Committee Members
}

\section{Committee on Laws and Regulations of the National Conference on Weights and Measures}

\author{
Raymond Johnson, New Mexico \\ John Albert, Missouri \\ Tim Lloyd, Montana \\ Richard Lewis, Georgia \\ Louis Sakin, Towns of Hopkinton/Northbridge, Massachusetts \\ Associate Membership Committee Representative: Steve Grabski, Walmart \\ Packaging and Labeling Subcommittee: Christopher Guay, Procter and Gamble \\ Canadian Technical Advisor: Lance Robertson, Measurement Canada \\ NIST Technical Advisors: Lisa Warfield, David Sefcik
}




\section{Past Chairmen of the Committee}

\section{Conference}

41

42

43

44

45

46

47

48

49

50

51

52

53

54

55

56

57

58

59

60

61

62

63

64

65

66

67

68

69

\section{Chairman}

G. H. Leithauser, MD

F. M. Greene, CT

F. M. Greene, CT

G. L. Johnson, KY

R. Williams, NY

J. H. Lewis, WA

J. H. Lewis, WA

J. H. Lewis, WA

J. H. Lewis, WA

L. Barker, WV

L. Barker, WV

M. Jennings, TN

W. A. Kerlin, CA

J. F. Lyles, VA

J. F. Lyles, VA

S. D. Andrews, FL

S. D. Andrews, FL

S. D. Andrews, FL

R. M. Leach, MI

R. L. Thompson, MD

C. H. Vincent, Dallas, TX

C. H. Vincent, Dallas, TX

J. T. Bennett, CT

R. W. Probst, WI

D. I. Offner, MO

J. J. Bartfai, NY

J. J. Bartfai, NY

J. J. Bartfai, NY

W. R. Mossberg, CA

\section{Conference Chairman}

70

71

72

73

74

75

76

77

78

79

80

81

82

83

84

85

86

87

88

89

90

91

92

93

94

95

96

97

98
E. Skluzacek, MN

D. Stagg, $A L$

A. Nelson, CT

K. Simila, OR

K. Simila, OR

S. B. Colbrook, IL

A. Nelson, CT

B. Bloch, CA

F. Clem, $\mathrm{OH}$

B. Bloch, CA

S. Rhoades, AZ

L. Straub, MD

S. Millay, ME

K. Angell, WV

K. Angell, WV

S. Morrison, CA

R. Williams, TN

P. D’Errico, NJ

D. Johannes, CA

D. Johannes, CA

J. Gomez, NM

J. Benavides, TX

J. Cassidy, MA

Vicky Dempsey, $\mathrm{OH}$

Joe Gomez, NM

Joe Benavides, TX

John Gaccione, NY

Judy Cardin, WI

Judy Cardin, WI 


\section{Table of Acronyms}

\begin{tabular}{|c|c|}
\hline Acronym & Term \\
\hline AMAV & Adjusted Maximum Allowable Variation \\
\hline ANGW & Adjusted Nominal Gross Weight \\
\hline AOSA & Association of Official Seed Analysts \\
\hline ASEL & Adjusted Sample Error Limit \\
\hline ASTM & American Society for Testing Materials International \\
\hline CFR & Code of Federal Regulations \\
\hline CGA & Compressed Gas Association \\
\hline EPA & Environmental Protection Agency \\
\hline FDA & Food and Drug Administration \\
\hline FDCA & Food, Drug and Cosmetic Act \\
\hline FPLA & Fair Packaging and Labeling Act \\
\hline FSIS & Food Safety and Inspection Service of the USDA \\
\hline FTC & Federal Trade Commission \\
\hline HB 130 & $\begin{array}{l}\text { NIST Handbook 130, Uniform Laws and Regulations in the areas } \\
\text { of Legal Metrology and Engine Fuel Quality }\end{array}$ \\
\hline HB 133 & $\begin{array}{l}\text { NIST Handbook 133, Checking the Net Contents of Packaged } \\
\text { Goods }\end{array}$ \\
\hline HB 44 & $\begin{array}{l}\text { NIST Handbook 44, Specifications, Tolerances, and Other } \\
\text { Technical Requirements for Weighing and Measuring Devices }\end{array}$ \\
\hline LNQC & Labeled Net Quantity of Content \\
\hline MA & Moisture Allowance \\
\hline MAV & Maximum Allowable Variation \\
\hline MSDS & Material Safety Data Sheets \\
\hline NGW & Nominal Gross Weight \\
\hline NIST & National Institute of Standards and Technology \\
\hline UME & Unreasonable Minus Errors \\
\hline SEL & Sample Error Limit \\
\hline TTB & Alcohol and Tobacco Tax and Trade Bureau \\
\hline UPLR & Uniform Packaging and Labeling Regulation \\
\hline USDA & U.S. Department of Agriculture \\
\hline
\end{tabular}




\section{Table of Content}

Use the bookmark pane for navigation with in this document.

Page

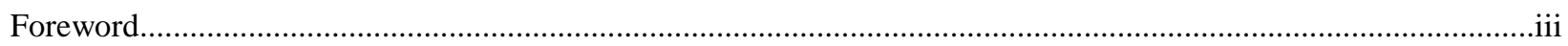

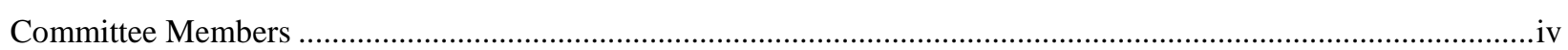

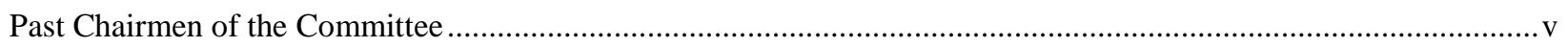

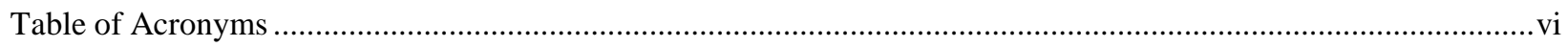

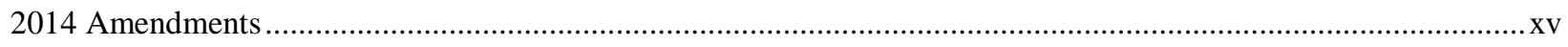

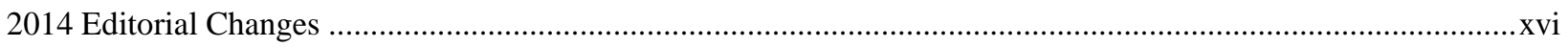

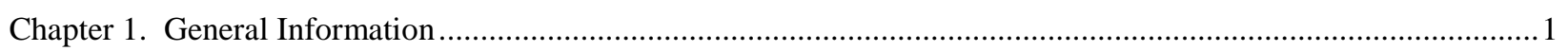

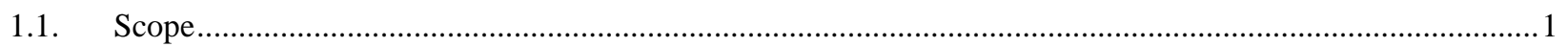

1.1.1. When and Where to Use Package Checking Procedures.............................................................

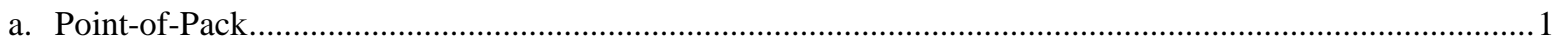

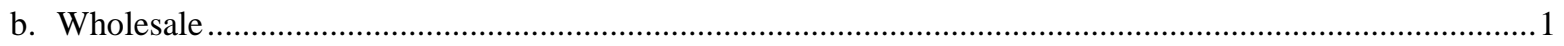

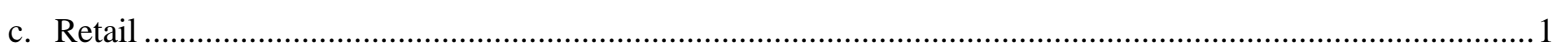

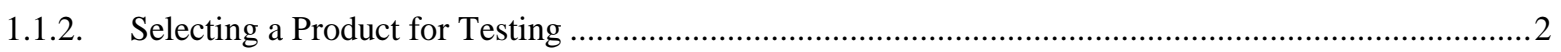

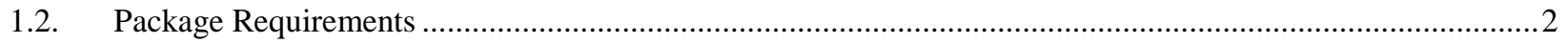

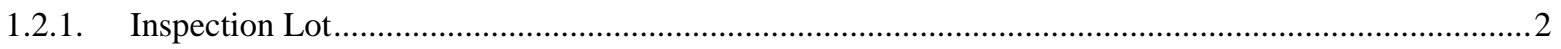

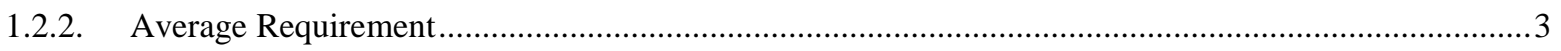

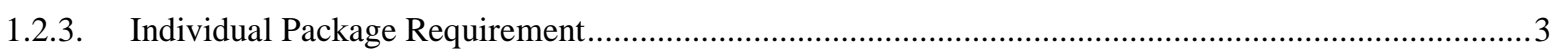

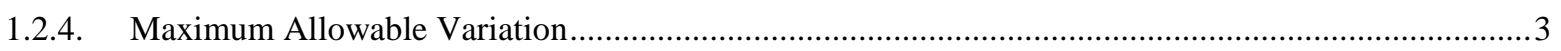

1.2.5. Exceptions to the Average and Individual Package Requirements ................................................

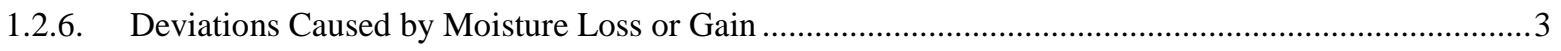

1.2.6.1. Applying a Moisture Allowance ....................................................................................4

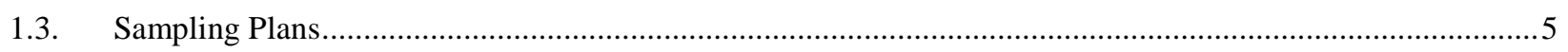

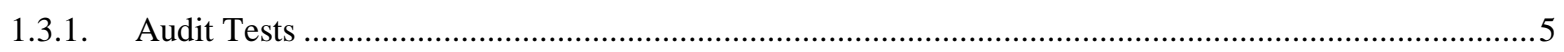

1.4. Other Regulatory Agencies Responsible for Package Regulations and Applicable Requirements..................5

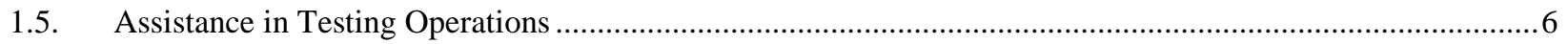

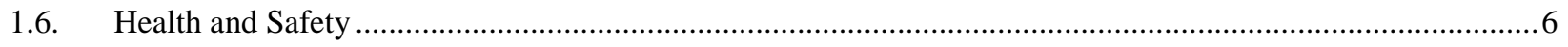

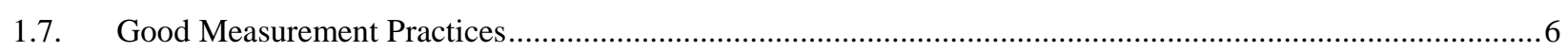

1.7.1. Traceability Requirements for Measurement Standards and Test Equipment.....................................6

1.7.2. Certification Requirements for Standards and Test Equipment ..................................................

Chapter 2. Test Procedures for Packages Labeled by Weight - Gravimetric Testing ...........................................9 


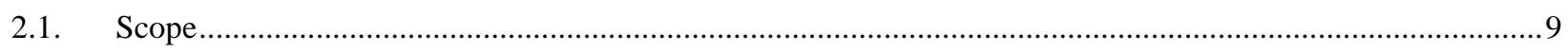

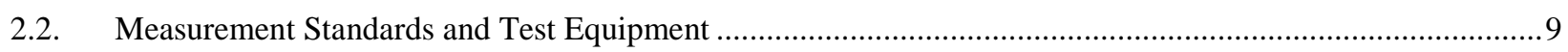

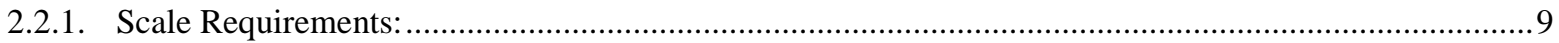

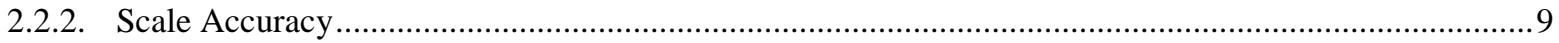

2.2.3. Scale Tolerance ....................................................................................................................... 10

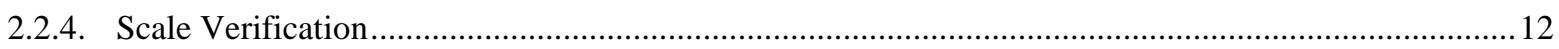

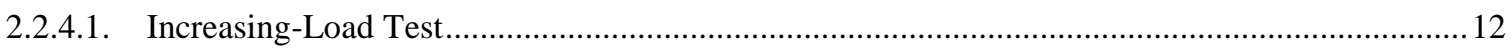

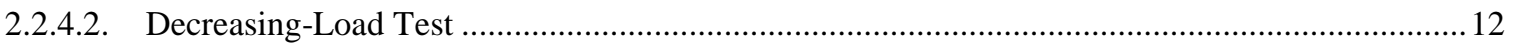

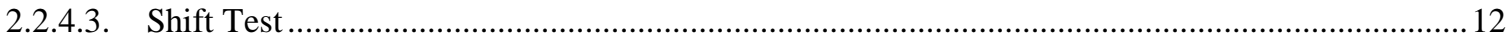

2.2.4.4. Return to Zero ........................................................................................................................ 13

2.2.5. Other Test Equipment Requirements ...............................................................................................13

2.3. Basic Test Procedure for Gravimetric Testing of Net Weight ....................................................................13

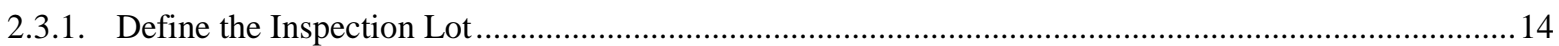

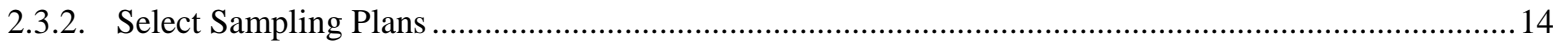

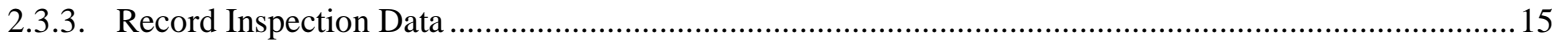

2.3.3.1. Procedure for Recording Data ............................................................................................15

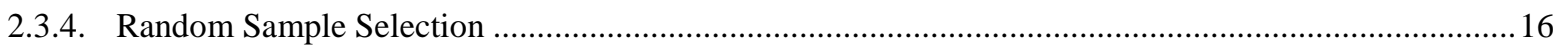

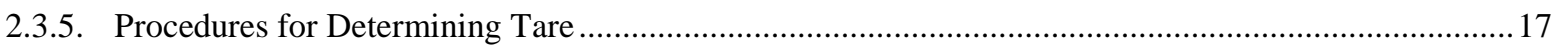

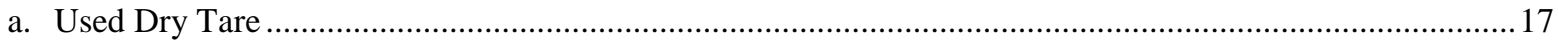

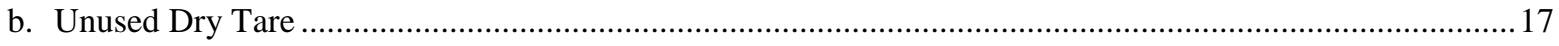

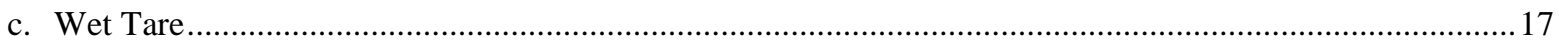

2.3.5.1. Determination of Tare Sample and Average Tare Weight .........................................................18

2.3.5.2. Special Procedures for Determining Tare ………................................................................19

a. Aerosol Containers ..................................................................................................................... 19

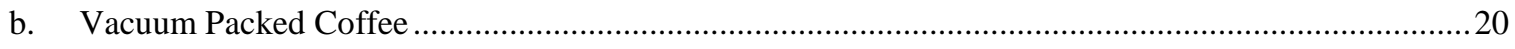

2.3.6. Determine Nominal Gross Weight and Package Error.......................................................................20

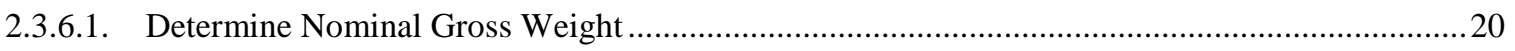

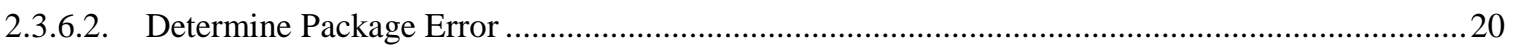

2.3.6.3. Compute Total Package Error …………………........................................................................21

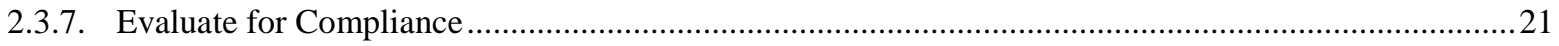

2.3.7.1. Maximum Allowable Variation (MAV) Requirement: ................................................................21

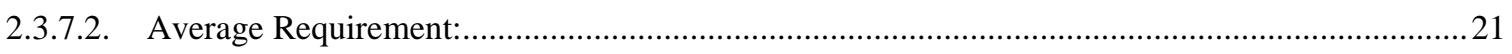

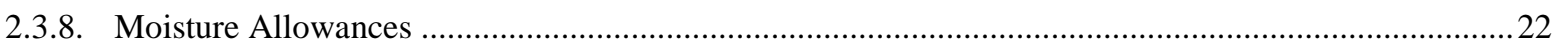

2.3.8.1. Applying Moisture Loss before Determining Package Errors .......................................................22

2.3.8.2. Applying Moisture Allowance after Determining Package Errors................................................25

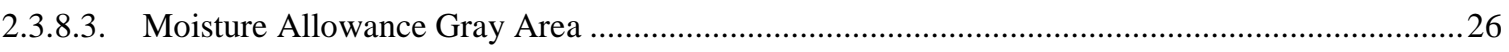

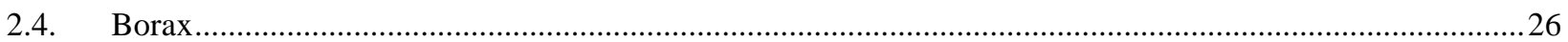




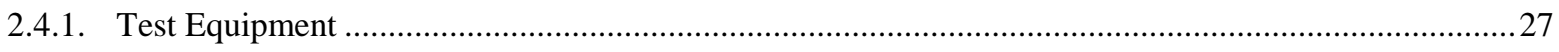

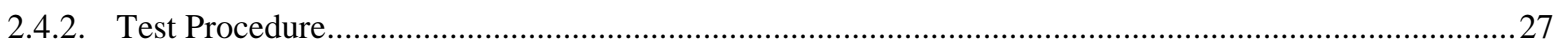

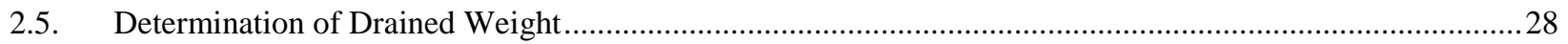

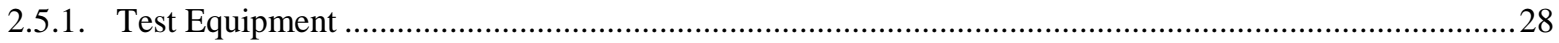

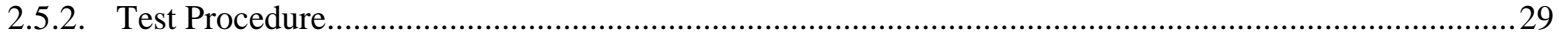

2.6. Net Weight of Encased-in-Ice and Ice Glazed Products ...............................................................................29

2.6.1. Net Weight of Encased in Ice and Frozen Block Product ..................................................................29

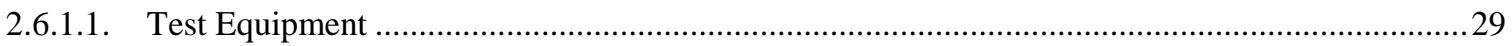

2.6.1.2. Test Procedure for Encased-in-Ice Product Only ........................................................................ 30

2.6.2. Net Weight of Ice Glazed Seafood, Meat, Poultry or Similar Products ..................................................31

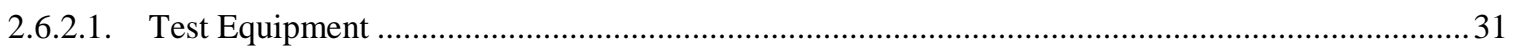

2.6.2.2. Test Procedures for Ice-Glazed Product Only ……................................................................... 31

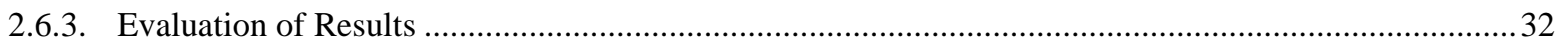

Chapter 3. Test Procedures - For Packages Labeled by Volume ……............................................................................33

3.1. Scope

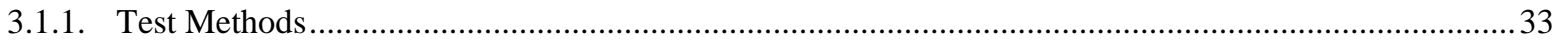

3.2. Gravimetric Test Procedure for Non-Viscous Liquids......................................................................... 34

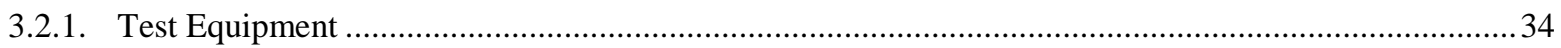

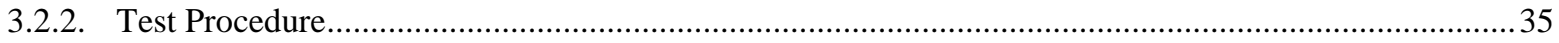

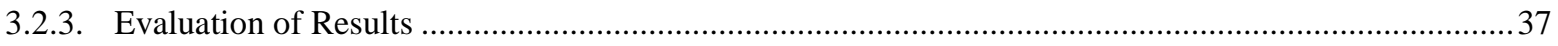

3.3. Volumetric Test Procedure for Non-Viscous Liquids...................................................................................

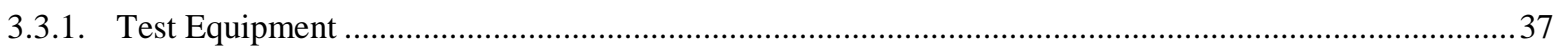

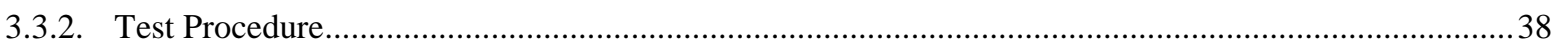

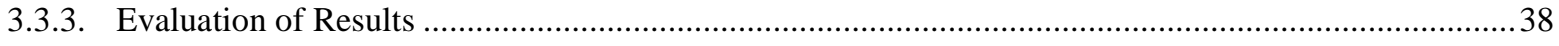

3.4. Volumetric Test Procedures for Viscous Fluids - Headspace ……...........................................................38

3.4.1. Test Equipment ....................................................................................................................

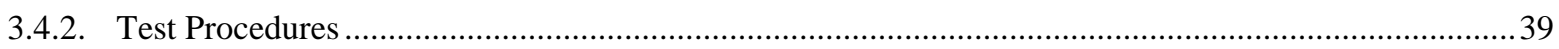

a. Test Procedure for Testing Oils, Syrups, and other Viscous Liquids with a Smooth and Level

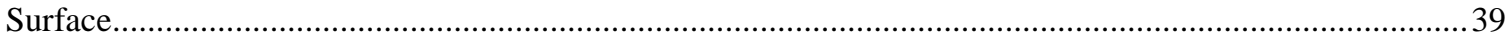

b. Test Procedure for Testing Mayonnaise, Salad Dressing, and Water Immiscible Products with

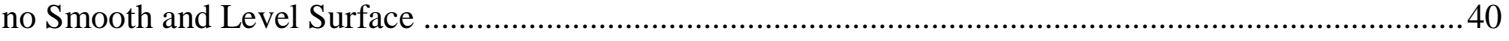

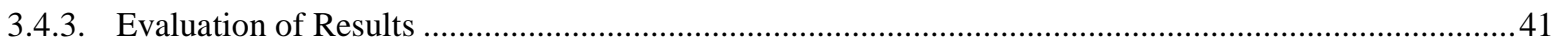

3.5. Goods Labeled by Capacity - Volumetric Test Procedure ….....................................................................41 


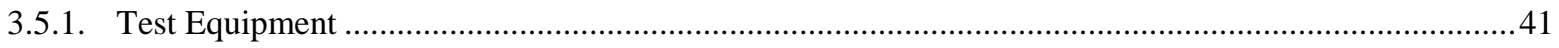

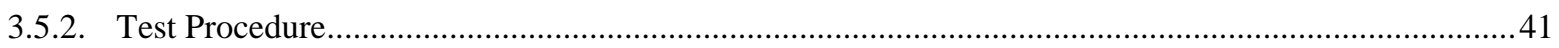

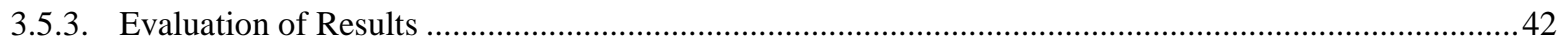

3.6. Pressed and Blown Glass Tumblers and Stemware ……........................................................................42

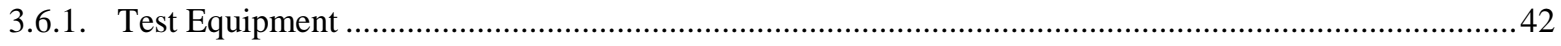

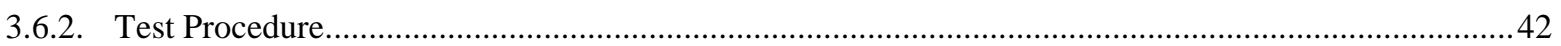

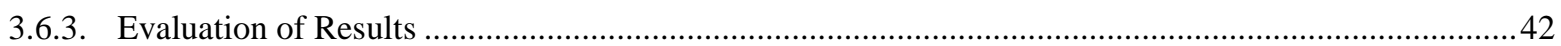

3.7. Volumetric Test Procedure for Paint, Varnish, and Lacquers - Non-aerosol ................................................43

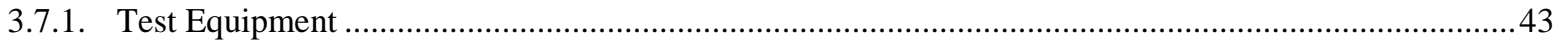

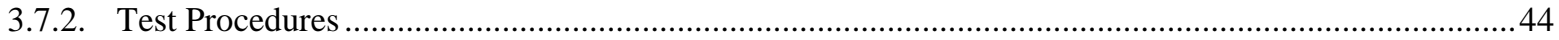

a. Field (Retail) Auditing Procedure ………………................................................................................. 44

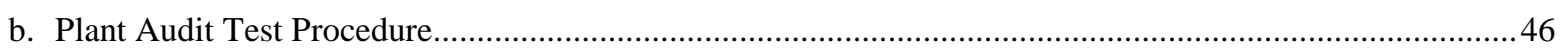

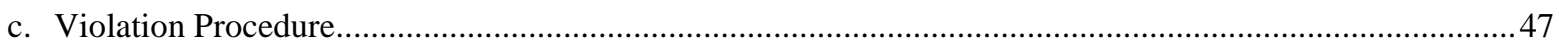

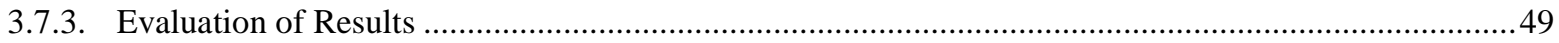

3.8. Testing Viscous Materials - Such As Caulking Compounds and Pastes ....................................................49

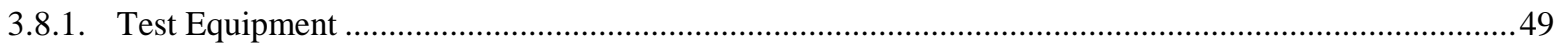

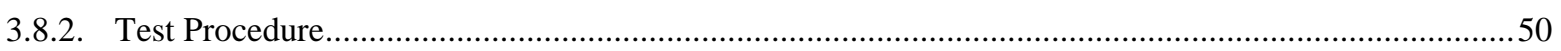

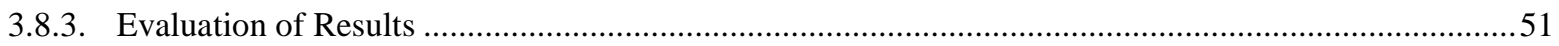

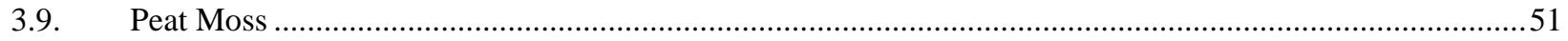

3.9.1. Compressed Volume Packages ……………........................................................................................51

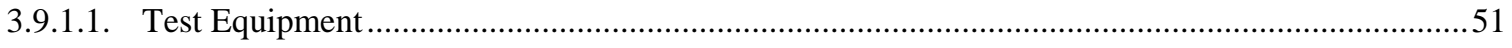

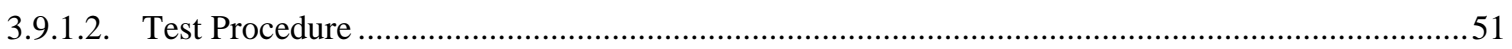

3.9.2. Uncompressed Volume Packages .................................................................................................... 52

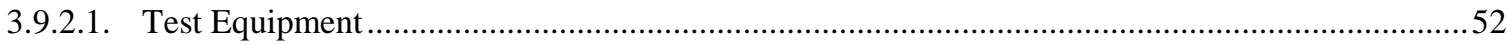

3.9.2.2. Test Procedure …………………................................................................................................ 52

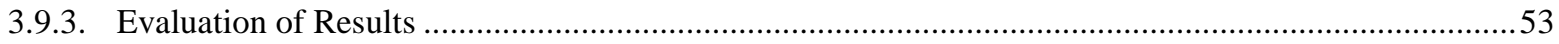

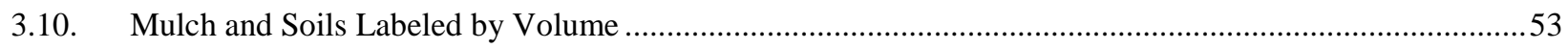

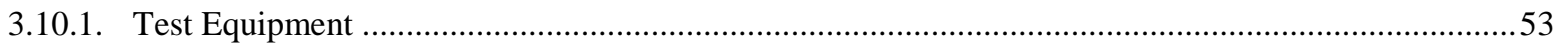

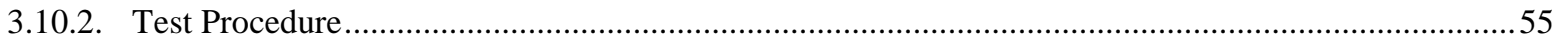

3.10.3. Evaluation of Results.................................................................................................................... 55

3.11. Ice Cream Novelties ..........................................................................................................................5

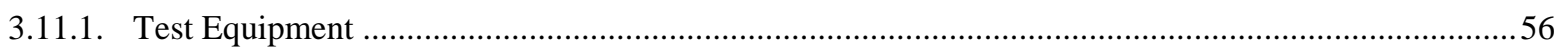

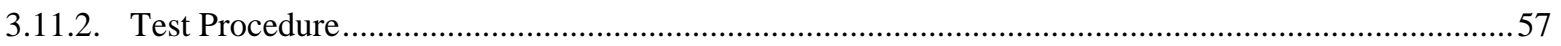

3.11.3. Evaluation of Results........................................................................................................... 59

3.12. Fresh Oysters Labeled by Volume …….......................................................................................................... 
3.12.1. Test Equipment ................................................................................................................... 59

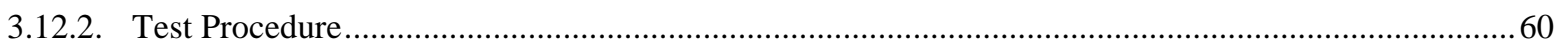

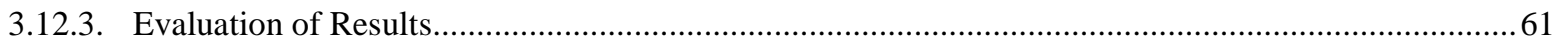

3.13. Determining the Net Contents of Compressed Gas in Cylinders ..............................................................61

3.13.1. Test Equipment ..........................................................................................................................62

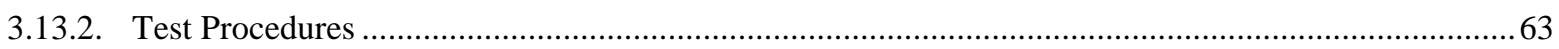

a. Test Procedure for Cylinders Labeled by Weight ................................................................................63

b. Test Procedure for Cylinders Labeled by Volume ..........................................................................................64

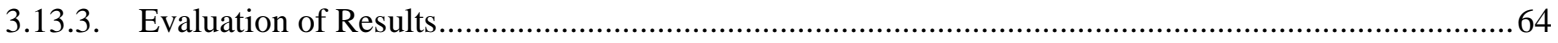

3.14. Firewood - (Volumetric Test Procedure for Packaged Firewood with a Labeled Volume of

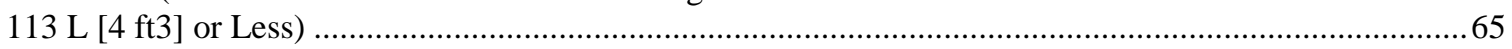

3.14.1. Test Equipment Linear Measure. Take all measurements in increments of $0.5 \mathrm{~cm}$ (3/16 in)

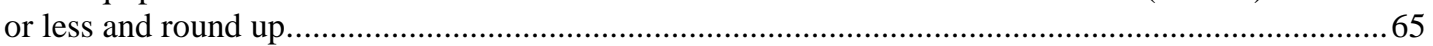

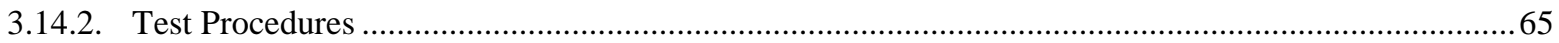

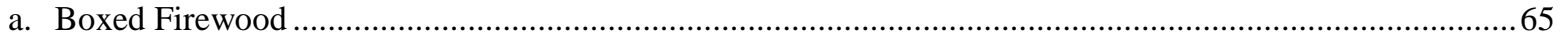

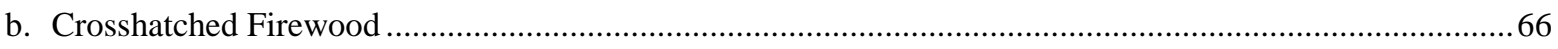

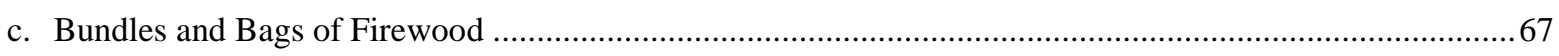

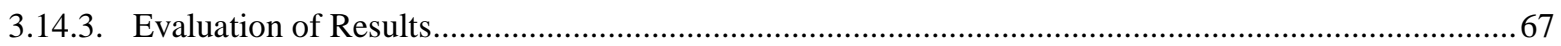

Chapter 4. Test Procedures - Packages Labeled by Count, Linear Measure, Area, Thickness, and Combinations of

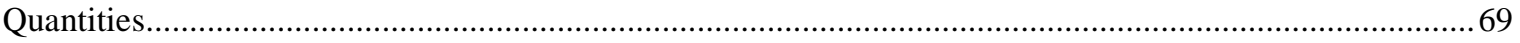

4.1. Scope

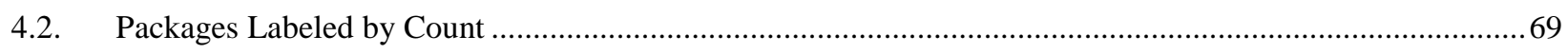

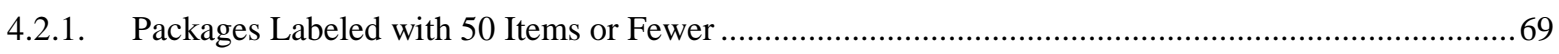

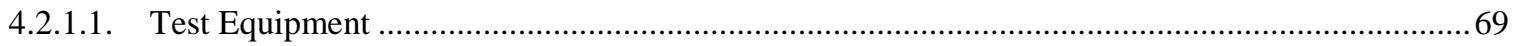

4.2.1.2. Test Procedure.......................................................................................................................69

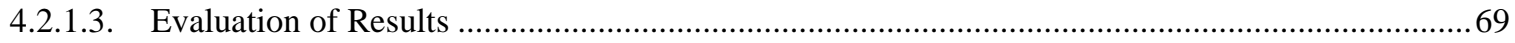

4.2.2. Packages Labeled by Count of More than 50 Items ..................................................................... 70

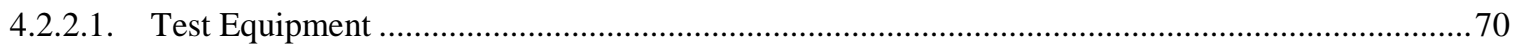

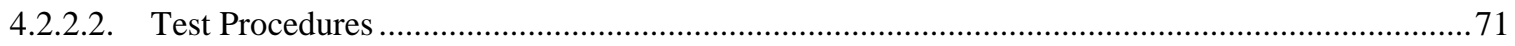

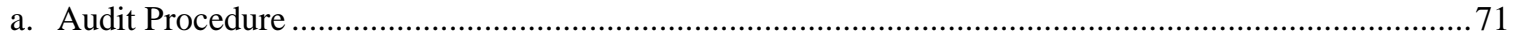

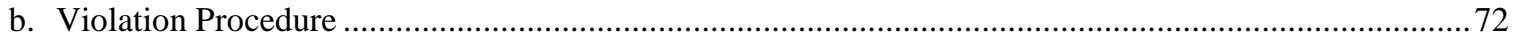

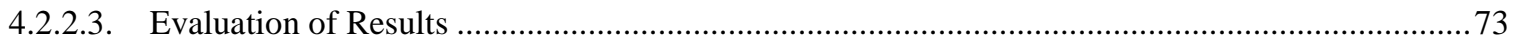

4.3. Paper Plates and Sanitary Paper Products ............................................................................................ 74

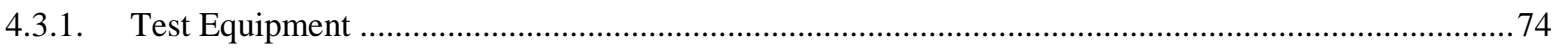

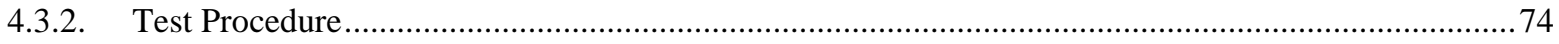

4.3.3. Evaluation of Results.......................................................................................................... 75

4.4. Special Test Requirements for Packages Labeled by Linear or Square Measure (area) ................................75 


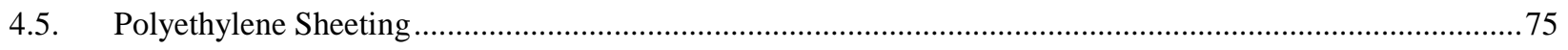

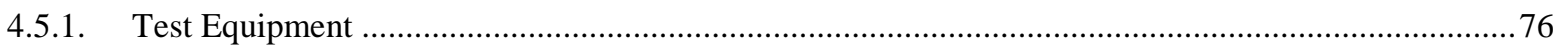

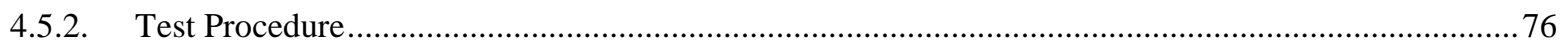

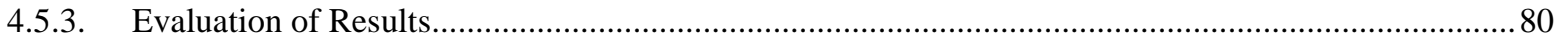

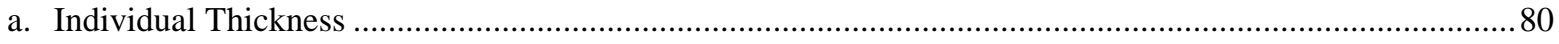

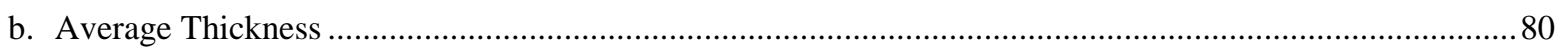

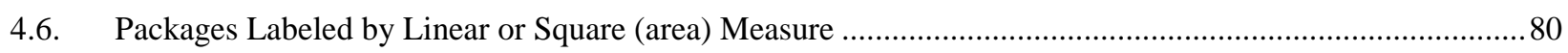

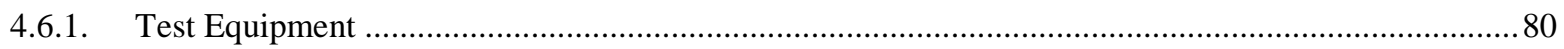

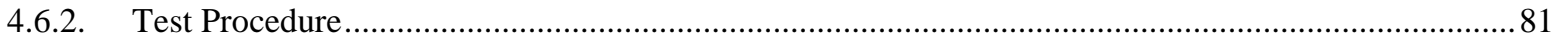

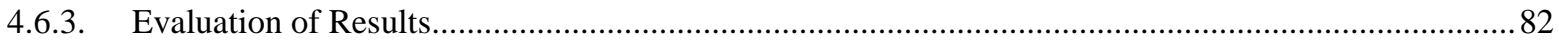

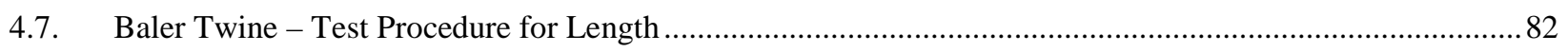

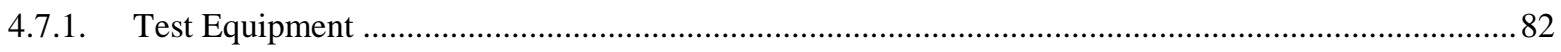

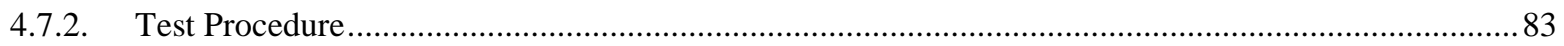

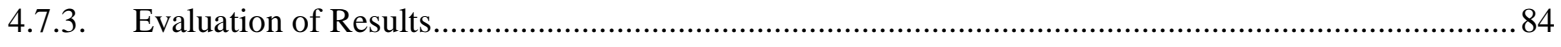

4.8. Procedure for Checking the Area Measurement of Chamois ........................................................................84

4.8.1. Template Test Method (for field audits) ............................................................................................ 85

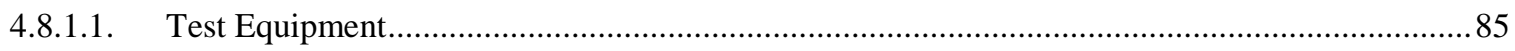

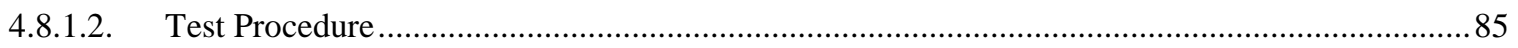

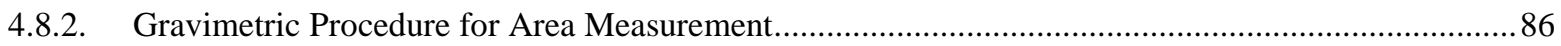

4.8.2.1. Test Equipment................................................................................................................... 86

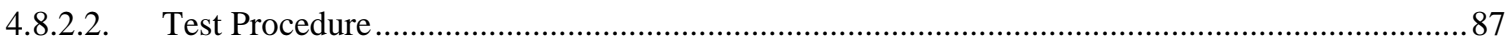

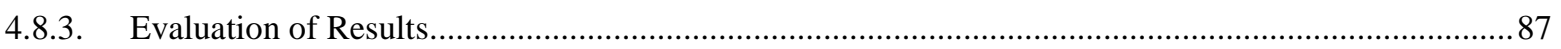

4.9. Procedure for Checking the Contents of Specific Agriculture Seed Packages Labeled by Count ...................88

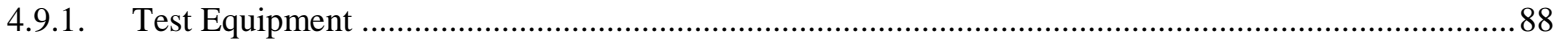

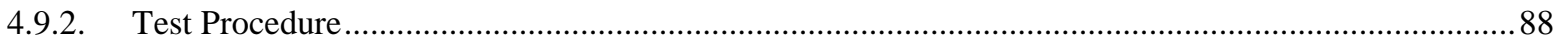

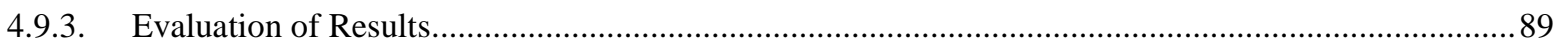

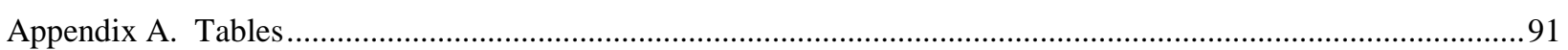

Table 1-1. Agencies Responsible for Package Regulations and Applicable Requirements ..........................91

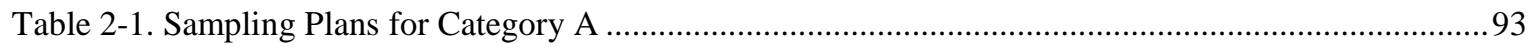

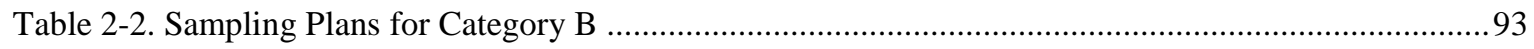

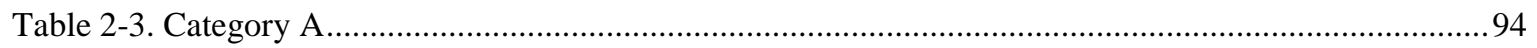

Table 2-4. Category B ....................................................................................................................... 97

Table 2-5. Maximum Allowable Variations (MAVs) for Packages Labeled by Weight .................................98

Table 2-6. Maximum Allowable Variations for Packages Labeled by Liquid and Dry Volume .................. 100

Table 2-7. Maximum Allowable Variations (MAVs) for Packages Labeled by Count ................ 103

Table 2-8. Maximum Allowable Variations for Packages Labeled by Length, (Width), or Area. 104 
Table 2-9. U.S. Department of Agriculture, Meat and Poultry Groups and Lower Limits for Individual Packages (Maximum Allowable Variations).

Table 2-10. Exceptions to the Maximum Allowable Variations for Textiles, Polyethylene Sheeting and Film, Mulch and Soil Labeled by Volume, Packaged Firewood, and Packages Labeled by Count with 50 Items or Fewer, and Specific Agricultural Seeds Labeled by Count.

Table 2-11. Accuracy Requirements for Packages Labeled by Low Count (50 or Fewer)

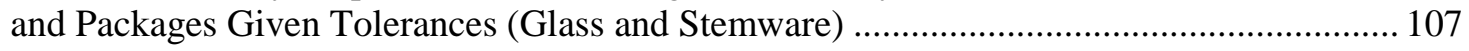

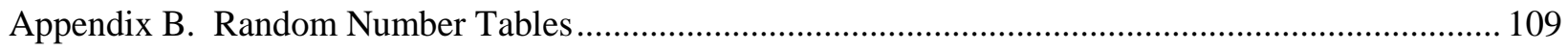

Appendix C. Model Inspection Report Forms …............................................................................. 117

Random Package Report .................................................................................................... 119

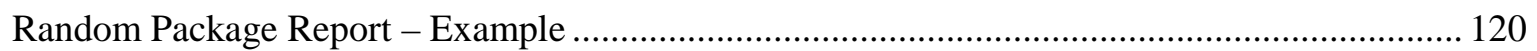

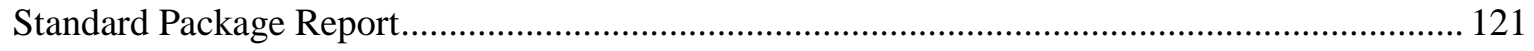

Standard Package Report - Example................................................................................ 122

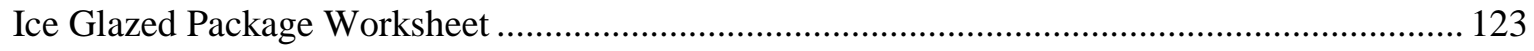

Ice Glazed Package Worksheet - Example .......................................................................... 124

Ice Glazed Package Report................................................................................................ 125

Ice Glazed Package Report - Example................................................................................. 126

Worksheet for Determining the Free Liquid and Net Volume of Oysters.................................. 127

Worksheet for Determining the Free Liquid and Net Volume of Oysters - Example ................. 128

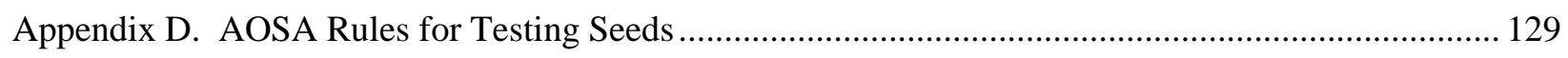

Appendix E. General Tables of Units of Measurement .......................................................................... 135

Section 1. Tables of Metric Units of Measurement ................................................................................ 135

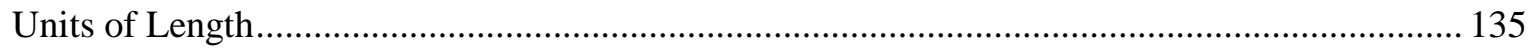

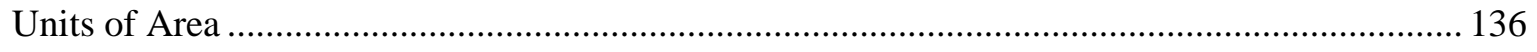

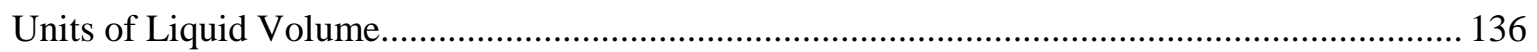

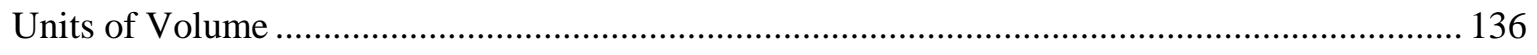

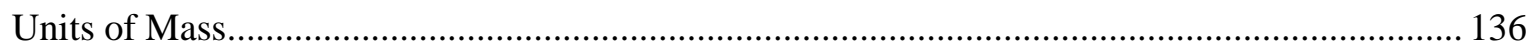

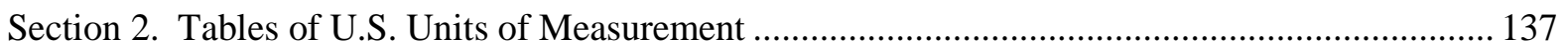

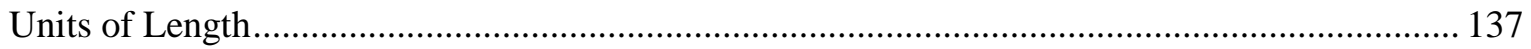

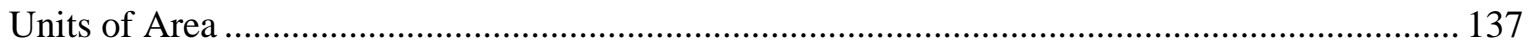

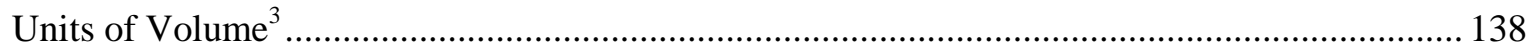

Gunter's or Surveyors Chain Units of Measurement …............................................................ 138

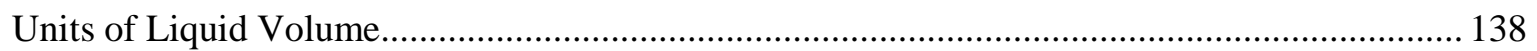

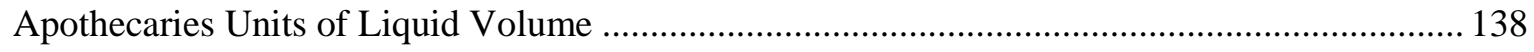

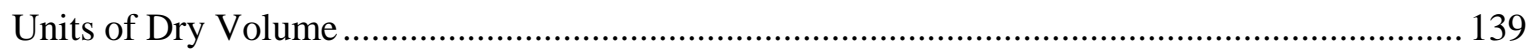

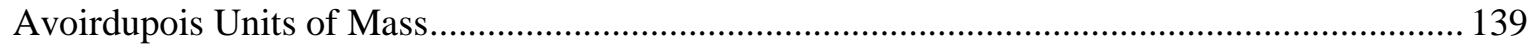

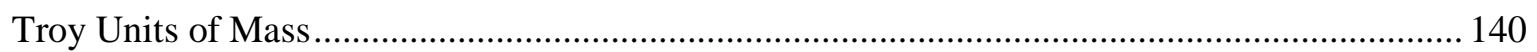

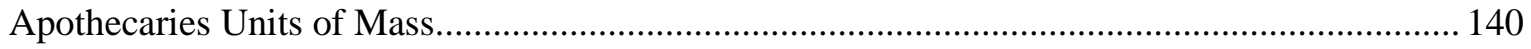




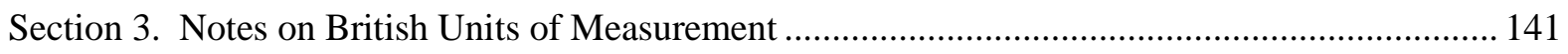

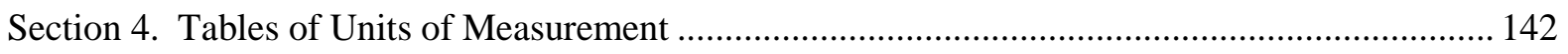

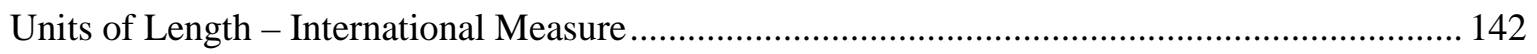

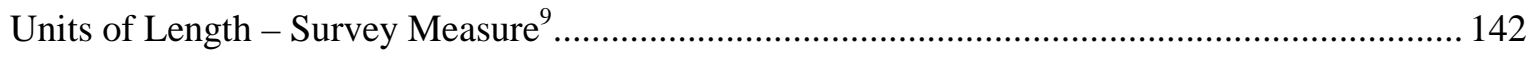

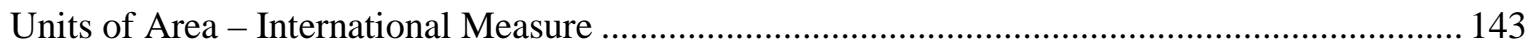

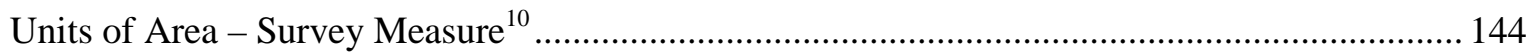

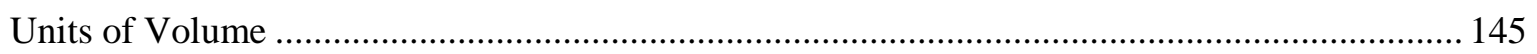

Units of Capacity or Volume - Dry Volume Measure ............................................................. 146

Units of Capacity or Volume - Liquid Volume Measure.......................................................... 147

Units of Mass Not Less Than Avoirdupois Ounces ................................................................. 148

Units of Mass Not Greater Than Pounds and Kilograms ....................................................... 149

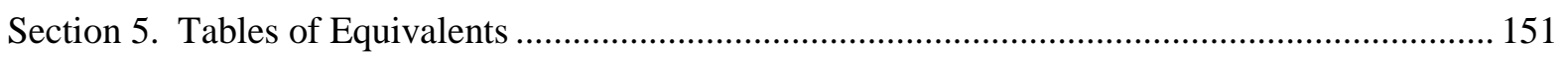

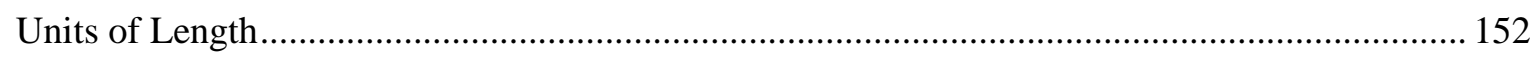

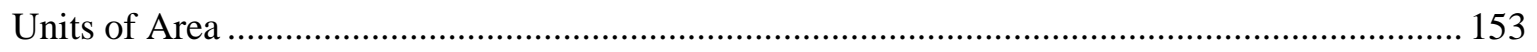

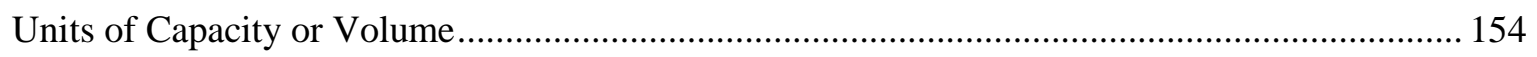

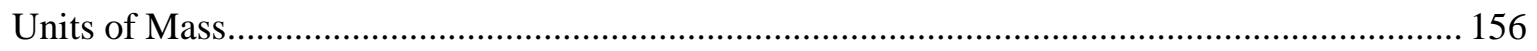

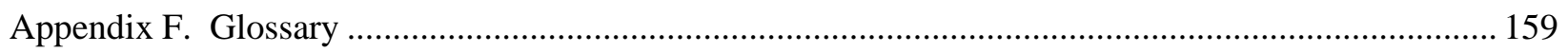

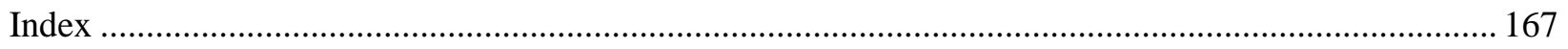

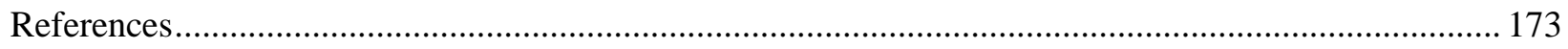




\section{Amendments}

The following table indicates the items amended by the $99^{\text {th }}(2014)$ National Conference on Weights and Measures (NCWM). As appropriate, the text on the cited pages indicates the changes to a Handbook 133 section, or paragraph as “Added 2014” or "Amended 2014." Unless otherwise noted, the effective date of the regulations added or amended in 2014 is January 1, 2015.

\begin{tabular}{|c|c|c|c|c|}
\hline Chapter & $\begin{array}{c}\text { L\&R } \\
\text { Committee } \\
\text { Item No. }\end{array}$ & Section & Action & Page \\
\hline \multirow{3}{*}{$\begin{array}{c}\text { Chapter 3. Test } \\
\text { Procedures - For } \\
\text { Packages Labeled by } \\
\text { Volume }\end{array}$} & \multirow{5}{*}{$260-2$} & $\begin{array}{l}\text { 3.12. Fresh Oysters Labeled by } \\
\text { Volume }\end{array}$ & Amended & 59 \\
\hline & & 3.12.1. Test Equipment & Amended & 59 \\
\hline & & 3.12.2. Test Procedure & Amended & 60 \\
\hline \multirow{2}{*}{$\begin{array}{c}\text { Appendix C. Model } \\
\text { Inspection Report } \\
\text { Forms }\end{array}$} & & $\begin{array}{l}\text { Worksheet for Determining the Free } \\
\text { Liquid and Net Volume of Oysters }\end{array}$ & Addition & 127 \\
\hline & & $\begin{array}{l}\text { Worksheet for Determining the Free } \\
\text { Liquid and Net Volume of Oysters - } \\
\text { Example }\end{array}$ & Addition & 128 \\
\hline
\end{tabular}




\section{Editorial Changes}

The following items were deemed editorial in nature based on the following criteria: 1) the modified text did not change the meaning or procedure outlined, 2) modified text corrected an omission or clarified how the text was written, or 3) the item itself was reformatted and relocated in the text to make the organization of the content more meaningful.

\begin{tabular}{|c|c|c|c|}
\hline Chapter & Section & Action & Page \\
\hline All Chapters & & $\begin{array}{l}\text { All references to "inch-pound" } \\
\text { has been changed to "U.S. } \\
\text { customary." }\end{array}$ & \\
\hline $\begin{array}{l}\text { Chapter 4. Test Procedures - } \\
\text { Packages Labeled by Count, } \\
\text { Linear Measure, Area, } \\
\text { Thickness, and Combinations } \\
\text { of Quantities }\end{array}$ & $\begin{array}{l}\text { 4.5. Polyethylene Sheet, 4.5.2. } \\
\text { Test Procedure, Item } 3 . \\
\text { Text Box. }\end{array}$ & $\begin{array}{l}\text { Corrected the minimum density } \\
\text { for linear medium density } \\
\text { polyethylene plastics } \\
\mathrm{g} / \mathrm{cm}^{3} \text { to } \underline{0.93 \mathrm{~g} / \mathrm{cm}^{3 .}}\end{array}$ & 77 \\
\hline
\end{tabular}




\section{Chapter 1. General Information}

\subsection{Scope}

Routine verification of the net contents of packages is an important part of any weights and measures program to facilitate value comparison and fair competition. Consumers have the right to expect packages to bear accurate net content information. Those manufacturers whose products are sold in such packages have the right to expect that their competitors will be required to adhere to the same laws and regulations.

The procedures in this handbook are recommended for use to verify the net quantity of contents of packages kept, offered, or exposed for sale, or sold by weight, measure (including volume, and dimensions), or count at any location (e.g., at the point-of-pack, in storage warehouses, retail stores, and wholesale outlets).

\subsubsection{When and Where to Use Package Checking Procedures}

An effective program will typically include testing at each of the following levels.

\section{a. Point-of-Pack}

Testing packages at the "point-of-pack" has an immediate impact on the packaging process. Usually, a large number of packages of a single product are available for testing at one place. This allows the inspector to verify that the packer is following current good packaging practices. Inspection at the point-of-pack also provides the opportunity to educate the packer about the legal requirements that products must meet, and may permit resolution of any net content issues or other problems that arise during the testing. Point-of-pack testing is not always possible because packing locations can be in other states or countries. Work with other state, county, and city jurisdictions to encourage point-of-pack inspection on products manufactured in their geographic jurisdictions. Point-of-pack inspections cannot entirely replace testing at wholesale or retail outlets, because this type of inspection does not include imported products or the possible effects of product distribution and moisture loss. Point-of-pack inspections only examine the manufacturing process. Therefore, an effective testing program will also include testing at wholesale and retail outlets.

\section{b. Wholesale}

Testing packages at a distribution warehouse is an alternative to testing at the point-of-pack with respect to being able to test large quantities of, and a variety of products. Wholesale testing is a very good way to monitor products imported from other countries and to follow up on products suspected of being under filled or underweight based on consumer complaints or findings made during other inspections, including those done at retail outlets.

\section{c. Retail}

Testing packages at retail outlets evaluates the soundness of the manufacturing, distributing, and retailing processes of the widest variety of goods at a single location. It is acceptable and practical for weights and measures jurisdictions to monitor packaging procedures and to detect 
present or potential problems. Generally, retail package testing is not conducive to checking large quantities of individual products of any single production lot. Therefore, follow-up inspections of a particular brand or lot code number at a number of retail and wholesale outlets, and ultimately at the point-of-pack are extremely important aspects in any package-checking scheme. After the evaluation of an inspection lot is completed, the jurisdiction should consider what, if any, further investigation or follow-up is warranted. At the point-of-sale, a large number of processes may affect the quality or quantity of the product. Therefore, there may be many reasons for any inspection lot being out of compliance. A shortage in weight or measure may result from mishandling the product in the store or the retailer's failure to rotate stock. Shortages may also be caused through mishandling by a distributor or failure of some part of the packaging process. Shortages may also be caused by moisture loss (desiccation) if the product is packaged in permeable media. Therefore, being able to determine the cause of an error in order to correct defects is more difficult when retail testing is used.

(Amended 2010)

\subsection{2. $\quad$ Selecting a Product for Testing}

Any commodity sold by weight, measure, or count may be tested. The product to be tested may be chosen in several ways. The decision may be based on different factors, such as (1) marketplace surveys (e.g., jurisdiction-wide surveys of all soft drinks or breads), (2) surveys based on sales volume, or (3) audit testing (see Section 1.3. "Sampling Plans") to cover as large a product variety as possible at food, farm, drug, hardware stores, or specialty outlets, discount and department stores. Follow-up of possible problems detected in audit testing or in review of past performance tends to concentrate inspection resources on particular commodity types, brand names, retail or wholesale locations, or even particular neighborhoods. The expected benefits for the public must be balanced against the cost of testing. Expensive products should be tested because of their cost per unit. However, inexpensive items should also be tested because the overall cost to individual purchasers may be considerable over an extended period of time. Store packaged items, which are usually perishable and not subject to other official monitoring, should be routinely tested because they are offered for sale where they are packed. Products on sale and special products produced for local consumption should not be overlooked because these items sell quickly in large amounts.

Regardless of where the test occurs, remember that it is the inspector's presence in the marketplace through routine unannounced testing that ensures equity and fair competition in the manufacturing and distribution process. Finally, always follow-up on testing to ensure that the problems are corrected; otherwise, the initial testing may be ineffective.

\subsection{Package Requirements}

The net quantity of content statement must be "accurate," but reasonable variations are permitted. Variations in package contents may be a result of deviations in filling. The limits for acceptable variations are based on current good manufacturing practices in the weighing, measuring, and packaging process. The first requirement is that accuracy is applied to the average net contents of the packages in the lot. The second requirement is applied to negative errors in individual packages. These requirements apply simultaneously to the inspection of all lots of packages except as specified in Section 1.2.5. "Exceptions to the Average and Individual Package Requirements.”

\subsubsection{Inspection Lot}

An "inspection lot" (called a "lot" in this handbook) is defined as a collection of identically labeled (except for quantity or identity in the case of random packages) packages available for inspection at 
one time. The collection of packages will pass or fail as a whole based on the results of tests on a sample drawn from the lot. This handbook describes procedures to determine if the packages in an "inspection lot" contain the declared net quantity of contents and if the individual packages' variations are within acceptable limits.

\subsubsection{Average Requirement}

In general, the average net quantity of contents of packages in a lot must at least equal the net quantity of contents declared on the label. Plus or minus variations from the declared net weight, measure, or count are permitted when they are caused by unavoidable variations in weighing, measuring, or counting the contents of individual packages that occur in current good manufacturing practice. Such variations must not be permitted to the extent that the average of the quantities in the packages of a particular commodity or a lot of the commodity that is kept, offered, exposed for sale, or sold, is below the stated quantity. (See Section 3.6. "Pressed and Blown Glass Tumblers and Stemware" and Section 4.2.1. "Packages Labeled with 50 Items or Fewer" for exceptions to this requirement.)

\subsubsection{Individual Package Requirement}

The variation of individual package contents from the labeled quantity must not be "unreasonably large." In this handbook, packages that are under filled by more than the Maximum Allowable Variation (MAV) specified for the package are considered unreasonable errors. Unreasonable shortages are not generally permitted, even when overages in other packages in the same lot, shipment, or delivery compensate for such shortage. This handbook does not specify limits of overfilling (with the exception of textiles), which is usually controlled by the packer for economic, compliance, and other reasons.

(Amended 2010)

\subsubsection{Maximum Allowable Variation}

The limit of the "reasonable minus variation" for an under filled package is called a "Maximum Allowable Variation" (MAV). An MAV is a deviation from the labeled weight, measure, or count of an individual package beyond which the deficiency is considered an unreasonable minus error. Each sampling plan limits the number of negative package errors permitted to be greater than the MAV.

(Amended 2010)

\subsubsection{Exceptions to the Average and Individual Package Requirements}

There is an exemption from the average requirement for packages labeled by count with 50 items or fewer. The reason for this exemption is that the package count does not follow a "normal" distribution even if the package is designed to hold the maximum count indicated by the label declaration (e.g., egg cartons and packages of chewing gum). Another exception permits an "allowable difference" in the capacity of glass tumblers and stemware because mold capacity doesn't follow a normal distribution.

\subsubsection{Deviations Caused by Moisture Loss or Gain}

Deviations from the net quantity of contents caused by the loss or gain of moisture from the package are permitted when they are caused by ordinary and customary exposure to conditions that normally occur in good distribution practice and that unavoidably result in change of weight or measure. 
According to regulations adopted by the U.S. Environmental Protection Agency, no moisture loss is recognized on pesticides. (See Code of Federal Regulations 40 CFR Part 156.10.)

\subsubsection{Applying a Moisture Allowance}

Some packaged products may lose or gain moisture and, therefore, lose or gain weight or volume after packaging. The amount of moisture loss depends upon the nature of the product, the packaging material, the length of time it is in distribution, environmental conditions, and other factors. Moisture loss may occur even when manufacturers follow good distribution practices. Loss of weight "due to exposure" may include solvent evaporation, not just loss of water. For loss or gain of moisture, the moisture allowances may be applied before or after the package errors are determined.

To apply an allowance before determining package errors, adjust the Nominal Gross Weight (see Section 2.3.6. "Determine Nominal Gross Weight and Package Errors”), so the package errors are increased by an amount equal to the moisture allowance. This approach is used to account for moisture loss in both the average and individual package errors.

It is also permissible to apply the moisture allowances after individual package errors and average errors are determined.

\section{Example:}

A sample of a product that could be subject to moisture loss might fail because the average error is minus or the error in several of the sample packages are found to be unreasonable errors (i.e., the package error is greater than the Maximum Allowable Variation (MAV) permitted for the package's labeled quantity).

You may apply a moisture allowance after determining the package errors by adding the allowance to the Sample Error Limit (SEL) and then, comparing the average error to the SEL to determine compliance. The moisture allowance must be added to the MAV before evaluating sample errors to identify unreasonable minus errors.

(Amended 2010)

This handbook provides "moisture allowances" for some meat and poultry products, flour, pasta, and dry pet food. (See Chapter 2, Table 2-3. "Moisture Allowances") These allowances are based on the premise that when the average net weight of a sample is found to be less than the labeled weight, but not by an amount that exceeds the allowable limit, either the lot is declared to be within the moisture allowance or more information must be collected before deciding lot compliance or noncompliance.

Test procedures for flour, some meat, and poultry are based on the concept of a "moisture allowance" also known as a "gray area" or "no decision" area (see Section 2.3.8. "Moisture Allowances"). When the average net weight of a sample is found to be less than the labeled weight, but not more than the boundary of the "gray area," the lot is said to be in the "gray" or "no decision" area. The gray area is not a tolerance. More information must be collected before lot compliance or noncompliance can be decided. Appropriate enforcement should be taken on packages found short weight and outside of the "moisture allowance" or "gray area."

(Amended 2002) 


\subsection{Sampling Plans}

This handbook contains two sampling plans used to inspect packages: "Category A" and "Category B." Use the "Category B" Sampling Plans to test meat and poultry products at point-of-pack locations that are subject to U.S. Department of Agriculture Food Safety and Inspection Service (FSIS) requirements. When testing all other packages, use the "Category A" Sampling Plan.

Inspections by weights and measures officials must provide the public with the greatest benefit at the lowest possible cost. Sampling reduces the time to inspect a lot of packages, so a greater number of items can be inspected. Net content inspection, using sampling plans for marketplace surveillance, protects consumers who cannot verify the net quantity of contents. This ensures fair trade practices and maintains a competitive marketplace. It also encourages manufacturers, distributors, and retailers to follow good manufacturing and distribution practices.

Testing a "sample" of packages from a lot instead of every package is efficient, but the test results have a "sampling variability" that must be corrected before determining if the lot passes or fails. The "Category A" sampling plans give acceptable lots a $97.5 \%$ probability of passing. An "acceptable” lot is defined as one in which the "average" net quantity of contents of the packages equals or exceeds the labeled quantity. The "Category B" sampling plans give acceptable lots at least a $50 \%$ probability of passing. The sampling plans used in this handbook are statistically valid. That means the test acceptance criteria are statistically adjusted, so they are both valid and legally defensible. This handbook does not discuss the statistical basis, risk factors, or provide the operating characteristic curves for the sampling plans. For information on these subjects, see explanations on "acceptance sampling" in statistical reference books.

A randomly selected sample is necessary to ensure statistical validity and reliable data. This is accomplished by using random numbers to determine which packages are chosen for inspection. Improper collection of sample packages can lead to bias and unreliable results.

\subsection{1. $\quad$ Audit Tests}

Audits may be used to speed the process of detecting possible net content violations. These audit procedures may include:

- $\quad$ using smaller sample sizes;

- $\quad$ using tare lists provided by manufacturers to spot check; or

- selecting samples without collecting a random sample.

These audit procedures allow spot checking of more products than is possible with the more structured techniques, but do not take the place of "Category A" or "Category B” testing.

Do not take enforcement action using audit test results. If, after an audit test, there is suspicion that the package lot is not in compliance, use the appropriate "Category A" or "Category B" sampling plan to determine if the lot complies with the package requirements.

\subsection{Other Regulatory Agencies Responsible for Package Regulations and Applicable Requirements}

In the United States, several federal agencies issue regulations regarding package labeling and net contents. The U.S. Department of Agriculture (USDA) regulates meat and poultry. The Food and Drug Administration (FDA) regulates food, drugs, cosmetic products, and medical devices under the Food, Drug, 
and Cosmetic Act (FDCA) and the Fair Packaging and Labeling Act (FPLA). The Federal Trade Commission (FTC) regulates most non-food consumer packaged products as part of the agency's responsibility under the FPLA. The Environmental Protection Agency (EPA) regulates pesticides. The Bureau of Alcohol and Tobacco Tax and Trade Bureau (TTB) in the U.S. Department of the Treasury promulgates regulations for packaged tobacco and alcoholic beverages as part of its responsibility under the Federal Alcohol Administration Act.

Packaged goods produced for distribution and sale also come under the jurisdiction of state and local weights and measures agencies that adopt their own legal requirements for packaged goods. Federal statutes set requirements that pre-empt state and local regulations that are or may be less stringent or not identical to federal regulation depending on the federal law that authorizes the federal regulation. The application of Handbook 133 procedures occurs in the context of the concurrent jurisdiction among federal, state, and local authorities. Therefore, all agencies using this handbook should keep abreast of the revisions to federal agency regulations that may contain sampling or testing information not in the regulations at the time of publication of this handbook. (See Appendix A, Table 1-1. "Agencies Responsible for Package Regulations and Applicable Requirements" for information on the responsible agencies for package regulations. The requirements of this handbook must be used when testing products concurrently subject to pre-emptive federal regulations.)

\subsection{Assistance in Testing Operations}

If the storage, display, or location of any lot of packages requires special equipment or an abnormal amount of labor for inspection, the owner or the operator of the business must supply the equipment and/or labor as required by the weights and measures official.

\subsection{Health and Safety}

This handbook cannot address all of the health and safety issues associated with its use. The inspector is responsible for determining the appropriate safety and health practices and procedures before starting an inspection (e.g., contact the establishment's health and safety official). Comply with all handling, health, and safety warnings on package labels and those contained in any associated material safety data sheets (MSDS). The inspector must also comply with federal, state, and local health and safety laws, and other appropriate requirements in effect at the time and location of the inspection. Contact your supervisor to obtain information regarding your agency's health and safety policies and to obtain appropriate safety equipment.

\subsection{Good Measurement Practices}

The procedures in this handbook are designed to be technically sound and represent good measurement practices. To assist in documenting tests, we have included "model” inspection report forms designed to record the information.

\subsubsection{Traceability Requirements for Measurement Standards and Test Equipment}

Each test procedure presented in this handbook includes a list of the equipment needed to perform the inspection. The scales and other measurement standards used (e.g., balances, mass standards, volumetric, and linear measures) to conduct any test must be traceable to the International System of Units (SI), usually through the National Institute of Standards and Technology (NIST). Standards must be used in the manner for which they were designed and calibrated. 


\subsubsection{Certification Requirements for Standards and Test Equipment}

All measurement standards and test equipment identified in this handbook or associated with the test procedures must be calibrated or standardized before initial use. This must be done according to the calibration procedures and other instructions found on NIST's Laboratory Metrology and Calibration Procedures website at http://www.nist.gov/pml/wmd/labmetrology/calibration or using other recognized procedures (e.g., those adopted for use by a state weights and measures laboratory). After initial certification, the standards must be routinely recertified according to your agency's measurement assurance policies. 
Handbook 133, Checking the Net Contents of Packaged Goods (2015)

THIS PAGE INTENTIONALLY LEFT BLANK 


\section{Chapter 2. Test Procedures for Packages Labeled by Weight - Gravimetric Testing}

\subsection{Scope}

The gravimetric test method uses weight measurement to determine the net quantity of contents of packaged goods. This chapter includes general test methods to determine the net quantity of contents of packages labeled in terms of weight. Gravimetric testing is the preferred method of testing most products because it reduces destructive testing and improves measurement accuracy.

\subsection{Measurement Standards and Test Equipment}

\subsubsection{Scale Requirements:}

Use a scale (for this handbook the term "scale" includes balances) that has at least 100 scale divisions. It must have a load-receiving element of sufficient size and capacity to hold the packages during weighing. It also requires a scale division no larger than $1 / 6$ of the Maximum Allowable Variation (MAV) for the package size being weighed. The MAV/6 requirement ensures that the scale has adequate resolution to determine the net contents of the packages. Subsequent references to product test results requiring the agreement to within one scale division are based on scale divisions that are equal to or only slightly smaller than the MAV/6. (See Appendix A, Table 2-5. "Maximum Allowable Variations (MAVs) for Packages Labeled by Weight.”)

\section{Example:}

The MAV for packages labeled with a net weight $113 \mathrm{~g}(0.25 \mathrm{lb})$ is $7.2 \mathrm{~g}(0.016 \mathrm{lb})$. Divide $(\div)$ the MAV by 6 to obtain the maximum scale division that can be used to determine the gross, tare and net weights for a package size.

$$
7.2 g(0.016) \div 6=1.2 g(0.002 \mathrm{lb})
$$

In this example, a $1 \mathrm{~g}(0.002 \mathrm{lb})$ scale division would be the maximum scale division appropriate for weighing these packages.

(Amended 2010)

\subsubsection{Scale Accuracy}

Verify the accuracy of a scale before each initial daily use, each use at a new location, or when there is any indication of abnormal equipment performance (e.g., erratic indications). Recheck the scale accuracy if it is found that the lot does not pass, so there can be confidence that the test equipment is not at fault.

Scales used to check packages must meet the acceptance tolerances specified for their accuracy class in the current edition of NIST Handbook 44 (HB 44) "Specifications, Tolerances, and Other Technical Requirements for Weighing and Measuring Devices." The tolerances for Class II and Class III scales are presented in HB 44, Section 2.20. Scales, “T.N. Tolerances Applicable to Devices Marked I, II, III, III L, and IIII.” 
Note: If the package checking scale is not marked with a "class" designation, use Table 2-1. "Class of Scale" to determine the applicable tolerance.

Always use good weighing and measuring practices. For example, be sure to use weighing and measuring equipment according to the manufacturer's instructions and make sure the environment is suitable. Place scales and other measuring equipment (e.g., flasks and volumetric measures) on a rigid support and maintain them in a level condition if being level is a requirement to ensure accuracy.

\subsubsection{Scale Tolerance}

Follow this procedure to determine the scale tolerance:

1. Determine the total number of divisions (i.e., the minimum increment or graduation indicated by the scale) of the scale by dividing the scale's capacity by the minimum division.

\section{Example:}

A scale with a capacity of $5000 \mathrm{~g}$ and a minimum division of $0.1 \mathrm{~g}$ has 50000 divisions.

$$
5000 \div 0.1 \mathrm{~g}=50000 \text { division }
$$

2. From Table 2-1. "Class of Scale", determine the class of the scale using the minimum scale division and the maximum number of scale divisions.

\section{Example:}

On a scale with a minimum division of $0.1 \mathrm{~g}$ and 50000 total scale divisions the appropriate class is "II."

Note: If a scale is used where the number of scale divisions is between 5001 and 10000 and the division size is $0.1 \mathrm{~g}$ or greater and is not marked with an accuracy Class II marking, Class III scale tolerances apply.

3. Determine the number of divisions for any test load by dividing the value of the mass standard being applied by the minimum division indicated by the scale.

4. Determine the tolerance from Table 2-2. "Acceptance Tolerances for Class of Scale Based on Test Load in Divisions" in divisions appropriate for the test load and class of scale 


\section{Example:}

If the scale has a minimum division of $0.1 \mathrm{~g}$ and a $1500 \mathrm{~g}$ mass standard is applied, the test load is equal to 15000 divisions (1500/0.1). On a Class II scale with a test load between 5001 and 20000 divisions, Table 2-2. "Acceptance Tolerances for Class of Scale Based on Test Load in Divisions" indicates the tolerance is plus or minus one division.

\begin{tabular}{|c|c|c|c|}
\hline \multicolumn{4}{|c|}{$\begin{array}{l}\text { Table } 2-1 . \\
\text { Class of Scale }\end{array}$} \\
\hline \multirow[t]{2}{*}{ Value of Scale Division ${ }^{1}$} & \multicolumn{2}{|c|}{$\begin{array}{c}\text { Minimum and Maximum Number of } \\
\text { Divisions }\end{array}$} & \multirow[t]{2}{*}{ Class of Scale } \\
\hline & Minimum & Maximum & \\
\hline $1 \mathrm{mg}$ to $0.05 \mathrm{~g}$ & 100 & 100000 & II \\
\hline $0.1 \mathrm{~g}$ or more & 5000 & 100000 & II \\
\hline $\begin{array}{c}0.1 \mathrm{~g} \text { to } 2 \mathrm{~g} \\
0.0002 \mathrm{lb} \text { to } 0.005 \mathrm{lb} \\
0.005 \mathrm{oz} \text { to } 0.125 \mathrm{oz}\end{array}$ & 100 & 10000 & III \\
\hline $\begin{array}{c}5 \mathrm{~g} \text { or more } \\
0.01 \mathrm{lb} \text { or more } \\
0.25 \mathrm{oz} \text { or more }\end{array}$ & 500 & 10000 & III \\
\hline \multicolumn{4}{|c|}{$\begin{array}{l}{ }^{1} \text { On some scales, manufacturers designated and marked the scale with a verification division (e) for } \\
\text { testing purposes ( } \mathrm{e}=1 \mathrm{~g} \text { and } \mathrm{d}=0.1 \mathrm{~g} \text { ). For scales marked Class II, the verification division is large } \\
\text { than the minimum displayed division. The minimum displayed division must be differentiated from the } \\
\text { verification scale division by an auxiliary reading means such as a vernier, rider, or at least a significan } \\
\text { digit that is differentiated by size, shape, or color. Where the verification division is less than or equal } \\
\text { to the minimum division, use the verification division instead of the minimum division. Where scales } \\
\text { are made for use with mass standards (e.g., an equal arm balance without graduations on the indicator) } \\
\text { the smallest mass standard used for the measurement is the minimum division. }\end{array}$} \\
\hline
\end{tabular}

Table 2-2.

Acceptance Tolerances for Class of Scale Based on Test Load in Divisions

\begin{tabular}{|c|c|c|}
\hline \hline \multicolumn{2}{|c|}{ Test Load in Divisions } & \multirow{2}{*}{ Tolerance } \\
\hline Class II Scale & Class III Scale & \multirow{2}{*}{ Plus or Minus 0.5 Division } \\
\hline 0 to 5000 & 0 to 500 & \multirow{2}{*}{ Plus or Minus 1.0 Division } \\
\hline 5001 to 20000 & 501 to 2000 & \multirow{2}{*}{ Plus or Minus 1.5 Divisions } \\
\hline 20001 or more & 2001 to 4000 & Plus or Minus 2.5 Divisions \\
\hline Not Applicable & 4001 or more & \\
\hline
\end{tabular}




\subsubsection{Scale Verification}

Use the following procedures to verify the scale. These procedures, which are based on those required in NIST Handbook 44, have been modified to reduce the amount of time required for testing scales in field situations.

Do not use a scale if it has an error that exceeds the specified tolerance in Table 2-2 in any of the performance tests described in the following section.

\subsubsection{Increasing-Load Test}

Use certified mass standards to conduct an "increasing-load test" with all test loads centered on the load-receiving element. Start the test with the device on zero and progress with increasing test loads to a "maximum test load" of at least $10 \%$ more than the gross weight of the packages to be tested. Use at least three different test loads of approximately equal value to test the device up to the "maximum test load." Verify the accuracy of the device at each test load. Include the package tare weight as one of the test points.

\subsubsection{Decreasing-Load Test}

For all types of scales, other than one with a beam indicator or equal-arm balance, conduct a "decreasing-load test" with all test loads centered on the load-receiving element. Use the same test loads used in the "increasing-load test" of this section, and start at the "maximum test load." Remove the test loads in the reverse order of the increasing-load test until all test loads are removed. Verify the accuracy of the scale at each test load.

\subsubsection{Shift Test}

When conducting a Shift Test on Bench Scales or Balances, use a test load equal to one-third of the "maximum test load" used for the "increasing-load test." For bench scales (see Figure 2-1. "Bench Scales or Balances") apply the test load as nearly as possible at the center of each quadrant of the load receiving element as shown in Figure 2-1. "Bench Scale or Balances."

For Equal-Arm Balances, use a test load equal to one-half capacity centered successively at four points positioned equidistance between the center and the front, left, back, and right edges of each pan as shown (see Figure 2-2. "Equal-Arm Balance”). For example, where the load-receiving element is a rectangular or circular shape, place the test load in the center of the area represented by the shaded area. 


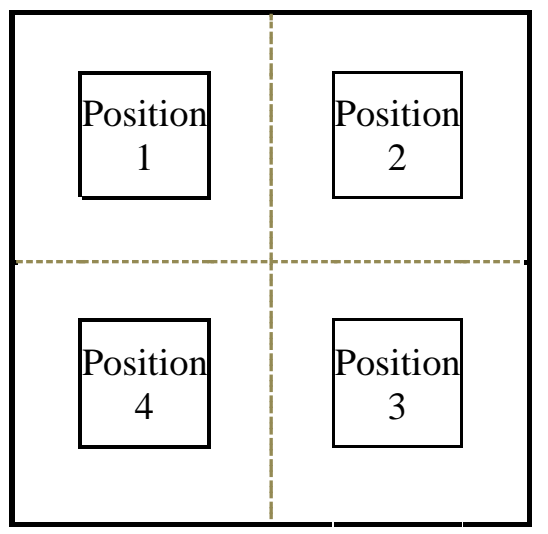

Figure 2-1. Bench Scales or Balances

(Amended 2010)

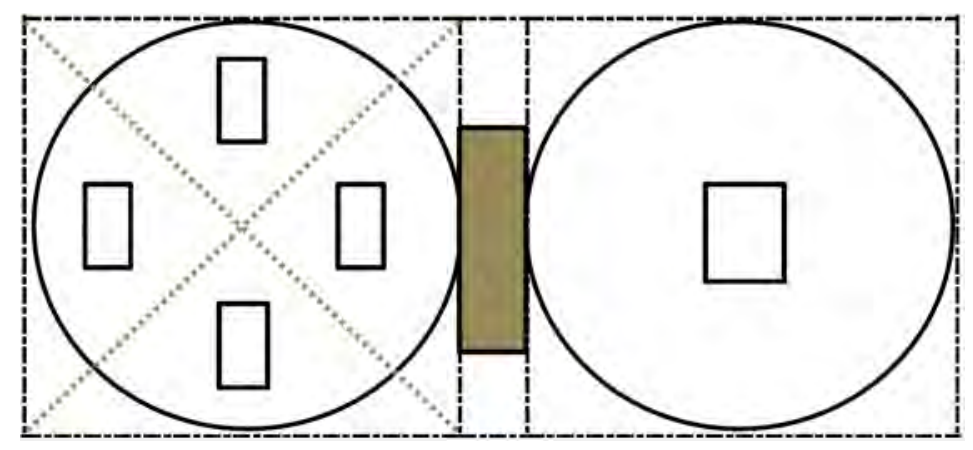

Figure 2-2. Equal-Arm Balance

\subsubsection{Return to Zero}

Conduct the return to zero test whenever all the test weights from the scale are removed; check to ensure that it returns to a zero indication.

\subsubsection{Other Test Equipment Requirements}

Specifications, tolerances, and other technical requirements for the other measurement standards and test equipment cited in this handbook are specified in the following NIST publications. These publications may be obtained from the Office of Weights and Measures (http://www.nist.gov/pml/wmd/).

- Mass Standards - Use NIST Handbook 105-1, "Specifications and Tolerances for Reference Standards and Field Standard Weights and Measures - Field Standard Weights (NIST Class F)” (1990)

- Volumetric Flasks and Cylinders - Use NIST Handbook 105-2, "Specifications and Tolerances for Reference Standards and Field Standard Weights and Measures - Field Standard Measuring Flasks” (1996)

- Stopwatches - Use NIST Handbook 105-5, "Specifications and Tolerances for Reference Standards and Field Standard Weights and Measures - Field Standard Stopwatches” (1997)

- Thermometers - Use NIST Handbook 105-6, "Specifications and Tolerances for Reference Standards and Field Standard Weights and Measures - Specifications and Tolerances for Thermometers” (1997)

\subsection{Basic Test Procedure for Gravimetric Testing of Net Weight}

The following steps apply when gravimetrically testing any type of packaged product except Borax and glazed or frozen foods. If the tested products contain Borax, refer to Section 2.4, "Borax.” If encased-inice or ice glazed food is tested, refer to Section 2.6. "Determining the Net Weight of Encased-in-Ice and Ice Glazed Products.” 
1. Identify and define the inspection lot.

2. Select the sampling plan.

3. Record inspection data using an official inspection report.

4. Select the random sample.

5. Select and determine tare.

6. Determine nominal gross weight and package errors.

7. Evaluate compliance with the Maximum Allowable Variation (MAV) requirement and the average requirement.

Each step will be described in more detail in the following sections.

\subsubsection{Define the Inspection Lot}

The official defines which packages are to be tested and the size of the inspection lot. The lot may be smaller or larger than the production lot defined by the packer. Only take action on the packages contained in the lot that has been defined.

Lots may be made up of either standard or random weight packages. Standard packages are those with identical net content declarations such as containers of soda in $2 \mathrm{~L}$ bottles and $2.26 \mathrm{~kg}(5 \mathrm{lb})$ packages of flour. "Random packages" are those with differing or no fixed pattern of weight, such as packages of meat, poultry, fish, or cheese.

Note: Normally, there will never be access to the entire "production lot" from a manufacturer. The "inspection lot" is selected from packages that are available for inspection/test at any location in the distribution chain.

Note: When packages are tested in retail stores, it is not necessary to sort by lot code. If lot codes are mixed during retail testing, be sure to record the lot codes for all of the packages included in the sample so that the inspector and other interested parties can follow up on the information. For special reasons, such as a large number of packages or the prior history of problems with the product or store, the inspector may choose to define a lot as only one type of packaged product (e.g., ground beef). Another reason to narrowly define the lot is if the results of an audit test indicate the possibility of a shortage in one particular lot code within a particular product.

\section{Example:}

An inspection lot should consist of all of the cans of a single brand of peach halves, labeled with a net quantity of $453 \mathrm{~g}(1 \mathrm{lb})$.

\subsubsection{Select Sampling Plans}

This handbook contains two sampling plans used to inspect packages: "Category A" and "Category B.” Use the "Category B” Sampling Plans to test meat and poultry products at point-of- 
pack locations that are subject to U.S. Department of Agriculture (USDA) Food Safety and Inspection Service (FSIS) requirements. When testing all other packages, use the "Category A" Sampling Plan.

Use Appendix A, Table 2-1. “Sampling Plans for Category A,” to conduct “Category A” inspections.

Use Appendix A, Table 2-2. “Sampling Plans for Category B,” to conduct “Category B” inspections.

\subsubsection{Record Inspection Data}

Use an official inspection report to record information. Attach additional worksheets, test notes, and other information as needed. This handbook provides random and standard packaged products model inspection report forms in Appendix C, "Model Inspection Report Forms." (Refer to Appendix C for instructions on how to complete the forms' box numbers.) Modify the model reports and the box numbers to meet your agency's needs. Other formats that contain more or less information may be acceptable. The procedure below describes how to record inspection data using the "Model Inspection Report Forms" in Appendix C. The same information should be recorded regardless of the form used.

Note: Inspection reports should be legible and complete. Good recordkeeping practices typically include record retention for a specified period of time.

\subsubsection{Procedure for Recording Data}

1. Record the product identity, packaging description, lot code, location of test, and other pertinent data.

2. Record the labeled net quantity of contents in Box 1. Record both metric and U.S. customary declarations if they are provided on the package label.

\section{Example:}

If the labeled weight is $453 \mathrm{~g}(1 \mathrm{lb})$, record this in Box 1 .

Note: When the declaration of net quantity on the package includes both the International System of Units (SI) (metric) and U.S. customary units, the larger of the two declarations must be verified. The rounding rules in NIST Handbook 130, "Uniform Packaging and Labeling Regulations" permit packers to round declarations up or down based on their knowledge of their package filling targets and the accuracy of packaging equipment.

3. Determine the larger of the values by converting the SI declaration to U.S. customary units, or vice versa, using conversion factors that are accurate to at least six places. Compare the values, and use the larger value in computing the nominal gross weight (see later steps). Indicate on the report which of the declarations is being verified when packages labeled with two units of measure are encountered.

\section{Example:}

If the net weight declared on a package is $1 \mathrm{lb}$, the metric equivalent (accurate to six significant digits) is $453.592 \mathrm{~g}$. Do not round down or truncate values in the calculations until the nominal gross weight is determined and recorded. If the package is also labeled $454 \mathrm{~g}$, then the metric declaration is larger than the U.S. customary declaration and should be used to verify the net contents of the package. 
4. Record the unit of measure in Box 2. The unit of measure is the minimum division of the unit of measurement used to conduct the test. If a scale is used that reads to thousandths of a pound, the unit of measure is $0.001 \mathrm{lb}$ even if the scale division is $0.002 \mathrm{lb}$ or $0.005 \mathrm{lb}$.

\section{Examples:}

If the scale has a scale division of $0.5 \mathrm{~g}$, the unit of measure is $0.1 \mathrm{~g}$. If a weighed package that has an error of " $-0.5 \mathrm{~g}$," record the error as " -5 " using "dimensionless units."

$$
-0.5 \mathrm{~g} \div 0.1=5 \text { dimensionless units }
$$

If the scale indicates in increments of $0.002 \mathrm{lb}$, the unit of measure is $0.001 \mathrm{lb}$. If a weighed package has an error of " +0.016 ," record the error as " +16 " using "dimensionless units."

$$
0.016 \div 0.001=16 \text { dimensionless units }
$$

Note: When using dimensionless units, multiply package errors by the unit of measure to obtain the package error in weight.

Note: The Basic Test Procedure does not prohibit the use of units of weight instead of dimensionless units when recording package errors, nor does it prohibit the use of net content computer programs to determine product compliance. Refer to Appendix F. "Glossary,” for the definition of dimensionless units.

5. Enter the appropriate MAV value in Box 3 for the type of package (weight, volume, etc.), the labeled net contents, and the unit of measure using the Tables in Appendix A, 2-5 through 2-10.

6. Determine the MAV in dimensionless units and record in Box 4 on the Standard Package Report Form (a dimensionless unit is obtained by dividing the MAV recorded in Box 3 by the unit of measure recorded in Box 2).

7. Determine how many minus package errors are permitted to exceed the MAV, (errors known as unreasonable minus errors or UMEs), see Column 4 in either Table 2-1. "Sampling Plans for Category A" or Table 2-2. "Sampling Plans for Category B" (refer to Appendix A). Record this number in Box 8.

\subsubsection{Random Sample Selection}

It is important to select a random sample when conducting an official package inspection. Follow the steps below to select your sample. If the packages for the sample are not randomly selected, the test results may not be statistically valid.

1. Count the number of packages comprising the inspection lot or estimate the size to within $5 \%$ and record the inspection lot size in Box 5.

2. Determine sample size using Appendix A, Table 2-1, "Sampling Plans for Category A" or Table 2-2, "Sampling Plans for Category B." In Column 1, find the size of the inspection lot (the number recorded in Box 5 of the report form). Read across from Column 1 to find 
the appropriate sample size in Column 2 and record this number in Box 6 of the report form.

3. Randomly select a sample from the inspection lot. Random number tables (see Appendix B. "Random Number Tables") or a calculator that is able to generate random numbers may be used to identify the sample.

Note: If the inspector and the party that is ultimately responsible for the packing and declaration of net weight for the product agree to an alternative method of sample selection, document how the sample packages were selected as part of the inspection record.

\subsubsection{Procedures for Determining Tare}

There are three types of tare for the inspection of packaged goods. The tare weight may vary considerably from package to package as compared with the variability of the package net contents, even for packages in the same production lot. Although this is not common for most packaging, the basic test procedure in this handbook considers the variation for all tare materials.

\section{a. Used Dry Tare}

Used Dry Tare is used tare material that has been air dried, or dried in some manner to simulate the unused tare weight. It includes all packaging materials that can be separated from the packaged product, either readily (e.g., by shaking) or by washing, scraping, ambient air drying, or other techniques involving more than "normal" household recovery procedures, but not including laboratory procedures like oven drying. Labels, wire closures, staples, prizes, decorations, and such are considered tare. Used Dry Tare is available regardless of where the packages are tested. The net content verification procedures described in this handbook reference Used Dry Tare.

Note: When testing frozen foods with Used Dry Tare, the frost found inside frozen food packages is included as part of the net contents, except in instances in which glazed or frozen foods are tested according to Section 2.6. "Net Weight of Encased-in-Ice and Ice Glazed Products.”

\section{b. Unused Dry Tare}

Unused Dry Tare is all unused packaging materials (including glue, labels, ties, etc.) that contain or enclose a product. It includes prizes, gifts, coupons, or decorations that are not part of the product. If testing packages in retail store locations where they are packaged, and sold in small quantities to the ultimate consumers, the basic test procedure may be modified by using samples of the packaging material available in the store.

\section{c. Wet Tare}

Wet Tare is used tare material where no effort is made to dry the tare material. Free-flowing liquids are considered part of the tare weight.

Wet tare procedures must not be used to verify the labeled net weight of packages of meat and poultry packed at an official United States Department of Agriculture (USDA) facility and bearing a USDA seal of inspection. The USDA Food Safety and Inspection Service (FSIS) adopted specific sections of the $20054^{\text {th }}$ Edition of NIST HB 133 by reference in 2008 but not the "wet tare" method for determining net weight compliance. FSIS considers the free-flowing liquids in packages of meat and poultry products, including single-ingredient, raw poultry 
products, to be integral components of these products (see Federal Register, September 9, 2008 [Volume 73, Number 175] [Final Rule - pages 52189-52193]).

If the jurisdiction uses wet tare to determine net weight, follow the procedures described below that reference Used Dry Tare, except make no effort to dry the tare material. If Wet Tare is used to verify the net weight of the packages, the inspector must allow for moisture loss.

(Amended 2010)

\subsubsection{Determination of Tare Sample and Average Tare Weight}

Except in the instance of applying Unused Dry Tare, use this procedure for selecting and determining the tare sample and average tare weight. Depending upon the initial tare sample results, additional tare samples may need to be taken.

1. Determine the initial tare sample size using Column 5 under initial tare sample size in Appendix A. Table 2-1. "Sampling Plans for Category A" or Column 3 under initial tare sample size in Appendix A, Table 2-2. "Sampling Plans for Category B." Record the initial tare sample size in Box 7 on the appropriate form located in Appendix C. Model Inspection Report Forms.

Note: The initial tare sample size is considered the total tare sample size for the inspection lot when the sample size is less than 12 .

2. Except in the instance of applying Unused Dry Tare, select the packages for the initial tare sample from the sample packages. Mark the first two (three or five) packages in the order the random numbers were selected; these packages provide the initial tare sample.

3. Determine the gross weight of each package and record it in Block a, "Gross Wt," under the headings "Pkg. 1," "Pkg. 2," "Pkg. 3," etc. on the report form.

4. Except for aerosol or other pressurized packages, open the sample packages, empty, clean, and dry them as appropriate for the packaging material.

5. Determine the tare weight for each package in the initial tare sample and record the value in Block b, “Tare Wt” under the appropriate package number column.

6. For sample sizes of 12 or more, subtract the individual tare weights from the respective package gross weights (Block a, minus Block b, on the report form) to obtain the net weight for each package and record each value in Block c, "Net Wt," on the report form.

7. Determine and record the "Range of Package Errors $\left(\mathrm{R}_{\mathrm{c}}\right)$ " for the initial tare sample in Box 9 on the report form. The range is the difference between the package errors.

(Amended 2002)

8. Determine and record the "Range of Tare Weights $\left(\mathrm{R}_{\mathrm{t}}\right)$ " in Box 10 .

9. Compute the ratio $R_{c} / R_{t}$ by dividing the value in Box 9 by the value in Box 10. Record the resulting value in Box 11. $R_{c}$ and $R_{t}$ must both be in the same unit of measure or both in dimensionless units. 
10. Determine and record in Box 12 the total number of tare samples to be opened for the tare determination from either Appendix A, Table 2-3. "Category A" or Table 2-4. "Category B.”

$>$ In the first column (titled Ratio of $\mathrm{R}_{\mathrm{c}} / \mathrm{R}_{\mathrm{t}}$ ), locate the range in which the computed $\mathrm{R}_{\mathrm{c}} / \mathrm{R}_{\mathrm{t}}$ falls. Then, read across to the column headed with the appropriate sample size.

$>$ If the total number of packages to open equals the number already opened, go to Step 11.

$>$ If the total number of packages to open is greater than the number of packages already opened, compute the number of additional packages to open for the tare determination.

$>$ Open and weigh as per Steps 3, 4, and 5 and go to Step 11. Enter the total number of tare samples in Box 12.

11. Determine the average tare weight using the tare weight values for all the packages opened and record the average tare weight in Box 13.

\subsection{Unused Dry Tare}

The average tare weight may be determined using samples of Unused Dry Tare when testing meat, poultry, or any other products that are not subject to regulation of the Food and Drug Administration (FDA). You may utilize Unused Dry Tare samples when conducting inspections at locations where the point-of-pack and sale are identical (e.g., store-packed products in a supermarket meat case). To determine Unused Dry Tare at the point-of-sale, randomly select two (2) samples of Unused Dry Tare, and weigh each separately. If there is no measurable variation in weight between the samples, proceed with the test using the weight of one of the samples. If the weight of the two (2) initial samples varies, randomly select three (3) additional tare samples and determine the average weight of all five (5) samples. Use this value as the average tare weight.

\subsubsection{Special Procedures for Determining Tare}

\section{a. Aerosol Containers}

Aerosol containers: are handled differently for two reasons. First, regulations in NIST HB 130 under the "Uniform Packaging and Labeling Regulation" (UPLR) require that packages designed "to deliver" the product under pressure, "must state the net quantity of the contents that will be expelled when the instructions for use as shown on the container are followed." This means that any product retained in aerosol containers after full dispersion is included in the tare weight. Second, aerosol containers must not be opened because they are pressurized; for safety reasons they should not be punctured or opened. When emptying aerosol containers to determine a tare weight, exhaust them in a well-ventilated area (e.g., under an exhaust hood or outdoors) at least $15 \mathrm{~m}$ (50 ft) from any source of open flame or spark. 
To ensure that the container properly dispenses the product, read and follow any dispensing instructions on the package. If shaking during use is specified in the instructions, periodically shake (at least two or three times during expulsion of the product). If directions are not given, shake the container five times with a brisk wrist twisting motion. If the container has a ball agitator, continue the shaking procedure for one minute after the ball has shaken loose.

\section{b. Vacuum Packed Coffee}

The gross weight of a container (typically a metal can) of vacuum-packed coffee will be more after the seal is broken and air enters the can. In the procedure to determine the tare weight of the packaging material, correct the gross weight determined for unopened cans as follows. Use the initial tare sample packages, weigh, and record the gross weight of the product-filled cans before and after breaking the vacuum seal. Compute the average gross weight difference (open weight minus sealed weight) and record this in Box 13a of the report form. The nominal gross weight equals the average tare weight minus the average difference in gross weights plus the labeled weight (Box 14): Box 13 - Box 13a + Box 1.

(Amended 2002)

\subsubsection{Determine Nominal Gross Weight and Package Error}

\subsubsection{Determine Nominal Gross Weight}

A nominal gross weight is used to calculate package errors. To compute the nominal gross weight, add the average tare weight (recorded in Box 13) to the labeled weight (recorded in Box 1). Record in Box 14.

The nominal gross weight is represented by the formula:

$$
\text { Nominal gross weight }=\text { average tare }+ \text { labeled weight }
$$

\subsubsection{Determine Package Error}

To obtain the package error, subtract the nominal gross weight from each package's gross weight. The package error is represented by the formula:

(Added 2010)

$$
\text { Package error }=\text { gross weight }- \text { nominal gross weight }
$$

Determine the errors of the packages opened for tare by subtracting the nominal gross weight recorded in Box 14 from the individual package gross weights recorded for each package (Pkg. 1, Pkg. 2, etc.) in Block a, "Gross Wt." The nominal gross weight must be used, rather than the actual net weight, for each package to determine the package error. This ensures that the same average tare weight is used to determine the error for every package in the sample, not just the unopened packages.

- Standard Packages. - Record the package error in the appropriate plus or minus column on the report form for each package opened for tare.

- Random Packages. - Determine the package error for the tare sample using a nominal gross weight for each package so that all of the package errors are determined with the same tare weight value. Record the package error on the Random Package Report Form 
in the appropriate plus or minus column under Package Errors.

Note: Converting the package error to dimensionless units allows the inspector to record the package errors as whole numbers disregarding decimal points and zeroes in front and unit of measure after the number. This section does not prohibit the use of software or units of weight instead of dimensionless units.

\section{Example:}

If weighing in $0.001 \mathrm{lb}$ increments, the unit of measure is $0.001 \mathrm{lb}$. If the package error for the first package opened for tare is $+0.008 \mathrm{lb}$, instead of recording $0.008 \mathrm{lb}$ in the plus column, record the error as " 8 " in the plus column. If the second package error is $+0.060 \mathrm{lb}$, record the package error as " 60 " in the plus column, and so on.

Determine the errors for the rest of the sample by subtracting the nominal gross weight (Box 14) from the gross weight of each of the unopened sample packages. Record the package errors in the "Package Errors" section of the report form using either units of weight (lb or g) or dimensionless units.

\subsubsection{Compute Total Package Error}

Add all the package errors for the packages in the sample. Be sure to subtract the minus package errors from the plus package errors and to record the total net error in Box 15, indicating the positive or negative value of the error.

(Amended 2010)

\subsubsection{Evaluate for Compliance}

The following steps lead the inspector through the process to determine if a sample passes or fails. If the product is subject to moisture allowance, follow the procedures under Section 2.3.8. "Moisture Allowances” to correct the MAV.

\subsubsection{Maximum Allowable Variation (MAV) Requirement:}

1. Compare each minus package error with the MAV recorded in Box 3 or Box 4 (if using dimensionless units). Circle the package errors that exceed the MAV. These are "Unreasonable Minus Errors." Record the number of unreasonable minus errors found in the sample in Box 16.

2. Compare the number in Box 16 with the number of unreasonable errors allowed (recorded in Box 8). If the number found exceeds the allowed number, the lot fails. Record in Box 17 whether the number of unreasonable errors found is less or more than allowed.

\subsubsection{Average Requirement:}

1. Determine the average error by dividing the total error recorded in Box 15 by the sample size recorded in Box 6. Record the average error in Box 18 if using dimensionless units or in Box 19 if using units of weight.

2. Compute the average error in terms of weight (if working in dimensionless units up to 
this time) by multiplying the average error in dimensionless units by the unit of measure and record the value in Box 19. If the average error is positive, the inspection lot passes the average requirement. If the average error is negative, the inspection lot fails under a "Category B" test. Record in Box 20.

Note: If the total error recorded in Box 15 is a plus value, and Box 17 is "No," (the number of unreasonable errors is equal to or less than the number allowed, recorded in Box 8), the lot passes.

3. If the average error is a negative value when testing under the Sampling Plans for "Category A," compute the Sample Error Limit (SEL) as follows:

$>$ Compute the Sample Standard Deviation and record it in Box 21.

$$
s=\sqrt{\frac{1}{n-1} \sum_{i=1}^{n}\left(\mathrm{X}_{i}-\overline{\mathrm{X}}\right)^{2}}
$$

Obtain the Sample Correction Factor from Column 3 of Appendix A. Table 2-1. "Sampling Plans for Category A" test. Record this value in Box 22.

$>$ Compute the Sample Error Limit using the formula:

Sample Error Limit (Box 23)= Sample Standard Deviation (Box 21) x Sample Correction Factor (Box 22)

4. Compliance Evaluation of the Average Error:

$>$ If the value of the Average Error (Box 18) is smaller than the Sample Error Limit (Box 23), the inspection lot passes.

$>$ If the value of the Average Error (disregarding the sign) (Box 18) is larger than the Sample Error Limit (Box 23), the inspection lot fails. However, if the product is subject to moisture loss, the lot does not necessarily fail. Follow the procedures under "Moisture Allowances" in this chapter.

\subsubsection{Moisture Allowances}

When no predetermined allowance is found in NIST HB 133, the potential for moisture loss must be considered. Inspectors should follow their jurisdiction's guidance for making their determination on an acceptable moisture allowance.

(Added 2010)

If the product tested is subject to moisture loss, provide for the moisture allowance by following one of the two procedures listed below.

\subsubsection{Applying Moisture Loss before Determining Package Errors}

1. Determine the percent value of the moisture allowance if the product is listed below. (See Table 2-3. "Moisture Allowances.”) 


\begin{tabular}{|c|c|c|}
\hline \multicolumn{3}{|c|}{$\begin{array}{c}\text { Table 2-3. } \\
\text { Moisture Allowances }\end{array}$} \\
\hline $\begin{array}{l}\text { Verifying the labeled } \\
\text { net weight of packages } \\
\text { of: }\end{array}$ & $\begin{array}{c}\text { Moisture } \\
\text { Allowance is: }\end{array}$ & Notes \\
\hline Flour & $3 \%$ & \\
\hline Dry pet food & $3 \%$ & $\begin{array}{l}\text { Dry pet food means all extruded dog and cat foods and } \\
\text { baked treats packaged in Kraft paper bags and/or cardboard } \\
\text { boxes with a moisture content of } 13 \% \text { or less at time of } \\
\text { pack. }\end{array}$ \\
\hline Pasta products & $3 \%$ & $\begin{array}{l}\text { Pasta products means all macaroni, noodle, and like } \\
\text { products packaged in kraft paper bags, paperboard cartons, } \\
\text { and/or flexible plastic bags with a moisture content of } 13 \% \\
\text { or less at the time of pack. }\end{array}$ \\
\hline Borax & $\begin{array}{c}\text { See } \\
\text { Section } 2.4 .\end{array}$ & \\
\hline \multicolumn{3}{|r|}{ Wet Tare Only ${ }^{1}$} \\
\hline Fresh poultry & $3 \%$ & $\begin{array}{l}\text { Fresh poultry is defined as poultry above a temperature of } \\
-3^{\circ} \mathrm{C}\left(26^{\circ} \mathrm{F}\right) \text { that yields or gives when pushed with the } \\
\text { thumb. }\end{array}$ \\
\hline Franks or hot dogs & $2.5 \%$ & \\
\hline $\begin{array}{l}\text { Bacon, fresh sausage, } \\
\text { and luncheon meats }\end{array}$ & $0 \%$ & $\begin{array}{l}\text { For packages of bacon, fresh sausage, and luncheon meats, } \\
\text { there is no moisture allowance if there is no free-flowing } \\
\text { liquid or absorbent material in contact with the product and } \\
\text { the package is cleaned of clinging material. Luncheon } \\
\text { meats are any cooked sausage product, loaves, jellied } \\
\text { products, cured products, and any sliced sandwich-style } \\
\text { meat. This does not include whole hams, briskets, roasts, } \\
\text { turkeys, or chickens requiring further preparation to be } \\
\text { made into ready-to-eat sliced product. When there is no } \\
\text { free-flowing liquid inside the package and there are no } \\
\text { absorbent materials in contact with the product, Wet Tare } \\
\text { and Used Dried Tare are equivalent. }\end{array}$ \\
\hline \multicolumn{3}{|c|}{$\begin{array}{l}{ }^{1} \text { Wet tare procedures must not be used to verify the labeled net weight of packages of meat and poultry } \\
\text { packed at an official United States Department of Agriculture (USDA) facility and bearing a USDA seal } \\
\text { of inspection. The Food Safety and Inspection Service (FSIS) adopted specific sections of the } 2005 \\
4^{\text {th }} \text { edition of NIST HB } 133 \text { by reference in } 2008 \text { but not the "Wet Tare" method for determining net } \\
\text { weight compliance. FSIS considers the free-flowing liquids in packages of meat and poultry products, } \\
\text { including single-ingredient, raw poultry products, to be integral components of these products (see } \\
\text { Federal Register, September 9, } 2008 \text { [Volume } 73 \text {, Number } 175 \text { ] [Final Rule - pages 52189-52193]). }\end{array}$} \\
\hline
\end{tabular}

(Amended 2010 and 2013)

Note: There is no moisture allowance when inspecting meat and poultry from a USDA inspected plant when Used Dry Tare and “Category A” sampling plans are used. 
Note: For the Wet Tare Only section of Table 2-3, free-flowing liquid and liquid absorbed by packaging materials in contact with the product are part of the wet tare.

(Added 2010)

2. To compute moisture allowance, multiply the labeled quantity by the decimal percent value of the allowance. Record this value in Box 13a.

\section{Example:}

Labeled net quantity of flour is $907 \mathrm{~g}(2 \mathrm{lb})$

Moisture Allowance is $3 \%(0.03)$

Moisture Allowance $=907 \mathrm{~g}(2 \mathrm{lb}) \times 0.03=27 \mathrm{~g}(0.06 \mathrm{lb})$

3. If the Moisture Allowance is known in advance (e.g., flour, pasta products, and dry pet food), it can be applied by adjusting the Nominal Gross Weight used to determine the sample package errors. The Moisture Allowance in Box 13a is subtracted from the Nominal Gross Weight to obtain an Adjusted Nominal Gross Weight which is entered in Box 14. The Nominal Gross Weight is defined in Section 2.3.6.1. as the sum of the Labeled Weight and the Average Tare Weight from Box 13.

\section{Example:}

Use a Labeled Weight of $907 \mathrm{~g}(2 \mathrm{lb})$ and an Average Tare Weight of $14 \mathrm{~g}$ (0.03 lb)

The calculation is:

Labeled Net Quantity of Contents $907 \mathrm{~g}(2 \mathrm{lb})+$ Average Tare Weight $14 \mathrm{~g}$ $(0.03 \mathrm{lb})=921 \mathrm{~g}(2.03 \mathrm{lb})-$ Moisture Allowance $27 \mathrm{~g}(0.06 \mathrm{lb})=$ Adjusted Nominal Gross Weight of $894 \mathrm{~g}(1.97 \mathrm{lb})$

This result is entered in Box 14.

4. Determine package errors by subtracting the Adjusted Nominal Gross Weight from the Gross Weights of the Sample Packages.

\section{Example:}

The calculation is:

\section{Gross Weight of the Sample Packages - Adjusted Nominal Gross Weight = Package Error}

Note: When the Nominal Gross Weight is adjusted by subtracting the Moisture Allowance value(s) the Maximum Allowable Variation(s) is not changed. This is because the errors that will be found in the sample packages have been adjusted by subtracting the Moisture Allowance (e.g., $3 \%$ ) from the Nominal Gross Weight. That increases the individual package errors by the amount of the moisture allowance (e.g., $3 \%$ ). If the value(s) of the MAV(s) were also adjusted it would result in doubling the allowance. MAV is always based on the labeled net quantity.

(Added 2010) 


\subsubsection{Applying Moisture Allowance after Determining Package Errors}

Adjustments can be made when the value of the Moisture Allowance is determined following the test (e.g., after the sample fails or if a packer provides reasonable moisture allowance based on data obtained using a scientific method) using the following approach:

If the sample fails the Average Requirement but has no unreasonable package errors, only Step 1 is used. If the sample passes the Average Requirement but fails because the sample included one or more Unreasonable Minus Errors, only Step 2 is used.

If the sample fails the Average and MAV Requirements, both of the following steps are applied.

1. Use the following approach to apply a Moisture Allowance to the Average Requirement after the test is completed:

the Moisture Allowance is computed;

\section{Example:}

$3 \% \times 907 g(2 \mathrm{lb})=27 g(0.06 \mathrm{lb})$

added to the Sample Error Limit;

\section{Example:}

If the Sample Error Limit is 0.023, add 0.06 to obtain an Adjusted Sample Error Limit of 0.083)

the Adjusted Sample Error Limit is then compared to the Average Error of the Sample; and

$>$ if the average error (disregarding sign) in Box 18 is smaller than the Adjusted Sample Error Limit, the sample passes.

\section{HOWEVER,}

$>$ if the average error (disregarding sign) in Box 18 is larger than the Adjusted Sample Error Limit, the sample fails.

2. To apply Moisture Allowance to the MAV(s) after the test, the following method is recommended:

compute Moisture Allowance;

\section{Example:}

$3 \% \times 907 g(2 \mathrm{lb})=27 g(0.06 \mathrm{lb})$

$>$ add to MAV for labeled net quantity of the package to get Adjusted Maximum Allowable Variations ; 


\section{Example:}

MAV for $907 \mathrm{~g}(2 \mathrm{lb})$ is $31.7 \mathrm{~g}(0.07 \mathrm{lb})+27 \mathrm{~g}(0.06 \mathrm{lb})=$

Adjusted Maximum Allowable Variation(s) of $58.7 \mathrm{~g}(0.13 \mathrm{lb})$

compare each minus package error to the Adjusted MAV;

mark package errors that exceed the Adjusted MAV and record the number of unreasonable minus errors found in the sample; and

$>$ if this number exceeds the number of unreasonable errors allowed, the sample fails.

(Added 2010)

\subsubsection{Moisture Allowance Gray Area}

When the average error of a lot of fresh poultry, franks/hot dogs, or pasta products is minus but does not exceed the established "moisture allowance" or "gray area," contact the packer or plant management personnel to determine what information is available on the lot in question. Questions to the plant management representative may include:

- Is a quality control program in place?

- What information is available concerning the lot in question?

- If net weight checks were completed, what were the results of those checks?

- What adjustments, if any, were made to the target weight?

Note: If the plant management has data on the lot, such data may help to substantiate that the "lot" had met the net content requirements at the point of manufacture.

This handbook provides "moisture allowances" for some meat and poultry products, flour, pasta products, and dry pet food. These allowances are based on the premise that when the average net weight of a sample is found to be less than the labeled weight, but not by an amount that exceeds the allowable limit, either the lot is declared to be within the moisture allowance or further investigation can be conducted.

Reasonable variations from net quantity of contents caused by the loss or gain of moisture from the package are permitted when caused by ordinary and customary exposure to conditions that occur under good distribution practices. If evidence is obtained and documented to prove that the lot was shipped from the packaging plant in a short-weight condition or was distributed under inappropriate or damaging distribution practices, appropriate enforcement action should be taken.

(Amended 2010 and 2013)

\subsection{Borax}

Use the following procedure to determine if packages of borax are labeled correctly. This procedure applies to packages of powdered or granular products consisting predominantly (more than $50 \%$ ) of borax. Such commodities are labeled by weight. Borax can lose more than $23 \%$ of its weight due to moisture loss. However, it does not lose volume upon moisture loss, and this property makes possible a method of volume testing based on a density determination in the event that the net weight of the product 
does not meet the average or individual package requirements. This method may be used for audit testing to identify possible short-filling by weight at point-of-pack. Since the density of these commodities can vary at point-of-pack, further investigation is required to determine whether such short-filling has occurred.

\subsubsection{Test Equipment}

- $\quad$ Metal density cup with a capacity of $550.6 \mathrm{~mL}$ or (1 dry pt)

- Metal density funnel with slide-gate and stand

- Scale or balance having a scale division not larger than $1 \mathrm{~g}$ or (0.002 lb)

- Rigid straightedge or ruler

- Pan suitable for holding overflow of density cup

\subsubsection{Test Procedure}

1. Follow Section 2.3.1. through 2.3.7 to define the inspection lot, use a "Category A" sampling plan in the inspection; select a random sample, determine tare and package errors and evaluate results.

2. If the lot does not comply by weight with the sampling plan requirements (either the average or individual package requirements), select the lightest package, and record the net weight of this package.

3. Determine the empty weight of the density cup.

4. Place the density cup in the pan and put the funnel on top of the density cup. Close the funnel slide-gate.

5. Pour sufficient commodity into the funnel so that the density cup can be filled to overflowing.

6. Quickly remove the slide-gate from the funnel, allowing the commodity to flow into the density cup.

7. Carefully, without agitating the density cup, remove the funnel and level off the commodity with the ruler or straightedge. Hold the ruler or straightedge at a right angle to the rim of the cup, and carefully draw it back across the top of the density cup to leave an even surface.

8. Weigh (in pounds) the filled density cup to determine gross weight. Subtract the empty density cup weight from the gross weight. This will give the net weight of the commodity.

9. Multiply the package net weight (in pounds) found for the package under test by 550.6.

10. Divide the answer just obtained (Step 9) by the weight of the commodity in the density cup, determined in Step 8 above. The result is the net volume of commodity in the package in milliliters. 
11. Compare the net volume of the commodity in the package with the volume declared on the package. The volume declaration must not appear on the principal display panel. Instead, it will appear on the back or side of the package and may appear as:

Volume mL per NIST Handbook 133

Note: $1 \mathrm{~mL}=1 \mathrm{~cm}^{3}$

12. If the net volume of commodity in the lightest package equals or exceeds the declared volume on the package, treat the lot as being in compliance based on volume and take no further action. If the net volume of borax in the lightest package is less than the declared volume on the package, further compliance testing will be necessary.

13. Take further steps to determine if the lot was in compliance with net weight requirements at point-of-pack or was short-filled by weight. To determine this, perform a laboratory moisture loss analysis to ascertain the weight of the original borax product when it was fully hydrated; obtain additional data at the location of the packager; and/or investigate the problem with the packager of the commodity.

\subsection{Determination of Drained Weight}

Since the weight per unit volume of a drained product is of the same order of magnitude as that of the packaging liquid that is drained off, an "average nominal gross weight" cannot be used in checking packages of this type. The entire sample must be opened. The procedure is based upon a test method accepted by the U.S. Food and Drug Administration (FDA).

A tare sample is not needed because all the packages in the sample will be opened and measured.

The weight of the container plus drained-away liquid is determined. This weight is then subtracted from the gross weight to determine the package error.

\subsubsection{Test Equipment}

- Scales and weights recommended in Section 2.2. "Measurement Standards and Test Equipment" are suitable for the determination of drained weight.

- $\quad$ Sieves

$>$ For drained weight of $1.36 \mathrm{~kg}$ or $(3 \mathrm{lb})$ or less, one $20 \mathrm{~cm}$ or (8 in) No. 8 mesh U.S. Standard Series sieve, receiving pan, and cover;

$>$ For drained weight greater than $1.36 \mathrm{~kg}$ or $(3 \mathrm{lb})$, one $30 \mathrm{~cm}$ or (12 in) sieve, with same specifications as above;

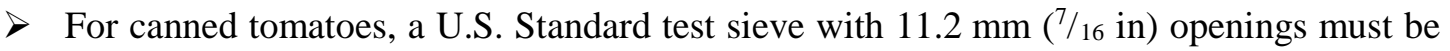
used.

NOTE: The sieve is used, if is necessary, to determine the percentage of solids in the container. 
- Stopwatch

(Amended 2010)

\subsubsection{Test Procedure}

1. Follow the Section 2.3.1 through Section 2.3.4. to define an inspection lot, select "Category A" or a "Category B" sampling plan in the inspection (depending on the location of test); and select a random sample.

2. Use Appendix C. "Standard Package Report." Fill out Boxes 1 through 8. Determine and record on a worksheet the weight of the receiving pan.

3. Determine and record on a worksheet the gross weight of each individual package comprising the sample.

4. Pour the contents of the first package into the dry sieve with the receiving pan beneath it, incline sieve to an angle between $17^{\circ}$ to $20^{\circ}$ from horizontal to facilitate drainage, and allow the liquid from the product to drain into receiving pan for two minutes. (Do not shake or shift material on the sieve.) Remove sieve and product.

5. Weigh the receiving pan, liquid, wet container, and any other tare material. (Do not include sieve and product.) Record this weight as tare and receiving pan on the worksheet.

6. Subtract the weight of the receiving pan, determined in Step 2, from the weight obtained in Step 5 to obtain the package tare weight (which includes the weight of the liquid). Record package tare weight on the worksheet with the associated gross weight of the package.

7. Subtract the tare weight, found in Step 6, from the corresponding package gross weight determined in Step 3 to obtain the drained weight of that package. Record package net weight on the worksheet. Determine the package error (drained weight - labeled drained weight) and record on worksheet.

8. Repeat Steps 4 through 7 for the remaining packages in the sample, cleaning and drying the sieve and receiving pan between measurements of individual packages.

9. Transfer the individual package errors to the Standard Pack Report form.

10. To determine lot conformance, return to Section 2.3.7. "Evaluate for Compliance.”

\subsection{Net Weight of Encased-in-Ice and Ice Glazed Products}

\subsubsection{Net Weight of Encased in Ice and Frozen Block Product}

Note: For determining the net weight of ice glazed seafood, meat, poultry, or similar products, follow the procedure in Section 2.6.2. "Net Weight of Ice Glazed Seafood, Meat, Poultry or Similar Products.”

\subsubsection{Test Equipment}

- Balance and weights (used to verify accuracy) 
- Partial immersion thermometer or equivalent with $1{ }^{\circ} \mathrm{C}\left(2^{\circ} \mathrm{F}\right)$ graduations and a $-35^{\circ} \mathrm{C}$ to $+50^{\circ} \mathrm{C}\left(-30^{\circ} \mathrm{F}\right.$ to $\left.+120^{\circ} \mathrm{F}\right)$ accurate to $\pm 1^{\circ} \mathrm{C}\left( \pm 2{ }^{\circ} \mathrm{F}\right)$

- Water source and hose with an approximate flow rate of $4 \mathrm{~L}$ to $15 \mathrm{~L}$ (1 gal to 4 gal) per minute for thawing blocks and other products

- Sink or other receptacle [i.e., bucket with a capacity of approximately $15 \mathrm{~L}$ (4 gal)] for thawing blocks and other products

- A wire mesh basket (e.g., used for testing large frozen blocks of shrimp) or a container that is large enough to hold the contents of one package (e.g., $2.27 \mathrm{~kg}$ or [5 lb] box of shrimp) and has openings small enough to retain all pieces of the product (e.g., an expanded metal test tube basket lined with standard 16-mesh screen)

- Number 8 mesh, $20 \mathrm{~cm}$ (8 in) or $30 \mathrm{~cm}$ (12 in) sieve

- Means to determine a $30^{\circ}$ angle

- Pan for weighing the thawed and drained product

- Stopwatch

\subsubsection{Test Procedure for Encased-in-Ice Product Only}

1. Follow Section 2.3.1. through 2.3.4. to define the inspection lot, select a sampling plan and select a random sample.

2. Place the unwrapped frozen seafood, meat, poultry, or similar products in the wire mesh basket or an open container to thaw (e.g., it is not placed in a plastic bag) and immerse in a $15 \mathrm{~L}$ (4 gal) or larger container of fresh water at a temperature between $23^{\circ} \mathrm{C}$ to $29^{\circ} \mathrm{C}\left(75^{\circ} \mathrm{F}\right.$ to $\left.85^{\circ} \mathrm{F}\right)$. Submerge the basket so that the top of the basket extends above the water level.

3. Maintain a continuous flow of water into the bottom of the container to keep the temperature within the specified range. This is accomplished by maintaining a constant flow of warm water into the container holding the product (e.g., place a bucket in a sink to catch the overflow, and feed warm water into the bottom of the bucket through a hose).

Note: Direct immersion does not result in the product absorbing moisture because the freezing process causes the tissue to lose its ability to hold water.

4. As soon as the product thaws, determined by loss of rigidity, transfer all material to a sieve $(20 \mathrm{~cm}$ [8 in] for packages less than $453 \mathrm{~g}$ [1 lb] or $30 \mathrm{~cm}$ [12 in] for packages weighing more than $453 \mathrm{~g}$ [1 lb]) and distribute it evenly over the sieve.

5. Without shifting the product, incline the sieve $30^{\circ}$ from the horizontal position to facilitate drainage, and drain for two minutes.

6. While the product is draining, place pan on scale and tare the scale reading to zero. 
7. At the end of the drain time, immediately transfer the product to the tared pan for weighing to determine the net weight of the product.

(Amended 2010)

\subsubsection{Net Weight of Ice Glazed Seafood, Meat, Poultry or Similar Products}

For ice glazed seafood, meat, poultry or similar products, determine the net weight after removing the glaze using the following procedure.

\subsubsection{Test Equipment}

- Balance and weights (used to verify accuracy)

- Continuous cold water source

- Number 8 sieve and receiving pan, $20 \mathrm{~cm}$ (8 in) for packages $453 \mathrm{~g}$ (1 lb) or less. A $30 \mathrm{~cm}$ (12 in) for packages more than $453 \mathrm{~g}(1 \mathrm{lb})$.

- Means to determine a $17^{\circ}$ to $20^{\circ}$ angle

- Stopwatch

\subsubsection{Test Procedures for Ice-Glazed Product Only}

1. Follow the Section 2.3.1. through Section 2.3.4. to define an inspection lot, select "Category A" or a "Category B" sampling plan in the inspection (depending on the location of test), and select a random sample.

2. Fill out the header information on boxes 1 through 8 on the Ice Glazed Package Report form (See Appendix C). A tare sample is not needed. Record package price, price per pound, lot size, sample size, and unit of measure in Step 1 of the Ice Glazed Package Worksheet (See Appendix C).

Note: Use an official inspection report to record the inspection information. Attach additional worksheets, test notes, and other information as needed. This handbook provides an Ice Glazed Worksheet and Ice Glazed Package Report form in Appendix C. Modify the worksheet, package report and the box numbers to meet your agency's needs. Other formats that contain more or less information may be acceptable.

3. Number each package. Weigh each package for gross package weight and enter in Row 1 “Gross Pkg. Weight” on worksheet.

4. Enter the labeled net weight in Row 2 "Labeled Net Weight" for each package on the worksheet. If dual units, determine and enter the larger of the two units.

5. Record the maximum allowable variation on Row 3 "MAV" on the worksheet.

6. Weigh receiving pan and record the weight in Row 4, "Receiving Pan Weight" on the worksheet. 
7. Deglaze the product. Remove a package from low temperature storage; open it immediately and place the contents in the sieve or other draining device (e.g., colander) under a gentle spray of cold water. Carefully agitate the product. Handle with care to avoid breaking the product. Continue the spraying process until all ice glaze, that is seen or felt is removed. In general, the product should remain rigid; however, the ice glaze on certain products, usually smaller sized commodities, sometimes cannot be removed without partial thawing of the product. Nonetheless, remove all ice glaze because it may be a substantial part of the package weight.

8. Transfer the product to the sieve (if the product is not already in the sieve). Without shifting the product, incline the sieve to an angle of $17^{\circ}$ to $20^{\circ}$ to facilitate drainage and drain (into waste receptacle or sink) for two minutes using a stopwatch.

9. At the end of the drain time, immediately transfer the entire product to the receiving pan for weighing to determine the net weight.

10. Place the product and receiving pan on the scale and weigh. Record the net weight in Row 5 on the ice glazed package worksheet. The net weight of product is equal to the weight of the receiving pan and the product minus the receiving pan weight.

11. The package error is equal to the net weight of the product minus the labeled weight. Record the package error in Row 6.

12. Repeat Steps 2 through 10 for each package in the sample, cleaning the sieve, cleaning and drying the receiving pan between package measurements.

13. Transfer data from the Ice Glazed Package Worksheet to the Ice Glazed Package Report.

\subsubsection{Evaluation of Results}

Follow the procedures in Section 2.3.7. "Evaluate for Compliance."

(Amended 2010) 


\section{Chapter 3. Test Procedures - For Packages Labeled by Volume}

\subsection{Scope}

Use these procedures to determine the net contents of packaged goods labeled in fluid volume such as milk, water, beer, oil, paint, distilled spirits, soft drinks, juices, liquid cleaning supplies, or chemicals. This chapter also includes procedures for testing the capacities of containers such as paper cups, bowls, glass tumblers, and stemware.

These procedures do not cover berry baskets and rigid-dry measures that are covered by specific code requirements in NIST Handbook 44 "Specifications, Tolerances, and Other Technical Requirements for Weighing and Measuring Devices.”

\subsubsection{Test Methods}

The gravimetric procedure may be used to verify the net quantity of contents of packages labeled in volume when the density (density means the weight of a specific volume of liquid determined at a reference temperature) of the product being tested does not vary excessively from one package to another.

If the density varies from one package to another, test each package using the volumetric test procedures described in this chapter. Special test methods are required for a number of unique products so care should be taken to select the correct test procedure.

\section{Reference Temperature:}

In addition to possible package-to-package variations in product density, the temperature of the liquid will affect the volume of product. The product will expand or contract based on a rise or fall in product temperature.

\section{Example:}

The volume of a liquid cleaning product might be $5 \mathrm{~L}(1.32 \mathrm{gal})$ at $20^{\circ} \mathrm{C}\left(68{ }^{\circ} \mathrm{F}\right)$ and $5.12 \mathrm{~L}$ (1.35 gal) at $25^{\circ} \mathrm{C}\left(77^{\circ} \mathrm{F}\right)$, which represents a $2.2 \%$ change in volume.

Note: This extreme example is for illustrative purposes. A $2.2 \%$ volume change will not occur in normal testing.

Use the reference temperature specified in Table 3-1. "Reference Temperatures for Liquids" to determine volume. When checking liquid products labeled by volume using the gravimetric procedure, maintain the packages used to determine product densities at reference temperatures. If testing the packages in a sample volumetrically, each package in the sample must be maintained at or corrected to the reference temperature when its volume is determined.

Note: When checking liquid products using a volumetric or gravimetric procedure, the temperature of the samples must be maintained at the reference temperature $\pm 2{ }^{\circ} \mathrm{C}\left( \pm 5^{\circ} \mathrm{F}\right)$. 
Table 3-1.

Reference Temperatures for Liquids

\begin{tabular}{|c|c|c|}
\hline If the liquid commodity is: & $\begin{array}{l}\text { Volume is determined at the } \\
\text { reference temperature of: }\end{array}$ & $\begin{array}{c}\text { Code of Federal Regulation } \\
\text { Reference* }\end{array}$ \\
\hline Beer & $4^{\circ} \mathrm{C}\left(39.1^{\circ} \mathrm{F}\right)$ & 27 CFR, Part 7.10 \\
\hline Distilled Spirits & $15.56^{\circ} \mathrm{C}\left(60^{\circ} \mathrm{F}\right)$ & 27 CFR, Part 5.11 \\
\hline $\begin{array}{l}\text { Frozen food - sold and consumed } \\
\text { in the frozen state }\end{array}$ & At the frozen temperature & 21 CFR §101.105(b)(2)(i) \\
\hline Petroleum & $15.6^{\circ} \mathrm{C}\left(60^{\circ} \mathrm{F}\right)$ & 16 CFR §500.8(b) \\
\hline $\begin{array}{l}\text { Refrigerated food (e.g., milk and } \\
\text { other dairy products labeled } \\
\text { "KEEP REFRIGERATED") }\end{array}$ & $4^{\circ} \mathrm{C}\left(40^{\circ} \mathrm{F}\right)$ & 21 CFR §101.105(b)(2)(ii) \\
\hline $\begin{array}{l}\text { Other liquids and wine (e.g., } \\
\text { includes liquids sold in a } \\
\text { refrigerated state for immediate } \\
\text { customer consumption such as } \\
\text { soft-drinks, bottled water and } \\
\text { others that do not require } \\
\text { refrigeration) }\end{array}$ & $20^{\circ} \mathrm{C}\left(68^{\circ} \mathrm{F}\right)$ & $\begin{array}{l}\text { Food: } 21 \text { CFR 101.105(b)(2)(iii) } \\
\text { Non-Food: } 16 \text { CFR } \S 500.8(b) \\
\text { Wine: } 27 \text { CFR, Part } 4.10 \text { (b) }\end{array}$ \\
\hline
\end{tabular}

(Amended 2010)

\subsection{Gravimetric Test Procedure for Non-Viscous Liquids}

\subsubsection{Test Equipment}

- A scale that meets the requirements in Chapter 2, Section 2.2. "Measurement Standards and Test Equipment."

Note: To verify that the scale has adequate resolution for use, it is first necessary to determine the density of the liquid; next verify that the scale division is no larger than MAV/6 for the package size under test. The smallest graduation on the scale must not exceed the weight value for MAV/6.

\section{Example:}

Assume the inspector is using a scale with $1 \mathrm{~g}(0.002 \mathrm{lb})$ increments to test packages labeled $1 \mathrm{~L}$ (33.8 fl oz) that have an MAV of $29 \mathrm{~mL}$ (1 fl oz). Also, assume the inspector finds that the weight of $1 \mathrm{~L}$ of the liquid is $943 \mathrm{~g}(2.078 \mathrm{lb})$. This will result in an MAV/6 value in weight of $4.715 \mathrm{~g}(0.010 \mathrm{lb})$ :

$$
\begin{array}{ll}
29 \mathrm{~mL} / 6=4.8 \mathrm{~mL} & (1 \mathrm{fl} \mathrm{oz} / 6=0.166 \mathrm{fl} \mathrm{oz}) \\
943 \mathrm{~g} / 1000 \mathrm{~mL}=0.943 \mathrm{~g} / \mathrm{mL} & (2.078 \mathrm{lb} / 33.6 \mathrm{fl} \mathrm{oz}=0.0618 \mathrm{lb} / \mathrm{fl} \mathrm{oz}) \\
4.8 \mathrm{~mL} \times 0.943 \mathrm{~g} / \mathrm{mL}=4.5264 \mathrm{~g} & (0.1666 \mathrm{fl} \mathrm{oz} \times 0.0618 \mathrm{lb} / \mathrm{fl} \mathrm{oz}=0.010 \mathrm{lb})
\end{array}
$$

In this example, the $1 \mathrm{~g}(0.002 \mathrm{lb})$ scale division is smaller than the MAV/6 value of $4.5264 \mathrm{~g}$ $(0.010 \mathrm{lb})$ so the scale is suitable for making a density determination. 
- A partial immersion thermometer (or equivalent) with a range of $-35^{\circ} \mathrm{C}$ to $+50{ }^{\circ} \mathrm{C}\left(30{ }^{\circ} \mathrm{F}\right.$ to $\left.120^{\circ} \mathrm{F}\right)$, at least $1^{\circ} \mathrm{C}\left(1^{\circ} \mathrm{F}\right)$ graduations, and with a tolerance of $\pm 1^{\circ} \mathrm{C}\left( \pm 2{ }^{\circ} \mathrm{F}\right)$.

- Volumetric measures

Note: When checking packages labeled in SI units, flask sizes of $100 \mathrm{~mL}, 200 \mathrm{~mL}, 500 \mathrm{~mL}$, $1 \mathrm{~L}, 2 \mathrm{~L}, 4 \mathrm{~L}$, and $5 \mathrm{~L}$ and a $50 \mathrm{~mL}$ cylindrical graduate with $1 \mathrm{~mL}$ divisions may be used. When checking packages labeled in U.S. customary units the use of measuring flasks and graduates with capacities of gill, half-pint, pint, quart, half-gallon, gallon, and a $2 \mathrm{fl} \mathrm{oz}$ cylindrical graduate, graduated to $1 / 2 \mathrm{fl} \mathrm{dr}$ is recommended.

- Defoaming agents may be necessary for testing liquids such as beer and soft drinks that effervesce or are carbonated. Two such products are Hexanol or Octanol (Capryl Alcohol*).

*Note: The mention of trade or brand names does not imply that these products are endorsed or recommended by the U.S. Department of Commerce over similar products commercially available from other manufacturers.

- Bubble level at least $15.24 \mathrm{~cm}$ (6 in) in length

- Stopwatch

\subsubsection{Test Procedure}

1. Follow Section 2.3.1. "Define the Inspection Lot." Use a "Category A" sampling plan in the inspection. Select a random sample.

2. Bring the sample packages and their contents to the reference temperature as specified in Table 3-1. "Reference Temperatures for Liquids." To determine if the liquid is at its reference temperature, immerse the thermometer in the liquid before starting the test. Verify the temperature again immediately after the flask and liquid is weighed. If the product requires mixing for uniformity, mix it before opening in accordance with any instructions specified on the package label. Shaking liquids, such as flavored milk, often entraps air that will affect volume measurements, so use caution when testing these products. Often, less air is entrapped if the package is gently rolled to mix the contents.

3. For milk, select a volumetric measure equal to or one size smaller than the label declaration. For all other products, select a volumetric measure that is one size smaller than the label declaration.

(Amended 2004)

\section{Example:}

If testing a $1 \mathrm{~L}$ bottle of juice or a soft drink, select a $500 \mathrm{~mL}$ volumetric measure.

Note: When determining the density of milk, if the product from the first container does not fill the volumetric measure to the nominal capacity graduation, product may be added from another container as long as product integrity is maintained (i.e., brand, identity, lot code, and temperature).

4. Prepare a clean volumetric measure to use according to the following procedure: 
Because flasks are ordinarily calibrated on a "to deliver" basis, they must be "wet down" before using. Immediately before use, fill the volumetric flask(s) or graduate with water. The water should be at the reference temperature of the product being tested. Fill the flask(s) with water to a point slightly below the top graduation on the neck. The flask should be emptied in 30 seconds ( \pm 5 seconds). Tilt the flask gradually so the flask walls are splashed as little as possible as the flask is emptied. When the main flow stops, the flask should be nearly inverted. Hold the flask in this position for 10 seconds more and touch off the drop of water that adheres to the tip. If necessary, dry the outside of the flask. The flask or graduate is then ready to fill with liquid from a package. This is called the "wet down" condition.

Note: When using a volumetric measure that is calibrated "to contain," the measure must be dry before each measurement.

$>$ If the liquid effervesces or foams when opened or poured (such as carbonated beverages), add two drops of a defoaming agent to the bottom of the flask before filling with the liquid. If working with a carbonated beverage, make all density determinations immediately upon placing the product into the standard. This reduces the chance of volume changes occurring from the loss of carbonization.

5. If the flask capacity is equal to the labeled volume, pour the liquid into the volumetric measure tilting the package to a nearly vertical position. If the flask capacity is smaller than the package's labeled volume, fill the flask to its nominal capacity graduation.

6. Position the flask on a level surface at eye level. For clear liquids, place a material of some dark color outside the flask immediately below the level of the meniscus. Read the volume from the lowest point of the meniscus. For opaque liquids, read volume from the center top rim of the liquid surface.

7. Evaluate the density variation.

Select a volumetric measure equal to or one size smaller than the labeled volume (depending on the product) and prepare it as described in Step 4 of this section. Then determine and record its empty weight.

Determine acceptability of the liquid density variation, using two packages as follows:

- Determine the gross weight of the first package.

- Pour the liquid from the first package into a flask. Measure exactly to the nominal capacity marked on the neck of the measure.

- Weigh the filled flask and subtract its empty weight to obtain the weight of the liquid. Determine density by dividing the weight of the liquid by the capacity of the flask.

- Determine the weight of the liquid from a second package using the same procedure.

- If the difference between the densities of the two packages exceeds one division, 
use the volumetric procedure in Section 3.3. "Volumetric Test Procedure for NonViscous Liquids.”

8. Determine the Average Used Dry Tare Weight of the sample according to provisions of Section 2.3.5. "Procedures for Determining Tare."

9. Calculate the Average Product Density by adding the densities of the liquid from the two packages and dividing the sum by two.

10. Calculate the "nominal gross weight" using the following formula if the flask capacity is equal to the labeled volume:

Nominal Gross Weight $=($ Average Product Density [in weight units] $)+$ (Average Used Dry Tare Weight)

Note: If the flask size is smaller than the labeled volume, the following formula is used:

$$
\begin{gathered}
\text { Nominal Gross Weight }=(\text { Average Product Density } \times \\
{[\text { Labeled Volume/Flask Capacity] })+(\text { Average Used Dry Tare Weight })}
\end{gathered}
$$

11. Weigh the remaining packages in the sample.

12. Subtract the nominal gross weight from the gross weight of each package to obtain package errors in terms of weight. All sample packages are compared to the nominal gross weight.

13. To convert the average error or package error from weight to volume, use the following formula: Package Error in Volume $=$ Package Error in Weight/Average Product Density Per Volume
Unit of Measure

\subsubsection{Evaluation of Results}

Follow the procedures in Chapter 2, Section 2.3.7. "Evaluate for Compliance" to determine lot conformance.

\subsection{Volumetric Test Procedure for Non-Viscous Liquids}

If it is determined that the densities of the liquids vary beyond the specified limit, use the volumetric test procedure below to test the product.

\subsubsection{Test Equipment}

- A partial immersion thermometer (or equivalent) with a range of $-35^{\circ} \mathrm{C}$ to $+50{ }^{\circ} \mathrm{C}\left(30{ }^{\circ} \mathrm{F}\right.$ to $\left.120^{\circ} \mathrm{F}\right)$, at least $1^{\circ} \mathrm{C}\left(1^{\circ} \mathrm{F}\right)$ graduations, and with a tolerance of $\pm 1^{\circ} \mathrm{C}\left( \pm 2{ }^{\circ} \mathrm{F}\right)$.

- $\quad$ Volumetric measures

Note: When checking packages labeled in SI units, flask sizes of $100 \mathrm{~mL}, 200 \mathrm{~mL}$, $500 \mathrm{~mL}, 1 \mathrm{~L}, 2 \mathrm{~L}, 4 \mathrm{~L}$, and $5 \mathrm{~L}$ and a $50 \mathrm{~mL}$ cylindrical graduate with $1 \mathrm{~mL}$ divisions may be used. When checking packages labeled in U.S. customary units the use of 
measuring flasks and graduates with capacities of gill, half-pint, pint, quart, halfgallon, gallon, and a $2 \mathrm{fl} \mathrm{oz}$ cylindrical graduate, graduated to $1 / 2 \mathrm{fl} \mathrm{dr}$ is recommended.

- Defoaming agents may be necessary for testing liquids such as beer and soft drinks that effervesce or are carbonated. Two such products are Hexanol or Octanol (Capryl Alcohol*).

*Note: The mention of trade or brand names does not imply that these products are endorsed or recommended by the U.S. Department of Commerce over similar products commercially available from other manufacturers.

- Bubble level at least $15.24 \mathrm{~cm}$ (6 in) in length

- Stopwatch

\subsubsection{Test Procedure}

1. Follow Steps 1 through 6 in Section 3.2. "Gravimetric Test Procedure for Non-Viscous Liquids” for each package in the sample.

2. In Step 5, drain the container into the flask for one minute after the stream of liquid breaks into drops.

3. Read the package errors directly from the graduations on the measure. The reference temperature must be maintained within $\pm 2{ }^{\circ} \mathrm{C}\left( \pm 5^{\circ} \mathrm{F}\right)$ for the entire sample.

\subsubsection{Evaluation of Results}

Follow the procedures in Chapter 2, Section 2.3.7. "Evaluate for Compliance" to determine lot conformance.

\subsection{Volumetric Test Procedures for Viscous Fluids - Headspace}

Depending on how level the surface of the commodity is, use one of two headspace test procedures. Use the headspace test procedure in Section 3.4.2.a. to determine volume where the liquid has a level surface (e.g., oils, syrups, and other viscous liquids). Use the procedure in Section 3.4.2.b. to determine volume where the commodity does not have a level surface (e.g., mayonnaise and salad dressing).

Before conducting either of the following volumetric test procedures, follow Section 2.3.1. "Define the Inspection Lot." Use a "Category A" sampling plan in the inspection; select a random sample, then use one of the following procedures to determine lot compliance.

\subsubsection{Test Equipment}

- Micrometer depth gage (ends of rods fully rounded) $0 \mathrm{~mm}$ to $225 \mathrm{~mm}$ (0 in to 9 in) or longer

- $\quad$ Level (at least $15 \mathrm{~cm}$ (6 in) in length)

- Laboratory pipets and/or buret 
Class A $100 \mathrm{~mL}$ buret as defined by the latest version of the ASTM E287-2, "Standard Specification for Laboratory Glass Graduated Burets.”

Class A pipets, calibrated "to deliver "as defined by the latest version of ASTM E96902, "Standard Specification for Glass Volumetric (Transfer) Pipets."

- Volumetric measures

- Water

- Rubber bulb syringe

- Plastic disks that are $3 \mathrm{~mm}\left({ }^{1} / 8\right.$ in) thick with diameters equal to the seat diameter or larger than the brim diameter of each container to be tested. The diameter tolerance for the disks is $50 \mu \mathrm{m}( \pm 0.05 \mathrm{~mm}[ \pm 0.002 \mathrm{in}])$. The outer edge should be smooth and beveled at a $30^{\circ}$ angle with the horizontal to $800 \mu \mathrm{m}(0.8 \mathrm{~mm} \mathrm{[1/32} \mathrm{in])} \mathrm{thick} \mathrm{at} \mathrm{the} \mathrm{edge.} \mathrm{Each} \mathrm{disk} \mathrm{must}$ have a $20 \mathrm{~mm}(3 / 4 \mathrm{in})$ diameter hole through its center and a series of $1.5 \mathrm{~mm}\left({ }^{1} / 16 \mathrm{in}\right)$ diameter holes $25 \mathrm{~mm}(1 \mathrm{in})$ apart around the periphery of the disk and $3 \mathrm{~mm}(1 / 8 \mathrm{in})$ from the outer edge. All edges must be smooth.

- Stopwatch

- Partial immersion thermometer (or equivalent) with $1^{\circ} \mathrm{C}\left(2^{\circ} \mathrm{F}\right)$ graduations and a range of $-35^{\circ} \mathrm{C}$ to $+50^{\circ} \mathrm{C}\left(-30^{\circ} \mathrm{F}\right.$ to $\left.+120^{\circ} \mathrm{F}\right)$ accurate to $\pm 1^{\circ} \mathrm{C}\left( \pm 2{ }^{\circ} \mathrm{F}\right)$

\subsubsection{Test Procedures}

\section{a. Test Procedure for Testing Oils, Syrups, and other Viscous Liquids with a Smooth and Level Surface}

Use the volumetric headspace procedure described in this section to determine volume when the commodity has a level surface. Open every package in the sample.

Note: Make all measurements on a level surface.

1. Bring the temperature of both the liquid and the water to be used to measure the volume of the liquid to the reference temperature specified in Table 3-1. "Reference Temperatures for Liquids." Verify with a thermometer that the product has maintained the reference temperature.

2. Measure the headspace of the package at the point of contact with the liquid using a depth gauge with a fully rounded, rather than a pointed, rod end. If necessary, support the package to prevent the bottom of the container from distorting.

3. Empty, clean, and dry the package.

4. Refill the container with water measured from a volumetric standard to the original liquid headspace level measured in Step 2 of this procedure until the water touches the depth gauge. 
5. Determine the amount of water used in Step 4 of this procedure to obtain the volume of the liquid and calculate the "package error" based on that volume.

$$
\text { "Package Error" = Labeled Value - Measured Volume }
$$

\section{b. Test Procedure for Testing Mayonnaise, Salad Dressing, and Water Immiscible Products with no Smooth and Level Surface}

Use the following volumetric headspace procedure to determine volume when the commodity does not have a level surface (e.g., mayonnaise, salad dressing, and other water immiscible products without a level liquid surface). The procedure guides the inspector to determine the amount of headspace above the product in the package and the volume of the container. Determine the product volume by subtracting the headspace volume from the container volume. Open every package in the sample.

(Amended 2010)

Note: Make all measurements on a level surface.

1. Bring the temperature of both the commodity and the water used to measure the volume to the appropriate temperature designated in Table 3-1. "Reference Temperatures for Liquids.”

2. Open the first package and place a disk larger than the package container opening over the opening.

3. Measurement Procedure

D Deliver water from a flask (or flasks), graduate, or buret, through the central hole in the disk onto the top of the product until the container is filled. If it appears that the contents of the flask may overfill the container, do not empty the flask. Add water until all of the air in the container has been displaced and the water begins to rise in the center hole of the disk. Stop the filling procedure when the water fills the center disk hole and domes up slightly due to the surface tension. Do not add additional water after the level of the water dome has dropped.

If the water dome breaks on the surface of the disk, the container has been overfilled and the test is void; dry the container and start over.

4. To obtain the headspace capacity, record the volume of water used to fill the container and subtract $1 \mathrm{~mL}(0.03 \mathrm{fl} \mathrm{oz})$, which is the amount of water held in the hole in the disk specified.

5. Empty, clean, and dry the package container.

6. Using Steps 3 and 4 of this procedure, refill the package container with water measured from a volumetric measure to the maximum capacity of the package, subtract $1 \mathrm{~mL}$ (0.03 $\mathrm{fl} \mathrm{oz}$ ), and record the amount of water used as the container volume; and

7. From the container volume determined in Step 6 of this procedure, subtract the headspace capacity in Step 4 of this procedure to obtain the measured volume of the 
product.

8. Calculate the "package error" for that volume where "package error" equals labeled volume minus the measured volume of the product.

\subsubsection{Evaluation of Results}

For either of the above procedures, follow the procedures in Section 2.3.7. "Evaluate for Compliance" to determine lot conformance.

\subsection{Goods Labeled by Capacity - Volumetric Test Procedure}

\subsubsection{Test Equipment}

Use the test equipment in Section 3.4. under "Volumetric Test Procedures for Viscous Fluids Headspace” (except for the micrometer depth gage) to perform this test procedure.

\subsubsection{Test Procedure}

Note: Make all measurements on a level surface.

1. Before conducting any of the following volumetric test procedures, refer to Section 2.3.1. "Define the Inspection Lot." Use a "Category A" sampling plan in the inspection; select a random sample.

2. When testing goods labeled by capacity, use water at a reference temperature of $20^{\circ} \mathrm{C} \pm 2{ }^{\circ} \mathrm{C}\left(68^{\circ} \mathrm{F} \pm 5^{\circ} \mathrm{F}\right)$.

3. Select a sample container and place a disk larger than the container opening over the opening.

4. Measurement Procedure:

$>$ Add water to the container using flask (or flasks), graduate, or buret corresponding to labeled capacity of the container. If it appears that the contents of the flask may overfill the container, do not empty the flask. Add water until all of the air in the container has been displaced and the water begins to rise in the center hole of the disk. Stop filling the container when the water fills the center disk hole and domes up slightly due to the surface tension.

$>$ If the water dome breaks on the surface of the disk, the container has been overfilled and the test is void; dry the container and start over.

$>$ Record the amount of water used to fill the container and subtract $1 \mathrm{~mL}(0.03 \mathrm{fl} \mathrm{oz})$ this is the amount of water held in the hole in the disk specified) to obtain the total container volume.

5. Test the other containers in the sample according to Steps 3 and 4 of this procedure.

6. To determine package errors, subtract the total container volume obtained in Step 4 of this procedure from the labeled capacity of the container. 


\subsubsection{Evaluation of Results}

Follow the procedures in Section 2.3.7. "Evaluate for Compliance” to determine lot compliance.

\section{6. $\quad$ Pressed and Blown Glass Tumblers and Stemware}

This handbook provides a tolerance to the labeled capacity of glass tumblers and stemware. The average requirement does not apply to the capacity of these products. See Table 3-2. "Allowable Differences for Pressed and Blown Glass Tumblers and Stemware.”

\subsubsection{Test Equipment}

Use the test equipment in Section 3.4. under "Volumetric Test Procedures for Viscous Fluids Headspace” (except for the micrometer depth gage) to perform this test procedure.

\subsubsection{Test Procedure}

1. Follow Section 2.3.1. "Define the Inspection Lot" and determine which sampling plan to use in the inspection, select a random sample, and then use the volumetric test procedure in Section 3.5. "Goods Labeled by Capacity - Volumetric Test Procedure" to determine container capacity and volume errors.

2. Compare the individual container error with the allowable difference that applies in Table 3-2. "Allowable Differences for Pressed and Blown Glass Tumblers and Stemware." If a package contains more than one container, all of the containers in the package must meet the allowable difference requirements in order for the package to pass.

\begin{tabular}{|c|c|}
\hline \multicolumn{2}{|c|}{ Table 3-2. } \\
Allowable Differences for Pressed and Blown Glass Tumblers and Stemware \\
\hline \hline Unit of Measure & \\
\hline If the capacity in metric units is: & The allowable difference is: \\
\hline $200 \mathrm{~mL}$ or less & $\pm 10 \mathrm{~mL}$ \\
\hline More than $200 \mathrm{~mL}$ & $\pm 5 \%$ of the labeled capacity \\
\hline If the capacity in U.S. customary units is: & Then the allowable difference is: \\
\hline 5 fl oz or less & $\pm 1 / 4$ fl oz \\
\hline More than $5 \mathrm{fl} \mathrm{oz}$ & $\pm 5 \%$ of the labeled capacity \\
\hline
\end{tabular}

\subsubsection{Evaluation of Results}

Count the packages in the sample with volume errors greater than the allowable difference and compare the resulting number with the number given in Column 3. (Table 2-11, Appendix A)

- If the number of containers in the sample with errors exceeding the allowable difference exceeds the number allowed in Column 3, the lot fails.

- If the number of packages with errors exceeding the allowable difference is less than or equal to the number in Column 3, the lot passes. 
Note: The average capacity error is not calculated because the lot passes or fails based on the individual volume errors. Act on the individual units containing errors exceeding the allowable difference.

\subsection{Volumetric Test Procedure for Paint, Varnish, and Lacquers - Non-aerosol}

Use one of three different test methods depending upon the required degree of accuracy and the location of the inspection. The procedures include both retail and in-plant audits, and a "possible violation" method that is designed for laboratory or in plant use because of cleanup and product collection requirements. The procedures are suitable to use with products labeled by volume and packaged in cylindrical containers with separate lids that can be resealed.

\subsubsection{Test Equipment}

- A scale that meets the requirements in Section 2.2. "Measurement Standards and Test Equipment”

- Volumetric measures

- Micrometer depth gage (ends of rods fully rounded), $0 \mathrm{~mm}$ to $225 \mathrm{~mm}$ (0 in to $9 \mathrm{in}$ )

- Diameter (Pi) tape measure, $5 \mathrm{~cm}$ to $30 \mathrm{~cm}$ (2 in to 12 in)

- Spanning bar, $2.5 \mathrm{~cm}$ by $2.5 \mathrm{~cm}$ by $30 \mathrm{~cm}$ or (1 in by 1 in by 12 in)

- $\quad$ Rule, 30 cm (12 in)

- Paint solvent or other solvent suitable for the product being tested

- $\quad$ Cloth, $30 \mathrm{~cm}$ (12 in) square

- Wood, $5 \mathrm{~cm}$ (2 in) thick, by $15 \mathrm{~cm}$ (6 in) wide, by $30 \mathrm{~cm}$ (12 in) long

- Rubber mallet

- Metal disk, $6.4 \mathrm{~mm}(1 / 4 \mathrm{in})$ thick and slightly smaller than the diameter of package container bottom

- Rubber spatula

- Level at least $15 \mathrm{~cm}$ (6 in) in length

- Micrometer (optional)

- Stopwatch 


\subsubsection{Test Procedures}

\section{a. Field (Retail) Auditing Procedure}

Conduct a retail audit using the following test procedure that is suitable for checking cylindrical containers up to $4 \mathrm{~L}$ ( 1 gal) in capacity. Use Step 2 in the retail audit test procedure with any size container except $4 \mathrm{~L}$ (1 gal), but Step 3 must be used for containers with capacities of $4 \mathrm{~L}$ (1 gal). The method determines the volume of a single can in the sample selected as most likely to contain the smallest volume of product. Do not empty any containers since only their critical dimensions are being measured.

The configuration of the bottom of the can, paint clinging to the lid, and slight variations in the wall and label thicknesses of the paint container may produce an uncertainty estimated to be at least $0.6 \%$ in this auditing procedure. Therefore, this method is recommended solely to eliminate from more rigorous testing those packages that appear to be full measure. Use the violation procedures when the volume determined in Step 10 is less than the labeled volume or in any case where short measure is suspected.

Note: When instructed to record a measurement in a column, refer to the numbered columns in the "Audit Worksheet for Checking Paint" in this section.

1. Select a random sample. A tare sample is not needed.

2. For containers less than $4 \mathrm{~L}$ or $(1 \mathrm{gal})$ :

$>$ Measure the outside diameter of each container near its middle to the closest $0.02 \mathrm{~mm}$ (0.001 in) using a diameter tape. Record the measurements in Column 3.

$>$ Place the containers on a level surface and using the micrometer depth gage, record their heights in Column 1 on the worksheet.

$>$ If the range of outside diameters exceeds $0.125 \mathrm{~mm}(0.005 \mathrm{in})$ or the range in heights exceeds $1.58 \mathrm{~mm}$ (0.062 $5 \mathrm{in})$, do not use this procedure. If the ranges are within the specified limits, weigh all cans in the sample, select the container with the lightest gross weight, and remove its lid. Continue with Step 4 below.

3. For $4 \mathrm{~L}$ (1 gal) containers:

$>$ Gross weigh each package in the sample.

$>$ Select the package with the lightest gross weight and remove its lid.

4. Use a direct reading diameter tape measure to measure the outside diameter of the selected container near its top, middle (already measured if Step 2 was followed), and bottom to the closest $0.02 \mathrm{~mm}$ (0.001 in). Record these measurements in Columns 2, 3, and 4 . Add the three diameter values and divide by three to obtain the average diameter and record this value in Column 5.

5. If a micrometer is available, measure the wall and the paper label thickness of the container; otherwise, assume the wall and label thicknesses given in Table 3-3. 
“Thickness of Paint Can Walls and Labels” below:

Subtract twice the thickness of the wall of the can and paper label from the average can diameter (Step 4) to obtain the average liquid diameter. Record the liquid diameter in Column 6.

6. On a level surface, place the container on the circular metal disk that is slightly smaller in diameter than the lower rim of the can so the bottom of the container nests on the disk to eliminate any "sag" in the bottom of the container.

7. Place the spanning bar and depth gage across the top of the paint can and mark the location of the spanning bar on the rim of the paint container. Measure the distance to the liquid level, to the nearest $20 \mu \mathrm{m}(0.02 \mathrm{~mm})(0.001 \mathrm{in})$, at three points in a straight line. Take measurements at points approximately $1 \mathrm{~cm}(3 / 8$ in) from the inner rim for

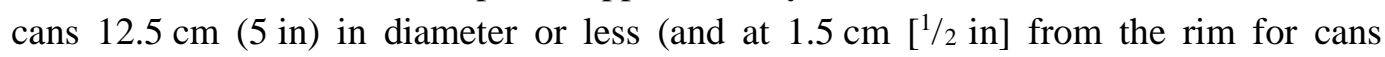
exceeding $12.5 \mathrm{~cm}$ [5 in]) in diameter and at the center of the can. Add the three readings and divide by three to obtain the average distance to the liquid level in the container. Record the average distance to the liquid level in Column 7.

8. Measure the distance to the bottom of the container at three points in a straight line in the same manner as outlined in Step 7. Add the three readings and divide by three to obtain the average height of the container and record it in Column 8.

9. Subtract the average distance to the liquid level (Column 7) from the average height of the container (Column 8) to obtain the average height of the liquid column and record it in Column 9.

10. Determine the volume of paint in the container by using the following formula:

$$
\text { Volume }=0.7854 D^{2} H
$$

Where $\mathrm{D}=$ average liquid diameter (Column 6) and $\mathrm{H}=$ average liquid height (Column 9)

11. Record this value in Column 10. If the calculated volume is less than labeled volume, go to the Section 3.7.2.c. "Violation Procedure." 


\begin{tabular}{|c|c|}
\hline \multicolumn{2}{|c|}{$\begin{array}{c}\text { Table 3-3. } \\
\text { Thickness of Paint Can Walls and Labels }\end{array}$} \\
\hline Can Size & Wall Thickness \\
\hline $4 \mathrm{~L}$ (1 gal) & \multirow{2}{*}{$250 \mu \mathrm{m}(0.25 \mathrm{~mm})[0.010 \mathrm{in}]$} \\
\hline $2 \mathrm{~L}(1 / 2 \mathrm{gal})$ & \\
\hline $1 \mathrm{~L}(1 \mathrm{qt})$ & \multirow{2}{*}{$230 \mu \mathrm{m}(0.23 \mathrm{~mm})[0.009 \mathrm{in}]$} \\
\hline $500 \mathrm{~mL}(1 \mathrm{pt})$ & \\
\hline $250 \mathrm{~mL}$ & $200 \mu \mathrm{m}(0.20 \mathrm{~mm})[0.008 \mathrm{in}]$ \\
\hline \multicolumn{2}{|c|}{$\begin{array}{l}\text { Label Thickness* for all can sizes: } 100 \mu \mathrm{m}(0.10 \mathrm{~mm})[0.004 \mathrm{in}] \\
\text { (*Paper only - ignore labels lithographed directly onto the container) }\end{array}$} \\
\hline
\end{tabular}

Note: Use the following format to develop worksheets to perform audits and determine the volume when checking paint. Follow the procedure and it will indicate the column in which the various measurements made can be recorded.

\begin{tabular}{|c|c|c|c|c||c|c|c|c||}
\hline \multicolumn{7}{|c|}{ Example: Audit Worksheet for Checking Paint } \\
(add additional rows as needed)
\end{tabular}

\section{b. Plant Audit Test Procedure}

Use the following procedure to conduct an in-plant audit inspection. This method applies to a container that probably contains the smallest volume of product. Duplicate the level of fill with water in a can of the same dimensions as the one under test. Use this method to check any size of package if the liquid level is within the measuring range of the depth gage. If any paint is clinging to the sidewall or lid, carefully scrape the paint into the container using a rubber spatula.

Note: When instructed to record a measurement in a column, refer to the numbered columns in the "Audit Worksheet for Checking Paint" in Section 3.7.2.a.

1. Follow Steps 1 through 6 of the Field Retail Audit Test in Section 3.7.2.a.

2. Place the spanning bar and depth gage across the top of the paint can. Measure the liquid level at the center of the surface and record the level in Column 7. 
3. Select an empty can with the same bottom configuration as the container under test and with a diameter and height equal to that of the container under test within plus or minus the following tolerances:

- For $500 \mathrm{~mL}$ or $(1 \mathrm{pt})$ cans - within $25 \mu \mathrm{m}(0.025 \mathrm{~mm})(0.001 \mathrm{in})$

- For $1 \mathrm{~L}$ or $(1 \mathrm{qt})$ cans - within $50 \mu \mathrm{m}(0.05 \mathrm{~mm})$ (0.002 in)

- For $2 \mathrm{~L}$ or ( $1 / 2 \mathrm{gal})$ cans - within $75 \mu \mathrm{m}(0.075 \mathrm{~mm})(0.003 \mathrm{in})$

- For $4 \mathrm{~L}$ or (1 gal) cans - within $100 \mu \mathrm{m}(0.1 \mathrm{~mm})$ (0.004 in)

4. Set the empty can on a level work surface with a circular metal disk that is slightly smaller in diameter than the bottom can rim underneath the can to eliminate sag. Set up the spanning bar and depth gage as in Step 2 above. Fill the container with water from a volumetric measure of the same volume as the labeled volume. Measure the distance to the liquid level at the center of the container and record this level in Column 7 below the reading recorded in Step 2. If this distance is equal to or greater than the distance determined in Step 2, assume that the package is satisfactory. If the distance is less than the distance determined in Step 2, the product may be short measure. When the audit test indicates that short measure is possible use the "Violation Procedure" in Section 3.7.2.c.

(Amended 2010)

\section{c. Violation Procedure}

Use the following method if the liquid level is within the measuring range of the micrometer.

Note: Do not shake or invert the containers selected as the sample.

1. Follow Section 2.3.1. "Define the Inspection Lot" to determine which "Category A" sampling plan to use; select a random sample. The steps noted with an (*) are required if there is paint adhering to the lid and it cannot be removed by scraping into the can.

2. Determine the gross weight of these packages and record in Column 2 of the "Example Worksheet for Possible Violation in Checking Paint” worksheet. (in this section).

3. Record the labeled volume of the first tare sample package in Column 1 of the worksheet. Use a circular metal disk to eliminate can "sag" and remove the lid. If paint clings to the lid of the container, scrape it off with a spatula.

4.* If paint that adheres to the lid cannot be completely removed by scraping the paint into the can, determine the weight of the lid plus any adhering paint. Clean (dry) the paint lid with solvent and weigh again. Subtract the clean (dry) lid weight from the lid weight with paint (wet) to determine the weight of the paint adhering to the lid. Record this weight in Column 3.

5. Place the spanning bar and depth gage across the top of the paint can. Mark the location of the spanning bar on the rim of the paint container. Measure the distance to the liquid level at the center of the container to the nearest $20 \mu \mathrm{m}(0.02 \mathrm{~mm})(0.001 \mathrm{in})$. Record the distance in Column 4. 
6. Empty and clean the sample container and lid with solvent; dry and weigh the container and lid. Record the tare weight in Column 5.

7. Set up the container in the same manner as in Step 3.

8. Place the spanning bar at the same location on the rim of the paint container as marked in Step 5. With the depth gage set as described in Step 5, deliver water into the container in known amounts until the water reaches the same level occupied by the paint as indicated by the depth gage. Record this volume of water (in $\mathrm{mL}$ or $\mathrm{fl} \mathrm{oz}$ ) in Column 6 of the worksheet. This is the volume occupied by the paint in the container. Follow Steps 9a, 10a, and 11a if scraping does not remove the paint from the lid. In order to determine if gravimetric testing can be used to test the other packages in the sample, follow only Steps 9, 10, and 11 when no paint adheres to the lid.

9. Subtract the weight of the container (Column 5) from the gross weight (Column 2) to arrive at the net weight of paint in the selected container. Record the net weight in Column 7 of the worksheet.

9a.* Subtract the weight of the container (Column 5) and the weight of product on the lid (Column 3) from the gross weight (Column 2) to arrive at the net weight of paint in the container. Record in Column 7 (excluding the weight of the paint on the lid).

10. Calculate the weight of the labeled volume of paint (for the first package opened for tare).

net weight (Column 7) $\times$ labeled volume (Column 1$) \div$ volume of paint in can (Column 6)

Record this value in Column 8.

10a.* Calculate the package volume $=$

volume in can (Column 6) + (lid weight [Column 3] $\times$

volume in can [Column 6] $\div$ net weight [Column 7])

Record it in Column 9 of the worksheet.

11. Calculate the package error. Use the following formula if paint does not adhere to the lid.

$$
\text { Package error }=(\text { Column } 6 \text { value })-(\text { labeled volume })
$$

11a.* Use the following formula if paint does adhere to the lid and will not come off by scraping.

$$
\text { Package error }=(\text { Column } 9 \text { value })-(\text { labeled volume })
$$

12. Repeat Steps 2 through 11 for the second package chosen for tare. 


\begin{tabular}{|c|c|c|c|c|c|c|c|c|}
\hline \multicolumn{7}{|c|}{ Example Worksheet for Possible Violation in Checking Paint } \\
(add additional rows as needed)
\end{tabular}

Note: A gravimetric procedure can be used if the weights of the labeled volume for the first two packages do not differ from each other by more than one division on the scale (if they meet this criterion, check the rest of the sample gravimetrically and record in Column 8).

13. Use Section 2.3.6. to determine the "Nominal Gross Weight” as follows:

The nominal gross weight equals the sum of the average weight of the labeled volume (average of values recorded in Column 8) plus the average tare (average of values recorded in Column 3) for the packages selected for tare.

Note that the weight of a given volume of paint often varies considerably from container to container; therefore, volumetric measurements may prove necessary for the entire sample.

\subsubsection{Evaluation of Results}

Follow the procedures in Section 2.3.7. "Evaluate for Compliance” to determine lot conformance.

\section{8. $\quad$ Testing Viscous Materials - Such As Caulking Compounds and Pastes}

Use the following procedure for any package of viscous material labeled by volume. It is suitable for very viscous materials such as cartridge-packed caulking compounds, glues, pastes, and other similar products. It is best to conduct this procedure in a laboratory using a hood to ventilate solvent fumes. If used in the field, use in a well-ventilated area. Except for the special measurement procedures to determine the weight of the labeled volume, this procedure follows the basic test procedure.

\subsubsection{Test Equipment}

- A scale that meets the requirements in Section 2.2. "Measurement Standards and Test Equipment.”

- Pycnometer, a vessel of known volume used for weighing semifluids. The pycnometer can be bought or made. If it is made, refer to it as a "density cup." To make a $150 \mathrm{~mL}$ or $5 \mathrm{fl} \mathrm{oz}$ density cup, cut off the lip of a $150 \mathrm{~mL}$ beaker with an abrasive saw and grind the lip flat on a lap wheel. The slicker plate is available commercially. The metrology laboratory should calibrate the density cup gravimetrically with respect to the contained volume using the procedure as defined by the latest version of ASTM E542-01, "Standard Practice for Calibration of Laboratory Volumetric Apparatus.” 
Note: If applicable, comply with any special instructions furnished by the manufacturer to calibrate a pycnometer that has not been calibrated. It is not necessary to reweigh or recalibrate for each test; however, mark the pieces of each unit to prevent interchange of cups and slicker plates.

- Appropriate solvents (water, Stoddard solvent, kerosene, alcohol, etc.)

- Caulking gun (for cartridge packed products)

\subsubsection{Test Procedure}

1. Follow the procedures in Section 2.3.1. "Define the Inspection Lot." Use a "Category A" sampling plan in the inspection; and select a random sample.

2. Weigh a calibrated pycnometer and slicker plate and record as "pycnometer weight" and record the volume of the pycnometer.

3. Determine the gross weight of the first package and record the weight value. Open the package and transfer the product to the pycnometer by filling it to excess. Use a caulking gun to transfer product from the caulking cartridges. If using a pycnometer, cover it with a lid and screw the cap down tightly. Excess material will be forced out through the hole in the lid, so the lid must be clean. If using a density cup, place the slicker plate over $3 / 4$ of the cup mouth, press down and slowly move the plate across the remainder of the opening. With the slicker plate in place, clean all the exterior surfaces with solvent and dry.

4. Completely remove the product from the package container; clean the package container with solvent; dry and weigh it to determine the tare weight.

5. Weigh the filled pycnometer or filled density cup with slicker plate and record this weight. Subtract the weight of the empty pycnometer from the filled weight to determine the net weight of the product contained in the pycnometer and record this weight.

6. Clean the pycnometer and repeat Steps 3, 4, and 5 for the second package in the tare sample.

7. Determine acceptability of the density variation on the two packages selected for tare. If the difference between the densities of the two packages exceeds one division of the scale, do not use the gravimetric procedure to determine the net quantity of contents. Instead, use the procedure in steps 9,10 , and 11 .

\section{Weight of Product in Pycnometer $\div$ Pycnometer Volume $=$ Product Density}

Note: If the gravimetric procedure can be used, perform Steps 8, 10, and 11for each package in the sample.

8. Calculate the weight of product corresponding to the labeled volume of product according to the following formula:

$$
\text { Product Density } \times \text { Labeled Volume }=\text { Labeled Weight }
$$

9. Test each package individually by determining the product density in each package using the pycnometer and record the gross, tare, and net weight of each package. Subtract the 
weight of the labeled volume (determined for each package) from the net weight of product to arrive at each individual package error in units of weight.

10. Convert the package errors to units of volume using the following formula:

$$
\begin{aligned}
& \text { Package Error }(\text { volume })= \\
& (\text { Package Error [weight] } \times \text { Pycnometer Volume }) \div(\text { Weight of Product in Pycnometer })
\end{aligned}
$$

11. Record the package errors on the report form, using an appropriate unit of measure.

\subsubsection{Evaluation of Results}

Follow the procedures in Section 2.3.7. "Evaluate for Compliance” to determine lot conformance.

\subsection{Peat Moss}

\subsubsection{Compressed Volume Packages}

\subsubsection{Test Equipment}

- $\quad$ Tape measure

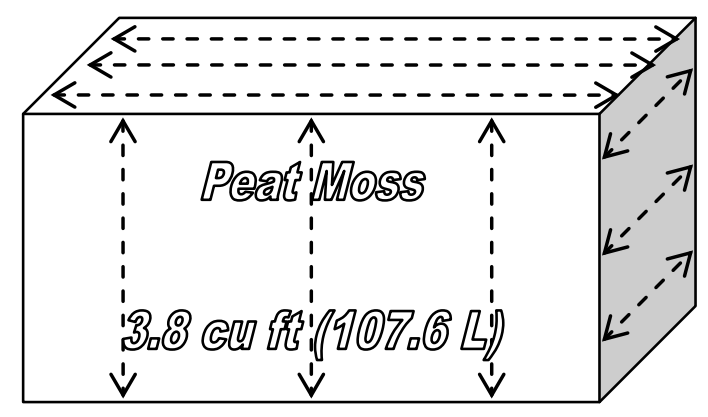

Figure 3-1. Peat Moss

\subsubsection{Test Procedure}

1. Follow Section 2.3.1. "Define the Inspection Lot." Use a "Category A" sampling plan in the inspection; select a random sample.

2. For each dimension (length, width, and height) take three equidistant measurements.

3. Calculate the average of each dimension.

4. Multiply the averages to obtain the compressed cubic volume as follows:

$$
\text { average height } \times \text { average width } \times \text { average length }=\text { cubic measurement }
$$

5. Subtract the labeled volume from the measured volume to determine package error. (Amended 2010) 


\subsubsection{Uncompressed Volume Packages}

Use the following method to test peat moss sold using an uncompressed volume as the declaration of content. The procedure as defined by the latest version of ASTM D2978-03, "Standard Test Method for Volume of Processed Peat Materials.”

\subsubsection{Test Equipment}

- $12.7 \mathrm{~mm}$ (or $1 / 2$ in) sieve

- Use one of the following measures as appropriate for the package size. (Refer to Table 3-4. "Specifications for Test Measures for Mulch and Soils" for additional information on test measure construction.)

28.3 L (1 ft $\left.\mathrm{ft}^{3}\right)$ measure with inside dimensions of $30.4 \mathrm{~cm}$ (12 in) by $30.4 \mathrm{~cm}$ (12 in) by $30.4 \mathrm{~cm}$ (12 in). Mark the inside of the measure with horizontal lines every $1.2 \mathrm{~cm}(1 / 2 \mathrm{in})$ so that package errors can be directly determined

$100 \mathrm{~L}\left(3.5 \mathrm{ft}^{3}\right)$ measure with inside dimensions of $50 \mathrm{~cm}$ (19.68 in) by $50 \mathrm{~cm}$ (19.68 in) by $40 \mathrm{~cm}$ (15.74 in). The inside of the measure should be marked with horizontal lines every $1.2 \mathrm{~cm}(1 / 2 \mathrm{in})$ so that package errors can be directly determined

- Straight edge, $50.8 \mathrm{~cm}$ (20 in) in length

- Sheet for catching overflow of material

- Level (at least $15.24 \mathrm{~cm}$ (6 in) in length)

\subsubsection{Test Procedure}

1. Follow Section 2.3.1. "Define the Inspection Lot." Use a "Category A" sampling plan in the inspection; select a random sample.

2. Open each package in turn, remove the contents, and pass them through the sieve directly into the measuring container (overfilling it). Use this method for particulate solids (such as soils or other garden materials) labeled in cubic dimensions or dry volume. Some materials may not pass through the sieve for peat moss; in these instances, separate the materials by hand (to compensate for packing and settling of the product after packaging) before filling the measure.

Note: Separated material (product not passing through the sieve) must be included in the product volume.

3. Shake the measuring container with a rotary motion at one rotation per second for 5 seconds. Do not lift the measuring container when rotating it. If the package contents are greater than the measuring container capacity, level the measuring container contents with a straightedge using a zigzag motion across the top of the container.

4. Empty the container. Repeat the filling operations as many times as necessary, noting the partial fill of the container for the last quantity delivered using the interior horizontal 
markings as a guide.

5. Record the total volume.

6. To compute each package error, subtract the labeled quantity from the total volume and record it.

\subsubsection{Evaluation of Results}

Follow the procedures in Section 2.3.7. "Evaluate for Compliance" to determine lot conformance for either procedure.

\subsection{Mulch and Soils Labeled by Volume}

Mulch is defined as "any product or material except peat or peat moss that is advertised, offered for sale, or sold for primary use as a horticultural, above-ground dressing, for decoration, moisture control, weed control, erosion control, temperature control, or other similar purposes.”

Soil is defined as "any product or material, except peat or peat moss that is advertised or offered for sale, or sold for primary use as a horticultural growing media, soil amendment, and/or soil replacement."

\subsubsection{Test Equipment}

- A test measure appropriate for the package size that meets the specifications for test measures in Table 3-4. "Specifications for Test Measures for Mulch and Soils"

- Drop cloth/polyethylene sheeting for catching overflow of material

- Level (at least 15 cm [6 in] in length) 


\begin{tabular}{|c|c|c|c|c|c|c|}
\hline \multicolumn{7}{|c|}{$\begin{array}{l}\text { Table 3-4. } \\
\text { Specifications for Test Measures for Mulch and Soils }\end{array}$} \\
\hline \multirow{2}{*}{$\begin{array}{l}\text { Nominal } \\
\text { Capacity } \\
\text { of Test } \\
\text { Measure }\end{array}$} & \multirow{2}{*}{$\begin{array}{l}\text { Actual } \\
\text { Volume of the } \\
\text { Measure }^{4}\end{array}$} & \multicolumn{3}{|c|}{ " Interior Wall Dimensions ${ }^{1}$} & \multirow{2}{*}{$\begin{array}{c}\text { Marked } \\
\text { Intervals } \\
\text { on } \\
\text { Interior } \\
\text { Wall }^{3}\end{array}$} & \multirow{2}{*}{$\begin{array}{l}\text { Volume } \\
\text { Equivalen } \\
\text { of Marked } \\
\text { Intervals }\end{array}$} \\
\hline & & Length & Width & Height $^{2}$ & & \\
\hline $\begin{array}{c}30.2 \mathrm{~L} \\
(1.07 \mathrm{cu} \mathrm{ft}) \\
\text { for testing } \\
\text { packages that } \\
\text { contain less than } \\
28.3 \mathrm{~L} \\
(1 \mathrm{cu} \mathrm{ft} \text { or } \\
25.7 \text { dry qt) }\end{array}$ & $\begin{array}{l}31.9 \mathrm{~L} \\
(1.13 \mathrm{cu} \mathrm{ft})\end{array}$ & $\begin{array}{c}213.4 \mathrm{~mm} \\
(8.4 \mathrm{in})\end{array}$ & $\begin{array}{c}203.2 \mathrm{~mm} \\
\quad(8 \mathrm{in})\end{array}$ & $\begin{array}{c}736.6 \mathrm{~mm} \\
(29 \mathrm{in})\end{array}$ & $\begin{array}{c}12.7 \mathrm{~mm} \\
(1 / 2 \mathrm{in})\end{array}$ & $\begin{array}{l}550.6 \mathrm{~mL} \\
\left(33.6 \mathrm{in}^{3}\right)\end{array}$ \\
\hline $\begin{array}{c}28.3 \mathrm{~L} \\
(1 \mathrm{cu} \mathrm{ft})\end{array}$ & $\begin{array}{c}28.3 \mathrm{~L} \\
(1 \mathrm{cu} \mathrm{ft})\end{array}$ & $\begin{array}{l}304.8 \mathrm{~mm} \\
\quad(12 \mathrm{in})\end{array}$ & $\begin{array}{c}304.8 \mathrm{~mm} \\
(12 \mathrm{in})\end{array}$ & $\begin{array}{l}304.8 \mathrm{~mm} \\
\quad(12 \mathrm{in})\end{array}$ & & $\begin{array}{l}1179.8 \mathrm{~mL} \\
\left(72 \mathrm{in}^{3}\right)\end{array}$ \\
\hline \multirow[t]{2}{*}{$\begin{array}{c}56.6 \mathrm{~L} \\
(2 \mathrm{cu} \mathrm{ft})\end{array}$} & \multirow[t]{2}{*}{$\begin{array}{c}63.7 \mathrm{~L} \\
(2.25 \mathrm{cu} \mathrm{ft})\end{array}$} & $\begin{array}{l}304.8 \mathrm{~mm} \\
(12 \mathrm{in})\end{array}$ & $\begin{array}{l}304.8 \mathrm{~mm} \\
\quad(12 \mathrm{in})\end{array}$ & $\begin{array}{l}685.8 \mathrm{~mm} \\
\quad(27 \mathrm{in})\end{array}$ & & \\
\hline & & $\begin{array}{l}406.4 \mathrm{~mm} \\
\text { (16 in) }\end{array}$ & $\begin{array}{l}228.6 \mathrm{~mm} \\
\quad(9 \mathrm{in})\end{array}$ & $\begin{array}{l}685.8 \mathrm{~mm} \\
\text { (27 in) }\end{array}$ & & \\
\hline \multirow[t]{2}{*}{$\begin{array}{c}84.9 \mathrm{~L} \\
(3 \mathrm{cu} \mathrm{ft})\end{array}$} & \multirow[t]{2}{*}{$\begin{array}{c}92 \mathrm{~L} \\
(3.25 \mathrm{cu} \mathrm{ft})\end{array}$} & $\begin{array}{l}304.8 \mathrm{~mm} \\
(12 \mathrm{in})\end{array}$ & $\begin{array}{l}304.8 \mathrm{~mm} \\
\quad(12 \mathrm{in})\end{array}$ & $\begin{array}{l}990.6 \mathrm{~mm} \\
\text { (39 in) }\end{array}$ & & \\
\hline & & $\begin{array}{l}406.4 \mathrm{~mm} \\
(16 \mathrm{in})\end{array}$ & $\begin{array}{l}228.6 \mathrm{~mm} \\
\quad(9 \mathrm{in})\end{array}$ & $\begin{array}{l}990.6 \mathrm{~mm} \\
(39 \mathrm{in})\end{array}$ & & \\
\hline \multicolumn{7}{|c|}{$\begin{array}{l}\text { Measures are typically constructed of } 1.27 \mathrm{~cm}(1 / 2 \text { in) marine plywood. A transparent sidewall is useful for } \\
\text { determining the level of fill, but must be reinforced if it is not thick enough to resist distortion. If the measure has a } \\
\text { clear front, place the level gage at the back (inside) of the measure so that the markings are read over the top of the } \\
\text { mulch. }\end{array}$} \\
\hline \multicolumn{7}{|c|}{$\begin{array}{l}{ }^{1} \text { Other interior dimensions are acceptable if the test measure approximates the configuration of the package under } \\
\text { test and does not exceed a base configuration of the package cross-section. }\end{array}$} \\
\hline \multicolumn{7}{|c|}{${ }^{2}$ The height of the test measure may be reduced, but this will limit the volume of the package that can be tested. } \\
\hline \multicolumn{7}{|c|}{$\begin{array}{l}{ }^{3} \text { When lines are marked in boxes, they should extend to all sides of the measure to improve readability. It is } \\
\text { recommended that a line indicating the MAV level also be marked to reduce the possibility of reading errors when } \\
\text { the level of the mulch is at or near the MAV. }\end{array}$} \\
\hline $\begin{array}{l}{ }^{4} \text { The Nominal Capa } \\
\text { dry measure with th } \\
\text { If the measures are } \\
\text { that plus errors (ove }\end{array}$ & $\begin{array}{l}\text { ity is given to iden } \\
\text { listed dimensions. } \\
\text { uilt to the dimensio } \\
\text { fill) can be measur }\end{array}$ & $\begin{array}{l}y \text { the size of } \\
\text { is based on } t \\
\text { shown above } \\
\text { accurately. }\end{array}$ & $\begin{array}{l}\text { ages that can } \\
\text { nost commor } \\
\text { actual volun }\end{array}$ & $\begin{array}{l}\text { tested in a s } \\
\text { ckage sizes } \\
\text { will be larger }\end{array}$ & $\begin{array}{l}\text { gle measure } \\
\text { mulch in th } \\
\text { han the nom }\end{array}$ & $\begin{array}{l}\text { nent using the } \\
\text { marketplace. } \\
\text { nal volume so }\end{array}$ \\
\hline
\end{tabular}

(Amended 2010) 


\subsubsection{Test Procedure}

1. Follow the Section 2.3.1. "Define the Inspection Lot." Use a "Category A" sampling plan in the inspection, and select a random sample.

2. Open each package in turn. Empty the contents of the package into a test measure and level the contents by hand. Do not rock, shake, drop, rotate, or tamp the test measure. Read the horizontal marks to determine package net volume.

Note: Some types of mulch are susceptible to clumping and compacting. Take steps to ensure that the material is loose and free flowing when placed into the test measure. Gently roll the bag before opening to reduce the clumping and compaction of material.

3. Exercise care in leveling the surface of the mulch/soil and determine the volume reading from a position that minimizes errors caused by parallax.

4. Determine package errors by subtracting the labeled volume from the package net volume in the measure. Record each package error.

$$
\text { Package Error = Package Net Volume - Labeled Volume }
$$

\subsubsection{Evaluation of Results}

Follow the procedures in Section 2.3.7. "Evaluate for Compliance" to determine lot conformance.

Note: In accordance with Appendix A, Table 2-10. Exceptions to the Maximum Allowable Variations for Textiles, Polyethylene Sheeting and Film, Mulch and Soil Labeled by Volume, Packaged Firewood, and Packages Labeled by Count with 50 Items or Fewer, and Specific Agricultural Seeds Labeled by Count, apply an MAV of $5 \%$ of the declared quantity to mulch and soil sold by volume. When testing mulch and soil with a net quantity in terms of volume, one package out of every 12 in the sample may exceed the $5 \%$ MAV (e.g., one in a sample of 12 packages; two in a sample of 24 packages; four in a sample of 48 packages). However, the sample must meet the average requirement of the "Category A" Sampling Plan.

\subsection{Ice Cream Novelties}

Note: The following procedure can be used to test packaged products that are solid or semisolid and that will not dissolve in, mix with, absorb, or be absorbed by the fluid into which the product will be immersed. For example, ice cream labeled by volume can be tested using ice water or kerosene as the immersion fluid.

Exception: Pelletized ice cream is beads of ice cream which are quick frozen with liquid nitrogen. The beads are relatively small, but can vary in shape and size. On April 17, 2009, the FDA issued a letter stating that this product is considered semisolid food, in accordance with 21 CFR 101.105(a). The FDA also addresses that the appropriate net quantity of content declaration for pelletized ice cream products be in terms of net weight.

(Added 2010)

The following volume displacement procedure uses a displacement vessel specifically designed for ice cream novelties such as ice cream bars, ice cream sandwiches, or cones. The procedure determines the 
volume of the novelty by measuring the amount of water displaced when the novelty is submerged in the vessel. Two displacements per sample are required to subtract the volume of sticks or cups.

The procedure first determines if the densities of the novelties are the same from package to package (in the same lot) so that a gravimetric test can be used to verify the labeled volume. If a gravimetric procedure is used, compute an average weight for the declared volume from the first two packages and weigh the remainder of the sample. If the gravimetric procedure cannot be used, use the volume displacement procedure for all of the packages in the sample.

\subsubsection{Test Equipment}

- A scale that meets the requirements in Section 2.2. "Measurement Standards and Test Equipment”

- Volumetric measures

- Displacement vessel with dimensions appropriate for the size of novelties being tested (see Figure 3-2, Example of a Displacement Vessel). It should include an interior baffle that reduces wave action when the novelty is inserted and a downward angled overflow spout to reduce dripping. Other designs may be used.

\section{Figure 3-2. Example of a Displacement Vessel}

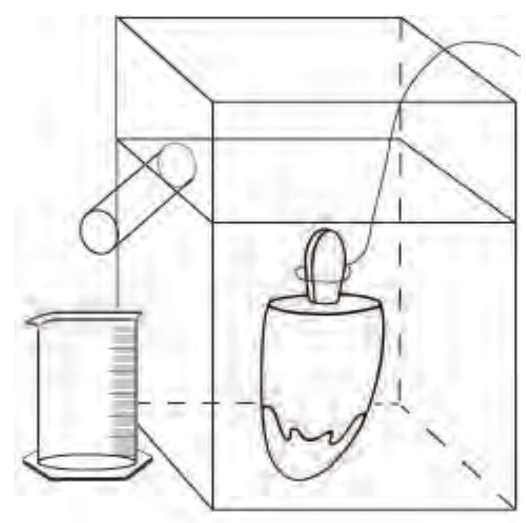

Note: This displacement vessel can be constructed or similar devices may be obtained from any laboratory equipment or science education supplier. The U.S. Department of Commerce does not endorse or recommend any particular device over similar commercially available products from other manufacturers.

- Thin wire, clamp, or tongs

- Freezer or ice chest and dry ice

- $\quad$ Single-edged razor or sharp knife (for sandwiches only)

- Ice water/kerosene maintained at $1{ }^{\circ} \mathrm{C}\left(33^{\circ} \mathrm{F}\right)$ or below

- Indelible marker (for ice pops only)

- Level, at least $15.24 \mathrm{~cm}$ (6 in) in length

- A partial immersion thermometer (or equivalent) with a range of $-1{ }^{\circ} \mathrm{C}$ to $+50^{\circ} \mathrm{C}\left(30^{\circ} \mathrm{F}\right.$ to $\left.120^{\circ} \mathrm{F}\right)$, at least $1^{\circ} \mathrm{C}\left(1^{\circ} \mathrm{F}\right)$ graduations, and with a tolerance of $\pm 1^{\circ} \mathrm{C}\left( \pm 2^{\circ} \mathrm{F}\right)$

- A table-top, laboratory-type jack of sufficient size to hold the displacement vessel

- Stopwatch 


\subsubsection{Test Procedure}

1. Follow the procedures in Section 2.3.1. "Define the Inspection Lot." Use a "Category A" sampling plan in the inspection; and select a random sample.

2. Maintain the samples at the reference temperature for frozen products that is specified in Table 3-1. "Reference Temperatures for Liquids" (i.e., $-18^{\circ} \mathrm{C}\left[0{ }^{\circ} \mathrm{F}\right]$ ). Place the samples in the freezer or ice chest until they are ready to be tested, and then remove packages from the freezer one at a time.

3. According to the type of novelty, prepare the sample products as follows:

$>$ *Ice-pop. Mark on the stick(s) with the indelible marker the point to which the pop will be submerged in the ice water. (After the ice-pop contents have been submerged, remove the novelty to determine the volume of the stick.)

$>{ }^{*}$ Cone. Make a small hole in the cone below the ice cream portion to allow air to escape.

$>$ Sandwich. Determine whether the declared volume is (a) the total volume of the novelty (that is, including the cookie portion) or (b) the volume of the ice-cream-like portion only. If the declared volume is the volume of only the ice-cream-like portion, shave off the cookie with a razor or knife, leaving some remnants of cookie to ensure that no ice cream is accidentally shaved off. Work quickly, and return the novelty to the freezer before the sandwich softens.

$>$ Cup. Remove the cap from the cup.

4. Fill the displacement vessel with ice water until it overflows the spout. Allow it to sit until dripping stops. Raise the displacement vessel as necessary and place the graduate beneath the spout.

5. Remove a package from the freezer, determine its gross weight, and record it.

6. Submerge the novelty as suggested until it is below the surface level of the water.

Ice-pop. Use a clamp, tongs, or your fingers to hold the stick(s) and submerge the pop to the level marked in Step 3 of the Test Procedure.

Cone. Shape the wire into a loop, and use it to push the cone, headfirst (ice cream portion first) into the ice water. Do not completely submerge the cone immediately: let water fill the cone through the hole made in Step 3 of the Test Procedure before completely submerging the novelty.

Sandwich or cup. Skewer the novelty with the thin wire or form a loop on the end of the wire to push the sandwich or ice-cream portion or cup completely below the liquid level.

7. Record the total water volume in the graduate. For a cone or sandwich, record the water volume as the net volume and go to Step 9. For ice-pops or cups, record the water volume in the graduate as the gross volume and go to Step 8. 
8. Refill the displacement vessel with water to overflowing and reposition the empty graduate under the spout. After the cup and novelty contents have been submerged, remove the novelty from the cup to determine the volume of the cup.

Ice-pop. Melt the ice pop off the stick or sticks. Submerge the stick or sticks to the line marked in Step 3. Record the volume of tare material (i.e., stick) by measuring the water displaced into the graduate. The net volume for the ice-pop is the gross volume recorded in Step 7 minus the volume of the tare materials in this step. Record this volume as the "volume of novelty." To determine the error in the package, subtract the labeled quantity from the volume of novelty.

$>$ Cup. Remove the novelty from the cup. Rinse the cup, and then submerge it in the displacement vessel. Small pinholes in the base of the cup can be made to make submersion easier. Record the volume of water displaced into the graduate by the cup as the volume of tare material. The net volume for the novelty is the gross volume determined in Step 7 minus the volume of the tare materials determined in this step. Record this as the net volume of the novelty. To determine the error in the package, subtract the labeled quantity from the volume of novelty.

9. Clean and air-dry the tare materials (sticks, wrappers, cup, lid, etc.). Weigh and record the weight of these materials for the package.

10. Subtract the tare weight from the gross weight to obtain the net weight and record this value.

11. Compute the weight of the labeled volume for the package using the following formula and then record the weight:

$$
\begin{gathered}
\text { Product Density }=(\text { gross weight in Step } 5) \div(\text { the total water volume in Step } 7) \\
\text { Weight of labeled volume }=(\text { labeled volume }) \times(\text { Product Density })
\end{gathered}
$$

12. Repeat Steps 3 through 11 for a second package.

13. If the weight of the labeled volumes in Step 11 for the two packages differs from each other by more than one division on the scale, the gravimetric test procedure cannot be used to test the sample for compliance. If this is the case, use Steps 3 through 8 for each of the remaining packages in the sample to determine their net volumes and package errors. Then go to evaluation of results. If the weights of the labeled volumes agree within one division, continue to Step 14 to test the rest of the sample using the gravimetric test procedure.*

14. Use Section 2.3.5.1. "Determination of Tare Sample and Average Tare Weight" to determine the Average Used Dry tare Weight of the sample.

15. Find the Average Product Density by adding the densities of the product from the two packages and dividing the sum by two.

16. Using the weight of labeled volume determined in Step 11, calculate the Average Product Weight by multiplying the weight of the labeled volume by the average product density.

*Average Product Weight $=$ Labeled Volume $\times$ Average Product Density 
17. Calculate the "nominal gross weight" using the formula:

$$
\text { Nominal Gross Weight = Average Product Weight }+ \text { Average Used Dry Tare Weight }
$$

18. Weigh the remaining packages in the sample.

19. Subtract the nominal gross weight from the gross weight of each package to obtain package errors in terms of weight.

Note: Compare the sample packages to the nominal gross weight.

20. Determine the average package error by totaling all package errors and dividing by the number of packages in the sample.

To convert the average error or package error from weight to volume, use the following formula:

$$
\text { Package Error in Volume }=(\text { Package Error in Weight }) \div(\text { Average Product Density })
$$

\subsubsection{Evaluation of Results}

Follow the procedures in Section 2.3.7. "Evaluate for Compliance" to determine lot conformance.

\subsection{Fresh Oysters Labeled by Volume}

Packaged fresh oysters removed from the shell must be labeled by volume. The maximum amount of permitted free liquid is limited to $15 \%$ by weight. Testing the quantity of contents of fresh oysters requires the inspector to determine total volume, total weight of solids and liquid, and the weight of the free liquid.

\subsubsection{Test Equipment}

- A scale that meets the requirements in Section 2.2. "Measurement Standards and Test Equipment”

- Volumetric measures

- Micrometer depth gage (ends of rods fully rounded), $0 \mathrm{~mm}$ to $228 \mathrm{~mm}$ (0 in to $9 \mathrm{in}$ )

- Strainer for determining the amount of drained liquid from shucked oysters. Use a strainer and a slightly smaller bottom receiving pan or tray constructed to the following specifications:

Sides: $5.08 \mathrm{~cm}(2 \mathrm{in})$

Area: $1935 \mathrm{~cm}^{2}\left(300 \mathrm{in}^{2}\right)$ or more for each $3.78 \mathrm{~L}$ (1 gal) of oysters 
Note: Strainers of smaller area dimensions are permitted to facilitate testing smaller containers.

Perforations:

Diameter: $6.35 \mathrm{~mm}(1 / 4 \mathrm{in})$

Location: $3.17 \mathrm{~cm}\left(1 \frac{1}{4} \mathrm{in}\right)$ apart in a square pattern, or perforations of equivalent area and distribution.

- $\quad$ Spanning bar, $2.54 \mathrm{~cm}$ by $2.54 \mathrm{~cm}$ by $30.48 \mathrm{~cm}$ (1 in by 1 in by 12 in)

- Rubber spatula

- Partial immersion thermometer, $1{ }^{\circ} \mathrm{C}\left(2{ }^{\circ} \mathrm{F}\right)$ graduations and a range of $-35^{\circ} \mathrm{C}$ to $+50^{\circ} \mathrm{C}$ $\left(-30^{\circ} \mathrm{F}\right.$ to $\left.+120^{\circ} \mathrm{F}\right)$ accurate to $\pm 1^{\circ} \mathrm{C}\left( \pm 2{ }^{\circ} \mathrm{F}\right)$

- Level, at least $15.24 \mathrm{~cm}$ (6 in) in length

- Stopwatch

(Amended 2014)

\subsubsection{Test Procedure}

Note: Test the oysters at a temperature of $7^{\circ} \mathrm{C}\left( \pm 1^{\circ} \mathrm{C}\right)\left(45^{\circ} \mathrm{F}\left[ \pm 2^{\circ} \mathrm{F}\right]\right)$

1. Follow the Section 2.3.1. "Define the Inspection Lot." Use a "Category A" sampling plan in the inspection; and select a random sample.

2. Determine and record the gross weight of a sample package.

3. Set the container on a level surface and open it. Use a depth gage to determine the level of fill. Lock the depth gauge. Mark the location of the gauge on the package.

4. Weigh a dry receiving pan and record the weight. Set strainer over the receiving pan.

5. Pour the contents from the container onto the strainer without shaking it. Drain for two minutes. Remove strainer with oysters. It is normal for oysters to include mucous (which is part of the product) that will not pass through the strainer, so do not force it.

6. Weigh the receiving pan and liquid and record the weight. Subtract the weight of the dry receiving pan from the weight of pan and liquid to obtain the weight of free liquid and record the value.

7. Clean, dry, and weigh the container and record the tare weight. Subtract the tare weight from the gross weight to obtain the total weight of the oysters and liquid and record this value.

8. Determine and record the percent of free liquid by weight as follows:

Note: This handbook provides a Worksheet for Determining the Free Liquid and Net Volume of Oysters in Appendix C. 


$$
\begin{aligned}
& \text { Percent of free liquid by weight }=[(\text { weight of free liquid }) \div \\
& \qquad \begin{array}{c}
\text { (weight of oysters }+ \text { liquid })] \times 100 . \\
\text { or } \\
\text { Where: } \\
f=\text { Weight of Free Liquid } \\
c=(\text { Net Weight of Oysters + Liquid })
\end{array}
\end{aligned}
$$

9. Set up the depth gauge on the dry package container as in Step 3. Pour water from the flasks and graduate as needed to re-establish the level of fill obtained in Step 3. Add the volumes delivered as the actual net volume for the container and record the value.

Note: Some containers will hold the declared volume only when filled to the brim; they may have been designed for other products, rather than for oysters. If the net volume is short measure (per Step 9), determine if the container will reach the declared volume only if filled to the brim. Under such circumstance, the package net volumes will all be short measure because the container cannot be filled to the brim with a solid and liquid mixture. A small headspace is required in order to get the lid into the container without losing any liquid.

(Amended 2014)

\subsubsection{Evaluation of Results}

Follow the procedures in Section 2.3.7. "Evaluate for Compliance” to determine lot conformance.

\subsection{Determining the Net Contents of Compressed Gas in Cylinders}

These procedures are for industrial compressed gas. Compressed gas may be labeled by weight (for example, Liquefied Petroleum [LP] gas, or carbon dioxide) or by volume. Acetylene, liquid oxygen, nitrogen, nitrous oxide, and argon are all filled by weight. Acetylene is sold by liters or by cubic feet. Helium, gaseous oxygen, nitrogen, air, and argon are filled according to pressure and temperature tables.

Checking the net contents of compressed gas cylinders depends on the method of labeling; those labeled by weight are generally checked by weight. Cylinders filled by using pressure and temperature charts must be tested using a pressure gauge that is connected to the cylinder. The volume is determined using the pressure and temperature of the cylinder.

\section{Safety Precautions:}

Be aware of the hazards of the high pressure found in cylinders of compressed gas. An inspector should handle compressed gas only if the inspector has been trained and is knowledgeable regarding the product, cylinder, fittings, and proper procedures (see Compressed Gas Association [CGA] pamphlet P-1, "Safe Handling of Compressed Gases in Containers," for additional information). Additional precautions that are necessary for personal safety are described in the CGA Handbook of Compressed Gases. All personnel testing compressed gases should have this manual for reference and be familiar with its contents. It is essential that the inspector be certain of the contents before connecting to the cylinder. 
Discharging a gas or cryogenic liquid through a system for which the material is not intended could result in a fire and/or explosion or property damage due to the incompatibility of the system and the product. Before connecting a cylinder to anything, be certain of the following:

1. Always wear safety glasses.

2. The cylinder is clearly marked or labeled with the correct name of the contents and that no conflicting marks or labels are present. Do not rely on the color of the cylinder to identify the contents of a cylinder. Be extremely careful with all gases because some react violently when mixed or when coming in contact with other substances. For example, oxygen reacts violently when it comes in contact with hydrocarbons.

3. The cylinder is provided with the correct Compressed Gas Association (CGA) connection(s) for the product. A proper connection will go together smoothly; so excessive force should not be used. Do not use an adapter to connect oxygen to non-oxygen cleaned equipment. When a cylinder valve is opened to measure the internal pressure, position the body away from the pressure gauge blowout plug or in front of the gauge if the gauge has a solid cast front case. If the bourdon tube should rupture, do not be in a position to suffer serious injuries from gas pressure or fragments of metal.

Note: The acetone in acetylene cylinders is included in the tare weight of the cylinder. Therefore, as acetylene is withdrawn from the cylinder, some acetone will also be withdrawn, changing the tare weight.

4. Thoroughly know the procedure and place emphasis on safety precautions before attempting any tests. Do not use charts referred to in the procedure until the necessary training has been completed. When moving a cylinder, always place the protective cap on the cylinder. Do not leave spaces between cylinders when moving them. This can lead to a "domino" effect if one cylinder is pushed over.

5. Open all valves slowly. A failure of the gauge or other ancillary equipment can result in injuries to nearby persons. Remember that high gas pressure can propel objects with great force. Gas ejected under pressure can also cause serious bodily injuries if someone is too close during release of pressure.

6. One of the gauges will be reserved for testing oxygen only and will be prominently labeled "For Oxygen Use Only.” This gauge must be cleaned for oxygen service and maintained in that "clean" condition. The other gauge(s) may be used for testing a variety of gases if they are compatible with one another.

7. Observe special precautions with flammable gas in cylinders in addition to the several precautions necessary for the safe handling of any compressed gas in cylinders. Do not "crack" cylinder valves of flammable gas before connecting them to a regulator or test gauge. This is extremely important for hydrogen or acetylene.

\subsubsection{Test Equipment}

- Scale that meets the requirements in Section 2.2. "Measurement Standards and Test Equipment.” Use a wooden or non-sparking metal ramp to roll the cylinders on the scale to reduce shock loading. 
- Two calibrated precision bourdon tube gauges or any other approved laboratory-type pressure-measuring device that can be accurately read within plus or minus $40 \mathrm{kPa}$ (5 psi). A gauge having scale increments of $200 \mathrm{kPa}(25 \mathrm{psi})$ or smaller shall be considered as satisfactory for reading within plus or minus $40 \mathrm{kPa}(5 \mathrm{psi})$. The range of both gauges shall be a minimum of $0 \mathrm{kPa}$ to $23 \mathrm{MPa}(0 \mathrm{psi}$ to $5000 \mathrm{psi}$ ) when testing cylinders using standard industrial cylinder valve connections. These standardized connections are listed in "CGA Standard V-1, Standard for Compressed Gas Cylinder Valve Outlet and Inlet Connections for use with Gas Pressures up to $21 \mathrm{MPa}$ (3000 psi)." For testing cylinders with cylinder valve connections rated for over $21 \mathrm{MPa}$ (3000 psi), the test gauge and its inlet connection must be rated at $14 \mathrm{MPa}(2000 \mathrm{psi})$ over the maximum pressure that the connection is rated for in CGA V-1.

\section{Notes:}

1. There are standard high-pressure industrial connections on the market that are being used up to their maximum pressure of $52 \mathrm{MPa}$ (7500 psi).

2. Any gauge or connectors used with oxygen cylinders must be cleaned for oxygen service, transported in a manner which will keep them clean and never used for any other gas including air or oxygen mixtures. Oxygen will react with hydrocarbons and many foreign materials that may cause a fire or explosion.

3. Use a separate gauge and fitting for each gas to be tested. If adapters must be used, do not use on oxygen systems.

- An approved and calibrated electronic temperature measuring device or three calibrated liquid-in-glass thermometers having either a digital readout or scale division of no more than $1^{\circ} \mathrm{F}\left(0.5^{\circ} \mathrm{C}\right)$. The electronic device equipped with a surface temperature sensor is preferred over a liquid-in-glass thermometer because of its shorter response time.

- Two box-end wrenches of $29 \mathrm{~mm}\left(1 \frac{1}{8} \mathrm{in}\right)$ for oxygen, nitrogen, carbon dioxide, argon, helium, and hydrogen and $22 \mathrm{~mm}(7 / 8$ in) for some sizes of propane. All industrial CGA connections are limited to these two hex sizes. Avoid using an adjustable wrench because of the tendency to round the edges of the fittings, which can lead to connections not being tightened properly.

\subsubsection{Test Procedures}

\section{a. Test Procedure for Cylinders Labeled by Weight}

1. Follow Section 2.3.1. "Define the Inspection Lot." Use a "Category A" sampling plan in the inspection; select a random sample.

2. The cylinder should be marked or stenciled with a tare weight. The marked value may or may not be used by the filling plant when determining the net weight of those cylinders sold or filled by weight. If there is a tare weight marked on the net contents tag or directly on the cylinder, then an actual tare weight was determined at the time of fill. If there is no tare weight marked on a tag or on the cylinder, then the stamped or stenciled tare weight is presumed to have been used to determine the net contents.

Note: Check the accuracy of the stamped tare weights on empty cylinders whenever possible. 
The actual tare weight must be within (a) $1 / 2 \%$ of the stamped tare weight for $9.07 \mathrm{~kg}$ (20 lb) tare weights or less or (b) $1 / 4 \%$ of the stamped tare weight for greater than $9.07 \mathrm{~kg}$ (20 lb) tare weights. (See NIST Handbook 130, "Method of Sale Regulation.”)

3. Place cylinder on scale and remove protective cap. The cap is not included in the tare weight. Weigh the cylinder and determine net weight, using either the stamped or stenciled tare weight, or the tare weight marked on the tag. Compare actual net weight with labeled net weight, or use the actual net weight to look up the correct volume declaration (for Acetylene Gas), and compare that with the labeled volume.

Note: Most producers will replace acetone in the cylinder before the cylinder is refilled, filling the cylinder with acetone to the stamped tare weight. Other producers, although not following recommended procedures, do not replace the acetone until it drops to a predetermined weight. In the latter situation, the refilling plant must note the actual tare weight of the cylinder and show it on the tag containing the net content statement or on the cylinder itself. Refer to tables for acetylene if necessary (if the acetylene is labeled by volume).

\section{b. Test Procedure for Cylinders Labeled by Volume}

1. Follow Section 2.3.1. "Define the Inspection Lot." Use a "Category A" sampling plan in the inspection; select a random sample.

2. Determine the temperature of the cylinders in the sample. Place the thermometer approximately halfway up a cylinder in contact with the outside surface. Take the temperature of three cylinders selected at random and use the average temperature of the three values.

3. Using the appropriate pressure gauge, measure the pressure of each cylinder in the sample.

4. Determine the cylinder nominal capacity from cylinder data tables or from the manufacturer. (These tables must be obtained in advance of testing.)

5. Using NIST Technical Note 1079 "Tables of Industrial Gas Container Contents and Density for Oxygen, Argon, Nitrogen, Helium, and Hydrogen" (available on-line at (http://www.nist.gov/pml/wmd), determine the value (SCF/CF) from the content tables at the temperature and pressure of the cylinder under test.

6. Multiply the cylinder nominal capacity by the value (SCF/CF) obtained from the content tables. This is the actual net quantity of gas.

7. Subtract the labeled net quantity from the actual net quantity to determine the error.

\subsubsection{Evaluation of Results}

Follow Section 2.3.7. "Evaluate for Compliance” to determine lot conformance. 


\subsection{Firewood - (Volumetric Test Procedure for Packaged Firewood with a Labeled Volume of $113 \mathrm{~L}\left[4 \mathrm{ft}^{3}\right]$ or Less)}

Unless otherwise indicated, take all measurements without rearranging the wood or removing it from the package. If the layers of wood are crosshatched or not ranked in discrete sections in the package, remove the wood from the package, re-stack, and measure accordingly.

\subsubsection{Test Equipment Linear Measure. Take all measurements in increments of $0.5 \mathrm{~cm}$ $(3 / 16$ in) or less and round up.}

- Binding Straps. Binding straps are used to hold wood bundles together if the bundles need to be removed from the package/wrapping material.

- $\quad$ Tracing paper

- Graduated template in square centimeters or square inches

\subsubsection{Test Procedures}

\section{a. Boxed Firewood}

1. Follow Section 2.3.1. "Define the Inspection Lot." Use a "Category A" sampling plan in the inspection; and select a random sample.

2. Open the box to determine the average height of wood within the box; measure the internal height of the box. Take three measurements (record as " $d_{1}, d_{2}$. .etc.") along each end of the stack. Measure from the bottom of a straightedge placed across the top of the box to the highest point on the two outermost top pieces of wood and the center-most top piece of wood. Round measurements down to the nearest $0.5 \mathrm{~cm}(1 / 8$ in). If pieces are obviously missing from the top layer of wood, take additional height measurements at the highest point of the uppermost pieces of wood located at the midpoints between the three measurements on each end of the stack. Calculate the average height of the stack by averaging these measurements and subtracting from the internal height of the box according to the following formula.

$$
\begin{gathered}
\text { Average Height of Stack }= \\
\text { (Internal Height of Box })-(\text { sum of measurements }) \div(\text { number of measurements })
\end{gathered}
$$

3. Determine the average width of the stack of wood in the box by taking measurements at three places along the top of the stack. Measure the inside distance from one side of the box to the other on both ends and in the middle of the box. Calculate the average width.

$$
\text { Average Width }=\left(W_{1}+W_{2}+W_{3}\right) \div(3)
$$

4. To determine the average length of the pieces of wood, remove the wood from the box and select the five pieces with the greatest girth. Measure the length of each of the five pieces from center-to-center. Calculate the average length of the five pieces.

$$
\text { Average Length }=\left(L_{1}+L_{2}+L_{3}+L_{4}+L_{5}\right) \div(5)
$$


5. Calculate the volume of the wood within the box. Use dimensions for height, width, and length.

$$
\text { Volume in liters }=(\text { height in } \mathrm{cm} \times \text { width in } \mathrm{cm} \times \text { length in } \mathrm{cm}) \div(1000)
$$

Volume in cubic feet $=($ height in inches $\times$ width in inches $\times$ length in inches $) \div(1728)$

6. For boxes of wood that are packed with the wood ranked in two discrete sections perpendicular to each other, calculate the volume of wood in the box as follows: (1) determine the average height, width, and length as in 1, 2 and 3 above for each discrete section, compute total volume, and (2) total the calculated volumes of the two sections. Take the width measurement for Volume $2\left(\mathrm{~V}_{2}\right)$ from the inside edge of the box adjacent to $\mathrm{V}_{2}$ to the plane separating $\mathrm{VR}_{1}$ and $\mathrm{V}_{2}$. Compute total volume by adding Volume $1\left(\mathrm{~V}_{1}\right)$ and $\mathrm{V}_{2}$ according to the following formula.

$$
\text { Total Volume }=V_{1}+V_{2}
$$

\section{b. Crosshatched Firewood}

Figure 3-3. Stacked Firewood

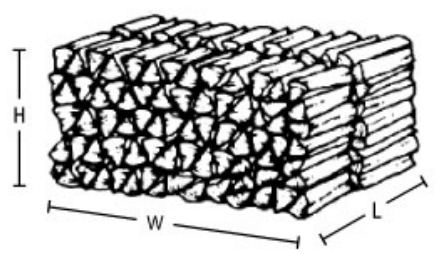

1. Follow Section 2.3.1. "Define the Inspection Lot." Use a "Category A" sampling plan in the inspection; and select a random sample.

2. Stack the firewood in a ranked and well-stowed geometrical shape that facilitates volume calculations (i.e., rectangular).

3. Determine the average measurements of the stack:

Note: The number of measurements for each dimension given below is the minimum that should be taken.

$>$ Height: Start at one end of the stack; measure the height of the stack on both sides at four equal intervals. Calculate and record the average height.

$>$ Length: Start at the base of the stack; Measure the length of the stack in four equal intervals. Calculate and record the average length.

Width: Select the five pieces with the greatest girth. Measure the length of the pieces, calculate and record the average piece length.

4. Calculate Volume:

Volume in liters $=($ Avg. Height $[\mathrm{cm}] \times$ Avg. Width $[\mathrm{cm}] \times$ Avg. Length in $[\mathrm{cm}]) \div 1000$

Volume in cubic feet $=($ Avg. Height [in] $\times$ Avg. Width [in] $\times$ Avg. Length [in] $) \div 1728$ 


\section{c. Bundles and Bags of Firewood}

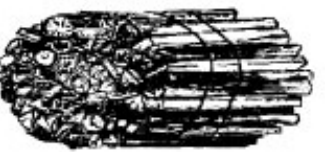

\section{Figure 3-4. Bundle of Firewood}

$>$ Follow Section 2.3.1. "Define the Inspection Lot." Use a "Category A" sampling plan in the inspection; and select a random sample.

$>$ Average area of ends: secure a strap around each end of the bundle or bag of wood to prevent movement during testing and to provide a definite perimeter. Use two or more straps to secure the wood.

$>$ Set one end of the bundle or bag on tracing paper large enough to cover the end completely. Draw a line around the perimeter of the bundle or bag on the tracing paper.

Transfer the tracing paper to a template graduated in square centimeters or square inches. Count the number of square centimeters or square inches that are enclosed within the perimeter line. Estimate portions of square centimeters or square inches not completely within the perimeter line to the nearest one-quarter square inch.

Repeat this process on the opposite end of the bundle or bag.

$>$ Calculate the Average Area:

$$
\text { Average Area }=(\text { Area } 1+\text { Area } 2) \div 2
$$

Average length of the pieces of wood - select the five pieces with the greatest girth and measure the length of the pieces. Calculate the average length of the pieces of wood:

$$
\text { Average Length }=\left(L_{1}+L_{2}+L_{3}+L_{4}+L_{5}\right) \div 5
$$

$>$ Calculate Volume:

$$
\begin{gathered}
\text { Volume in liters }=\left(\text { Average Area }\left[\mathrm{cm}^{2}\right] \times \text { Average Length }[\mathrm{cm}]\right) \div 1000 \\
\text { Volume in cubic feet }=\left(\text { Average Area }\left[\mathrm{in}^{2}\right] \times \text { Average Length }[\mathrm{in}]\right) \div 1728
\end{gathered}
$$

\subsubsection{Evaluation of Results}

Follow Section 2.3.7. "Evaluate for Compliance” to determine lot conformance.

Note: Specified in Appendix A, Table 2-10. "Exceptions to the Maximum Allowable Variations for Textiles, Polyethylene Sheeting and Film, Mulch and Soil Labeled by Volume, Packaged Firewood, and Packages Labeled by Count with 50 Items or Fewer." - Maximum allowable variations for individual packages are not applied to packages of firewood. 
Handbook 133, Checking the Net Contents of Packaged Goods (2015)

THIS PAGE INTENTIONALLY LEFT BLANK 


\section{Chapter 4. Test Procedures - Packages Labeled by Count, Linear Measure, Area, Thickness, and Combinations of Quantities}

\subsection{Scope}

The following procedures should be used to determine the net contents of products sold by count, area, thickness, and linear measure. If a package includes more than one declaration of quantity, each declaration must meet the package requirements.

A gravimetric procedure may be used to test products sold by measure or count if the density of the product does not vary excessively from one package to another. If the gravimetric procedure cannot be used, each package in the sample must be opened to measure or count the contents.

\subsection{Packages Labeled by Count}

If the labeled count is 50 items or fewer, use Section 4.2.1. "Packages Labeled with 50 Items or Fewer." If the labeled count is more than 50 items, see Section 4.2.2. "Packages Labeled by Count of More than 50 Items." If the labeled count is more than 50 items for corn, soybeans, field beans, and wheat seeds, see Section 4.9. "Procedure for Checking the Contents of Specific Agricultural Seed Packages Labeled by Count."

\subsubsection{Packages Labeled with 50 Items or Fewer}

\subsubsection{Test Equipment}

None.

\subsubsection{Test Procedure}

1. Follow Section 2.3.1. "Define the Inspection Lot.” Use a "Category A" sampling plan in the inspection; and select a random sample.

2. Open the packages and count the number of items in each. Record the number of packages that contain fewer than the labeled count.

\subsubsection{Evaluation of Results}

1. For the sample size indicated in Column 1 of Appendix A, Table 2-11. "Accuracy Requirements for Packages Labeled by Low Count (50 or Fewer) and Packages Given Tolerances (Glass and Stemware)," refer to Column 2 to determine the number of packages that are allowed to contain fewer than the labeled count.

2. If the number of packages in the sample that contain fewer than the labeled count exceeds the number permitted in Column 2, the sample and the lot fail to meet the package requirement.

Note: For statistical reasons, the average requirement does not apply to packages labeled 
by count of 50 or fewer items, and the MAV does not apply to the lot. It only applies to the packages in the sample.

3. Maximum Allowable Variations: The MAVs listed in Appendix A, Table 2-7. "Maximum Allowable Variations (MAVs) for Packages Labeled by Count" define the limits of reasonable variation for an individual package even though the MAV is not directly used in the sampling plan. Individual packages that are undercount by more than the MAV are considered defective. Even if the sample passes, these should be repacked, relabeled, or otherwise handled.

\section{Example:}

If testing a lot of 160 packages of pencils labeled "50 pencils," choose a random sample of 12 packages from the lot. If the scale cannot discriminate between differences in count, open every package and count the pencils. For example, assume the 12 package counts are: 50, 52, 50, 50, 51, 53, 52, 50, $50,50,47$, and 50.

Because only one package contains fewer than 50 pencils, the sample passes the test (refer to Appendix A. Table 2-11. "Accuracy Requirements for Packages Labeled by Low Count [50 or Fewer] and Packages Given Tolerances [Glass and Stemware]"). However, the package containing 47 pencils should not be introduced into commerce even though the lot complies with the package requirements because it is undercount by more than the MAV (1 item) permitted in Appendix A, Table 2-7. "Maximum Allowable Variations (MAVs) for Packages Labeled by Count.”

(Amended 2010)

\subsubsection{Packages Labeled by Count of More than 50 Items}

There are two procedures to determine count without opening all packages in the sample. The first is an audit procedure and the second is recommended for determining compliance and taking legal action. Both use the weight of a counted number of items in the package. If the weight of discrete items or numbers of items in a package varies excessively, the packaged items must be counted rather than weighed.

To determine if a gravimetric procedure can be used to inspect packages labeled by count, follow the steps below.

\subsubsection{Test Equipment}

Scale that meets the requirements in Section 2.2. "Measurement Standards and Test Equipment."

\section{Scale Sensitivity:}

First, determine if the scale being used is sensitive enough to determine the weight of individual items by doing the following:

1. For packages labeled with a count of 84 or higher, calculate the weight equivalent for the MAV/6 for the labeled count of the package. MAV/6 must be at least equal to onehalf scale division on a mechanical scale or one division on a digital scale. 
2. For packages with a labeled count of 83 or fewer, when each unit weighs at least two-scale divisions, consider the scale acceptable.

\section{Example:}

According to Appendix A, Table 2-7. Maximum Allowable Variations (MAVs) for Packages Labeled by Count, the MAV is 7 for a package labeled with a count of 250 items. The scale should be capable of measuring differences corresponding to MAV/6 or, in this example, the weight of one item.

$>$ If the scale meets the appropriate requirement, gravimetric testing can be used to determine package count or,

$>$ If the scale does not meet the criteria, count the content in each package in the sample.

\subsubsection{Test Procedures}

\section{a. Audit Procedure}

Use this procedure to audit lots of packages labeled by count of more than 50 items but not for determining lot compliance. Determine the lot compliance based on actual count or by using the "Violation Procedure" (b).

Note: The precision of this procedure is only $\pm 1 \%$.

1. Follow Section 2.3.1. "Define the Inspection Lot." Use a "Category A" sampling plan in the inspection; and select a random sample.

2. Select an initial tare sample according to Section 2.3.5.1. "Determination of Tare Sample and Average Tare Weight.”

3. Gross weigh the first package in the tare sample and record this weight.

4. Select the number of items from the first tare package that weighs the greater:

$>10 \%$ of the labeled count; or

$>$ a quantity equal to at least 50 minimum divisions on the scale.

\section{Example:}

Using a scale with $1 \mathrm{~g}$ divisions, the selected count must weigh at least 50 grams. If a scale with $0.001 \mathrm{lb}$ divisions is used, the selected count must weigh at least $0.05 \mathrm{lb}$. Record the count and weight.

5. Calculate the weight of the labeled count using the following formula:

Weight of the Labeled Count $=$ (labeled count $\times$ weight of items in Step 4$) \div($ Count of items in Step 4)

Record the result as "labeled count weight." 
6. Gross weigh the remaining packages of the tare sample and keep contents of opened packages separated in case all of the items must be counted.

7. Determine the Average Used Dry Tare Weight of the sample according to Section 2.3.5.1. "Determination of Tare Sample and Average Tare Weight."

8. Record the nominal gross weight by adding the weight of the labeled count and the average tare weight.

9. Subtract the nominal gross weight from the gross weight of the individual packages and record the errors.

$$
\begin{gathered}
\text { (Package error [weight]) }= \\
\text { (actual package gross weight) }- \text { (nominal gross weight) }
\end{gathered}
$$

10. Convert the package errors in units of weight to count using the following formula:

$$
\text { Package error }(\text { count })=\left(\begin{array}{c}
\text { Package error }[\text { weight }] \\
\text { weight })
\end{array} \times \text { labeled count }\right) \div(\text { labeled count }
$$

Round any fractional counts up to whole items in favor of the packager. Record the package error in units of count.

11. Compute the average error.

$>$ If the average error is minus, go to the "Violation Procedure" below.

$>$ If the average error is zero or positive, the sample is presumed to conform to the package requirements.

\section{b. Violation Procedure}

If possible, use the gravimetric procedure to determine compliance, to minimize the number of packages to be opened. This procedure combines the measurement of the weight of the number of units in the package with the determination of tare. Therefore, it will not be necessary to open more packages than the tare sample. If the audit procedure in this section has been used, the procedure below can be followed with the same sample if package contents have been kept separate and can still be counted. Use the following procedure to determine if the sample passes or fails.

1. Follow Section 2.3.1. "Define the Inspection Lot." Use a "Category A" sampling plan in the inspection; select a random sample.

2. Select an initial tare sample according to Section 2.3.5.1. "Determination of Tare Sample and Average Tare Weight.”

3. Gross weigh the packages selected for the tare sample and record these weights. Open these packages and determine the tare and net weights of the contents, and count the exact number of items in the packages. Record this information. 
4. Calculate and record the weights of the labeled counts for the first two packages using the formula:

Weight of labeled count $=($ labeled count $) \times($ contents weight $\div$ contents count $)$

To avoid round off errors, carry at least two extra decimal places in the calculation until the weight of the labeled count is obtained. To use the gravimetric procedure, the difference in weights of the labeled counts of the two packages must not exceed one scale division.

If the difference in weights exceeds this criterion, determine the actual count per package for every package in the sample recording plus and minus errors. Then, follow the procedures in Section 2.3.7. "Evaluate for Compliance" to determine lot conformance.

If the difference is within the criterion, average the weights of the labeled count and go on to Step 5.

5. Determine the Average Used Dry Tare Weight of the sample according to provisions in Section 2.3.5.1. "Determination of Tare Sample and Average Tare Weight.”

6. Determine and record the nominal gross weight by adding the average weight of the labeled count of items in the package Step 4 to the average tare weight Step 5.

7. Weigh the remaining packages in the sample, subtract the nominal gross weight from the gross weight of the individual packages, and record the errors.

Package Error (weight) $=($ Actual Package Gross Weight $)-($ Nominal Gross Weight $)$

8. Look up the MAV for the package size from Appendix A, Table 2-7. "Maximum Allowable Variations (MAVs) for Packages Labeled by Count” and convert it to weight using the formula:

$$
\begin{aligned}
& M A V(\text { weight })= \\
& (\text { MAV (count }) \times \text { Average Weight of Labeled Count [from Step 4] }) \div(\text { Labeled Count })
\end{aligned}
$$

9. Convert the MAV to dimensionless units by dividing the MAV (weight) by the unit of measure and record.

\subsubsection{Evaluation of Results}

Follow the procedures in Section 2.3.7. "Evaluate for Compliance” to determine lot conformance.

Convert back to count when completing the report form, using the following formula:

Average Package Error (count) $=($ Avg. Pkg. Error [dimensionless units] $) \times($ Unit of Measure $) \times$ (Labeled Count $) \div$ (Average Weight of Labeled Count) 


\section{3. $\quad$ Paper Plates and Sanitary Paper Products}

The following procedure is used to verify the size of paper plates and other sanitary paper products. It may also be used to verify the size declarations of other disposable dinnerware.

Note: Do not distort the item’s shape during measurement.

The count of sanitary paper products cannot be adequately determined by weighing. Variability in sheet weight and core weight requires that official tests be conducted by actual count. However, weighing can be a useful audit method. These products often declare total area as well as unit count and sheet size. If the actual sheet size measurements and the actual count comply with the average requirements, the total area declaration is assumed correct.

\subsubsection{Test Equipment}

- Steel tapes and rules. Determine measurements of length to the nearest division of the appropriate tape or rule.

\section{Metric units:}

For labeled dimensions $40 \mathrm{~cm}$ or less, linear measure: $30 \mathrm{~cm}$ in length, $1 \mathrm{~mm}$ divisions; or a $1 \mathrm{~m}$ rule with $0.1 \mathrm{~mm}$ divisions, overall length tolerance of $0.4 \mathrm{~mm}$.

For labeled dimensions greater than $40 \mathrm{~cm}, 30 \mathrm{~m}$ tape with $1 \mathrm{~mm}$ divisions.

\section{U.S. customary units:}

For labeled dimensions 25 in or less, use a 36 in rule with $1 / 64$ in or $1 / 100$ in divisions and an overall length tolerance of $1 / 64$ in.

For dimensions greater than $25 \mathrm{in}$, use a $100 \mathrm{ft}$ tape with in divisions and an overall length tolerance of $0.1 \mathrm{in}$.

\section{- Measuring Base}

Note: A measuring base may be made of any flat, sturdy material approximately $38 \mathrm{~cm}$ (15 in) square. Two vertical side pieces approximately $3 \mathrm{~cm}(1 \mathrm{in})$ high and the same length as the sides of the measuring base are attached along two adjoining edges of the measuring base to form a $90^{\circ}$ corner. Trim all white borders from two or more sheets of graph paper (10 divisions per centimeter or 20 divisions per inch). Place one sheet on the measuring base and position it so that one corner of graph paper is snug in the corner of the measuring base and vertical sides. Tape the sheet to the measuring base. Overlap other sheets on the first sheet so that the lines of top and bottom sheet coincide, expanding the graph area to a size bigger than plates to be measured; tape these sheets to the measuring base. Number each line from the top and left side of base plates: 1, 2, 3, etc.

\subsubsection{Test Procedure}

1.* Follow Section 2.3.1. "Define the Inspection Lot." Use a "Category A" sampling plan in the inspection; select a random sample. 
2.* Select an initial tare sample according to Section 2.3.5.1. "Determination of Tare Sample and Average Tare Weight.”

3. Open each package and select one item from each.

Note: Some packages of plates contain a combination of different-sized plates. In this instance, take a plate of each declared size from the package to represent all the plates of that size in the package. For example, if three sizes are declared, select three different plates from each package.

Note: Occasionally, packages of plates declared to be one size contain plates that can be seen by inspection to be of different sizes in the same package. In this instance, select the smallest plate and use the methods below to determine the package error. If the smallest plate is not short measure by more than the MAV, measure each size of plate in the package and calculate the average dimensions.

\section{Example:}

If five plates measure $21.41 \mathrm{~cm}$ (8.43 in) and 15 measure $21.74 \mathrm{~cm}$ (8.56 in), the average dimension for this package of 20 plates is $21.66 \mathrm{~cm}$ (8.53 in).

4. For paper plates: Place each item on the measuring base plate (or use the linear measure) with the eating surface down so two sides of the plate touch the sides of the measuring base.

5. For other products: Use either the measuring base or a linear measure to determine actual labeled dimensions (e.g., packages of napkins, rolls of paper towels). If testing folded products, be sure that the folds are pressed flat so that the measurement is accurate.

6. If the measurements reveal that the dimensions of the individual items vary, select at least 10 items from each package. Measure and average these dimensions. Use the average dimensions to determine package error in Step 7 below.

7. The package error equals the actual dimensions minus the labeled dimensions.

\subsubsection{Evaluation of Results}

Follow the procedures in Section 2.3.7. "Evaluate for Compliance” to determine lot conformance.

\subsection{Special Test Requirements for Packages Labeled by Linear or Square Measure (area)}

Products labeled by length (such as yarn) or area, often require the application of tension to the ends of the product in order to straighten the product before measuring. When testing yarn and thread, apply tension and use the specialized equipment as defined by the latest version of ASTM D1907/D1907M-12, "Standard Test Method for Linear Density of Yarn (Yarn Number) by the Skein Method," in conjunction with the sampling plans and package requirements described in this handbook. Use Section 2.3.7. "Evaluate for Compliance" to determine lot conformance.

\subsection{Polyethylene Sheeting}

Most polyethylene products are sold by length, width, thickness, area, and net weight. Accordingly, this procedure includes steps to test for each of these measurements. 


\subsubsection{Test Equipment}

- A scale that meets the requirements in Section 2.2. "Measurement Standards and Test Equipment.”

- Steel tapes and rules. Determine measurements of length to the nearest division of the appropriate tape or rule.

Metric units:

For labeled dimensions $40 \mathrm{~cm}$ or less, linear measure: $30 \mathrm{~cm}$ in length, $1 \mathrm{~mm}$ divisions; or a $1 \mathrm{~m}$ rule with $0.1 \mathrm{~mm}$ divisions, overall length tolerance of $0.4 \mathrm{~mm}$.

For labeled dimensions greater than $40 \mathrm{~cm}, 30 \mathrm{~m}$ tape with $1 \mathrm{~mm}$ divisions.

U.S. customary units:

For labeled dimensions 25 in or less, use a 36 in rule with $1 / 64$ in or $1 / 100$ in divisions and an overall length tolerance of $1 / 64$ in.

For dimensions greater than 25 in, use a $100 \mathrm{ft}$ tape with $1 / 16$ in divisions and an overall length tolerance of 0.1 in.

- Deadweight dial micrometer (or equal) equipped with a flat anvil, $6.35 \mathrm{~mm}$ or ( $1 / 4 \mathrm{in}$ ) diameter or larger, and a $4.75 \mathrm{~mm} \mathrm{(3/16}$ in) diameter flat surface on the head of the spindle. The anvil and spindle head surfaces should be ground and lapped, parallel to within $0.002 \mathrm{~mm}$ (0.0001 in), and should move on an axis perpendicular to their surfaces. The dial spindle should be vertical, and the dial should be at least $50.8 \mathrm{~mm}$ (2 in) in diameter. The dial indicator should be continuously graduated to read directly to $0.002 \mathrm{~mm}(0.0001 \mathrm{in})$ and should be capable of making more than one revolution. It must be equipped with a separate indicator to indicate the number of complete revolutions. The dial indicator mechanism should be fully jeweled. The frame should be of sufficient rigidity that a load of $1.36 \mathrm{~kg}$ (3 lb) applied to the dial housing, exclusive of the weight or spindle presser foot, will not cause a change in indication on the dial of more than $0.02 \mathrm{~mm}(0.001 \mathrm{in})$. The indicator reading must be repeatable to $0.0012 \mathrm{~mm}(0.00005 \mathrm{in})$ at zero. The mass of the probe head (total of anvil, weight $102 \mathrm{~g}$ or [3.6 oz], spindle, etc.) must be $113.4 \mathrm{~g}(4 \mathrm{oz})$. The micrometer should be operated in an atmosphere free from drafts and fluctuating temperature and should be stabilized at ambient room temperature before use.

- Gage blocks covering the range of thicknesses to be tested should be used to check the accuracy of the micrometer

- T-square

\subsubsection{Test Procedure}

1. Follow Section 2.3.1. "Define the Inspection Lot." Use a "Category A" sampling plan in the inspection; select a random sample. 
2. Be sure the product is not mislabeled. Check the label declaration to confirm that all of the declared dimensions are consistent with the required standards. The declaration on sheeting, film, and bags shall be equal to or greater than the weight calculated by using the formulas below. Calculate the final value to four digits and declare to three digits dropping the final digit (e.g., if the calculated value is $2.078 \mathrm{lb}$, then the declared net weight is truncated to $2.07 \mathrm{lb}$ ).

\section{Example:}

\section{Label -}

\section{Polyethylene Sheeting}

\section{$1.82 \mathrm{~m}(6 \mathrm{ft}) \times 30.48 \mathrm{~m}(100 \mathrm{ft})$}

101.6 $\mu \mathrm{m}$ (4 mil)

\section{$5.03 \mathrm{~kg}(11.1 \mathrm{lb})$}

3. Use the following formulas to compute a target net weight. The labeled weight should equal or exceed the target net weight or the package is not in compliance.

- For SI (metric) Dimensions:

$$
\text { Target Mass in Kilograms }=(T \times A \times D) \div 1000
$$

Where: $T$ = nominal thickness in centimeters

$A=$ nominal length in centimeters $\times$ nominal width (the nominal width for bags is twice the labeled width) in centimeters

$D=$ minimum density in grams per cubic centimeter*

Note: Check label for density declaration and type of polyethylene. Refer to Box * for density (D) value if not declared.

*Determined by the latest versions of ASTM Standard D1505, "Standard Method of Test for Density of Plastics by the Density-Gradient Technique” and ASTM Standard D883, "Standard Terminology Relating to Plastics."

For the purpose of this regulation, the minimum density (D) for linear low density polyethylene plastics (LLDPE) shall be $0.92 \mathrm{~g} / \mathrm{cm}^{3}$ (when D is not known).

For the purpose of this regulation, the minimum density (D) for linear medium density polyethylene plastics (LMDPE) shall be $0.93 \mathrm{~g} / \mathrm{cm}^{3}$ (when D is not known).

For the purpose of this regulation, the minimum density (D) for high density polyethylene plastics (HDPE) shall be $0.94 \mathrm{~g} / \mathrm{cm}^{3}$ (when D is not known). 
- For U.S. Customary Dimensions:

$$
\begin{gathered}
\text { Target Weight in Pounds }=T \times A \times D \times 0.03613 \\
\text { Where: } T=\text { nominal thickness in inches; } \\
A=\text { nominal area; that is the nominal length in inches } \times \text { nominal width (the } \\
\text { nominal width for bags is twice the labeled width) in inches; } \\
D=\text { minimum density in grams per cubic centimeter; } 0.03613 \text { is a factor for } \\
\text { converting } \mathrm{g} / \mathrm{cm}^{3} \text { to } \mathrm{ll}_{\mathrm{in}}{ }^{3} .
\end{gathered}
$$

4. Perform the calculations as shown in the following example. If the product complies with the label declaration, go to Step 5.

\section{Example:}

- For metric units:

$$
\begin{gathered}
\left(0.01016 \mathrm{~cm} \times\left[\left(1.82 \mathrm{~m} \times 100^{\mathrm{cm} / \mathrm{m}}\right) \times\left(30.48 \mathrm{~m} \times 100^{\mathrm{cm} / \mathrm{m}}\right)\right] \times 0.92 \mathrm{~g} / \mathrm{cm}^{3}\right) \div \\
1000 \mathrm{~g} / \mathrm{kg} \\
=\text { a target weight of } 5.18 \mathrm{~kg}
\end{gathered}
$$

In this example, the labeled net mass of $5.03 \mathrm{~kg}$ does not meet the target net mass, so the product is not in compliance.

- For U.S. customary units:

$$
\begin{aligned}
& (0.004 \mathrm{in}) \times\left[\left(6 \mathrm{ft} \times 12^{\mathrm{in} / \mathrm{ft}}\right) \times\left(100 \mathrm{ft} \times 12^{\mathrm{in} / \mathrm{ft}}\right)\right] \times 0.92 \mathrm{~g} / \mathrm{cm}^{3} \times 0.03613 \\
& =\text { a target weight of } 11.48 \mathrm{lb}
\end{aligned}
$$

In this example, the labeled net weight of $11.1 \mathrm{lb}$ does not meet the target net weight, so the product is not in compliance.

5. Select packages for tare samples according to Section 2.3.5.1. "Determination of Tare Sample and Average Tare Weight.”

6. Determine and record the gross weights of the initial tare sample.

7. Extend the product in the sample packages to their full dimensions and remove by hand all creases and folds.

8. Measure the length and width of the product to the closest $3 \mathrm{~mm}(1 / 8$ in). Make all measurements at intervals uniformly distributed along the length and width of the sample and record the results. Compute the average length and width, and record.

$>$ With rolls of product, measure the length of the roll at three points along the width of each roll and measure the width at a minimum of 10 points along the length of each roll. 
For folded products, such as drop cloths or tarpaulins, make three length measurements along the width of the sample and three width measurements along the length of the sample.

9. Determine and record the average tare weight according to Section 2.3.5.1. "Determination of Tare Sample and Average Tare Weight”.

10. Follow the procedures in Section 2.3.7. "Evaluate for Compliance" to determine the lot conformance requirements for length, width, and weight.

11. If the sample failed to meet the package requirements for any of these declarations, no further measurements are necessary. The lot fails to conform.

Note: If the sample meets the package requirements for the declarations of length, width, and weight proceed to Step 12 to verifying the thickness declaration.

12. Measure the thickness of the plastic sheet with a micrometer using the following guide. Place the micrometer on a solid level surface. If the dial does not read zero with nothing between the anvil and the spindle head, set it at zero. Raise and lower the spindle head or probe several times; it should indicate zero each time. If it does not, find and correct the cause before proceeding.

13. Take measurements at five uniformly distributed locations across the width at each end and five locations along each side of each roll in the sample. If this is not possible, take measurements at five uniformly distributed locations across the width of the product for each package in the sample.

14. When measuring the thickness, place the sample between the micrometer surfaces and lower the spindle head or probe near, but outside, the area where the measurement will be made. Raise the spindle head or probe a distance of $0.008 \mathrm{~mm}$ to $0.01 \mathrm{~mm}(0.0003$ in to $0.0004 \mathrm{in}$ ) and move the sheet to the measurement position. Drop the spindle head onto the test area of the sheet.

15. Read the dial thickness two seconds or more after the drop, or when the dial hand or digital readout becomes stationary. This procedure minimizes small errors that may occur when the spindle head or probe is lowered slowly onto the test area.

16. For succeeding measurements, raise the spindle head $0.008 \mathrm{~mm}$ to $0.01 \mathrm{~mm}(0.0003$ in to $0.0004 \mathrm{in}$ ) above the rest position on the test surface, move to the next measurement location, and drop the spindle head onto the test area. Do not raise the spindle head more than $0.01 \mathrm{~mm}(0.0004 \mathrm{in})$ above its rest position on the test area. Take measurements at least $6 \mathrm{~mm}(1 / 4 \mathrm{in})$ or more from the edge of the sheet.

17. Repeat Steps 12 through 16 above on the remaining packages in the sample and record all thickness measurements. Compute and record the average thickness for the individual package and apply the following MAV requirements.

(Amended 2012) 


\subsubsection{Evaluation of Results}

\section{a. Individual Thickness}

Note: Refer to Appendix A, Table 2-10. Exceptions to the MAVs for Textiles, Polyethylene Sheeting and Film , Mulch and Soil Labeled by Volume, Packaged Firewood, and Packages Labeled by Count with 50 Items or Fewer, and Specific Agricultural Seeds Labeled by Count.)

(Amended 2010)

- On polyethylene with a declared thickness greater than $25 \mu \mathrm{m}$ (1 mil or 0.001 in): an individual thickness measured may be up to $20 \%$ less than the declared thickness.

- On polyethylene with labeled thickness less than or equal to $25 \mu \mathrm{m}$ (1 mil or $0.001 \mathrm{in}$ ), individual thickness measurements may be up to $35 \%$ below the labeled thickness.

Count the number of values that are smaller than specified MAVs $(0.8 \times$ labeled thickness if $25 \mu \mathrm{m}$ [ 1 mil] or greater or $0.65 \times$ labeled thickness, if less than $25 \mu \mathrm{m}$ [1 mil]). If the number of values that fail to meet the thickness requirement exceeds the number of MAVs permitted for the sample size, the lot fails to conform to requirements. No further testing of the lot is necessary. If the number of MAVs for thickness measurements is less than or equal to the number permitted for the sample size, go on to Evaluation of Results - Average Thickness.

\section{b. Average Thickness}

The average thickness for any single package should be at least $96 \%$ of the labeled thickness. This is an MAV of $4 \%$ (refer to Appendix A, Table 2-10. Exceptions to the MAVs for Textiles, Polyethylene Sheeting and Film, Mulch and Soil Labeled by Volume, Packaged Firewood, and Packages Labeled by Count with 50 Items or Fewer, and Specific Agricultural Seeds Labeled by Count.) Circle and count the number of package average thickness values that are smaller than $0.96 \times$ labeled thickness. If the number of package average thicknesses circled exceeds the number of MAVs permitted for the sample size, the lot fails to conform to requirements. No further testing of the lot is necessary. If the number of MAVs for package average thickness is less than or equal to the number of MAVs permitted for the sample size, proceed to Section 2.3.7. "Evaluate for Compliance" to determine if the lot meets the package requirements for average thickness.

(Amended 2010)

\subsection{Packages Labeled by Linear or Square (area) Measure}

\subsubsection{Test Equipment}

- A scale or balance that meets the requirements in Section 2.2. "Measurement Standards and Test Equipment." Determine the suitability of the scale. Calculate the length or area of packaged product corresponding to MAV/6. If there is no suitable weighing device, all of the packages in the sample must be opened and measured.

- Steel tapes and rules - determine measurements of length to the nearest division of the appropriate tape or rule. 
Metric units:

For labeled dimensions $40 \mathrm{~cm}$ or less, linear measure: $30 \mathrm{~cm}$ in length, $1 \mathrm{~mm}$ divisions; or a $1 \mathrm{~m}$ rule with $0.1 \mathrm{~mm}$ divisions, overall length tolerance of $0.4 \mathrm{~mm}$.

For labeled dimensions greater than $40 \mathrm{~cm}, 30 \mathrm{~m}$ tape with $1 \mathrm{~mm}$ divisions.

U.S. customary units:

For labeled dimensions 25 in or less, use a 36 in rule with $1 /{ }_{64}$ in or $1 \frac{1}{100}$ in divisions and an overall length tolerance of $1 / 64$ in.

For dimensions greater than $25 \mathrm{in}$, use a $100 \mathrm{ft}$ tape with $1 / 16$ in divisions and an overall length tolerance of 0.1 in.

- $\quad$-square

\subsubsection{Test Procedure}

1. Follow Section 2.3.1. "Define the Inspection Lot." Use a "Category A" sampling plan in the inspection; select a random sample.

2. Select an initial tare sample according to Section 2.3.5.1. "Determination of Tare Sample and Average Tare Weight.”

3. Gross weigh the first package in the tare sample and record this weight.

4. Determine and record the measurements (to the nearest division of the appropriate tape or rule) of the packaged goods (length, width, area; depending upon which dimensions are declared on the label) and weigh the goods from the first package opened for tare determination.

Calculate and record the weight of the labeled measurements using the following formula:

$$
\begin{gathered}
\text { Weight of the labeled measurement }= \\
\text { (labeled measurement }) \times(\text { contents weight }) \div(\text { contents measurement })
\end{gathered}
$$

Look up and record the MAV in units of length or area measure (given in Appendix A, Table 2-8. "Maximum Allowable Variations for Packages Labeled by Length, (Width) or Area."

Note: See Appendix A, Table 2-10. "Exceptions to the MAVs for Textiles, and Polyethylene Sheeting and Film, Mulch and Soil Labeled by Volume, Packaged Firewood, and Packages Labeled by Count with 50 Items or Fewer, and Specific Agricultural Seeds Labeled by Count.”

5. Determine and record the tare weight of the first package opened.

6. Determine and record the measurements (length, width, area; depending upon which dimensions are declared on the label) of the product in the second package chosen for tare determination (to the nearest division of the appropriate tape or rule). Determine and record 
the tare weight of this package.

7. Calculate and record the weight of the labeled measurement for the second package using the following formula:

$$
\begin{gathered}
\text { Weight of the labeled measurement }= \\
\text { (labeled measurement }) \times(\text { contents weight } \div \text { contents measurement })
\end{gathered}
$$

The weights of the labeled measurement for two packages must not differ by more than one division on the scale. If they do, open all packages in the sample, measure individually, and compare them against the labeled measure to determine the package errors. If the criterion is met, go to Step 8.

8. Calculate the average weight of the labeled measurement and record.

9. Determine and record the average tare weight according to Section 2.3.5.1. "Determination of Tare Sample and Average Tare Weight."

10. Compute and record the nominal gross weight by adding the average weight of the labeled measurements to the average tare weight.

11. Compute package errors according to the following formula:

$$
\begin{gathered}
\text { Package error }(\text { weight })= \\
\text { (actual package gross weight })-(\text { nominal gross weight })
\end{gathered}
$$

12. Convert the MAV to units of weight using the following formula:

$$
\text { MAV (weight) = }
$$

(Avg. Wt. of label measurements $\times$ MAV [length] $) \div$ (labeled measurements)

Convert the MAV to dimensionless units by dividing the MAV (weight) by the unit of measure and record.

\subsubsection{Evaluation of Results}

Follow the procedure in Section 2.3.7. "Evaluate for Compliance” to determine lot conformance.

Convert back to dimensions when completing the report form using the following the formula:

Average Package Error (dimension) $=($ Avg. Pkg. Error [dimensionless units] $) \times($ Unit of Measure $)$

$\times$ (Labeled unit of measure $) \div($ Avg. Weight of Labeled dimension $)$

\subsection{Baler Twine - Test Procedure for Length}

\subsubsection{Test Equipment}

- A scale that meets the requirements in Section 2.2. "Measurement Standards and Test Equipment.” 
NOTE: A scale with $0.1 \mathrm{~g}(0.0002 \mathrm{lb})$ increments must be used for weighing twine samples. The recommended minimum load for weighing samples is 20 divisions.

- Steel tapes and rules - Determine measurements of length to the nearest division of the appropriate tape or rule.

\section{Metric units:}

For labeled dimensions $40 \mathrm{~cm}$ or less, linear measure: $30 \mathrm{~cm}$ in length, $1 \mathrm{~mm}$ divisions; or a $1 \mathrm{~m}$ rule with $0.1 \mathrm{~mm}$ divisions, overall length tolerance of $0.4 \mathrm{~mm}$.

For labeled dimensions greater than $40 \mathrm{~cm}, 30 \mathrm{~m}$ tape with $1 \mathrm{~mm}$ divisions.

U.S. customary units:

For labeled dimensions 25 in or less, use a 36 in rule with $1 / 64$ in or $1 / 100$ in divisions and an overall length tolerance of $1 / 64$ in.

For dimensions greater than $25 \mathrm{in}$, use a $100 \mathrm{ft}$ tape with $1 / 16$ in divisions and an overall length tolerance of $0.1 \mathrm{in}$.

- A hand-held straight-face spring scale of at least $4.53 \mathrm{~kg}$ (10 lb) capacity or a cordage-testing device that applies the specified tension to the twine being measured. When measuring twine samples or total roll length, apply $4.53 \mathrm{~kg}(10 \mathrm{lb})$ of tension to the twine.

\subsubsection{Test Procedure}

1. Follow Section 2.3.1. "Define the Inspection Lot." Use a "Category A" sampling plan in the inspection; select a random sample.

2. Select packages for tare samples. Determine gross weights of the initial tare sample and record.

3. Open the tare samples. Use the procedures for tare determination in Section 2.3.5.1. "Determination of Tare Sample and Average Tare Weight" to compute the average tare weight and record this value.

4. Randomly select four balls of twine from the packages that were opened for tare.

From each of the four balls of twine:

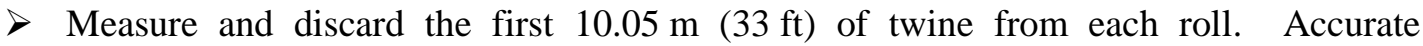
measurement requires applying tension to the ends of the twine before measuring in order to straighten the product.

$>$ Take two $30.48 \mathrm{~m}(100 \mathrm{ft})$ lengths of twine from inside each roll.

$>$ Weigh and record the weight of each piece separately and record the values. Compare the weight values to determine the variability of the samples. If the individual weights of the eight twine samples vary by more than one division on the scale, use one of the following steps: (1) if the lot is short, determine the actual length of the lightest-weight 
roll found in the lightest-weight package of the lot to confirm that the weight shortages reflect the shortages in the length of the rolls; or (2) determine the average weight-perunit of measure by taking ten $30.48 \mathrm{~m}$ (100 ft) lengths from inside the lightest weight package. Use this value to recalculate its length and determine lot compliance.

5. Weigh all of the sample lengths together and record the total value. Determine the total length of the samples (243.8 m or $800 \mathrm{ft}$, unless more than eight sample-lengths were taken) and record the value. Compute the average weight-per-unit-of-length by dividing the total weight by the total length of the pieces.

6. Determine the MAV for a package of twine (refer to Appendix A, Table 2-8. "Maximum Allowable Variations for Packages Labeled by Length, (Width), or Area”).

$>$ Record the total declared package length.

$>$ Multiply the MAV from Appendix A, Table 2-8. "Maximum Allowable Variations for Packages Labeled by Length, (Width), or Area” times the total package length to obtain the MAV for length and record this value.

$>$ Multiply the weight per unit of length (from Step 4) times the MAV for the total declared package length to obtain the MAV by weight and record this value.

$>$ Convert the MAV to dimensionless units and record.

7. Calculate the nominal gross weight and record.

Follow Section 2.3.6. "Determine Nominal Gross Weight and Package Error" to determine individual package errors. Determine errors using the following formula:

$$
\text { Package error }(\text { weight })=(\text { package gross weight })-(\text { nominal gross weight })
$$

To convert the package error in weight back to length, divide the weight by the average weight-per-unit-of-length.

\subsubsection{Evaluation of Results}

Follow the procedures in Section 2.3.7. "Evaluate for Compliance” to determine lot compliance.

\subsection{Procedure for Checking the Area Measurement of Chamois}

Chamois is natural leather made from skins of sheep and lambs that have been oil-tanned. Chamois are irregularly shaped, which makes area measurement difficult. Because of these characteristics, an accurate area determination can only be made using an internationally recognized method of conditioning (rehydrating) and measurement. Chamois is produced in a wet manufacturing process, so it has high moisture content at time of measurement. Chamois is hydroscopic; therefore, its dimensions and total area change as it loses or absorbs moisture. It is also subject to wrinkling. Because of the variation of the thickness and density, and therefore the weight per unit area of chamois, an estimated gross weight procedure cannot be used to verify the labeled area declaration.

Standard Test Conditions: As with all hydroscopic products, reasonable variations in measure must be allowed if caused by ordinary and customary exposure to atmospheric conditions that normally occur in 
good distribution practice. Both federal and international standards specify procedures to restore the moisture content of chamois so that tests to verify dimensions and area can be conducted.

Federal Test Method Standard 311, "Leather, Methods of Sampling and Testing,” (January 15, 1969) defines the standard atmospheric condition for chamois as $50 \pm 4 \%$ relative humidity and $23 \pm 2{ }^{\circ} \mathrm{C}$ $\left(73.4 \pm 3.6^{\circ} \mathrm{F}\right)$. The chamois is considered to be at equilibrium moisture when the difference in two successive weighings, made at $1 \mathrm{hr}$ intervals, is no greater than $0.25 \%$ (e.g., the maximum change in weight on a $100 \mathrm{~g}$ sample in two successive weighings is less than $0.25 \mathrm{~g}$ (250 mg).

The area of chamois is verified using a two-stage test procedure. The first stage is a field audit using the template test procedure. This test is used for field audits because it is simpler to perform and does not require the chamois to be conditioned. The field audit is used to identify chamois that are potentially under measure. It is not as accurate as the gravimetric procedure because some error results from reading the area from the template. The gravimetric procedure should be used for compliance testing because it includes conditioning (rehydrating) the chamois.

\subsubsection{Template Test Method (for field audits)}

Chamois is labeled in uniform sizes in terms of square decimeters and square feet, and are sized in increments of $1 / 4 \mathrm{ft}^{2}$ (e.g., $1 \mathrm{ft}^{2}, 1 \frac{11}{4} \mathrm{ft}^{2}$, and $1 \frac{1}{2} \mathrm{ft}^{2}$ ).

\subsubsection{Test Equipment}

Use a transparent, flexible template that is graduated in square centimeters or square inches and that has been verified for accuracy. The template must be large enough to completely cover the chamois under test.

\subsubsection{Test Procedure}

1. Select a random sample of chamois. Separate the chamois into different sizes and define the inspection lot by specific sizes.

2. Place the template over the chamois specimen on a smooth surface. Determine the area by counting the number of squares that cover the surface of the chamois. Estimate parts of the template that do not completely cover the chamois by adding the number of partially covered blocks. (See Figure 4-1.) Compute the total area and refer to Section 4.8.3. to determine if further action is necessary.

First Stage - Decision Criteria

If the average minus error exceeds $3 \%$ of the labeled area, the chamois may not be labeled accurately. To confirm the finding, the sample must be taken to a laboratory for conditioning and testing using the gravimetric test procedure. 


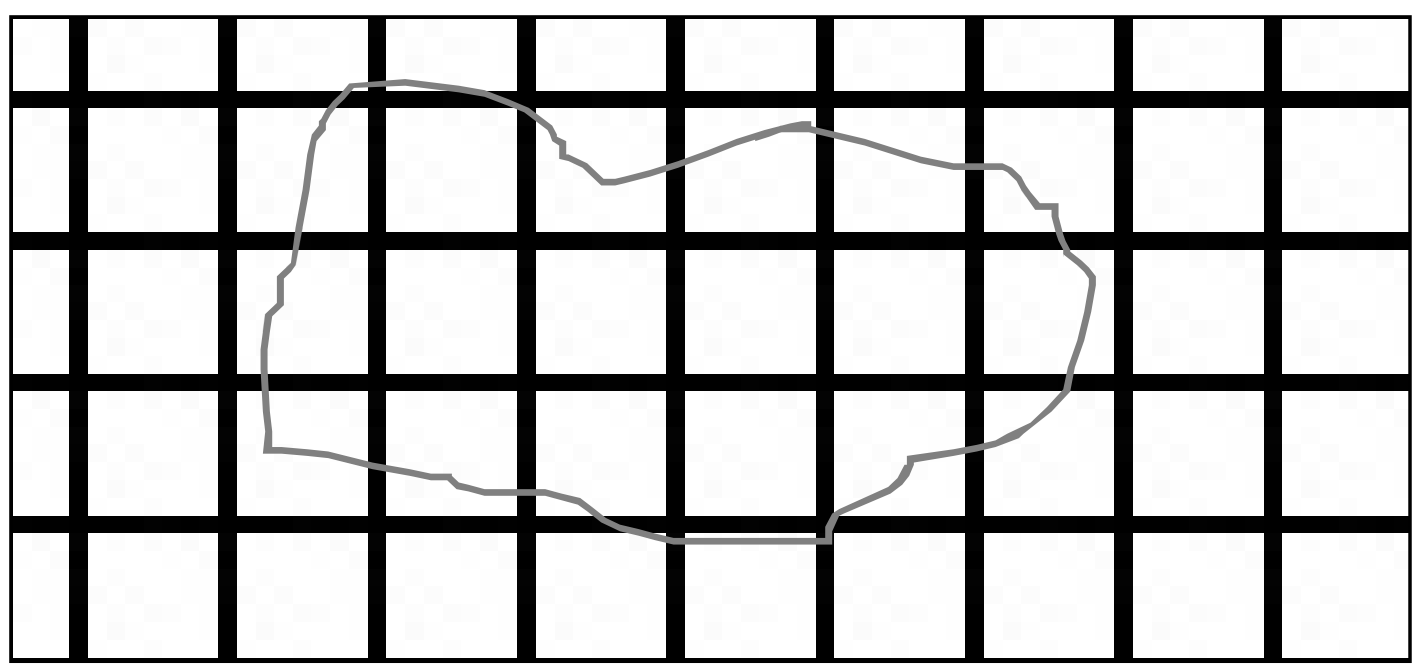

Figure 4-1.

Template

for

checking

the area of

chamois

\subsubsection{Gravimetric Procedure for Area Measurement}

This test cannot be performed in the field because the samples must be conditioned with water before testing. This method is intended for use in checking full or cut skins, or pattern shapes. Open and condition all of the packages in the sample before determining their area on the recommended paper. Conditioning and verifying chamois can be accomplished without destroying the product. When successful tests are completed, the chamois may be repackaged for sale, so do not destroy the packaging material.

\subsubsection{Test Equipment}

- Scale with a capacity of $1 \mathrm{~kg}$ that is accurate to at least $\pm 0.01 \mathrm{~g}$ and a load-receiving element of adequate size to properly hold the chamois

- Atomizer or trigger-type sprayer and sealable, airtight polyethylene bags

- Medium weight drawing paper (e.g., drawing paper, medium weight (100 lb), regular surface or comparable)

- Household iron with low temperature settings $30^{\circ} \mathrm{C}$ to $40^{\circ} \mathrm{C}\left(86^{\circ} \mathrm{F}\right.$ to $\left.104^{\circ} \mathrm{F}\right)$

- Rule or tape that is graduated in centimeters or inches

- Instrument for cutting paper (razor blade, scissors, or cutting board) 


\section{Sample conditioning}

1. Remove each sample from its package and weigh and record each weight. Using an atomizer-type sprayer, spray water in the amount of $25 \%$ of the weight of each skin uniformly over its area. Place wetted chamois in an airtight polyethylene bag; seal the bag, and leave it in this condition at room temperature for 24 hours.

2. Open the bag, remove the chamois, and reweigh the chamois to confirm that it retained maximum moisture. (This is done by confirming that the difference in the two consecutive weighings conducted an hour apart does not exceed $0.25 \%$.)

3. Place the chamois flat on a continuous piece of drawing paper. To remove wrinkles and make the chamois lie flat, use a normal domestic iron that is heated to a maximum of $30^{\circ} \mathrm{C}$ to $40^{\circ} \mathrm{C}\left(86^{\circ} \mathrm{F}\right.$ to $\left.104^{\circ} \mathrm{F}\right)$. Place the iron on the bottom of the skin, and iron the skin up from the center to the top. Then, iron the skin from the center out to each side. Iron until the skin is fully extended and perfectly flat.

\subsubsection{Test Procedure}

1. Immediately after ironing, carefully draw around the outline of the skin on the paper. Remove the skin; carefully cut along the outline of the skin; weigh the cutout pattern, and record to the nearest $0.1 \mathrm{~g}$ Sample Weight 1 (W1).

2. Lay out the pattern and cut an accurately measured rectangle of a size not less than one-half the area of the pattern. Weigh the cutout rectangle and record the weight to the nearest $0.1 \mathrm{~g}$ Sample Weight 2 (W2). Calculate the area of the rectangle cut from the patterns by multiplying length by width and record as Area (A) in centimeters or square inches.

For metric units - calculate the area of the original skin being checked as follows:

$$
\text { W1/W2 } \times A=\text { Skin Area in } \mathrm{cm}^{2} / 100=\text { Area in } \mathrm{dm}^{2}
$$

For U.S. customary units - calculate the area of the original skin being checked as follows:

$$
\text { W1/W2 } \times A=\text { Skin Area in } \text { in }^{2} / 144=\text { Area }^{2}
$$

\subsubsection{Evaluation of Results}

Compute the average error for the sample and follow the procedures in Section 2.3.7. "Evaluate for Compliance” to determine lot conformance.

The MAV for area declarations on chamois is $3 \%$ of the labeled area as specified in Appendix A, Table 2-8. "Maximum Allowable Variations for Packages Labeled by Length, (Width), or Area”. 


\subsection{Procedure for Checking the Contents of Specific Agriculture Seed Packages Labeled by Count}

The following method shall be employed when using a mechanical seed counter to determine the number of seeds contained in a sample of soybean (Glycine max), corn (Zea mays), wheat (Triticum aestivum) and field bean (Phaseolus vulgaris).

\subsubsection{Test Equipment}

- $\quad$ Mechanical seed counter.

- $\quad$ Moisture proof container.

\subsubsection{Test Procedure}

1. Testing samples shall be received and retained in moisture proof containers until the weight of the sample prepared for purity analysis is recorded. The sample shall be of at least 500 grams for soybean, corn, field beans, and 100 grams for wheat.

2. The seed counter shall be calibrated daily prior to use.

$>$ Prepare a calibration sample by counting 10 sets of 100 seeds. Visually examine each set to insure that it contains whole seeds. Combine the 10 sets of seeds to make a 1000 seed calibration sample. The seeds of the calibration sample should be approximately the same size and shape as the seeds in a sample being tested.

Note: If the seeds in a sample being tested are noticeably different in size or shape from those in the calibration sample, prepare another calibration sample with seeds of the appropriate size and shape. Periodically re-examine the calibration samples to insure that no seeds have been lost or added.

Carefully pour the 1000 seed calibration sample into the seed counter. Start the counter and run it until all the seeds have been counted.

Note: The seeds should not touch as they run through the counter. Record the number of seeds as displayed on the counter read out.

The seed count should not vary more than \pm 2 seeds from 1000 . If the count is not within this tolerance, clean the mirrors, adjust the feed rate and/or reading sensitivity. Rerun the calibration sample until it is within the \pm 2 seed tolerance.

Note: If the seed counter fails the calibration procedure and sample has been checked to ensure that it contains 1000 seeds, do not use the counter until it has been repaired.

3. Immediately after opening the container, mix and divide the sample to obtain a sample for purity analysis (refer to Appendix D: AOSA Rules for Testing Seeds).

4. Record the weight of this sample in grams to the appropriate number of decimal places.

5. Conduct the purity analysis to obtain pure seed for the seed count test. 
6. After the seed counter has been calibrated, test the pure seed portion from the purity test and record the number of seeds in the sample.

7. Calculation of results.

Calculate the number of seeds per pound to the nearest whole number using the following formula:

$$
\begin{gathered}
\text { Number of seeds per pound }=453.6 \mathrm{~g} / \mathrm{lb} \times \text { no. of seeds counted divided by } \\
\text { the weight }(\mathrm{g}) \text { of sample analyzed for purity }
\end{gathered}
$$

8. Determine the Maximum Allowable Variation (MAV).

$>$ Multiply the labeled seed count by $4 \%$ for soybean, $2 \%$ for corn, $5 \%$ for field bean, and $3 \%$ for wheat.

Note: Express the maximum allowable variation (the number of seeds) to the nearest whole number. Consider the results of two tests in accord with the maximum allowable variation if the difference, expressed as the number of seeds, is equal to or less than the maximum allowable variation.

\section{Example:}

Kind of seed: Corn

Label claim: 2275 seeds/lb

Lab Test: Purity working weight $=500.3 \mathrm{~g}$

Seed count of pure seed $=2479$ seeds

Number of seeds per pound $=453.6 \mathrm{~g} / \mathrm{lb} \times 2479$ seeds divided by $500.3 \mathrm{~g}=2247.6$ seeds/lb

Rounded to the nearest whole number $=2248$ seeds $/ \mathrm{lb}$

Calculate maximum allowable variation value for corn:

multiply label claim by $2 \%$

2275 seeds $/ \mathrm{lb} \times 0.02=45.5$ seeds $/ \mathrm{lb}$;

rounded to the nearest whole number $=46$ seeds $/ \mathrm{lb}$

Determine the difference between label claim and lab test:

2275 seeds $/ l b-2248$ seeds $/ l b=27$ seeds $/ l b$

The difference between the lab test and the label claim is less than the maximum allowable variation $(27<46)$; therefore, the two results are in accord with the maximum allowable variation.

\subsubsection{Evaluation of Results}

Follow the procedures in Section 2.3.7. "Evaluate for Compliance” to determine lot compliance. (Added 2010) 
Handbook 133, Checking the Net Contents of Packaged Goods (2015)

THIS PAGE INTENTIONALLY LEFT BLANK 


\section{Appendix A. Tables}

Table 1-1. Agencies Responsible for Package Regulations and Applicable Requirements

\begin{tabular}{|c|c|c|c|}
\hline Commodity & Responsible Agency & $\begin{array}{l}\text { NIST Handbook } 133 \\
\text { Sampling Plans }\end{array}$ & $\begin{array}{c}\text { Table of Maximum } \\
\text { Allowable } \\
\text { Variations } \\
\end{array}$ \\
\hline Meat and Poultry & $\begin{array}{l}\text { U.S. Department of } \\
\text { Agriculture/Food Safety } \\
\text { and Inspection Service } \\
\text { and state and local } \\
\text { weights and measures. }\end{array}$ & $\begin{array}{l}\text { Use Table 2-1. } \\
\text { Sampling Plans for } \\
\text { Category A to test } \\
\text { packages at other than } \\
\text { point of pack. } \\
\text { Use Table 2-2. Sampling } \\
\text { Plans for } \\
\text { Category B to test } \\
\text { packages in federally } \\
\text { inspected meat and } \\
\text { poultry plants. }\end{array}$ & $\begin{array}{l}\text { Table 2-9. U.S. } \\
\text { Department of } \\
\text { Agriculture, Meat and } \\
\text { Poultry, Groups and } \\
\text { Lower Limits for } \\
\text { Individual Packages }\end{array}$ \\
\hline $\begin{array}{l}\text { Foods, drugs, and } \\
\text { cosmetics subject to } \\
\text { the Food, Drug, and } \\
\text { Cosmetic Act } \\
\text { including those } \\
\text { packaged at the retail } \\
\text { store level that have } \\
\text { been in interstate } \\
\text { commerce } \\
\text { (e.g., seafood) or those } \\
\text { made with ingredients } \\
\text { that have been in } \\
\text { interstate commerce } \\
\text { and beer made from } \\
\text { substitutes for malted } \\
\text { barley (e.g., sorghum, } \\
\text { rice, or wheat) and } \\
\text { wine beverages with } \\
\text { an alcohol content of } \\
\text { less than } 7 \text { \% by } \\
\text { volume }\end{array}$ & $\begin{array}{l}\text { U.S. Food and Drug } \\
\text { Administration and state } \\
\text { and local weights and } \\
\text { measures } \\
\text { http://www.fda.gov }\end{array}$ & \multirow[t]{2}{*}{$\begin{array}{l}\text { Use Table 2-1. Sampling } \\
\text { Plans for Category A to } \\
\text { test packages at all } \\
\text { locations. }\end{array}$} & $\begin{array}{l}\text { Table 2-5. MAVs for } \\
\text { Packages Labeled by } \\
\text { Weight } \\
\text { Table 2-6. MAVs for } \\
\text { Packages Labeled by } \\
\text { Liquid or Dry } \\
\text { Volume } \\
\text { Table 2-7. MAVs for } \\
\text { Packages Labeled by } \\
\text { Count } \\
\text { Table 2-8. MAVs for } \\
\text { Packages Labeled by } \\
\text { Length (Width) or } \\
\text { Area } \\
\text { Table 2-10. } \\
\text { Exceptions to the } \\
\text { MAVs for Textiles, }\end{array}$ \\
\hline $\begin{array}{l}\text { Food products not } \\
\text { subject to the Federal } \\
\text { Food, Drug, and } \\
\text { Cosmetic Act, } \\
\text { including meat and } \\
\text { poultry products } \\
\text { packaged at the retail } \\
\text { store level }\end{array}$ & $\begin{array}{l}\text { State and local weights } \\
\text { and measures } \\
\text { http://www.nist.gov/pml/ } \\
\text { wmd/ }\end{array}$ & & $\begin{array}{l}\text { Table 2-8. MAVs for } \\
\text { Packages Labeled by } \\
\text { Length (Width) or } \\
\text { Area } \\
\text { Table 2-10. } \\
\text { Exceptions to the } \\
\text { MAVs for Textiles, } \\
\text { Polyethylene } \\
\text { Sheeting and Film, } \\
\text { Mulch and Soil } \\
\text { Labeled by Volume, } \\
\text { Packaged Firewood, } \\
\text { and Packages Labeled } \\
\text { by Count with } 50 \\
\text { Items or Fewer, and }\end{array}$ \\
\hline
\end{tabular}


Table 1-1. Agencies Responsible for Package Regulations and Applicable Requirements

\begin{tabular}{|c|c|c|c|}
\hline Commodity & Responsible Agency & $\begin{array}{l}\text { NIST Handbook } 133 \\
\text { Sampling Plans }\end{array}$ & $\begin{array}{c}\text { Table of Maximum } \\
\text { Allowable } \\
\text { Variations } \\
\end{array}$ \\
\hline $\begin{array}{l}\text { Non-food Consumer } \\
\text { Products }\end{array}$ & $\begin{array}{l}\text { Federal Trade } \\
\text { Commission } \\
\text { http://www.ftc.gov }\end{array}$ & & $\begin{array}{l}\text { Specific } \\
\text { Agriculture Seeds } \\
\text { Labeled by Count }\end{array}$ \\
\hline $\begin{array}{l}\text { Non-food Consumer } \\
\text { and Non-consumer } \\
\text { Products }\end{array}$ & $\begin{array}{l}\text { State and local weights } \\
\text { and measures }\end{array}$ & & \\
\hline $\begin{array}{l}\text { Alcohol and Tobacco } \\
\text { Products, except for } \\
\text { beer made from } \\
\text { substitutes for malted } \\
\text { barley (e.g., sorghum, } \\
\text { rice, or wheat) and } \\
\text { wine beverages with } \\
\text { an alcohol content of } \\
\text { less than } 7 \% \text { by } \\
\text { volume, which are } \\
\text { regulated by FDA }\end{array}$ & $\begin{array}{l}\text { Alcohol and Tobacco } \\
\text { Tax and Trade Bureau. } \\
\text { State and local weights } \\
\text { and measures } \\
\text { http://www.ttb.gov }\end{array}$ & & \\
\hline Pesticides & $\begin{array}{l}\text { U.S. Environmental } \\
\text { Protection Agency and } \\
\text { state and local weights } \\
\text { and measures } \\
\text { http://www.epa.gov }\end{array}$ & & \\
\hline
\end{tabular}




\begin{tabular}{|c|c|c|c|c|c|}
\hline 1 & 2 & 3 & 4 & 5 & 6 \\
\hline \multirow{2}{*}{$\begin{array}{c}\text { Inspection Lot } \\
\text { Size }\end{array}$} & \multirow{2}{*}{$\begin{array}{l}\text { Sample } \\
\text { Size }\end{array}$} & \multirow{2}{*}{$\begin{array}{l}\text { Sample } \\
\text { Correction } \\
\text { Factor }\end{array}$} & \multirow{2}{*}{$\begin{array}{c}\text { Number of } \\
\text { Minus Package } \\
\text { Errors Allowed } \\
\text { to Exceed the } \\
\text { MAV }^{1}\end{array}$} & \multicolumn{2}{|c|}{ Initial Tare Sample Size ${ }^{2}$} \\
\hline & & & & $\begin{array}{l}\text { Glass and } \\
\text { Aerosol } \\
\text { Packages }\end{array}$ & $\begin{array}{l}\text { All Other } \\
\text { Packages }\end{array}$ \\
\hline 1 & 1 & Apply MAV & \multirow{13}{*}{$0^{1}$} & \multirow{12}{*}{2} & \multirow{14}{*}{2} \\
\hline 2 & 2 & 8.985 & & & \\
\hline 3 & 3 & 2.484 & & & \\
\hline 4 & 4 & 1.591 & & & \\
\hline 5 & 5 & 1.242 & & & \\
\hline 6 & 6 & 1.049 & & & \\
\hline 7 & 7 & 0.925 & & & \\
\hline 8 & 8 & 0.836 & & & \\
\hline 9 & 9 & 0.769 & & & \\
\hline 10 & 10 & 0.715 & & & \\
\hline 11 & 11 & 0.672 & & & \\
\hline 12 to 250 & 12 & 0.635 & & & \\
\hline 251 to 3200 & 24 & 0.422 & & \multirow{2}{*}{3} & \\
\hline More than 3200 & 48 & 0.290 & $1^{1}$ & & \\
\hline \multicolumn{6}{|c|}{$\begin{array}{l}{ }^{1} \text { For mulch and soils packaged by volume see Table } 2-10 \text {. Exceptions to the Maximum Allowable } \\
\text { Variations - } 1 \text { package may exceed the MAV for every } 12 \text { packages in the sample. } \\
{ }^{2} \text { If sample size is } 11 \text { or fewer, the initial tare sample size and the total tare sample size is } 2 \text { samples. }\end{array}$} \\
\hline
\end{tabular}

\begin{tabular}{|c|c|c|c|}
\hline \multicolumn{4}{|c|}{ Table 2-2. Sampling Plans for Category B } \\
(for Use in USDA-Inspected Meat and Poultry Plants Only)
\end{tabular}


Table 2-3. Category A

\section{Total Number of Packages in Tare Sample}

Note: Total number of packages to be opened for tare determination.

Numbers include those packages opened for initial tare sample.

\begin{tabular}{|c|c|c|c|c|c|}
\hline Sample Size & 12 & \multicolumn{2}{|c|}{24} & \multicolumn{2}{|c|}{48} \\
\hline Initial Tare Sample Size & 2 & 2 & 3 & 2 & 3 \\
\hline Ratio of $R_{c} / R_{t}$ & & & & & \\
\hline $\begin{array}{l}\text { If range of tare equals “zero,” use } \\
\text { Initial Tare Sample Size. } \\
\text { If the ratio is “zero” based on a } \\
\text { "zero” range of package error, } \\
\text { open all of the packages in the } \\
\text { sample. }\end{array}$ & 2 & 2 & 3 & 2 & 3 \\
\hline $\begin{array}{l}\text { If the ratio is greater than } 0 \text { but } \\
\text { less than or equal to } 0.2\end{array}$ & 12 & 24 & 24 & 48 & 48 \\
\hline 0.21 to 0.60 & 12 & 24 & 24 & 48 & 48 \\
\hline 0.61 to 0.70 & 12 & 24 & 24 & 47 & 47 \\
\hline 0.71 to 0.80 & 12 & 23 & 23 & 47 & 47 \\
\hline 0.81 to 1.00 & 12 & 23 & 23 & 46 & 46 \\
\hline 1.01 to 1.10 & 11 & 23 & 23 & 46 & 46 \\
\hline 1.11 to 1.20 & 11 & 23 & 23 & 45 & 45 \\
\hline 1.21 to 1.30 & 11 & 22 & 22 & 45 & 45 \\
\hline 1.31 to 1.50 & 11 & 22 & 22 & 44 & 44 \\
\hline 1.51 to 1.60 & 11 & 22 & 22 & 43 & 43 \\
\hline 1.61 to 1.70 & 11 & 21 & 21 & 42 & 42 \\
\hline 1.71 to 1.80 & 10 & 21 & 21 & 42 & 42 \\
\hline 1.81 to 1.90 & 10 & 21 & 21 & 41 & 41 \\
\hline 1.91 to 2.00 & 10 & 20 & 20 & 41 & 41 \\
\hline 2.01 to 2.10 & 10 & 20 & 20 & 40 & 40 \\
\hline 2.11 to 2.20 & 10 & 20 & 20 & 39 & 39 \\
\hline 2.21 to 2.30 & 10 & 19 & 19 & 39 & 39 \\
\hline 2.31 to 2.40 & 9 & 19 & 19 & 38 & 38 \\
\hline 2.41 to 2.50 & 9 & 19 & 19 & 37 & 37 \\
\hline 2.51 to 2.60 & 9 & 18 & 18 & 37 & 37 \\
\hline 2.61 to 2.70 & 9 & 18 & 18 & 36 & 36 \\
\hline 2.71 to 2.80 & 9 & 18 & 18 & 35 & 35 \\
\hline
\end{tabular}




\begin{tabular}{|c|c|c|c|c|c|}
\hline \multicolumn{6}{|c|}{ Table 2-3. Category A } \\
\hline \multirow{3}{*}{$\begin{array}{c}\text { Sample Size } \\
\text { Initial Tare Sample Size }\end{array}$} & \multicolumn{5}{|c|}{$\begin{array}{l}\text { Total Number of Packages in Tare Sample } \\
\text { Note: Total number of packages to be opened for tare determination. } \\
\text { Numbers include those packages opened for initial tare sample. }\end{array}$} \\
\hline & \multirow{2}{*}{$\begin{array}{c}12 \\
2\end{array}$} & \multicolumn{2}{|c|}{24} & \multicolumn{2}{|c|}{48} \\
\hline & & 2 & 3 & 2 & 3 \\
\hline \multicolumn{6}{|l|}{ Ratio of $\mathbf{R}_{\mathrm{c}} / \mathbf{R}_{\mathrm{t}}$} \\
\hline 2.81 to 2.90 & 9 & 17 & 17 & 34 & 34 \\
\hline 2.91 to 3.00 & 8 & 17 & 17 & 34 & 34 \\
\hline 3.01 to 3.10 & 8 & 17 & 17 & 33 & 33 \\
\hline 3.11 to 3.30 & 8 & 16 & 16 & 32 & 32 \\
\hline 3.31 to 3.40 & 8 & 16 & 16 & 31 & 31 \\
\hline 3.41 to 3.50 & 8 & 15 & 15 & 30 & 30 \\
\hline 3.51 to 3.60 & 7 & 15 & 15 & 30 & 30 \\
\hline 3.61 to 3.70 & 7 & 15 & 15 & 29 & 29 \\
\hline 3.71 to 3.90 & 7 & 14 & 14 & 28 & 28 \\
\hline 3.91 to 4.00 & 7 & 14 & 14 & 27 & 27 \\
\hline 4.01 to 4.10 & 7 & 13 & 13 & 27 & 27 \\
\hline 4.11 to 4.20 & 7 & 13 & 13 & 26 & 26 \\
\hline 4.21 to 4.30 & 6 & 13 & 13 & 25 & 25 \\
\hline 4.31 to 4.40 & 6 & 12 & 12 & 25 & 25 \\
\hline 4.41 to 4.60 & 6 & 12 & 12 & 24 & 24 \\
\hline 4.61 to 4.70 & 6 & 12 & 12 & 23 & 23 \\
\hline 4.71 to 4.80 & 6 & 11 & 11 & 23 & 23 \\
\hline 4.81 to 4.90 & 6 & 11 & 11 & 22 & 22 \\
\hline 4.91 to 5.00 & 5 & 11 & 11 & 22 & 22 \\
\hline 5.01 to 5.10 & 5 & 11 & 11 & 21 & 21 \\
\hline 5.01 to 5.10 & 5 & 11 & 11 & 21 & 21 \\
\hline 5.11 to 5.20 & 5 & 10 & 10 & 21 & 21 \\
\hline 5.21 to 5.40 & 5 & 10 & 10 & 20 & 20 \\
\hline 5.41 to 5.60 & 5 & 10 & 10 & 19 & 19 \\
\hline 5.61 to 5.70 & 5 & 9 & 9 & 19 & 19 \\
\hline 5.71 to 5.80 & 5 & 9 & 9 & 18 & 18 \\
\hline 5.81 to 5.90 & 4 & 9 & 9 & 18 & 18 \\
\hline
\end{tabular}




\begin{tabular}{|c|c|c|c|c|c|}
\hline \multicolumn{6}{|c|}{ Table 2-3. Category A } \\
\hline \multirow{3}{*}{$\begin{array}{c}\text { Sample Size } \\
\text { Initial Tare Sample Size }\end{array}$} & \multicolumn{5}{|c|}{$\begin{array}{l}\text { Total Number of Packages in Tare Sample } \\
\text { Note: Total number of packages to be opened for tare determination. } \\
\text { Numbers include those packages opened for initial tare sample. }\end{array}$} \\
\hline & \multirow{2}{*}{$\frac{12}{2}$} & \multicolumn{2}{|c|}{24} & \multicolumn{2}{|c|}{48} \\
\hline & & 2 & 3 & 2 & 3 \\
\hline \multicolumn{6}{|l|}{ Ratio of $R_{c} / R_{t}$} \\
\hline 5.91 to 6.10 & 4 & 9 & 9 & 17 & 17 \\
\hline 6.11 to 6.20 & 4 & 8 & 8 & 17 & 17 \\
\hline 6.21 to 6.50 & 4 & 8 & 8 & 16 & 16 \\
\hline 6.51 to 6.70 & 4 & 8 & 8 & 15 & 15 \\
\hline 6.71 to 6.80 & 4 & 7 & 7 & 15 & 15 \\
\hline 6.81 to 7.00 & 4 & 7 & 7 & 14 & 14 \\
\hline 7.01 to 7.20 & 3 & 7 & 7 & 14 & 14 \\
\hline 7.21 to 7.40 & 3 & 7 & 7 & 13 & 13 \\
\hline 7.41 to 7.60 & 3 & 6 & 6 & 13 & 13 \\
\hline 7.61 to 8.00 & 3 & 6 & 6 & 12 & 12 \\
\hline 8.01 to 8.20 & 3 & 6 & 6 & 11 & 11 \\
\hline 8.21 to 8.50 & 3 & 5 & 5 & 11 & 11 \\
\hline 8.51 to 8.80 & 3 & 5 & 5 & 10 & 10 \\
\hline 8.81 to 9.00 & 2 & 5 & 5 & 10 & 10 \\
\hline 9.01 to 9.30 & 2 & 5 & 5 & 9 & 9 \\
\hline 9.31 to 9.70 & 2 & 4 & 4 & 9 & 9 \\
\hline 9.71 to 10.40 & 2 & 4 & 4 & 8 & 8 \\
\hline 10.41 to 10.90 & 2 & 4 & 4 & 7 & 7 \\
\hline 10.91 to 11.30 & 2 & 3 & 3 & 7 & 7 \\
\hline 11.31 to 12.50 & 2 & 3 & 3 & 6 & 6 \\
\hline 12.51 to 13.20 & 2 & 3 & 3 & 5 & 5 \\
\hline 13.21 to 13.90 & 2 & 2 & 3 & 5 & 5 \\
\hline 13.91 to 16.00 & 2 & 2 & 3 & 4 & 4 \\
\hline 16.01 to 19.10 & 2 & 2 & 3 & 3 & 3 \\
\hline 19.11 to 19.20 & 2 & 2 & 3 & 2 & 3 \\
\hline Initial Tare Sample Size & 2 & 2 & 3 & 2 & 3 \\
\hline
\end{tabular}


Table 2-4. Category B

\section{Total Number of Packages in Tare Sample}

Note: Total number of packages to be opened for tare determination. Numbers include those packages opened for initial tare sample.

\begin{tabular}{|c|c|c|}
\hline Sample Size & 10 & 30 \\
\hline Initial Tare Sample Size & 2 & 5 \\
\hline \multicolumn{3}{|l|}{ Ratio of $R_{c} / R_{t}$} \\
\hline $\begin{array}{l}\text { If the ratio is zero, based on a } \\
\text { "zero" range of tare, use Initial } \\
\text { Tare Sample Size. }\end{array}$ & & \\
\hline $\begin{array}{l}\text { If the ratio is "zero" based on a } \\
\text { "zero" range of package errors, } \\
\text { open all the packages in the } \\
\text { sample. }\end{array}$ & 2 & 5 \\
\hline $\begin{array}{l}\text { If the ratio is greater than } 0 \text { but } \\
\text { less than or equal to } 0.2\end{array}$ & 10 & 30 \\
\hline 0.21 to 0.40 & 10 & 29 \\
\hline 0.41 to 0.60 & 10 & 28 \\
\hline 0.61 to 0.80 & 9 & 26 \\
\hline 0.81 to 1.00 & 8 & 24 \\
\hline 1.01 to 1.20 & 8 & 23 \\
\hline 1.21 to 1.40 & 7 & 21 \\
\hline 1.41 to 1.60 & 7 & 19 \\
\hline 1.61 to 1.80 & 6 & 17 \\
\hline 1.81 to 2.00 & 5 & 15 \\
\hline 2.01 to 2.20 & 5 & 14 \\
\hline 2.21 to 2.40 & 5 & 13 \\
\hline 2.41 to 2.60 & 4 & 12 \\
\hline 2.61 to 2.80 & 4 & 11 \\
\hline 2.81 to 3.00 & 4 & 10 \\
\hline 3.01 to 3.20 & 3 & 9 \\
\hline 3.21 to 3.60 & 3 & 8 \\
\hline 3.61 to 3.80 & 3 & 7 \\
\hline 3.81 to 4.40 & 2 & 6 \\
\hline $\begin{array}{l}\text { If the ratio is greater than } 4.40 \text {, } \\
\text { use the Initial Tare Sample Size }\end{array}$ & 2 & 5 \\
\hline
\end{tabular}




\begin{tabular}{|c|c|}
\hline \multicolumn{2}{|c|}{$\begin{array}{l}\text { Do Not Use this Table for Meat and Poultry Products Subject to USDA Regulations - Use Table 2-9. } \\
\text { For Polyethylene Sheeting and Film, see Table 2-10. Exceptions to the MAVs. }\end{array}$} \\
\hline Labeled Quantity & Maximum Allowable Variations \\
\hline Less than $36 \mathrm{~g}, 0.08 \mathrm{lb}$, or $1.28 \mathrm{oz}$ & $10 \%$ of labeled quantity \\
\hline $\begin{array}{c}36 \mathrm{~g} \text { or more to } 54 \mathrm{~g} \\
\mathbf{0 . 0 8} \mathbf{l b} \text { or more to } \mathbf{0 . 1 2} \mathbf{~ l b} \\
1.28 \text { oz or more to } 1.92 \mathrm{oz}\end{array}$ & $\begin{array}{c}3.6 \mathrm{~g} \\
\mathbf{0 . 0 0 8} \mathbf{~ l b} \\
1 / 8 \mathrm{OZ}\end{array}$ \\
\hline $\begin{array}{l}\text { More than } 54 \mathrm{~g} \text { to } 81 \mathrm{~g} \\
\text { More than } \mathbf{0 . 1 2} \mathbf{~ l b} \text { to } \mathbf{0 . 1 8} \mathbf{~ l b} \\
\text { More than } 1.92 \mathrm{oz} \text { to } 2.88 \mathrm{oz}\end{array}$ & $\begin{array}{c}5.4 \mathrm{~g} \\
\mathbf{0 . 0 1 2} \mathbf{~ l b} \\
3 / 16 \mathrm{OZ}\end{array}$ \\
\hline $\begin{array}{l}\text { More than } 81 \mathrm{~g} \text { to } 117 \mathrm{~g} \\
\text { More than } \mathbf{0 . 1 8} \mathbf{l b} \text { to } \mathbf{0 . 2 6} \mathbf{~ l b} \\
\text { More than } 2.88 \mathrm{oz} \text { to } 4.16 \mathrm{oz}\end{array}$ & $\begin{array}{c}7.2 \mathrm{~g} \\
\mathbf{0 . 0 1 6 ~ l b} \\
1 / 4 \mathrm{OZ}\end{array}$ \\
\hline $\begin{array}{l}\text { More than } 117 \mathrm{~g} \text { to } 154 \mathrm{~g} \\
\text { More than } \mathbf{0 . 2 6} \mathbf{l b} \text { to } \mathbf{0 . 3 4} \mathbf{~ l b} \\
\text { More than } 4.16 \mathrm{oz} \text { to } 5.44 \mathrm{oz}\end{array}$ & $\begin{array}{c}9.0 \mathrm{~g} \\
\mathbf{0 . 0 2 0} \mathbf{~ l b} \\
5 / 16 \mathrm{OZ}\end{array}$ \\
\hline $\begin{array}{l}\text { More than } 154 \mathrm{~g} \text { to } 208 \mathrm{~g} \\
\text { More than } \mathbf{0 . 3 4} \mathbf{~ l b} \text { to } \mathbf{0 . 4 6} \mathbf{~ l b} \\
\text { More than } 5.44 \mathrm{oz} \text { to } 7.36 \mathrm{oz}\end{array}$ & $\begin{array}{c}10.8 \mathrm{~g} \\
\mathbf{0 . 0 2 4} \mathbf{l b} \\
3 / 8 \mathrm{OZ}\end{array}$ \\
\hline $\begin{array}{l}\text { More than } 208 \mathrm{~g} \text { to } 263 \mathrm{~g} \\
\text { More than } \mathbf{0 . 4 6} \mathbf{~ l b} \text { to } \mathbf{0 . 5 8} \mathbf{~ l b} \\
\text { More than } 7.36 \mathrm{oz} \text { to } 9.28 \mathrm{oz}\end{array}$ & $\begin{array}{c}12.7 \mathrm{~g} \\
\mathbf{0 . 0 2 8} \mathbf{~ l b} \\
7 / 16 \text { OZ }\end{array}$ \\
\hline $\begin{array}{l}\text { More than } 263 \mathrm{~g} \text { to } 317 \mathrm{~g} \\
\text { More than } \mathbf{0 . 5 8} \mathbf{~ l b} \text { to } \mathbf{0 . 7 0} \mathbf{~ l b} \\
\text { More than } 9.28 \mathrm{oz} \text { to } 11.20 \mathrm{oz}\end{array}$ & $\begin{array}{c}14.5 \mathrm{~g} \\
\mathbf{0 . 0 3 2} \mathbf{~ l b} \\
1 / 2 \mathrm{OZ}\end{array}$ \\
\hline $\begin{array}{c}\text { More than } 317 \mathrm{~g} \text { to } 381 \mathrm{~g} \\
\text { More than } \mathbf{0 . 7 0} \mathbf{~ l b} \text { to } \mathbf{0 . 8 4} \mathbf{~ l b} \\
\text { More than } 11.20 \mathrm{oz} \text { to } 13.44 \mathrm{oz}\end{array}$ & $\begin{array}{c}16.3 \text { g } \\
\mathbf{0 . 0 3 6 ~ l b} \\
9 / 16 \text { Oz }\end{array}$ \\
\hline $\begin{array}{l}\text { More than } 381 \mathrm{~g} \text { to } 426 \mathrm{~g} \\
\text { More than } \mathbf{0 . 8 4} \mathbf{~ l b} \text { to } \mathbf{0 . 9 4} \mathbf{~ l b} \\
\text { More than } 13.44 \mathrm{oz} \text { to } 15.04 \mathrm{oz}\end{array}$ & $\begin{array}{l}18.1 \mathrm{~g} \\
\mathbf{0 . 0 4 0 ~ l b} \\
5 / 8 \mathrm{Oz}\end{array}$ \\
\hline $\begin{array}{l}\text { More than } 426 \mathrm{~g} \text { to } 489 \mathrm{~g} \\
\text { More than } \mathbf{0 . 9 4} \mathbf{~ l b} \text { to } \mathbf{1 . 0 8} \mathbf{~ l b} \\
\text { More than } 15.04 \mathrm{oz} \text { to } 17.28 \mathrm{oz}\end{array}$ & $\begin{array}{c}19.9 \text { g } \\
\mathbf{0 . 0 4 4} \mathbf{~ l b} \\
11 / 16 \mathrm{OZ}\end{array}$ \\
\hline $\begin{array}{l}\text { More than } 489 \mathrm{~g} \text { to } 571 \mathrm{~g} \\
\text { More than } 1.08 \mathrm{lb} \text { to } 1.26 \mathrm{lb}\end{array}$ & $\begin{array}{c}21.7 \mathrm{~g} \\
0.048 \mathrm{lb}\end{array}$ \\
\hline $\begin{array}{l}\text { More than } 571 \mathrm{~g} \text { to } 635 \mathrm{~g} \\
\text { More than } 1.26 \mathrm{lb} \text { to } 1.40 \mathrm{lb}\end{array}$ & $\begin{array}{l}23.5 \mathrm{~g} \\
0.052 \mathrm{lb}\end{array}$ \\
\hline $\begin{array}{l}\text { More than } 635 \mathrm{~g} \text { to } 698 \mathrm{~g} \\
\text { More than } 1.40 \mathrm{lb} \text { to } 1.54 \mathrm{lb}\end{array}$ & $\begin{array}{c}25.4 \mathrm{~g} \\
0.056 \mathrm{lb}\end{array}$ \\
\hline
\end{tabular}




\begin{tabular}{|c|c|}
\hline \multicolumn{2}{|c|}{$\begin{array}{l}\text { Table 2-5. Maximum Allowable Variations (MAVs) for Packages Labeled by Weight } \\
\text { Do Not Use this Table for Meat and Poultry Products Subject to USDA Regulations - Use Table 2-9. } \\
\text { For Polyethylene Sheeting and Film, see Table 2-10. Exceptions to the MAVs. }\end{array}$} \\
\hline Labeled Quantity & "Maximum Allowable Variations \\
\hline $\begin{array}{c}\text { More than } 698 \mathrm{~g} \text { to } 771 \mathrm{~g} \\
\text { More than } 1.54 \mathrm{lb} \text { to } 1.70 \mathrm{lb}\end{array}$ & $\begin{array}{c}27.2 \mathrm{~g} \\
0.060 \mathrm{lb} \\
\end{array}$ \\
\hline $\begin{array}{l}\text { More than } 771 \mathrm{~g} \text { to } 852 \mathrm{~g} \\
\text { More than } 1.70 \mathrm{lb} \text { to } 1.88 \mathrm{lb}\end{array}$ & $\begin{array}{c}29.0 \mathrm{~g} \\
0.064 \mathrm{lb}\end{array}$ \\
\hline $\begin{array}{l}\text { More than } 852 \mathrm{~g} \text { to } 970 \mathrm{~g} \\
\text { More than } 1.88 \mathrm{lb} \text { to } 2.14 \mathrm{lb}\end{array}$ & $\begin{array}{c}31.7 \mathrm{~g} \\
0.070 \mathrm{lb}\end{array}$ \\
\hline $\begin{array}{l}\text { More than } 970 \mathrm{~g} \text { to } 1.12 \mathrm{~kg} \\
\text { More than } 2.14 \mathrm{lb} \text { to } 2.48 \mathrm{lb}\end{array}$ & $\begin{array}{c}35.3 \mathrm{~g} \\
0.078 \mathrm{lb}\end{array}$ \\
\hline $\begin{array}{l}\text { More than } 1.12 \mathrm{~kg} \text { to } 1.25 \mathrm{~kg} \\
\text { More than } 2.48 \mathrm{lb} \text { to } 2.76 \mathrm{lb}\end{array}$ & $\begin{array}{c}39.0 \mathrm{~g} \\
0.086 \mathrm{lb}\end{array}$ \\
\hline $\begin{array}{l}\text { More than } 1.25 \mathrm{~kg} \text { to } 1.45 \mathrm{~kg} \\
\text { More than } 2.76 \mathrm{lb} \text { to } 3.20 \mathrm{lb}\end{array}$ & $\begin{array}{c}42.6 \mathrm{~g} \\
0.094 \mathrm{lb}\end{array}$ \\
\hline $\begin{array}{l}\text { More than } 1.45 \mathrm{~kg} \text { to } 1.76 \mathrm{~kg} \\
\text { More than } 3.20 \mathrm{lb} \text { to } 3.90 \mathrm{lb}\end{array}$ & $\begin{array}{c}49 \mathrm{~g} \\
0.11 \mathrm{lb}\end{array}$ \\
\hline $\begin{array}{l}\text { More than } 1.76 \mathrm{~kg} \text { to } 2.13 \mathrm{~kg} \\
\text { More than } 3.90 \mathrm{lb} \text { to } 4.70 \mathrm{lb}\end{array}$ & $\begin{array}{c}54 \mathrm{~g} \\
0.12 \mathrm{lb}\end{array}$ \\
\hline $\begin{array}{l}\text { More than } 2.13 \mathrm{~kg} \text { to } 2.63 \mathrm{~kg} \\
\text { More than } 4.70 \mathrm{lb} \text { to } 5.80 \mathrm{lb}\end{array}$ & $\begin{array}{c}63 \mathrm{~g} \\
0.14 \mathrm{lb}\end{array}$ \\
\hline $\begin{array}{l}\text { More than } 2.63 \mathrm{~kg} \text { to } 3.08 \mathrm{~kg} \\
\text { More than } 5.80 \mathrm{lb} \text { to } 6.80 \mathrm{lb}\end{array}$ & $\begin{array}{c}68 \mathrm{~g} \\
0.15 \mathrm{lb}\end{array}$ \\
\hline $\begin{array}{l}\text { More than } 3.08 \mathrm{~kg} \text { to } 3.58 \mathrm{~kg} \\
\text { More than } 6.80 \mathrm{lb} \text { to } 7.90 \mathrm{lb}\end{array}$ & $\begin{array}{c}77 \mathrm{~g} \\
0.17 \mathrm{lb}\end{array}$ \\
\hline $\begin{array}{l}\text { More than } 3.58 \mathrm{~kg} \text { to } 4.26 \mathrm{~kg} \\
\text { More than } 7.90 \mathrm{lb} \text { to } 9.40 \mathrm{lb}\end{array}$ & $\begin{array}{c}86 \mathrm{~g} \\
0.19 \mathrm{lb}\end{array}$ \\
\hline $\begin{array}{l}\text { More than } 4.26 \mathrm{~kg} \text { to } 5.30 \mathrm{~kg} \\
\text { More than } 9.40 \mathrm{lb} \text { to } 11.70 \mathrm{lb}\end{array}$ & $\begin{array}{c}99 \mathrm{~g} \\
0.22 \mathrm{lb}\end{array}$ \\
\hline $\begin{array}{l}\text { More than } 5.30 \mathrm{~kg} \text { to } 6.48 \mathrm{~kg} \\
\text { More than } 11.70 \mathrm{lb} \text { to } 14.30 \mathrm{lb}\end{array}$ & $\begin{array}{c}113 \mathrm{~g} \\
0.25 \mathrm{lb}\end{array}$ \\
\hline $\begin{array}{l}\text { More than } 6.48 \mathrm{~kg} \text { to } 8.02 \mathrm{~kg} \\
\text { More than } 14.30 \mathrm{lb} \text { to } 17.70 \mathrm{lb}\end{array}$ & $\begin{array}{c}127 \mathrm{~g} \\
0.28 \mathrm{lb}\end{array}$ \\
\hline $\begin{array}{l}\text { More than } 8.02 \mathrm{~kg} \text { to } 10.52 \mathrm{~kg} \\
\text { More than } 17.70 \mathrm{lb} \text { to } 23.20 \mathrm{lb}\end{array}$ & $\begin{aligned} 140 \mathrm{~g} \\
0.31 \mathrm{lb}\end{aligned}$ \\
\hline $\begin{array}{l}\text { More than } 10.52 \mathrm{~kg} \text { to } 14.33 \mathrm{~kg} \\
\text { More than } 23.20 \mathrm{lb} \text { to } 31.60 \mathrm{lb}\end{array}$ & $\begin{array}{c}167 \mathrm{~g} \\
0.37 \mathrm{lb} \\
\end{array}$ \\
\hline $\begin{array}{l}\text { More than } 14.33 \mathrm{~kg} \text { to } 19.23 \mathrm{~kg} \\
\text { More than } 31.60 \mathrm{lb} \text { to } 42.40 \mathrm{lb}\end{array}$ & $\begin{aligned} 199 \mathrm{~g} \\
0.44 \mathrm{lb}\end{aligned}$ \\
\hline
\end{tabular}




\begin{tabular}{|}
\hline \begin{tabular}{|c|c|}
\hline Table 2-5. Maximum Allowable Variations (MAVs) for Packages Labeled by Weight \\
$\begin{array}{c}\text { Do Not Use this Table for Meat and Poultry Products Subject to USDA Regulations - Use Table 2-9. } \\
\text { For Polyethylene Sheeting and Film, see Table 2-10. Exceptions to the MAVs. }\end{array}$ \\
\hline \hline Labeled Quantity & Maximum Allowable Variations \\
\hline \hline More than $19.23 \mathrm{~kg}$ to $24.67 \mathrm{~kg}$ & $226 \mathrm{~g}$ \\
More than $42.40 \mathrm{lb}$ to $54.40 \mathrm{lb}$ & $0.50 \mathrm{lb}$ \\
\hline More than $24.67 \mathrm{~kg}$ & $2 \%$ of labeled quantity \\
\hline More than $54.40 \mathrm{lb}$ & \\
\hline
\end{tabular}
\end{tabular}

(Amended 2004)

\section{Table 2-6. Maximum Allowable Variations for Packages Labeled by Liquid and Dry Volume}

Do Not Use this Table for Meat and Poultry Products Subject to USDA Regulations For Mulch, see Table 2-10. Exceptions to the Maximum Allowable Variations, Use Table 2-9 for USDA -Regulated Products.

\begin{tabular}{|c|c|}
\hline Labeled Quantity & Maximum Allowable Variations (MAVs) \\
\hline $\begin{array}{c}3 \mathrm{~mL} \text { or less } \\
\mathbf{0 . 5 0} \mathbf{f l ~ o z ~ o r ~ l e s s ~} \\
0.18 \mathrm{in}^{3} \text { or less }\end{array}$ & $\begin{array}{c}0.5 \mathrm{~mL} \\
\mathbf{0 . 0 2} \mathbf{f l ~ o z} \\
0.03 \mathrm{in}^{3}\end{array}$ \\
\hline $\begin{array}{l}\text { More than } 3 \mathrm{~mL} \text { to } 8 \mathrm{~mL} \\
\text { More than } 0.18 \mathrm{in}^{3} \text { to } 0.49 \mathrm{in}^{3}\end{array}$ & $\begin{array}{l}1.0 \mathrm{~mL} \\
0.06 \mathrm{in}^{3}\end{array}$ \\
\hline $\begin{array}{l}\text { More than } 8 \mathrm{~mL} \text { to } 14 \mathrm{~mL} \\
\text { More than } 0.49 \text { in }^{3} \text { to } 0.92 \mathrm{in}^{3}\end{array}$ & $\begin{array}{l}1.5 \mathrm{~mL} \\
0.09 \mathrm{in}^{3}\end{array}$ \\
\hline $\begin{array}{l}\text { More than } 14 \mathrm{~mL} \text { to } 22 \mathrm{~mL} \\
\text { More than } \mathbf{0 . 5 0} \mathbf{f l ~ o z ~ t o ~} \mathbf{0 . 7 5} \mathbf{~ f l ~ o z} \\
\text { More than } 0.92 \text { in }^{3} \text { to } 1.35 \mathrm{in}^{3}\end{array}$ & $\begin{array}{c}1.7 \mathrm{~mL} \\
\mathbf{0 . 0 6} \mathbf{~ f l ~ o z} \\
0.10 \mathrm{in}^{3}\end{array}$ \\
\hline $\begin{array}{l}\text { More than } 22 \mathrm{~mL} \text { to } 66 \mathrm{~mL} \\
\text { More than } \mathbf{0 . 7 5} \mathbf{f l ~ o z ~ t o ~} 2.25 \mathbf{f l ~ o z} \\
\text { More than } 1.35 \text { in }^{3} \text { to } 4.06 \mathrm{in}^{3}\end{array}$ & $\begin{array}{c}3.8 \mathrm{~mL} \\
\mathbf{0 . 1 3} \mathbf{~ f l ~ o z} \\
0.23 \mathrm{in}^{3}\end{array}$ \\
\hline $\begin{array}{l}\text { More than } 66 \mathrm{~mL} \text { to } 125 \mathrm{~mL} \\
\text { More than } 2.25 \mathrm{fl} \mathrm{oz} \text { to } 4.25 \mathrm{fl} \mathrm{oz}^{3} \\
\text { More than } 4.06 \mathrm{in}^{3} \text { to } 7.66 \mathrm{in}^{3}\end{array}$ & $\begin{array}{c}5.6 \mathrm{~mL} \\
\mathbf{0 . 1 9} \mathbf{f l ~ o z} \\
0.34 \mathrm{in}^{3}\end{array}$ \\
\hline $\begin{array}{l}\text { More than } 125 \mathrm{~mL} \text { to } 170 \mathrm{~mL} \\
\text { More than } 4.25 \mathrm{fl} \mathrm{oz} \text { to } 5.75 \mathrm{fl} \mathrm{oz} \\
\text { More than } 7.66 \mathrm{in}^{3} \text { to } 10.37 \mathrm{in}^{3}\end{array}$ & $\begin{array}{c}7.3 \mathrm{~mL} \\
\mathbf{0 . 2 5} \mathbf{f l ~ o z}^{\mathbf{0}} \\
0.45 \mathrm{in}^{3}\end{array}$ \\
\hline $\begin{array}{l}\text { More than } 170 \mathrm{~mL} \text { to } 221 \mathrm{~mL} \\
\text { More than } 5.75 \mathrm{fl} \mathrm{oz} \text { to } 7.50 \mathrm{fl} \mathrm{oz} \\
\text { More than } 10.37 \mathrm{in}^{3} \text { to } 13.53 \mathrm{in}^{3}\end{array}$ & $\begin{array}{c}9.1 \mathrm{~mL} \\
\mathbf{0 . 3 1} \mathbf{f l ~ o z} \\
0.55 \mathrm{in}^{3}\end{array}$ \\
\hline $\begin{array}{l}\text { More than } 221 \mathrm{~mL} \text { to } 347 \mathrm{~mL} \\
\text { More than } 7.50 \mathbf{f l ~ o z} \text { to } \mathbf{1 1 . 7 5} \mathbf{f l ~ o z} \\
\text { More than } 13.53 \mathrm{in}^{3} \text { to } 21.20 \mathrm{in}^{3}\end{array}$ & $\begin{array}{c}11.2 \mathrm{~mL} \\
\mathbf{0 . 3 8} \mathbf{f l ~ o z} \\
0.68 \mathrm{in}^{3}\end{array}$ \\
\hline
\end{tabular}


Table 2-6. Maximum Allowable Variations for Packages Labeled by Liquid and Dry Volume

Do Not Use this Table for Meat and Poultry Products Subject to USDA Regulations

For Mulch, see Table 2-10. Exceptions to the Maximum Allowable Variations, Use Table 2-9 for USDA -Regulated Products.

\begin{tabular}{|c|c|}
\hline Labeled Quantity & Maximum Allowable Variations (MAVs) \\
\hline $\begin{array}{l}\text { More than } 347 \mathrm{~mL} \text { to } 502 \mathrm{~mL} \\
\text { More than } \mathbf{1 1 . 7 5} \mathbf{~ f l ~ o z ~ t o ~} \mathbf{1 7 . 0 0} \mathbf{f l ~} \mathbf{~ o z} \\
\text { More than } 21.20 \mathrm{in}^{3} \text { to } 30.67 \mathrm{in}^{3}\end{array}$ & $\begin{array}{l}14.7 \mathrm{~mL} \\
\mathbf{0 . 5} \mathbf{f l ~ o z} \\
0.90 \mathrm{in}^{3}\end{array}$ \\
\hline $\begin{array}{l}\text { More than } 502 \mathrm{~mL} \text { to } 621 \mathrm{~mL} \\
\text { More than } 17 \mathbf{f l ~ o z} \text { to } 21 \mathbf{f l ~ o z} \\
\text { More than } 30.67 \text { in }^{3} \text { to } 37.89 \mathrm{in}^{3}\end{array}$ & $\begin{array}{c}18.6 \mathrm{~mL} \\
\mathbf{0 . 6 3} \mathbf{~ f l ~ o z} \\
1.13 \mathrm{in}^{3}\end{array}$ \\
\hline $\begin{array}{l}\text { More than } 621 \mathrm{~mL} \text { to } 798 \mathrm{~mL} \\
\text { More than } 21 \mathrm{fl} \mathrm{oz} \text { to } 27 \mathrm{fl} \mathrm{oz} \\
\text { More than } 37.89 \text { in }^{3} \text { to } 48.72 \mathrm{in}^{3}\end{array}$ & $\begin{array}{c}22.1 \mathrm{~mL} \\
\mathbf{0 . 7 5} \mathbf{f l ~ o z} \\
1.35 \mathrm{in}^{3}\end{array}$ \\
\hline $\begin{array}{l}\text { More than } 798 \mathrm{~mL} \text { to } 916 \mathrm{~mL} \\
\text { More than } 27 \mathrm{fl} \mathrm{oz} \text { to } 31 \mathrm{fl} \mathrm{oz} \\
\text { More than } 48.72 \text { in }^{3} \text { to } 55.94 \mathrm{in}^{3}\end{array}$ & $\begin{array}{c}26.0 \mathrm{~mL} \\
\mathbf{0 . 8 8} \mathbf{~ f l ~ o z} \\
1.58 \mathrm{in}^{3}\end{array}$ \\
\hline $\begin{array}{l}\text { More than } 916 \mathrm{~mL} \text { to } 1.15 \mathrm{~L} \\
\text { More than } 31 \mathrm{fl} \mathrm{oz} \text { to } 39 \mathrm{fl} \mathrm{oz} \\
\text { More than } 55.94 \text { in }^{3} \text { to } 70.38 \mathrm{in}^{3}\end{array}$ & $\begin{array}{c}29 \mathrm{~mL} \\
\mathbf{1 ~ f l ~ o z} \\
1.80 \mathrm{in}^{3}\end{array}$ \\
\hline $\begin{array}{l}\text { More than } 1.15 \mathrm{~L} \text { to } 1.62 \mathrm{~L} \\
\text { More than } 39 \mathrm{fl} \mathrm{oz} \text { to } 55 \mathrm{fl} \mathrm{oz} \\
\text { More than } 70.38 \text { in }^{3} \text { to } 99.25 \mathrm{in}^{3}\end{array}$ & $\begin{array}{l}36 \mathrm{~mL} \\
\mathbf{1 . 2 5} \mathbf{f l ~ o z} \\
2.25 \mathrm{in}^{3}\end{array}$ \\
\hline $\begin{array}{l}\text { More than } 1.62 \mathrm{~L} \text { to } 2.04 \mathrm{~L} \\
\text { More than } 55 \text { fl oz to } 69 \mathrm{fl} \mathrm{oz} \\
\text { More than } 99.25 \text { in }^{3} \text { to } 124.5 \mathrm{in}^{3}\end{array}$ & $\begin{array}{l}44 \mathrm{~mL} \\
\mathbf{1 . 5} \mathbf{f l ~ o z} \\
2.70 \mathrm{in}^{3}\end{array}$ \\
\hline $\begin{array}{l}\text { More than } 2.04 \mathrm{~L} \text { to } 2.51 \mathrm{~L} \\
\text { More than } 69 \mathrm{fl} \mathrm{oz} \text { to } 85 \mathrm{fl} \mathrm{oz} \\
\text { More than } 124.5 \text { in }^{3} \text { to } 153.3 \mathrm{in}^{3}\end{array}$ & $\begin{array}{l}51 \mathrm{~mL} \\
\mathbf{1 . 7 5} \mathbf{~ f l ~ o z} \\
3.1 \mathrm{in}^{3}\end{array}$ \\
\hline $\begin{array}{l}\text { More than } 2.51 \mathrm{~L} \text { to } 3.04 \mathrm{~L} \\
\text { More than } 85 \text { fl oz to } \mathbf{1 0 3} \mathbf{f l ~ o z} \\
\text { More than } 153.3 \text { in }^{3} \text { to } 185.8 \mathrm{in}^{3}\end{array}$ & $\begin{array}{l}59 \mathrm{~mL} \\
\mathbf{2} \mathbf{f l ~ o z} \\
3.6 \mathrm{in}^{3}\end{array}$ \\
\hline $\begin{array}{l}\text { More than } 3.04 \mathrm{~L} \text { to } 4.73 \mathrm{~L} \\
\text { More than } \mathbf{1 0 3} \mathbf{~ f l ~ o z ~ t o ~} \mathbf{1 6 0} \mathbf{~ f l ~ o z} \\
\text { More than } 185.8 \text { in }^{3} \text { to } 288.7 \text { in }^{3}\end{array}$ & $\begin{array}{l}73 \mathrm{~mL} \\
2.5 \mathbf{f l ~ o z} \\
4.5 \mathrm{in}^{3}\end{array}$ \\
\hline $\begin{array}{l}\text { More than } 4.73 \mathrm{~L} \text { to } 5.48 \mathrm{~L} \\
\text { More than } \mathbf{1 6 0} \mathbf{~ f l ~ o z ~ t o ~} \mathbf{1 8 5 . 6} \mathbf{~ f l ~ o z} \\
\text { More than } 288.7 \text { in }^{3} \text { to } 334.9 \mathrm{in}^{3}\end{array}$ & $\begin{array}{l}88 \mathrm{~mL} \\
\mathbf{3 ~ f l ~ o z} \\
5.4 \mathrm{in}^{3}\end{array}$ \\
\hline $\begin{array}{l}\text { More than } 5.48 \mathrm{~L} \text { to } 7.09 \mathrm{~L} \\
\text { More than } \mathbf{1 8 5 . 6} \text { fl oz to } 240 \mathrm{fl} \mathrm{oz} \\
\text { More than } 334.9 \text { in }^{3} \text { to } 443.1 \mathrm{in}^{3}\end{array}$ & $\begin{array}{l}103 \mathrm{~mL} \\
3.5 \mathbf{f l ~ o z}^{\mathbf{~ o z}} \\
6.3 \mathrm{in}^{3}\end{array}$ \\
\hline $\begin{array}{l}\text { More than } 7.09 \mathrm{~L} \text { to } 8.04 \mathrm{~L} \\
\text { More than } 240 \mathbf{f l ~ o z ~ t o ~} 272 \mathbf{~ f l ~ o z} \\
\text { More than } 443.1 \text { in }^{3} \text { to } 490.8 \text { in }^{3}\end{array}$ & $\begin{array}{l}118 \mathrm{~mL} \\
\mathbf{4} \mathbf{~ f l ~ o z} \\
7.2 \mathrm{in}^{3}\end{array}$ \\
\hline
\end{tabular}


Table 2-6. Maximum Allowable Variations for Packages Labeled by Liquid and Dry Volume

Do Not Use this Table for Meat and Poultry Products Subject to USDA Regulations For Mulch, see Table 2-10. Exceptions to the Maximum Allowable Variations, Use Table 2-9 for USDA -Regulated Products.

\begin{tabular}{|c|c|}
\hline Labeled Quantity & Maximum Allowable Variations (MAVs) \\
\hline $\begin{array}{l}\text { More than } 8.04 \mathrm{~L} \text { to } 10.17 \mathrm{~L} \\
\text { More than } 272 \mathbf{f l ~ o z ~ t o ~} 344 \mathbf{f l ~ o z} \\
\text { More than } 490.8 \text { in }^{3} \text { to } 620.8 \mathrm{in}^{3}\end{array}$ & $\begin{array}{l}133 \mathrm{~mL} \\
\mathbf{4 . 5} \mathbf{f l ~ o z} \\
8.1 \mathrm{in}^{3}\end{array}$ \\
\hline $\begin{array}{l}\text { More than } 10.17 \mathrm{~L} \text { to } 11.59 \mathrm{~L} \\
\text { More than } 344 \mathbf{f l ~ o z ~ t o ~} 392 \mathbf{f l ~ o z} \\
\text { More than } 620.8 \text { in }^{3} \text { to } 707.4 \mathrm{in}^{3}\end{array}$ & $\begin{array}{l}147 \mathrm{~mL} \\
5 \mathbf{f l ~ o z} \\
9.0 \mathrm{in}^{3}\end{array}$ \\
\hline $\begin{array}{l}\text { More than } 11.59 \mathrm{~L} \text { to } 16.56 \mathrm{~L} \\
\text { More than } 392 \mathbf{f l ~ o z ~ t o ~} 560 \mathbf{f l ~ o z} \\
\text { More than } 707.4 \text { in }^{3} \text { to } 1010 \mathrm{in}^{3}\end{array}$ & $\begin{array}{l}177 \mathrm{~mL} \\
\mathbf{6 ~ f l ~ o z} \\
10.8 \mathrm{in}^{3}\end{array}$ \\
\hline $\begin{array}{l}\text { More than } 16.56 \mathrm{~L} \text { to } 18.92 \mathrm{~L} \\
\text { More than } \mathbf{5 6 0} \mathbf{~ f l ~ o z ~ t o ~} \mathbf{6 4 0} \mathbf{~ f l ~ o z ~ ( 5 ~ g a l ) ~} \\
\text { More than } 1010 \text { in }^{3} \text { into } 1155 \mathrm{in}^{3}\end{array}$ & $\begin{array}{c}207 \mathrm{~mL} \\
7 \mathbf{f l ~ o z} \\
12.6 \mathrm{in}^{3}\end{array}$ \\
\hline $\begin{array}{l}\text { More than } 18.92 \mathrm{~L} \text { to } 23.65 \mathrm{~L} \\
\text { More than } 640 \mathrm{fl} \mathrm{oz} \mathrm{to} 800 \mathbf{f l ~ o z} \\
\text { More than } 1155 \text { in }^{3} \text { to } 1443 \mathrm{in}^{3}\end{array}$ & $\begin{array}{l}236 \mathrm{~mL} \\
\mathbf{8} \mathbf{~ f l ~ o z} \\
14.4 \mathrm{in}^{3}\end{array}$ \\
\hline $\begin{array}{l}\text { More than } 23.65 \mathrm{~L} \text { to } 26.73 \mathrm{~L} \\
\text { More than } \mathbf{8 0 0} \mathbf{~ f l ~ o z ~ t o ~} \mathbf{9 0 4} \mathbf{f l ~ o z} \\
\text { More than } 1443 \text { in }^{3} \text { to } 1631 \mathrm{in}^{3}\end{array}$ & $\begin{array}{l}266 \mathrm{~mL} \\
\mathbf{9} \mathbf{~ f l ~ o z} \\
16.2 \mathrm{in}^{3}\end{array}$ \\
\hline $\begin{array}{l}\text { More than } 26.73 \mathrm{~L} \\
\text { More than } 904 \mathbf{~ f l ~ o z} \\
\text { More than } 1631 \text { in }^{3}\end{array}$ & $1 \%$ of labeled quantity \\
\hline
\end{tabular}

(Amended 2004) 
Table 2-7. Maximum Allowable Variations (MAVs) for Packages Labeled by Count

\begin{tabular}{|c|c|}
\hline Labeled Quantity & Maximum Allowable Variations (MAVs) \\
\hline 17 or less & 0 \\
\hline 18 to 50 & 1 \\
\hline 51 to 83 & 2 \\
\hline 84 to 116 & 3 \\
\hline 117 to 150 & 4 \\
\hline 151 to 200 & 5 \\
\hline 201 to 240 & 6 \\
\hline 241 to 290 & 7 \\
\hline 291 to 345 & 8 \\
\hline 346 to 400 & 9 \\
\hline 401 to 465 & 10 \\
\hline 466 to 540 & 11 \\
\hline 541 to 625 & 12 \\
\hline 626 to 725 & 13 \\
\hline 726 to 815 & 14 \\
\hline 816 to 900 & 15 \\
\hline 901 to 990 & 16 \\
\hline 991 to 1075 & 17 \\
\hline 1076 to 1165 & 18 \\
\hline 1166 to 1250 & 19 \\
\hline 1251 to 1333 & 20 \\
\hline 1334 or more & $\begin{array}{l}1.5 \% \text { of labeled count rounded off to the } \\
\text { nearest whole number }\end{array}$ \\
\hline
\end{tabular}


Table 2-8. Maximum Allowable Variations for Packages Labeled by Length, (Width), or Area (For Textiles, Polyethylene Sheeting and Film - Use Table 2-10)

\begin{tabular}{|c|c|}
\hline Labeled Quantity & $\begin{array}{c}\text { Maximum Allowable Variations (MAVs) } \\
\text { of Labeled Quantity }\end{array}$ \\
\hline $\begin{array}{l}1 \mathrm{~m} \text { or less } \\
1 \mathrm{yd} \text { or less }\end{array}$ & $3 \%$ \\
\hline $\begin{array}{l}\text { More than } 1 \mathrm{~m} \text { to } 43 \mathrm{~m} \\
\text { More than } 1 \mathrm{yd} \text { to } 48 \mathrm{yd}\end{array}$ & $1.5 \%$ \\
\hline $\begin{array}{l}\text { More than } 43 \mathrm{~m} \text { to } 87 \mathrm{~m} \\
\text { More than } 48 \mathrm{yd} \text { to } 96 \mathrm{yd}\end{array}$ & $2 \%$ \\
\hline $\begin{array}{l}\text { More than } 87 \mathrm{~m} \text { to } 140 \mathrm{~m} \\
\text { More than } 96 \mathrm{yd} \text { to } 154 \mathrm{yd}\end{array}$ & $2.5 \%$ \\
\hline $\begin{array}{l}\text { More than } 140 \mathrm{~m} \text { to } 301 \mathrm{~m} \\
\text { More than } 154 \mathrm{yd} \text { to } 330 \mathrm{yd}\end{array}$ & $3 \%$ \\
\hline $\begin{array}{l}\text { More than } 301 \mathrm{~m} \text { to } 1005 \mathrm{~m} \\
\text { More than } 330 \mathrm{yd} \text { to } 1100 \mathrm{yd}\end{array}$ & $4 \%$ \\
\hline More than $1005 \mathrm{~m}$ or $1100 \mathrm{yd}$ & $5 \%$ \\
\hline \multicolumn{2}{|c|}{ Maximum Allowable Variations for Packages Labeled by Area } \\
\hline \multicolumn{2}{|c|}{ The MAV for packages labeled by area is $3 \%$ of labeled quantity. } \\
\hline \multicolumn{2}{|c|}{ For Textiles, Polyethylene Sheeting and Film, see Table 2-10. Exceptions to the MAVs. } \\
\hline
\end{tabular}

(Amended 2004) 
Table 2-9. U.S. Department of Agriculture, Meat and Poultry Groups and Lower Limits for Individual Packages (Maximum Allowable Variations)

\begin{tabular}{|c|c|c|}
\hline \multicolumn{2}{|c|}{ Definition of Group and Labeled Quantity } & \multirow[b]{2}{*}{$\begin{array}{l}\text { Lower Limit for Individual Weights } \\
\text { (MAVs) }\end{array}$} \\
\hline $\begin{array}{l}\text { Homogenous Fluid } \\
\text { When Filled } \\
\text { (e.g., baby food or } \\
\text { containers of lard) }\end{array}$ & All Other Products & \\
\hline \multicolumn{2}{|c|}{ Less than $85 \mathrm{~g}$ or $3 \mathrm{oz}$} & $10 \%$ of labeled quantity \\
\hline $\begin{array}{l}85 \mathrm{~g} \text { or more to } 453 \mathrm{~g} \\
3 \mathrm{oz} \text { or more to } 16 \mathrm{oz}\end{array}$ & & $\begin{array}{c}7.1 \mathrm{~g} \\
0.016 \mathrm{lb}(0.25 \mathrm{oz})\end{array}$ \\
\hline \multirow[t]{4}{*}{$\begin{array}{l}\text { More than } 453 \mathrm{~g} \\
\text { More than } 16 \mathrm{oz}\end{array}$} & $\begin{array}{c}85 \mathrm{~g} \text { or more to } 198 \mathrm{~g} \\
3 \mathrm{oz} \text { to } 7 \mathrm{oz}\end{array}$ & $\begin{array}{c}14.2 \mathrm{~g} \\
0.031 \mathrm{lb}(0.5 \mathrm{oz})\end{array}$ \\
\hline & $\begin{array}{c}\text { More than } 198 \mathrm{~g} \text { to } 1.36 \mathrm{~kg} \\
7 \mathrm{oz} \text { to } 48 \mathrm{oz}\end{array}$ & $\begin{array}{c}28.3 \mathrm{~g} \\
0.062 \mathrm{lb}(1 \mathrm{oz})\end{array}$ \\
\hline & $\begin{array}{l}\text { More than } 1.36 \mathrm{~kg} \text { to } 4.53 \mathrm{~kg} \\
\text { More than } 48 \mathrm{oz} \text { to } 160 \mathrm{oz}\end{array}$ & $\begin{array}{c}42.5 \mathrm{~g} \\
0.094 \mathrm{lb}(1.5 \mathrm{oz})\end{array}$ \\
\hline & $\begin{array}{l}\text { More than } 4.53 \mathrm{~kg} \\
\text { More than } 160 \mathrm{oz}\end{array}$ & $1 \%$ of labeled quantity \\
\hline
\end{tabular}


Table 2-10. Exceptions to the Maximum Allowable Variations for Textiles, Polyethylene Sheeting and Film, Mulch and Soil Labeled by Volume, Packaged Firewood, and Packages Labeled by Count with 50 Items or Fewer, and Specific Agricultural Seeds Labeled by Count.

\begin{tabular}{|c|c|}
\hline & Maximum Allowable Variations (MAVs) \\
\hline $\begin{array}{c}\text { Polyethylene } \\
\text { Sheeting and Film }\end{array}$ & $\begin{array}{l}\text { Thickness } \\
\text { When the labeled thickness is } 25 \mu \mathrm{m} \text { ( } 1 \text { mil or } 0.001 \text { in) or less, any individual } \\
\text { thickness measurement of polyethylene film may be up to } 35 \% \text { below the labeled } \\
\text { thickness. } \\
\text { When the labeled thickness is greater than } 25 \mu \mathrm{m} \text { ( } 1 \text { mil or } 0.001 \text { in), individual } \\
\text { thickness measurements of polyethylene sheeting may be up to } 20 \% \text { less than the } \\
\text { labeled thickness. } \\
\text { The average thickness of a single package of polyethylene sheeting may be up to } \\
4 \text { \% less than the labeled thickness. } \\
\text { Weight } \\
\text { The MAV for individual packages of polyethylene sheeting and film shall be } 4 \% \\
\text { of the labeled quantity. }\end{array}$ \\
\hline Textiles & $\begin{array}{l}\text { The MAVs are: } \\
\text { For packages labeled with dimensions of } 60 \mathrm{~cm} \text { ( } 24 \text { in) or more: } \\
\quad 3 \% \text { percent of the labeled quantity for negative errors; and } \\
6 \% \text { of the labeled quantity for plus errors. } \\
\text { For packages labeled with dimensions less than } 60 \mathrm{~cm} \text { ( } 24 \mathrm{in}) \text { : } \\
6 \% \text { of the labeled quantity for negative errors; and } \\
12 \% \text { for plus errors. }\end{array}$ \\
\hline $\begin{array}{l}\text { Mulch And Soil } \\
\text { Labeled By Volume }\end{array}$ & $\begin{array}{l}\text { The MAVs are: } \\
\text { For individual packages: } 5 \% \text { of the labeled volume. } \\
\text { For example: One package may exceed the MAV for every } 12 \text { packages in the } \\
\text { sample (e.g., when the sample size is } 12 \text { or fewer, } 1 \text { package may exceed the } \\
\text { MAV and when the sample size is } 48 \text { packages, } 4 \text { packages may exceed the } \\
\text { MAV). }\end{array}$ \\
\hline
\end{tabular}


Table 2-10. Exceptions to the Maximum Allowable Variations for Textiles, Polyethylene Sheeting and Film, Mulch and Soil Labeled by Volume, Packaged Firewood, and Packages Labeled by Count with 50 Items or Fewer, and Specific Agricultural Seeds Labeled by Count.

\begin{tabular}{|c|c|}
\hline & Maximum Allowable Variations (MAVs) \\
\hline $\begin{array}{l}\text { Packaged Firewood } \\
\text { and Packages } \\
\text { Labeled by Count } \\
\text { with } 50 \text { Items or } \\
\text { Fewer }\end{array}$ & MAVs are not applied to these packages. \\
\hline $\begin{array}{l}\text { Specific Agricultural } \\
\text { Seeds Labeled } \\
\text { By Count }\end{array}$ & $\begin{array}{l}\text { The MAVS are: } \\
\begin{array}{ll}\text { For corn seed: } & 2 \% \text { of the labeled count } \\
\text { For soybean seed: } & 4 \% \text { of the labeled count } \\
\text { For field bean seed: } & 5 \% \text { of the labeled count } \\
\text { For wheat seed: } & 3 \% \text { of the labeled count }\end{array}\end{array}$ \\
\hline
\end{tabular}

(Amended 2010)

\begin{tabular}{|c|c|c|c||}
\hline \multicolumn{4}{|c|}{ Table 2-11. Accuracy Requirements for Packages Labeled by Low Count (50 or Fewer) } \\
and Packages Given Tolerances (Glass and Stemware)
\end{tabular}

(Amended 2004) 
Handbook 133, Checking the Net Contents of Packaged Goods (2015)

THIS PAGE INTENTIONALLY LEFT BLANK 


\section{Appendix B. Random Number Tables}

Reproduced from Million Random Digits, used with permission of the Rand Corporation, Copyright, 1955, The Free Press (http://www.rand.org/publications/classics/randomdigits)

All of the sampling plans presented in this handbook are based on the assumption that the packages constituting the sample are chosen at random from the inspection lot. Randomness in this instance means that every package in the lot has an equal chance of being selected as part of the sample. It does not matter what other packages have already been chosen, what the package net contents are, or where the package is located in the lot.

To obtain a random sample, two steps are necessary. First it is necessary to identify each package in the lot of packages with a specific number whether on the shelf, in the warehouse, or coming off the packaging line. Then it is necessary to obtain a series of random numbers. These random numbers indicate exactly which packages in the lot shall be taken for the sample.

\section{The Random Number Table}

The random number tables in Appendix B are composed of the digits from 0 through 9, with approximately equal frequency of occurrence. This appendix consists of 8 pages. On each page digits are printed in blocks of columns and blocks of rows. The printing of the table in blocks is intended only to make it easier to locate specific columns and rows.

\section{Random Starting Place}

Starting Page. The Random Digit pages are pages 110 through 116. You can use the day of the week to determine the starting page or use the first page for the first lot you test in a location, the second page for the second lot, and so on, moving to the following page for each new lot.

Starting Column and Row. You may choose a starting page in the random number table and with eyes closed, drop a pencil anywhere on the page to indicate a starting place in the table.

For example, assume that testing takes place on the $3^{\text {rd }}$ day of the week. Start with Table 3 of Appendix B. Assume you dropped your pencil on the page and it has indicated a starting place at Column 22, Row 45. That number is 1.

If one-digit random numbers are needed, record them, going down the column to the bottom of the page and then to the top of the next column, and so on. Ignore duplicates and record zero (0) as ten (10). Following on from the last example, these numbers are 3, 2, 9, 8, etc. If two-digit random numbers are needed, rule off the pages, and further pages if necessary, in columns of two digits each. If there is a single column left on the page, ignore this column, and rule the next page in columns of two. Again, ignore duplicate numbers and record 00 as 100 . For example, using the same starting place as in the last example (Table 3, Column 22, Row 45), the recorded two-digit numbers would be 11, 34, 26, 95, etc. When three-digit numbers are needed, rule the page in columns of three. Record 000 as 1000 . Starting on Table 3, Column 22, Row 45, the recorded numbers would be 119, 346, 269, 959, etc. 


\section{TABLE 1 - RANDOM DIGITS}

\begin{tabular}{|c|c|c|c|c|c|c|c|c|c|}
\hline 11164 & 36318 & 75061 & 37674 & 26320 & 75100 & 10431 & 20418 & 19228 & 91792 \\
\hline 21215 & 91791 & 76831 & 58678 & 87054 & 31687 & 93205 & 43685 & 19732 & 08468 \\
\hline 10438 & 44482 & 66558 & 37649 & 08882 & 90870 & 12462 & 41810 & 01806 & 02977 \\
\hline 36792 & 26236 & 33266 & 66583 & 60881 & 97395 & 20461 & 36742 & 02852 & 50564 \\
\hline 73944 & 04773 & 12032 & 51414 & 82384 & 38370 & 00249 & 80709 & 72605 & 67497 \\
\hline 49563 & 12872 & 14063 & 93104 & 78483 & 72717 & 68714 & 18048 & 25005 & 04151 \\
\hline 64208 & 48237 & 41701 & 73117 & 33242 & 42314 & 83049 & 21933 & 92813 & 04763 \\
\hline 51486 & 72875 & 38605 & 29341 & 80749 & 80151 & 33835 & 52602 & 79147 & 08868 \\
\hline 99756 & 26360 & 64516 & 17971 & 48478 & 09610 & 04638 & 17141 & 09227 & 10606 \\
\hline 71325 & 55217 & 13015 & 72907 & 00431 & 45117 & 33827 & 92873 & 02953 & 85474 \\
\hline 65285 & 97198 & 12138 & 53010 & 94601 & 15838 & 16805 & 61004 & 43516 & 17020 \\
\hline 17264 & 57327 & 38224 & 29301 & 31381 & 38109 & 34976 & 65692 & 98566 & 29550 \\
\hline 95639 & 99754 & 31199 & 92558 & 68368 & 04985 & 51092 & 37780 & 40261 & 14479 \\
\hline 61555 & 76404 & 86210 & 11808 & 12841 & 45147 & 97438 & 60022 & 12645 & 62000 \\
\hline 78137 & 98768 & 04689 & 87130 & 79225 & 08153 & 84967 & 64539 & 79493 & 74917 \\
\hline 62490 & 99215 & 84987 & 28759 & 19177 & 14733 & 24550 & 28067 & 68894 & 38490 \\
\hline 24216 & 63444 & 21283 & 07044 & 92729 & 37284 & 13211 & 37485 & 10415 & 36457 \\
\hline 16975 & 95428 & 33226 & 55903 & 31605 & 43817 & 22250 & 03918 & 46999 & 98501 \\
\hline 59138 & 39542 & 71168 & 57609 & 91510 & 77904 & 74244 & 50940 & 31553 & 62562 \\
\hline 29478 & 59652 & 50414 & 31966 & 87912 & 87154 & 12944 & 49862 & 96566 & 48825 \\
\hline 96155 & 95009 & 27429 & 72918 & 08457 & 78134 & 48407 & 26061 & 58754 & 05326 \\
\hline 29621 & 66583 & 62966 & 12468 & 20245 & 14015 & 04014 & 35713 & 03980 & 03024 \\
\hline 12639 & 75291 & 71020 & 17265 & 41598 & 64074 & 64629 & 63293 & 53307 & 48766 \\
\hline 14544 & 37134 & 54714 & 02401 & 63228 & 26831 & 19386 & 15457 & 17999 & 18306 \\
\hline 83403 & 88827 & 09834 & 11333 & 68431 & 31706 & 26652 & 04711 & 34593 & 22561 \\
\hline 67642 & 05204 & 30697 & 44806 & 96989 & 68403 & 85621 & 45556 & 35434 & 09532 \\
\hline 64041 & 99011 & 14610 & 40273 & 09482 & 62864 & 01573 & 82274 & 81446 & 32477 \\
\hline 17048 & 94523 & 97444 & 59904 & 16936 & 39384 & 97551 & 09620 & 63932 & 03091 \\
\hline 93039 & 89416 & 52795 & 10631 & 09728 & 68202 & 20963 & 02477 & 55494 & 39563 \\
\hline 82244 & 34392 & 96607 & 17220 & 51984 & 10753 & 76272 & 50985 & 97593 & 34320 \\
\hline 96990 & 55244 & 70693 & 25255 & 40029 & 23289 & 48819 & 07159 & 60172 & 81697 \\
\hline 09119 & 74803 & 97303 & 88701 & 51380 & 73143 & 98251 & 78635 & 27556 & 20712 \\
\hline 57666 & 41204 & 47589 & 78364 & 38266 & 94393 & 70713 & 53388 & 79865 & 92069 \\
\hline 46492 & 61594 & 26729 & 58272 & 81754 & 14648 & 77210 & 12923 & 53712 & 87771 \\
\hline 08433 & 19172 & 08320 & 20839 & 13715 & 10597 & 17234 & 39355 & 74816 & 03363 \\
\hline 10011 & 75004 & 86054 & 41190 & 10061 & 19660 & 03500 & 68412 & 57812 & 57929 \\
\hline 92420 & 65431 & 16530 & 05547 & 10683 & 88102 & 30176 & 84750 & 10115 & 69220 \\
\hline 35542 & 55865 & 07304 & 47010 & 43233 & 57022 & 52161 & 82976 & 47981 & 46588 \\
\hline 86595 & 26247 & 18552 & 29491 & 33712 & 32285 & 64844 & 69395 & 41387 & 87195 \\
\hline 72115 & 34985 & 58036 & 99137 & 47482 & 06204 & 24138 & 24272 & 16196 & 04393 \\
\hline 07428 & 58863 & 96023 & 88936 & 51343 & 70958 & 96768 & 74317 & 27176 & 29600 \\
\hline 35379 & 27922 & 28906 & 55013 & 26937 & 48174 & 04197 & 36074 & 65315 & 12537 \\
\hline 10982 & 22807 & 10920 & 26299 & 23593 & 64629 & 57801 & 10437 & 43965 & 15344 \\
\hline 90127 & 33341 & 77806 & 12446 & 15444 & 49244 & 47277 & 11346 & 15884 & 28131 \\
\hline 63002 & 12990 & 23510 & 68774 & 48983 & 20481 & 59815 & 67248 & 17076 & 78910 \\
\hline 40779 & 86382 & 48454 & 65269 & 91239 & 45989 & 45389 & 54847 & 77919 & 41105 \\
\hline 43216 & 12608 & 18167 & 84631 & 94058 & 82458 & 15139 & 76856 & 86019 & 47928 \\
\hline 96167 & 64375 & 74108 & 93643 & 09204 & 98855 & 59051 & 56492 & 11933 & 64958 \\
\hline 70975 & 62693 & 35684 & 72607 & 23026 & 37004 & 32989 & 24843 & 01128 & 74658 \\
\hline 85812 & 61875 & 23570 & 75754 & 29090 & 40264 & 80399 & 47254 & 40135 & 69916 \\
\hline
\end{tabular}


TABLE 2 - RANDOM DIGITS

\begin{tabular}{|c|c|c|c|c|c|c|c|c|c|}
\hline 40603 & 16152 & 83235 & 37361 & 98783 & 24838 & 39793 & 80954 & 76865 & 32713 \\
\hline 40941 & 53585 & 69958 & 60916 & 71018 & 90561 & 84505 & 53980 & 64735 & 85140 \\
\hline 73505 & 83472 & 55953 & 17957 & 11446 & 22618 & 34771 & 25777 & 27064 & 13526 \\
\hline 39412 & 16013 & 11442 & 89320 & 11307 & 49396 & 39805 & 12249 & 57656 & 88686 \\
\hline 57994 & 76748 & 54627 & 48511 & 78646 & 33287 & 35524 & 54522 & 08795 & 56273 \\
\hline 61834 & 59199 & 15469 & 82285 & 84164 & 91333 & 90954 & 87186 & 31598 & 25942 \\
\hline 91402 & 77227 & 79516 & 21007 & 58602 & 81418 & 87838 & 18443 & 76162 & 51146 \\
\hline 58299 & 83880 & 20125 & 10794 & 37780 & 61705 & 18276 & 99041 & 78135 & 99661 \\
\hline 40684 & 99948 & 33880 & 76413 & 63839 & 71371 & 32392 & 51812 & 48248 & 96419 \\
\hline 75978 & 64298 & 08074 & 62055 & 73864 & 01926 & 78374 & 15741 & 74452 & 49954 \\
\hline 34556 & 39861 & 88267 & 76068 & 62445 & 64361 & 78685 & 24246 & 27027 & 48239 \\
\hline 65990 & 57048 & 25067 & 77571 & 77974 & 37634 & 81564 & 98608 & 37224 & 49848 \\
\hline 16381 & 15069 & 25416 & 87875 & 90374 & 86203 & 29677 & 82543 & 37554 & 89179 \\
\hline 52458 & 88880 & 78352 & 67913 & 09245 & 47773 & 51272 & 06976 & 99571 & 33365 \\
\hline 33007 & 85607 & 92008 & 44897 & 24964 & 50559 & 79549 & 85658 & 96865 & 24186 \\
\hline 38712 & 31512 & 08588 & 61490 & 72294 & 42862 & 87334 & 05866 & 66269 & 43158 \\
\hline 58722 & 03678 & 19186 & 69602 & 34625 & 75958 & 56869 & 17907 & 81867 & 11535 \\
\hline 26188 & 69497 & 51351 & 47799 & 20477 & 71786 & 52560 & 66827 & 79419 & 70886 \\
\hline 12893 & 54048 & 07255 & 86149 & 99090 & 70958 & 50775 & 31768 & 52903 & 27645 \\
\hline 33186 & 81346 & 85095 & 37282 & 85536 & 72661 & 32180 & 40229 & 19209 & 74939 \\
\hline 79893 & 29448 & 88392 & 54211 & 61708 & & 61227 & 81690 & 42265 & 20310 \\
\hline 48449 & 15102 & 44126 & 19438 & 23382 & 14985 & 37538 & 30120 & 82443 & 11152 \\
\hline 94205 & 04259 & 68983 & 50561 & 06902 & 10269 & 22216 & 70210 & 60736 & 58772 \\
\hline 38648 & 09278 & 81313 & 77400 & 41126 & 52614 & 93613 & 27263 & 99381 & 49500 \\
\hline 04292 & 46028 & 75666 & 26954 & 34979 & 68381 & 45154 & 09314 & 81009 & 05114 \\
\hline 17026 & 49737 & 5875 & 12139 & 59391 & 81830 & 30185 & & & 40899 \\
\hline 48070 & 76848 & 02531 & 97737 & 10151 & 18169 & 31709 & 74842 & 85522 & 74092 \\
\hline 30159 & 95450 & 83778 & 46115 & 991 & 97718 & 98440 & 15076 & 21199 & 20492 \\
\hline 12148 & 92231 & 31361 & 60650 & 54695 & 30035 & 22765 & 91386 & 70399 & 79270 \\
\hline 73838 & 77067 & 24863 & 97576 & 01139 & 54219 & 02959 & 45696 & 98103 & 78867 \\
\hline 73547 & 43759 & 95632 & 39555 & & & 694 & 02647 & 17050 & 49869 \\
\hline 07277 & 93217 & 79421 & 21769 & 83572 & 48019 & 17327 & 99638 & 87035 & 89300 \\
\hline 65128 & 48334 & 07493 & 28098 & 52087 & 55519 & 83718 & 60904 & 48721 & 17522 \\
\hline 38716 & 61380 & 0212 & 05099 & & & 01780 & & 19528 & 07727 \\
\hline 31921 & 76458 & 73720 & 08657 & 74922 & 61335 & 41690 & 41967 & 50691 & 30508 \\
\hline 723 & & & & & & & & & 94827 \\
\hline 24219 & 41090 & 08531 & 61578 & 08236 & 41140 & 76335 & 91189 & 66312 & 44000 \\
\hline 31309 & & & & & & & & & 29119 \\
\hline 20750 & 97024 & 72619 & 66628 & 66509 & 31206 & 55293 & 24249 & 02266 & 39010 \\
\hline 28537 & 84395 & 26654 & 37851 & 80590 & 53446 & 34385 & 86893 & 87713 & 26842 \\
\hline 97929 & & & & & & & & & 04206 \\
\hline 40568 & & & & & & & & & 74247 \\
\hline 41483 & 92935 & 7061 & 78252 & 40498 & 431 & 68646 & 33023 & 64333 & 64083 \\
\hline 93040 & 66476 & 24990 & 41099 & 65135 & & 976 & 87282 & 63693 & 55299 \\
\hline 76869 & 39300 & 84978 & 07504 & 36835 & 72748 & 47644 & 48542 & 25076 & 68626 \\
\hline 02982 & & & & & & & & & \\
\hline 94479 & 76500 & 39170 & 06629 & & 487 & 49822 & 440 & 44335 & 26474 \\
\hline 52291 & 75822 & 95966 & 9092 & 650 & 759 & 526 & 633 & 70664 & 60082 \\
\hline 03684 & 03600 & 52831 & 55381 & 970 & 199 & 41295 & 29118 & 18710 & 64851 \\
\hline 58939 & 28366 & 86765 & 67465 & 45421 & 74228 & 01095 & 50987 & 83833 & 37216 \\
\hline
\end{tabular}




\section{TABLE 3 - RANDOM DIGITS}

\begin{tabular}{|c|c|c|c|c|c|c|c|c|c|}
\hline 37100 & 62492 & 63642 & 47638 & 13925 & 80113 & 88067 & 42575 & 44078 & 62703 \\
\hline 53406 & 13855 & 38519 & 29500 & 62479 & 01036 & 87964 & 44498 & 07793 & 21599 \\
\hline 55172 & 81556 & 18856 & 59043 & 64315 & 38270 & 25677 & 01965 & 21310 & 28115 \\
\hline 40353 & 84807 & 47767 & 46890 & 16053 & 32415 & 60259 & 99788 & 55924 & 22077 \\
\hline 18899 & 09612 & 77541 & 57675 & 70153 & 41179 & 97535 & 82889 & 27214 & 03482 \\
\hline 8141 & 25340 & 92551 & 11326 & 60939 & 79355 & 41544 & 88926 & 09111 & 86431 \\
\hline 51559 & 91159 & 81310 & 63251 & 91799 & 41215 & 87412 & 35317 & 74271 & 11603 \\
\hline 2214 & 33386 & 73459 & 79359 & 65867 & 39269 & 57527 & 69551 & 17495 & 91456 \\
\hline 15089 & 50557 & 33166 & 87094 & 52425 & 21211 & 41876 & 42525 & 36625 & 63964 \\
\hline 6461 & 00604 & 11120 & 22254 & 16763 & 19206 & 67790 & 88362 & 01880 & 37911 \\
\hline 28177 & 44111 & 15705 & 73835 & 69399 & 33602 & 13660 & 84342 & 97667 & 80847 \\
\hline 66953 & 44737 & 81127 & 07493 & 07861 & 12666 & 85077 & 95972 & 96556 & 80108 \\
\hline 19712 & 27263 & 84575 & 49820 & 19837 & 69985 & 34931 & 67935 & 71903 & 82560 \\
\hline 68756 & 64757 & 19987 & 92222 & 11691 & 42502 & 00952 & 47981 & 97579 & 93408 \\
\hline 75022 & 65332 & 98606 & 29451 & 57349 & 39219 & 08585 & 31502 & 96936 & 96356 \\
\hline 11323 & 70069 & 90269 & 89266 & 46413 & 61615 & 66447 & 49751 & 15836 & 97343 \\
\hline 55208 & 63470 & 18158 & 25283 & 19335 & 53893 & 87746 & 72531 & 16826 & 52605 \\
\hline 11474 & 08786 & 05594 & 67045 & 13231 & 51186 & 71500 & 50498 & 59487 & 48677 \\
\hline 81422 & 86842 & 60997 & 79669 & 43804 & 78690 & 58358 & 87639 & 24427 & 66799 \\
\hline 21771 & 75963 & 23151 & 90274 & 08275 & 50677 & 99384 & 94022 & 84888 & 80139 \\
\hline 42278 & 12160 & 32576 & 14278 & 34231 & 20724 & 27908 & 02657 & 19023 & 07190 \\
\hline 17697 & 60114 & 63247 & 32096 & 32503 & 04923 & 17570 & 73243 & 76181 & 99343 \\
\hline 05686 & 30243 & 34124 & 02936 & 71749 & 03031 & 72259 & 26351 & 77511 & 00850 \\
\hline 52992 & 46650 & 89910 & 57395 & 39502 & 49738 & 87854 & 71066 & 84596 & 33115 \\
\hline 94518 & 93984 & 81478 & 67750 & 89354 & 01080 & 25988 & 84359 & 31088 & 13655 \\
\hline 00184 & 72186 & 78906 & 75480 & 71140 & 15199 & 69002 & 08374 & 22126 & 23555 \\
\hline 87462 & 63165 & 79816 & 61630 & 50140 & 95319 & 79205 & 79202 & 67414 & 60805 \\
\hline 88692 & 58716 & 12273 & 48176 & 86038 & 78474 & 76730 & 82931 & 51595 & 20747 \\
\hline 20094 & 42962 & 41382 & 16768 & 13261 & 13510 & 04822 & 96354 & 72001 & 68642 \\
\hline 60935 & 81504 & 50520 & 82153 & 27892 & 18029 & 79663 & 44146 & 72876 & 67843 \\
\hline 51392 & 85936 & 43898 & 50596 & 81121 & 98122 & 69196 & 54271 & 12059 & 62539 \\
\hline 54239 & 41918 & 79526 & 46274 & 24853 & 67165 & 12010 & 04923 & 20273 & 89405 \\
\hline 57892 & 73394 & 07160 & 90262 & 48731 & 46648 & 70977 & 58262 & 78359 & 50436 \\
\hline 02330 & 74736 & 53274 & 44468 & 53616 & 35794 & 54838 & 39114 & 68302 & 26855 \\
\hline 76115 & 29247 & 55342 & 51299 & 79908 & 36613 & 68361 & 18864 & 13419 & 34950 \\
\hline 63312 & 81886 & 29085 & 20101 & 38037 & 34742 & 78364 & 39356 & 40006 & 49800 \\
\hline 27632 & 21570 & 34274 & 56426 & 00330 & 07117 & 86673 & 46455 & 66866 & 76374 \\
\hline 06335 & 62111 & 44014 & 52567 & 79480 & 45886 & 92585 & 87828 & 17376 & 35254 \\
\hline 64142 & 87676 & 21358 & 88773 & 10604 & 62834 & 63971 & 03989 & 21421 & 76086 \\
\hline 28436 & 25468 & 75235 & 75370 & 63543 & 76266 & 27745 & 31714 & 04219 & 00699 \\
\hline 09522 & 83855 & 85973 & 15888 & 29554 & 17995 & 37443 & 11461 & 42909 & 32634 \\
\hline 93714 & 15414 & 93712 & 02742 & 34395 & 21929 & 38928 & 31205 & 01838 & 60000 \\
\hline 15681 & 53599 & 58185 & 73840 & 88758 & 10618 & 98725 & 23146 & 13521 & 47905 \\
\hline 77712 & 23914 & 08907 & 43768 & 10304 & 61405 & 53986 & 61116 & 76164 & 54958 \\
\hline 78453 & 54844 & 61509 & 01245 & 91199 & 07482 & 02534 & 08189 & 62978 & 55516 \\
\hline 24860 & 68284 & 19367 & 29073 & 93464 & 06714 & 45268 & 60678 & 58506 & 23700 \\
\hline 37284 & 06844 & 78887 & 57276 & 42695 & 03682 & 83240 & 09744 & 63025 & 60997 \\
\hline 35488 & 52473 & 37634 & 32569 & 39590 & 27379 & 23520 & 29714 & 03743 & 08444 \\
\hline 51595 & 59909 & 35223 & 44991 & 29830 & 56614 & 59661 & 83397 & 38421 & 17503 \\
\hline 90660 & 35171 & 30021 & 91120 & 78793 & 16827 & 89320 & 08260 & 09181 & 53616 \\
\hline
\end{tabular}


TABLE 4 - RANDOM DIGITS

\begin{tabular}{|c|c|c|c|c|c|c|c|c|c|}
\hline 54723 & 56527 & 53076 & 38235 & 42780 & 22716 & 36400 & 48028 & 78196 & 92985 \\
\hline 84828 & 81248 & 25548 & 34075 & 43459 & 44628 & 21866 & 90350 & 82264 & 20478 \\
\hline 65799 & 01914 & 81363 & 05173 & 23674 & 41774 & 25154 & 73003 & 87031 & 94368 \\
\hline 87917 & 38549 & 48213 & 71708 & 92035 & 92527 & 55484 & 32274 & 87918 & 22455 \\
\hline 26907 & 88173 & 71189 & 28377 & 13785 & 87469 & 35647 & 19695 & 33401 & 51998 \\
\hline 68052 & 65422 & 88460 & 06352 & 42379 & 55499 & 60469 & 76931 & 83430 & 24560 \\
\hline 42587 & 68149 & 88147 & 99700 & 56124 & 53239 & 38726 & 63652 & 36644 & 50876 \\
\hline 97176 & 55416 & 67642 & 05051 & 89931 & 19482 & 80720 & 48977 & 70004 & 03664 \\
\hline 53295 & 87133 & 38264 & 94708 & 00703 & 35991 & 76404 & 82249 & 22942 & 49659 \\
\hline 23011 & 94108 & 29196 & 65187 & 69974 & 01970 & 31667 & 54307 & 40032 & 30031 \\
\hline 75768 & 49549 & 24543 & 63285 & 32803 & 18301 & 80851 & 89301 & 02398 & 99891 \\
\hline 86668 & 70341 & 66460 & 75648 & 78678 & 27770 & 30245 & 44775 & 56120 & 44235 \\
\hline 56727 & 72036 & 50347 & 33521 & 05068 & 47248 & 67832 & 30960 & 95465 & 32217 \\
\hline 27936 & 78010 & 09617 & 04408 & 18954 & 61862 & 64547 & 52453 & 83213 & 47833 \\
\hline 31994 & 69072 & 37354 & 93025 & 38934 & 90219 & 91148 & 62757 & 51703 & 84040 \\
\hline 02985 & 95303 & 15182 & 50166 & 11755 & 56256 & 89546 & 31170 & 87221 & 63267 \\
\hline 9965 & 10206 & 95830 & 95406 & 33845 & 87588 & 70237 & 84360 & 19629 & 72568 \\
\hline 45587 & 29611 & 98579 & 42481 & 05359 & 36578 & 56047 & 68114 & 58583 & 16313 \\
\hline 01071 & 08530 & 74305 & 77509 & 16270 & 20889 & 99753 & 88035 & 55643 & 18291 \\
\hline 90209 & 68521 & 14293 & 39194 & 68803 & 32052 & 39413 & 26883 & 83119 & 69623 \\
\hline 04982 & 68470 & 27875 & 15480 & 13206 & & 83601 & 03172 & 17 & 01520 \\
\hline 19740 & 24637 & 97377 & 32112 & 74283 & 69384 & 49768 & 64141 & 02024 & 85380 \\
\hline 50197 & 79869 & 86497 & 68709 & 42073 & 28498 & 82750 & 43571 & 77075 & 07123 \\
\hline 46954 & 67536 & 28968 & 81936 & 95999 & 04319 & 09932 & 66223 & 45491 & 69503 \\
\hline 82549 & 62676 & 31123 & 49899 & 70512 & 95288 & 15517 & 85352 & 21987 & 08669 \\
\hline 1798 & 1600 & 80018 & 4742 & 06103 & 60786 & 014 & 75967 & 29948 & 21454 \\
\hline 57666 & 29055 & 46518 & 01487 & 30136 & 14349 & 56159 & 47408 & 78311 & 25896 \\
\hline 29805 & 64994 & 66872 & 62230 & 41385 & 58066 & 96600 & 99301 & 85976 & 84194 \\
\hline 06711 & 34939 & 19599 & 76247 & 87879 & 97114 & 74314 & 39599 & 43544 & 36255 \\
\hline 13934 & 46885 & 58315 & 88366 & 06138 & 37923 & 11192 & 90757 & 10831 & 01580 \\
\hline 28549 & 98327 & 99943 & 25377 & 17628 & & & 16728 & 02 & 33892 \\
\hline 0871 & 61803 & 25767 & 55484 & 90997 & 869 & 64027 & 01020 & 39518 & 34693 \\
\hline 47704 & 38355 & 71708 & 80117 & 11361 & 88875 & 22315 & 38048 & 42891 & 87885 \\
\hline 62611 & 19698 & 09304 & & & & & 56545 & 15 & 28891 \\
\hline 03047 & 83981 & 11916 & 09267 & 67316 & 87952 & 27045 & 62536 & 32180 & 60936 \\
\hline 2 & 5 & & & & & & & & 97107 \\
\hline 01764 & 25959 & 69293 & 89875 & 72710 & 49659 & 66632 & 25314 & 95260 & 22146 \\
\hline $117 €$ & 548 & 1 & & & & & & & 16124 \\
\hline 31736 & 31695 & 11523 & 64213 & 91190 & 10145 & 34231 & 36405 & 65860 & 48771 \\
\hline 97155 & 48706 & 52239 & 21831 & 49043 & 18650 & 72246 & 43729 & 63368 & 53822 \\
\hline 31181 & 49672 & 17237 & & & & & 67342 & 86 & 36106 \\
\hline 321 & & & & & & & & & 49445 \\
\hline 0706 & 759 & 71743 & 69285 & 30395 & 81818 & & 52055 & 20289 & 16911 \\
\hline 26622 & 74184 & 75166 & 96748 & 34729 & 61289 & 36908 & 73686 & 84641 & 45130 \\
\hline 02805 & 52676 & 22519 & 47848 & 68210 & 23954 & 63085 & 87729 & 14176 & 45410 \\
\hline 323 & & & & & & & & & 75925 \\
\hline 2633 & & 39331 & & 010 & & & 47236 & & 90371 \\
\hline 95274 & 09508 & 81012 & 42413 & 112 & 193 & 686 & 04192 & 78 & 84366 \\
\hline 24275 & 39632 & & & & & 081 & 15364 & 02317 & 89548 \\
\hline 36116 & 42128 & 65401 & 94199 & 51058 & 10759 & 47244 & 99830 & 64255 & 40516 \\
\hline
\end{tabular}




\section{TABLE 5 - RANDOM DIGITS}

\begin{tabular}{|c|c|c|c|c|c|c|c|c|c|}
\hline 47505 & 02008 & 20300 & 87188 & 42505 & 40294 & 04404 & 59286 & 95914 & 07191 \\
\hline 13350 & 08414 & 64049 & 94377 & 91059 & 74531 & 56228 & 12307 & 87871 & 97064 \\
\hline 33006 & 92690 & 69248 & 97443 & 38841 & 05051 & 33756 & 24736 & 43508 & 53566 \\
\hline 55216 & 63886 & 06804 & 11861 & 30968 & 74515 & 40112 & 40432 & 18682 & 02845 \\
\hline 1991 & 26228 & 14801 & 19192 & 45110 & 39937 & 81966 & 23258 & 99348 & 61219 \\
\hline 71025 & 28212 & 10474 & 27522 & 16356 & 78456 & 46814 & 28975 & 01014 & 91458 \\
\hline 65522 & 15242 & 84554 & 74560 & 26206 & 49520 & 65702 & 54193 & 25583 & 54745 \\
\hline 27975 & 54923 & 90650 & 06170 & 99006 & 75651 & 77622 & 20491 & 53329 & 12452 \\
\hline 07300 & 09704 & 36099 & 61577 & 34632 & 55176 & 87366 & 19968 & 33986 & 46445 \\
\hline 54357 & 13689 & 19569 & 03814 & 47873 & 34086 & 28474 & 05131 & 46619 & 41499 \\
\hline 00977 & 04481 & 42044 & 08649 & 83107 & 02423 & 46919 & 59586 & 58337 & 32280 \\
\hline 13920 & 78761 & 12311 & 92808 & 71581 & 85251 & 11417 & 85252 & 61312 & 10266 \\
\hline 08395 & 37043 & 37880 & 34172 & 80411 & 05181 & 58091 & 41269 & 22626 & 64799 \\
\hline 46166 & 67206 & 01619 & 43769 & 91727 & 06149 & 17924 & 42628 & 57647 & 76936 \\
\hline 87767 & 77607 & 03742 & 01613 & 83528 & 66251 & 75822 & 83058 & 97584 & 45401 \\
\hline 29880 & 95288 & 21644 & 46587 & 11576 & 30568 & 56687 & 83239 & 76388 & 17857 \\
\hline 36248 & 36666 & 14894 & 59273 & 04518 & 11307 & 67655 & 08566 & 51759 & 41795 \\
\hline 12386 & 29656 & 30474 & 25964 & 10006 & 86382 & 46680 & 93060 & 52337 & 56034 \\
\hline 52068 & 73801 & 52188 & 19491 & 76221 & 45685 & 95189 & 78577 & 36250 & 36082 \\
\hline 41727 & 52171 & 56719 & 06054 & 34898 & 93990 & 89263 & 79180 & 39917 & 16122 \\
\hline 49319 & 74580 & 57470 & 14600 & 22224 & 49028 & 93024 & 21414 & 90150 & 15686 \\
\hline 88786 & 76963 & 12127 & 25014 & 91593 & 98208 & 27991 & 12539 & 14357 & 69512 \\
\hline 84866 & 95202 & 43983 & 72655 & 89684 & 79005 & 85932 & 41627 & 87381 & 38832 \\
\hline 11849 & 26482 & 20461 & 99450 & 21636 & 13337 & 55407 & 01897 & 75422 & 05205 \\
\hline 54966 & 17594 & 57393 & 73267 & 87106 & 26849 & 68667 & 45791 & 87226 & 74412 \\
\hline 10959 & 33349 & 80719 & 96751 & 25752 & 17133 & 32786 & 34368 & 77600 & 41809 \\
\hline 22784 & 07783 & 35903 & 00091 & 73954 & 48706 & 83423 & 96286 & 90373 & 23372 \\
\hline 86037 & 61791 & 33815 & 63968 & 70437 & 33124 & 50025 & 44367 & 98637 & 40870 \\
\hline 80037 & 65089 & 85919 & 74391 & 36170 & 82988 & 52311 & 59180 & 37846 & 98028 \\
\hline 72751 & 84359 & 15769 & 13615 & 70866 & 37007 & 74565 & 92781 & 37770 & 76451 \\
\hline 18532 & 03874 & 66220 & 79050 & 66814 & 76341 & 42452 & 65365 & 07167 & 90134 \\
\hline 22936 & 22058 & 49171 & 11027 & 07066 & 14606 & 11759 & 19942 & 21909 & 15031 \\
\hline 66397 & 76510 & 81150 & 00704 & 94990 & 68204 & 07242 & 82922 & 65745 & 51503 \\
\hline 89730 & 23272 & 65420 & 35091 & 16227 & 87024 & 56662 & 59110 & 11158 & 67508 \\
\hline 81821 & 75323 & 96068 & 91724 & 94679 & 88062 & 13729 & 94152 & 59343 & 07352 \\
\hline 94377 & 82554 & 53586 & 11432 & 08788 & 74053 & 98312 & 61732 & 91248 & 23673 \\
\hline 68485 & 49991 & 53165 & 19865 & 30288 & 00467 & 98105 & 91483 & 89389 & 61991 \\
\hline 07330 & 07184 & 86788 & 64577 & 47692 & 45031 & 36325 & 47029 & 27914 & 24905 \\
\hline 10993 & 14930 & 35072 & 36429 & 26176 & 66205 & 07758 & 07982 & 33721 & 81319 \\
\hline 20801 & 15178 & 64453 & 83357 & 21589 & 23153 & 60375 & 63305 & 37995 & 66275 \\
\hline 79241 & 35347 & 66851 & 79247 & 57462 & 23893 & 16542 & 55775 & 06813 & 63512 \\
\hline 43593 & 39555 & 97345 & 58494 & 52892 & 55080 & 19056 & 96192 & 61508 & 23165 \\
\hline 29522 & 62713 & 33701 & 17186 & 15721 & 95018 & 76571 & 58615 & 35836 & 66260 \\
\hline 88836 & 47290 & 67274 & 78362 & 84457 & 39181 & 17295 & 39626 & 82373 & 10883 \\
\hline 65905 & 66253 & 91482 & 30689 & 81313 & 01343 & 37188 & 37756 & 04182 & 19376 \\
\hline 44798 & 69371 & 07865 & 91756 & 42318 & 63601 & 53872 & 93610 & 44142 & 89830 \\
\hline 35510 & 99139 & 32031 & 27925 & 03560 & 33806 & 85092 & 70436 & 94777 & 57963 \\
\hline 50125 & 93223 & 64209 & 49714 & 73379 & 89975 & 38567 & 44316 & 60262 & 10777 \\
\hline 25173 & 90038 & 63871 & 40418 & 23818 & 63250 & 05118 & 52700 & 92327 & 55449 \\
\hline 68459 & 90094 & 44995 & 93718 & 83654 & 79311 & 18107 & 12557 & 09179 & 28416 \\
\hline
\end{tabular}


Appendix B. Random Number Tables

TABLE 6 - RANDOM DIGITS

\begin{tabular}{|c|c|c|c|c|c|c|c|c|c|}
\hline 96195 & 07059 & 13266 & 31389 & 87612 & 88004 & 31843 & 83469 & 22793 & 14312 \\
\hline 22408 & 94958 & 19095 & 58035 & 43831 & 32354 & 83946 & 57964 & 70404 & 32017 \\
\hline 53896 & 23508 & 16227 & 56929 & 74329 & 12264 & 26047 & 66844 & 47383 & 42202 \\
\hline 22565 & 02475 & 00258 & 79018 & 70090 & 37914 & 27755 & 00872 & 71553 & 56684 \\
\hline 49438 & 20772 & 60846 & 69732 & 07612 & 70474 & 46483 & 21053 & 95475 & 53448 \\
\hline 65620 & 34684 & 00210 & 04863 & 01373 & 19978 & 61682 & 69315 & 46766 & 83768 \\
\hline 20246 & 26941 & 41298 & 04763 & 19769 & 25865 & 95937 & 03545 & 93561 & 73871 \\
\hline 09433 & 09167 & 35166 & 32731 & 73299 & 41137 & 37328 & 28301 & 61629 & 05040 \\
\hline 95552 & 73456 & 16578 & 88140 & 80059 & 50296 & 07656 & 01396 & 83099 & 09718 \\
\hline 76053 & 05150 & 69125 & 69442 & 16509 & 03495 & 26427 & 58780 & 27576 & 31342 \\
\hline 34822 & 35843 & 78468 & 82380 & 52313 & 71070 & 71273 & 10768 & 86101 & 51474 \\
\hline 07753 & 04073 & 58520 & 80022 & 28185 & 16432 & 86909 & 82347 & 10548 & 83929 \\
\hline 04204 & 94434 & 62798 & 81902 & 29977 & 57258 & 87826 & 35003 & 46449 & 76636 \\
\hline 96770 & 19440 & 29700 & 42093 & 64369 & 69176 & 29732 & 37389 & 34054 & 28680 \\
\hline 65989 & 62843 & 10917 & 34458 & 81936 & 84775 & 39415 & 10622 & 36102 & 16753 \\
\hline 06644 & 94784 & 66995 & 61812 & 54215 & 01336 & 75887 & 57685 & 66114 & 76984 \\
\hline 88950 & 46077 & 34651 & 12038 & 87914 & 20785 & 39705 & 73898 & 12318 & 78334 \\
\hline 21482 & 95422 & 02002 & 33671 & 46764 & 50527 & 46276 & 77570 & 68457 & 62199 \\
\hline 55137 & 61039 & 02006 & 69913 & 11291 & 87215 & 89991 & 26003 & 55271 & 08153 \\
\hline 98441 & 81529 & 59607 & 65225 & 49051 & 28328 & 85535 & 37003 & 87211 & 10204 \\
\hline 57168 & 30458 & 23892 & 07825 & 53447 & 53511 & & 42552 & 43135 & 57892 \\
\hline 71886 & 65334 & 38013 & 09379 & 83976 & 42441 & 14086 & 33197 & 82671 & 05037 \\
\hline 40418 & 59504 & 52383 & 07232 & 14179 & 59693 & 37668 & 26689 & 93865 & 78925 \\
\hline 28833 & 76661 & 47277 & 92935 & 63193 & 94862 & 60560 & 72484 & 29755 & 40894 \\
\hline 37883 & 62124 & 62199 & 49542 & 55083 & 20575 & 44636 & 92282 & 52105 & 77664 \\
\hline 44882 & 33592 & 6234 & 13821 & 86342 & 00135 & 87938 & 57995 & 34157 & 99858 \\
\hline 19082 & 13873 & 07184 & 21566 & 95320 & 28968 & 31911 & 06288 & 77271 & 76171 \\
\hline 45316 & 29283 & 89318 & 55806 & 89338 & 79231 & & 55477 & 19552 & 03471 \\
\hline 22788 & 55433 & 31188 & 74882 & 44858 & 69655 & 08096 & 70982 & 61300 & 23792 \\
\hline 08293 & 86193 & 05026 & 21255 & 63082 & 92946 & 28748 & 25423 & 45282 & 57821 \\
\hline 29223 & 70541 & 7115 & 84584 & & 33854 & & 77796 & 70698 & 99393 \\
\hline 22681 & 80110 & 31595 & 09246 & 39147 & 11158 & 43298 & 36220 & 88841 & 11271 \\
\hline 74580 & 90354 & 43744 & 22178 & 38084 & 60027 & 24201 & 71686 & 59767 & 33274 \\
\hline 69093 & 71364 & 8107 & 969 & 50005 & & & & 04676 & 35616 \\
\hline 40456 & 91234 & 58090 & 65342 & 95002 & 28447 & $21^{\prime} 700$ & 43137 & 13746 & 85959 \\
\hline 7292 & & & & & & & & & 38936 \\
\hline 61869 & 33093 & 81129 & 06481 & 89281 & 83629 & 819 & 63704 & 56329 & 10357 \\
\hline 40048 & 16520 & & & & & & & & 87614 \\
\hline 68773 & 97669 & 28656 & 89938 & 12917 & 25630 & 08068 & 19445 & 76250 & 24727 \\
\hline 09774 & 30751 & 49740 & 11385 & 91468 & 28900 & 76804 & 52460 & 52320 & 70493 \\
\hline 46139 & 6689 & & & & & & & 43439 & 53434 \\
\hline 26566 & 95323 & & 899 & & & & & 31730 & 62941 \\
\hline 06765 & 57141 & 48617 & 18282 & 13086 & 76064 & 83334 & 70192 & 15972 & 80429 \\
\hline 35384 & 90380 & 12317 & 89702 & 330 & 68835 & & 38010 & 52710 & 87604 \\
\hline 49333 & 78482 & 36199 & 11355 & 86044 & 88760 & 03724 & 22927 & 91716 & 92332 \\
\hline 45595 & & & & & & & & & \\
\hline 79819 & 15054 & 76174 & 122 & 068 & 068 & & & 75345 & 19779 \\
\hline 11971 & 62234 & 74857 & 46401 & 20817 & 57591 & & 49604 & 29604 & 30660 \\
\hline 11452 & 89318 & 53084 & 21993 & 62471 & 74101 & & 76536 & 58393 & 63718 \\
\hline 38746 & 81271 & 96260 & 98137 & 60275 & 22647 & 33103 & 50090 & 29395 & 10016 \\
\hline
\end{tabular}


TABLE 7 - RANDOM DIGITS

\begin{tabular}{|c|c|c|c|c|c|c|c|c|c|}
\hline 93369 & 13044 & 69686 & 78162 & 29132 & 51544 & 17925 & 56738 & 32683 & 83153 \\
\hline 19360 & 55049 & 94951 & 76341 & 38159 & 31008 & 41476 & 05278 & 03909 & 02299 \\
\hline 47798 & 89890 & 06893 & 65483 & 97658 & 74884 & 38611 & 27264 & 26956 & 83504 \\
\hline 69223 & 32007 & 03513 & 61149 & 66270 & 73087 & 16795 & 76845 & 44645 & 44552 \\
\hline 34511 & 50721 & 84850 & 34159 & 38985 & 75384 & 22965 & 55366 & 81632 & 78872 \\
\hline 4031 & 59329 & 58963 & 52220 & 76806 & 98715 & 67452 & 78741 & 58128 & 00077 \\
\hline 66722 & 85515 & 04723 & 92411 & 03834 & 12109 & 85185 & 37350 & 93614 & 15351 \\
\hline 71059 & 07496 & 38404 & 18126 & 37894 & 44991 & 45777 & 02070 & 38159 & 23930 \\
\hline 45478 & 86066 & 31135 & 33243 & 01190 & 47277 & 55146 & 56130 & 70117 & 83203 \\
\hline 97246 & 91121 & 89437 & 20393 & 76598 & 99458 & 76665 & 33793 & 37448 & 32664 \\
\hline 22982 & 5936 & 96417 & 34845 & 28942 & 65569 & 38253 & 77182 & 12996 & 19505 \\
\hline 48243 & 62993 & 47132 & 85248 & 79160 & 90981 & 71696 & 9609 & 33809 & 60839 \\
\hline 93514 & 4915 & 67960 & 82203 & 22598 & 94802 & 75332 & 5585 & 69542 & 79924 \\
\hline 69707 & 8303 & 93069 & 16216 & 01542 & 51771 & 16833 & 20922 & 94415 & 27617 \\
\hline 87467 & 91794 & 70814 & 12743 & 17543 & 04057 & 71231 & 11309 & 32780 & 83270 \\
\hline 81006 & 81498 & 59375 & 30502 & 44868 & 81279 & 23585 & 49678 & 70014 & 10523 \\
\hline 15458 & 3481 & 50187 & 43375 & 56644 & 72076 & 59403 & 5469 & 74760 & 69509 \\
\hline 33469 & 2510 & 23095 & 48016 & 22064 & 39774 & 07373 & 10555 & 33345 & 21787 \\
\hline 67198 & 07176 & 65996 & 18317 & 83083 & 11921 & 06254 & 68437 & 59481 & 54778 \\
\hline 58037 & 92261 & 85504 & 55690 & 63488 & 26451 & 43223 & 38009 & 50567 & 09191 \\
\hline 84983 & 8312 & 25519 & 56158 & 22390 & 12823 & 92390 & 28947 & 36708 & 25393 \\
\hline 35554 & 02935 & 72889 & 68772 & 79774 & 14336 & 50716 & 63003 & 36391 & 94074 \\
\hline 04368 & 7632 & 50962 & 71908 & 13105 & 76285 & 318 & 16884 & 11665 & 16594 \\
\hline 81311 & 60479 & 69985 & 30952 & 93067 & 70056 & 55229 & 83226 & 22555 & 66447 \\
\hline 03823 & 89887 & 55828 & 74452 & 21692 & 55847 & 15960 & 47521 & 27784 & 25728 \\
\hline 80422 & 4437 & 8797 & 6261 & 88300 & & & & & 49257 \\
\hline 61307 & 49468 & 43344 & 43700 & 14074 & 19739 & 032 & 99444 & 2545 & 23720 \\
\hline 83873 & 82557 & 10002 & 80093 & 74645 & 33109 & 15281 & 38759 & 42 & 69408 \\
\hline 38110 & 6855 & 28922 & 3758 & 22885 & 36706 & 92542 & 0270 & 99599 & 17983 \\
\hline 43892 & 91189 & 87226 & 56935 & 99836 & 85489 & 89693 & 49475 & 31941 & 78065 \\
\hline 93683 & 9664 & 3927 & 49885 & 4979 & & & & & 49428 \\
\hline 32748 & 02121 & 11972 & 96914 & 83264 & 89016 & 45140 & 20362 & 3242 & 86255 \\
\hline 49211 & 2963 & 38625 & 65312 & 52156 & 36400 & 67050 & 64058 & 5489 & 24165 \\
\hline 63365 & 4224 & 69475 & 57512 & 85097 & 05054 & & 96593 & & 53320 \\
\hline 63576 & 26373 & 44610 & 43748 & 90399 & 06770 & 71609 & 90916 & 69002 & 57180 \\
\hline 41078 & 036 & 524 & 3466 & 7613 & & & & & \\
\hline 70846 & 89558 & 64173 & 15381 & 67322 & 70097 & & 90767 & 17879 & 32697 \\
\hline 68800 & 4492 & 20162 & 32707 & 69510 & 82465 & 26821 & & 34615 & 35820 \\
\hline 44977 & 9525 & 51269 & 63747 & 30997 & 97213 & & & 05723 & 50168 \\
\hline 79354 & 63847 & 24395 & 53679 & 07667 & 67993 & 24634 & 78867 & 78516 & 00448 \\
\hline 14954 & 2299 & & & & & & & & 19050 \\
\hline 01711 & 8439 & 09446 & 33937 & 98956 & 85676 & & 05132 & 45886 & 49379 \\
\hline 62328 & 55328 & 45738 & 93940 & 15772 & 81975 & 91017 & 21387 & 57949 & 13992 \\
\hline 73004 & 62109 & 81907 & 71077 & 50322 & 66093 & 79921 & 61412 & 18347 & 21115 \\
\hline 34218 & 89445 & 03609 & 52336 & 19005 & 15179 & 94958 & 99448 & 11612 & 76981 \\
\hline 99159 & & 45886 & $808 / 5$ & 05196 & & & 39878 & 61548 & 56442 \\
\hline 92858 & 9949 & 15817 & 93372 & 34732 & 61584 & 72007 & 58597 & 43802 & 51066 \\
\hline 27396 & 97477 & 65554 & 71601 & & & 19487 & & 18676 & 41219 \\
\hline 37103 & 45309 & 30129 & 43380 & 66638 & 10841 & 77292 & 40288 & 25826 & 61431 \\
\hline 57347 & 97012 & 48428 & 20606 & 54138 & 75716 & 23741 & 50462 & 13221 & 47216 \\
\hline
\end{tabular}




\section{Appendix C. Model Inspection Report Forms}

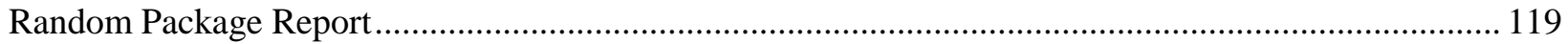

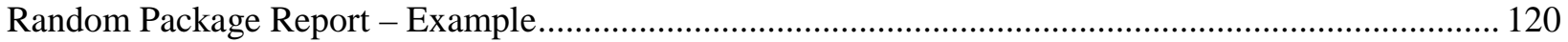

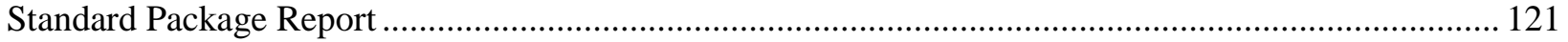

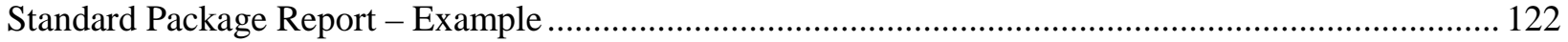

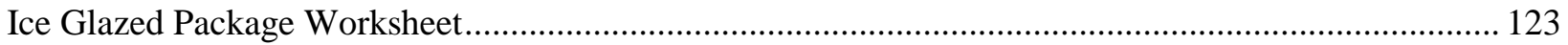

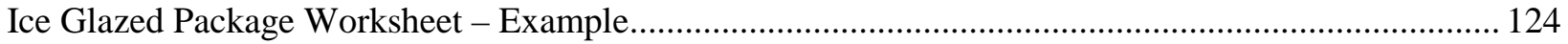

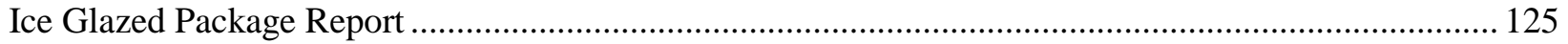

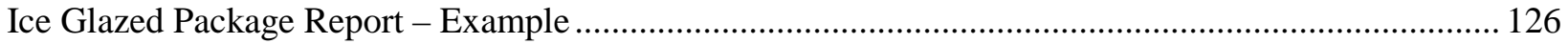

Worksheet for Determining the Free Liquid and Net Volume of Oysters .............................................. 127

Worksheet for Determining the Free Liquid and Net Volume of Oysters - Example............................ 128 
Handbook 133, Checking the Net Contents of Packaged Goods (2015)

THIS PAGE INTENTIONALLY LEFT BLANK 


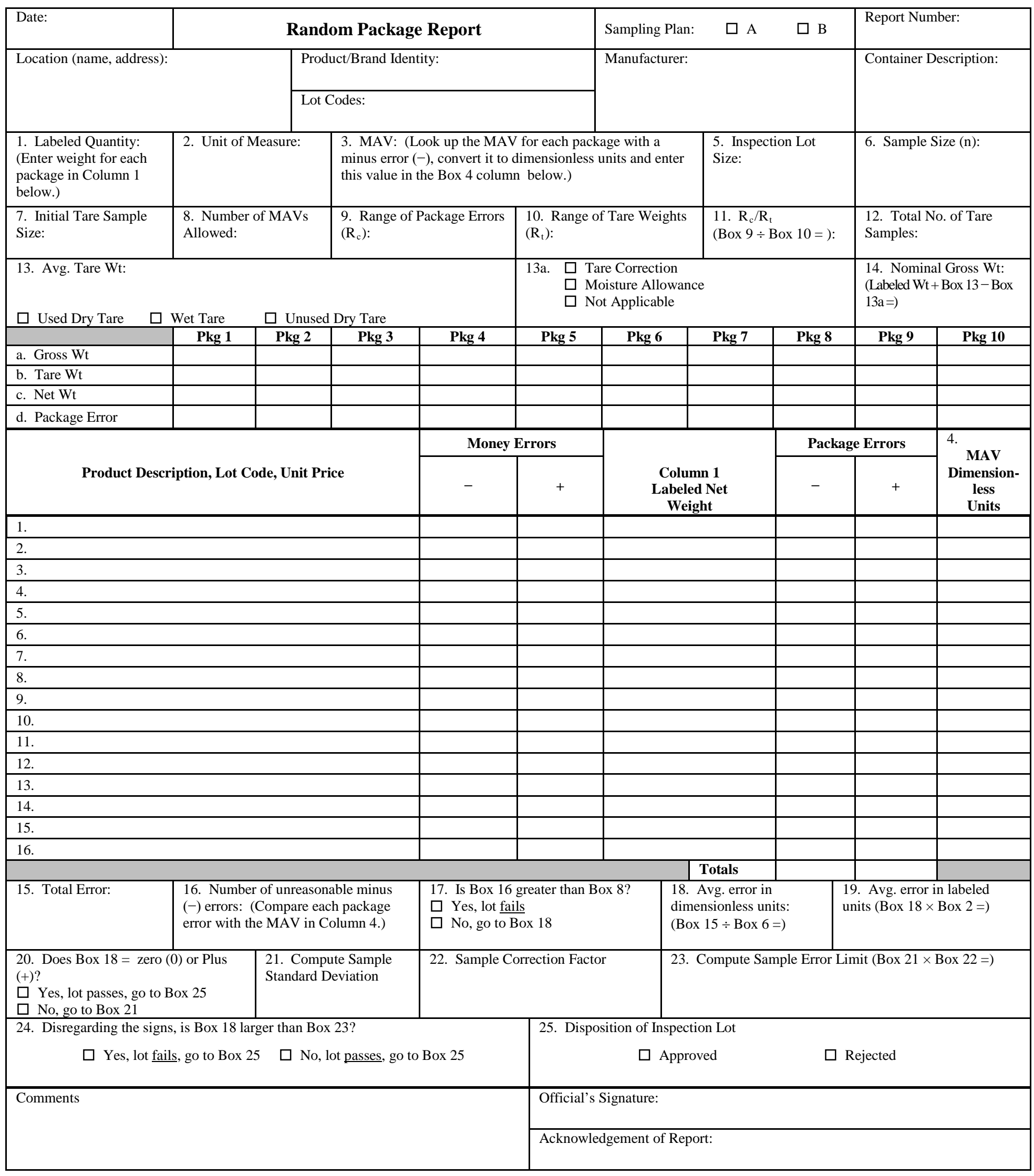




\begin{tabular}{|c|c|c|c|c|c|c|c|c|c|c|c|}
\hline $\begin{array}{l}\text { Date: } \\
\text { January 20, } 2010\end{array}$ & \multicolumn{5}{|c|}{ Random Package Report - Example } & \multicolumn{4}{|c|}{ Sampling Plan: } & \multicolumn{2}{|c|}{$\begin{array}{r}\text { Report Number: } \\
17\end{array}$} \\
\hline \multirow{2}{*}{\multicolumn{2}{|c|}{$\begin{array}{l}\text { Location (name, address): } \\
\text { L\&O Market } \\
\text { MacCorkle Ave. } \\
\text { Charleston, WV } 25171\end{array}$}} & \multicolumn{4}{|c|}{$\begin{array}{l}\text { Product/Brand Identity: } \\
\text { Ground Chuck }\end{array}$} & \multirow{2}{*}{\multicolumn{4}{|c|}{$\begin{array}{l}\text { Manufacturer: } \\
\text { Meat Dept. - L\&O Market }\end{array}$}} & \multirow{2}{*}{\multicolumn{2}{|c|}{$\begin{array}{l}\text { Container Description: } \\
25 \text { Tray w/soaker and } \\
\text { plastic wrap }\end{array}$}} \\
\hline & & \multicolumn{4}{|c|}{$\begin{array}{l}\text { Lot Codes: } \\
1,19,99\end{array}$} & & & & & & \\
\hline $\begin{array}{l}\text { 1. Labeled Quantity: } \\
\text { (Enter weight for each } \\
\text { package in Column } 1 \\
\text { below.) }\end{array}$ & \multicolumn{2}{|c|}{ 2. Unit of Measure: } & \multicolumn{5}{|c|}{$\begin{array}{l}\text { 3. MAV: (Look up the MAV for each package with a } \\
\text { minus error (-), convert it to dimensionless units and } \\
\text { enter this value in the Box } 4 \text { column below.) }\end{array}$} & \multicolumn{2}{|c|}{$\begin{array}{l}\text { 5. Inspection Lot } \\
\text { Size: } \\
\qquad 23\end{array}$} & \multicolumn{2}{|c|}{$\begin{array}{l}\text { 6. Sample Size (n): } \\
\qquad 12\end{array}$} \\
\hline $\begin{array}{l}\text { 7. Initial Tare Sample } \\
\text { Size: } \\
\qquad 2\end{array}$ & \multicolumn{2}{|c|}{$\begin{array}{l}\text { 8. Number of MAVs } \\
\text { Allowed: } \\
\qquad 0\end{array}$} & \multicolumn{2}{|c|}{$\begin{array}{l}\text { 9. Range of Package } \\
\text { Errors }\left(\mathrm{R}_{\mathrm{c}}\right) \text { : } \\
\qquad 10\end{array}$} & \multicolumn{3}{|c|}{$\begin{array}{l}\text { 10. Range of Tare Weights } \\
\left(\mathrm{R}_{\mathrm{t}}\right):\end{array}$} & \multicolumn{2}{|c|}{$\begin{array}{l}\text { 11. } \mathrm{R}_{\mathrm{c}} / \mathrm{R}_{\mathrm{t}} \\
(\operatorname{Box} 9 \div \operatorname{Box} 10=) \text { : } \\
\qquad 10\end{array}$} & \multicolumn{2}{|c|}{$\begin{array}{l}\text { 12. Total No. of Tare } \\
\text { Samples: }\end{array}$} \\
\hline \multirow{2}{*}{\multicolumn{5}{|c|}{$\begin{array}{ll}\text { 13. Avg. Tare Wt: } & 0.0205 \mathrm{lb}\end{array}$}} & \multirow{2}{*}{\multicolumn{5}{|c|}{$\begin{array}{ll}\text { 13a. } & \square \text { Tare Correction } \\
& \square \text { Moisture Allowance } \\
& \square \text { Not Applicable }\end{array}$}} & \multirow{2}{*}{\multicolumn{2}{|c|}{$\begin{array}{l}\text { 14. Nominal Gross Wt: } \\
\text { (Labeled Wt }+ \text { Box } 13-\text { Box } \\
13 a=) \\
\text { Label } W t+0.020 \mathrm{lb}\end{array}$}} \\
\hline & & & & & & & & & & & \\
\hline & Pkg 1 & Pkg 2 & Pkg 3 & Pkg 4 & Pkg 5 & Pkg & & Pkg 7 & Pkg 8 & Pkg 9 & Pkg 10 \\
\hline a. Gross Wt & $1.852 \mathrm{lb}$ & $1.223 \mathrm{lb}$ & & & & & & & & & \\
\hline b. Tare $\mathrm{Wt}$ & $0.020 \mathrm{lb}$ & $0.021 \mathrm{lb}$ & & & & & & & & & \\
\hline c. Net Wt & $1.832 \mathrm{lb}$ & $1.202 \mathrm{lb}$ & & & & & & & & & \\
\hline d. Package Error & -18 & -8 & & & & & & & & & \\
\hline & & & & Mone & Errors & & & & Pac & ge Errors & 4. \\
\hline Product Des & cription, Lo & de, Unit Pr & & - & + & & $\begin{array}{l}\text { Colun } \\
\text { abele } \\
\text { Weig }\end{array}$ & $\begin{array}{l}\text { in } 1 \\
\text { Net } \\
\text { ht }\end{array}$ & - & + & $\begin{array}{c}\text { Dimension- } \\
\text { less } \\
\text { Units }\end{array}$ \\
\hline 1. Ground Chuck - 1, & $19,99-\$ 1$ & per $1 b$ & & & & & 1.85 & & 18 & & \\
\hline 2. & & & & & & & 1.21 & & 7 & & \\
\hline 3. & & & & & & & 1.56 & & 8 & & \\
\hline 4. & & & & & & & 1.98 & & 14 & & \\
\hline 5. & & & & $\$ 0.04$ & & & 1.07 & & 23 & & 44 \\
\hline 6. & & & & & & & 1.55 & & 16 & & \\
\hline 7. & & & & & & & 1.02 & & 2 & & \\
\hline 8. & & & & $\$ 0.04$ & & & 1.44 & & 25 & & 56 \\
\hline 9. & & & & & & & 1.33 & & 16 & & \\
\hline 10. & & & & & & & 2.03 & & 20 & & 70 \\
\hline 11. & & & & & & & 1.73 & & 14 & & \\
\hline 12. & & & & & & & 1.16 & & 11 & & \\
\hline 13. & & & & & & & & & & & \\
\hline 14. & & & & & & & & & & & \\
\hline 15. & & & & & & & & & & & \\
\hline 16. & & & & & & & & & & & \\
\hline & & & & & & & & Totals & -174 & & \\
\hline $\begin{array}{r}\text { 15. Total Error: } \\
-174\end{array}$ & $\begin{array}{l}\text { 16. Numbe } \\
\text { errors: (Co } \\
\text { with the } M\end{array}$ & $\begin{array}{l}\text { unreasonab } \\
\text { re each pac } \\
\text { in Column } \\
0\end{array}$ & $\begin{array}{l}\text { minus (-) } \\
\text { ge error }\end{array}$ & $\begin{array}{l}\text { 17. Is Box } \\
\square \text { Yes, lo } \\
\square \text { No, go }\end{array}$ & $\begin{array}{l}6 \text { greater th } \\
\text { aails } \\
\text { Box } 18\end{array}$ & Box 8? & & $\begin{array}{r}\text { Avg. erro } \\
\text { lensionless } \\
\text { x } 15 \div \text { Bo } \\
-1\end{array}$ & $\begin{array}{l}\text { n } \\
\text { nits: } \\
6=) \\
5\end{array}$ & $\begin{array}{l}\text { 19. Avg. err } \\
\text { (Box } 18 \times \mathrm{Bc} \\
-C\end{array}$ & $\begin{array}{l}\text { labeled units } \\
=) \\
4 \mathrm{lb}\end{array}$ \\
\hline $\begin{array}{l}\text { 20. Does Box } 18=\text { Zer } \\
(+) \text { ? } \\
\square \text { Yes, lot passes, go t } \\
\square \text { No, go to Box } 21 \\
\end{array}$ & $\begin{array}{l}\text { (0) or Plus } \\
\text { Box } 25\end{array}$ & $\begin{array}{l}\text { 21. Comp } \\
\text { Standard I }\end{array}$ & $\begin{array}{l}\text { e Sample } \\
\text { viation } \\
721\end{array}$ & 22. Sampl & $\begin{array}{c}\text { Correction } \\
0.635\end{array}$ & ctor & & Compute & ample Error & $\begin{array}{l}\text { mit (Box 21> } \\
267\end{array}$ & × 22 =) \\
\hline $\begin{array}{l}\text { 24. Disregarding the si } \\
\square \text { Yes, lot fails, go }\end{array}$ & $\begin{array}{l}\text { ns, is Box } 18 \\
\text { to Box } 25\end{array}$ & $\begin{array}{l}\text { ger than Bo } \\
\text { No, lot pass }\end{array}$ & go to Box 2 & 25.1 & sposition o & $\begin{array}{r}\text { ispection } \\
\square \mathrm{A}\end{array}$ & $\begin{array}{l}\text { Lot } \\
\text { pprov }\end{array}$ & & $\nabla \operatorname{Rej}$ & & \\
\hline Comments & & & & Offic & l's Signatu & & & & & & \\
\hline & & & & Ackn & wledgemen & f Report: & & & & & \\
\hline
\end{tabular}




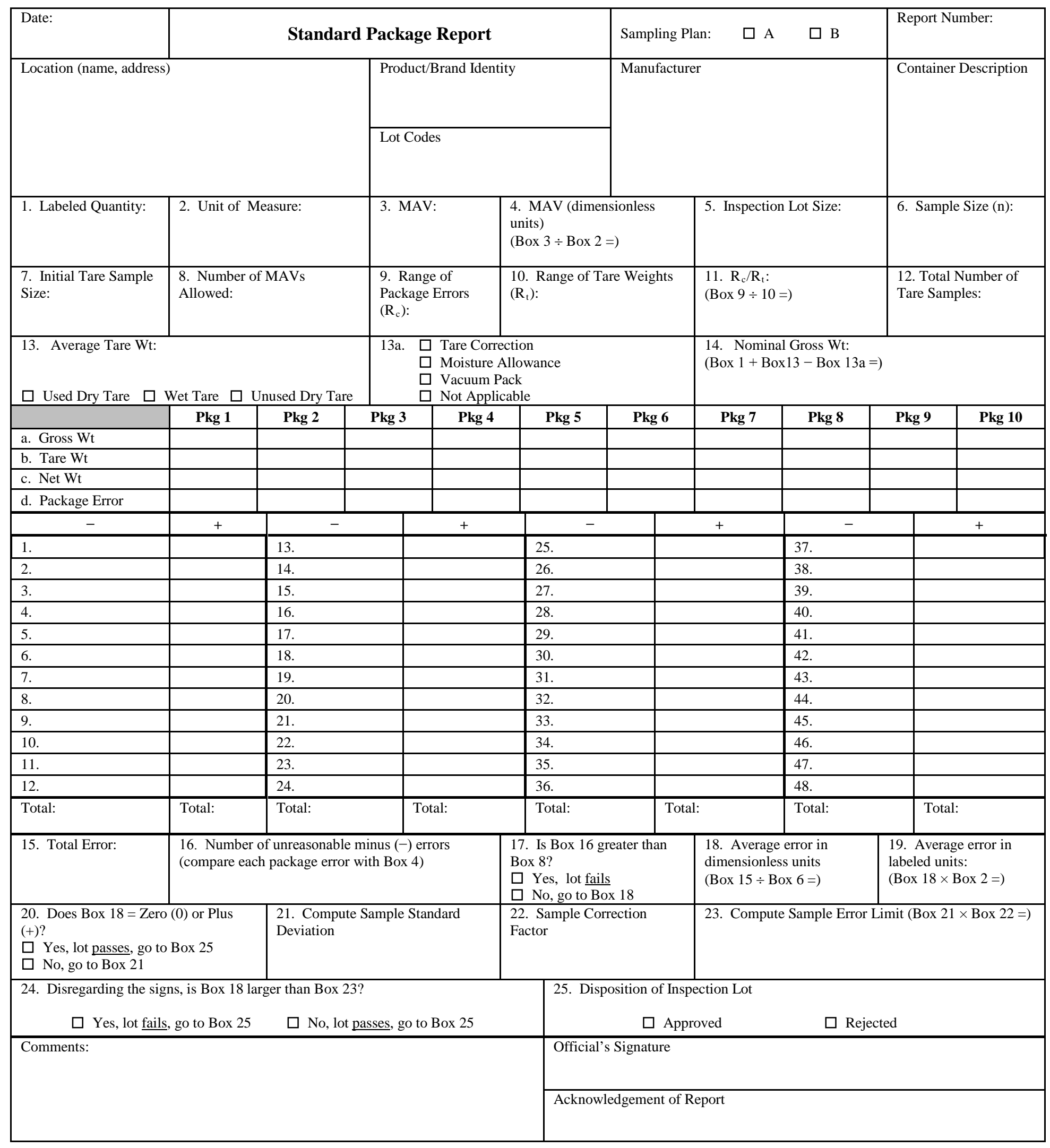




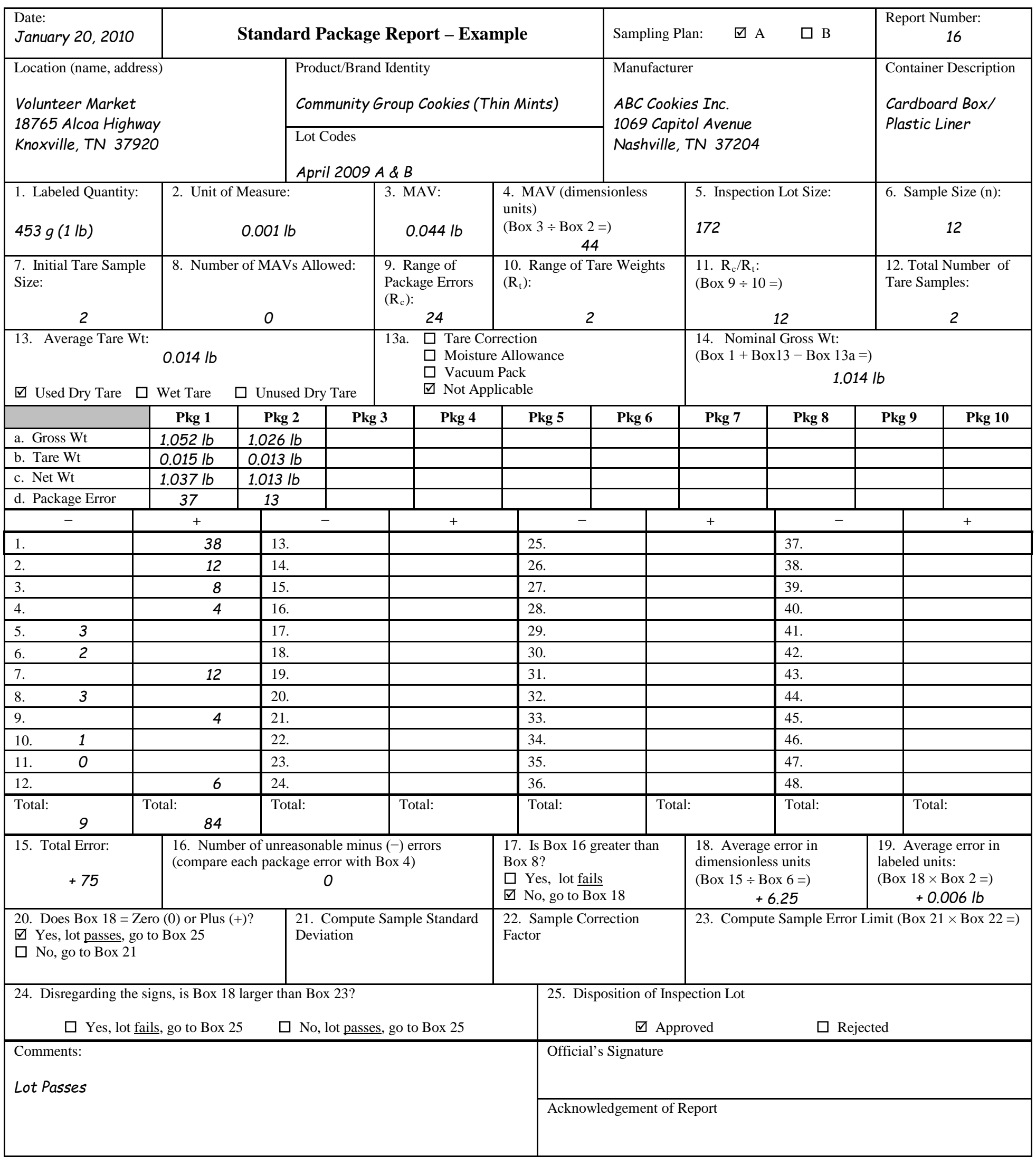




\section{STEP}

\section{Ice Glazed Package Worksheet}

1. Package Price (if standard pack) $\$$ Price Per Pound (if random pack) \$

Lot Size: Sample Size: Unit of Measure:

2. Number each package. Weigh each package for Gross Package Weight and enter Row 1.

3. Enter Labeled Net Weight in Row 2. (If dual units determine the larger unit.)

4. Record the Maximum Allowable Variation (MAV) in Row 3.

5. Weigh the receiving pan $=$ (enter in Row 4). (Clean and dry the receiving pan and verify the weight after each use. Thoroughly clean the sieve.)

6. Deglaze the product. Remove each package from the low temperature storage. Open the package immediately and place the contents in the sieve or other draining device (e.g., colander) under a gentle spray of cold water. Carefully agitate the product. Handle with care to avoid breaking the product. Continue the spraying process until all ice glaze that is seen or felt is removed.

7. Without shifting the product, incline the sieve to an angle of $17^{\circ}$ to $20^{\circ}$ (incline to facilitate drainage) and drain for 2 minutes using a stopwatch.

8. Immediate transfer the entire product to the receiving pan to determine the net weight.

9. To calculate the net weight (receiving pan and product) - (receiving pan) $=$ Net Weight (enter in Row 5)

10. Calculate \pm Package error (net weight [Row 5] - labeled net weight [Row 2]) $= \pm$ Error, (enter in Row 6).

\begin{tabular}{|c|c|c|c|c|c|c|c|c|c|c|c|c|c|}
\hline Row & Package & 1 & 2 & 3 & 4 & 5 & 6 & 7 & 8 & 9 & 10 & 11 & 12 \\
\hline 1 & $\begin{array}{l}\text { Gross Pkg. } \\
\text { Weight } \\
\text { (Step 3) }\end{array}$ & & & & & & & & & & & & \\
\hline 2 & $\begin{array}{l}\text { Labeled Net } \\
\text { Weight } \\
\text { (Step 4) }\end{array}$ & & & & & & & & & & & & \\
\hline 3 & $\begin{array}{l}\text { MAV } \\
\text { (Step 5) }\end{array}$ & & & & & & & & & & & & \\
\hline 4 & $\begin{array}{l}\text { Sieve and } \\
\text { Receiving } \\
\text { Pan Weight } \\
\text { (Step 6) }\end{array}$ & & & & & & & & & & & & \\
\hline 5 & $\begin{array}{l}\text { Net Weight } \\
\text { (Step 10) }\end{array}$ & & & & & & & & & & & & \\
\hline 6 & $\begin{array}{l} \pm \text { Error (Step } \\
11 \text { ) }\end{array}$ & & & & & & & & & & & & \\
\hline
\end{tabular}

Used Dry Tare

Transfer data from the "Ice Glazed Package Worksheet” to the "Ice Glazed Package Report” (Added 2010) 


\section{Ice Glazed Package Worksheet - Example}

\section{STEP}

1. Package Price (if standard pack) \$ 6.99 Price Per Pound (if random pack) \$

Lot Size: 6 Sample Size: $6 \quad 6 \quad$ Unit of Measure: $\_.001 \mathrm{lb}$

2. Number each package. Weigh each package for Gross Package Weight and enter Row 1.

3. Enter Labeled Net Weight in Row 2. (If dual units determine the larger unit.) $1 \mathrm{lb} / 453 \mathrm{~g}$

4. Record the Maximum Allowable Variation (MAV) in Row 3.

5. Weigh the receiving pan $=\underline{0.795 \mathrm{lb}}$ (enter in Row 4). (Clean and dry the receiving pan and verify the weight after each use. Thoroughly clean the sieve.)

6. Deglaze the product. Remove each package from the low temperature storage. Open the package immediately and place the contents in the sieve or other draining device (e.g., colander) under a gentle spray of cold water. Carefully agitate the product. Handle the product with care to avoid breaking the product. Continue the spraying process until all ice glaze that is seen or felt is removed.

7. Without shifting the product, incline the sieve to an angle of $17^{\circ}$ to $20^{\circ}$ (incline to facilitate drainage) and drain for 2 minutes using a stopwatch.

8. Immediately transfer the entire product to the receiving pan to determine the net weight.

9. To calculate the net weight (receiving pan and product) - (receiving pan) = Net Weight (enter in Row 5)

10. Calculate \pm Package error (net weight [Row 5] - labeled net weight [Row 2]) = \pm Error, (enter in Row 6).

\begin{tabular}{||c|l|c|c|c|c|c|c|c|c|c|c|c|c||}
\hline Row & \multicolumn{1}{|c|}{ Package } & $\mathbf{1}$ & $\mathbf{2}$ & $\mathbf{3}$ & $\mathbf{4}$ & $\mathbf{5}$ & $\mathbf{6}$ & $\mathbf{7}$ & $\mathbf{8}$ & $\mathbf{9}$ & $\mathbf{1 0}$ & $\mathbf{1 1}$ & $\mathbf{1 2}$ \\
\hline $\mathbf{1}$ & $\begin{array}{l}\text { Gross Pkg. } \\
\begin{array}{l}\text { Weight } \\
\text { (Step 3) }\end{array}\end{array}$ & 1.180 & 1.205 & 1.110 & 1.150 & 1.000 & 1.210 & & & & & & \\
\hline $\mathbf{2}$ & $\begin{array}{l}\text { Labeled Net } \\
\text { Weight } \\
\text { (Step 4) }\end{array}$ & 1.000 & 1.000 & 1.000 & 1.000 & 1.000 & 1.000 & & & & & & \\
\hline $\mathbf{3}$ & $\begin{array}{l}\text { MAV } \\
\text { (Step 5) }\end{array}$ & 0.044 & 0.044 & 0.044 & 0.044 & 0.044 & 0.044 & & & & & & \\
\hline $\mathbf{4}$ & $\begin{array}{l}\text { Receiving Pan } \\
\text { Weight } \\
\text { (Step 6) }\end{array}$ & 0.795 & 0.795 & 0.795 & 0.795 & 0.795 & 0.795 & & & & & & \\
\hline $\mathbf{5}$ & $\begin{array}{l}\text { Net Weight } \\
\text { (Step 10) }\end{array}$ & 0.985 & 0.975 & 1.000 & 1.030 & 0.930 & 0.980 & & & & & & \\
\hline $\mathbf{6}$ & $\begin{array}{l}\text { I Error } \\
\text { (Step 11) }\end{array}$ & -0.015 & -0.025 & 0 & +0.030 & -0.070 & -0.020 & & & & & & \\
\hline
\end{tabular}

Used Dry Tare $\underline{0.025 \mathrm{lb}}$

Transfer data from the "Ice Glazed Package Worksheet” to the "Ice Glazed Package Report” (Added 2010) 


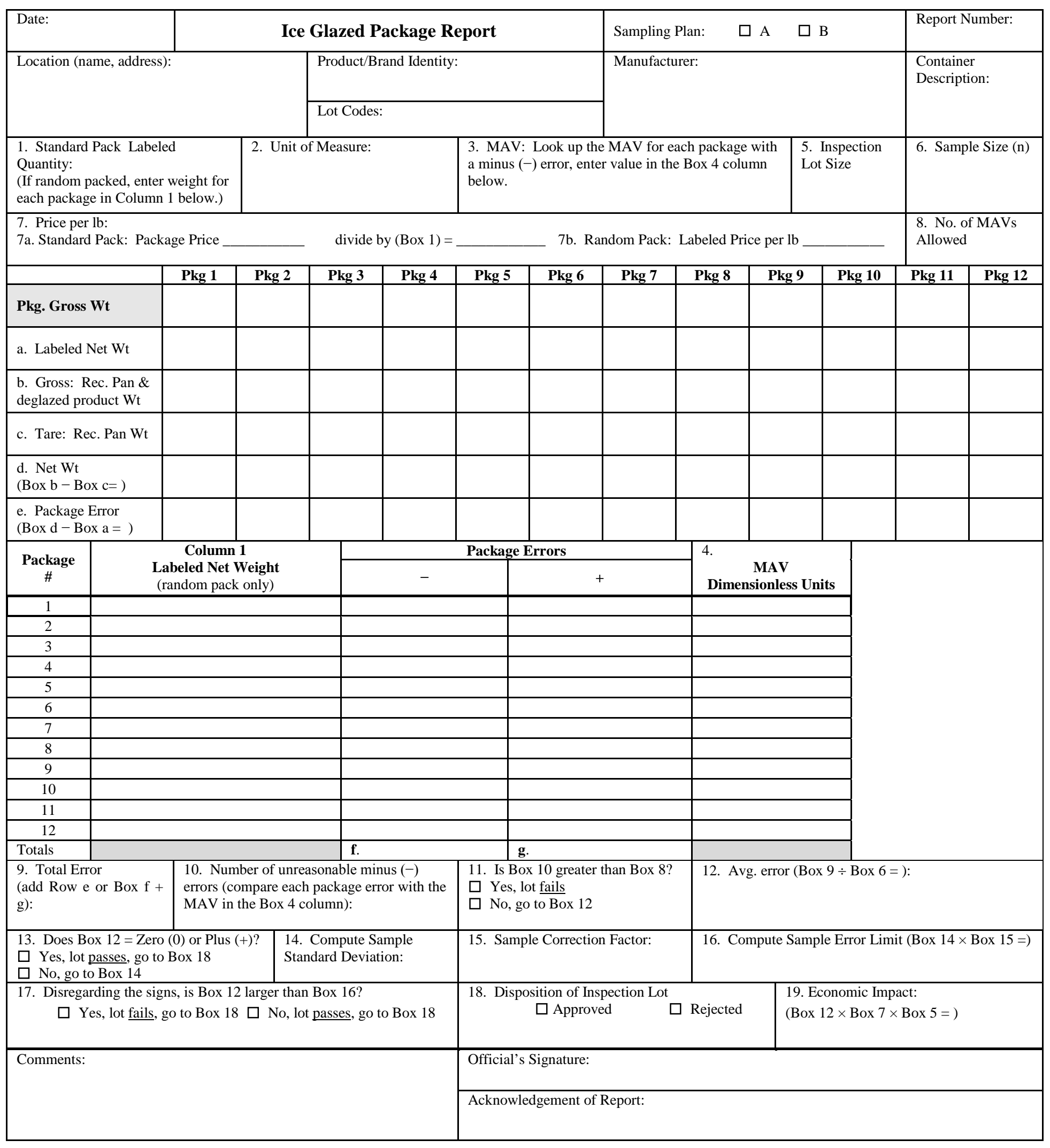




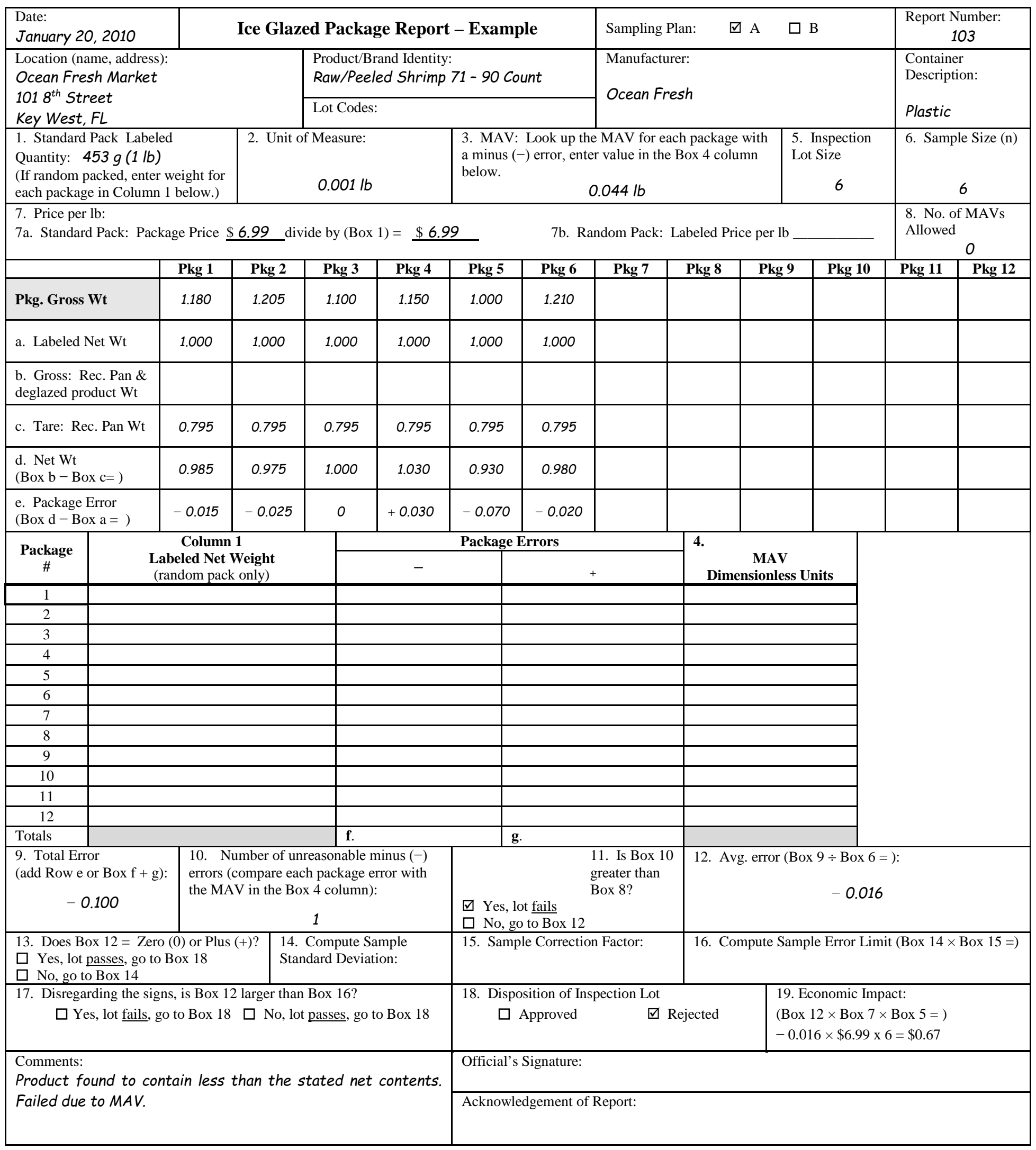




\section{NIST Technical Publications}

\section{Periodical}

J ournal of Research of the National Institute of Standards and Technology- Reports N IST research and development in metrology and related fields of physical science, engineering, applied mathematics, statistics, biotechnology, and information technology. Papers cover a broad range of subjects, with major emphasis on measurement methodology and the basic technology underlying standardization. Also included from time to time are survey articles on topics closely related to the Institute's technical and scientific programs. Issued six times a year.

\section{Nonperiodicals}

M onographs- M ajor contributions to the technical literature on various subjects related to the Institute's scientific and technical activities.

Handbooks - Recommended codes of engineering and industrial practice (including safety codes) developed in cooperation with interested industries, professional organizations, and regulatory bodies.

Special Publications - Include proceedings of conferences sponsored by NIST, NIST annual reports, and other special publications appropriate to this grouping such as wall charts, pocket cards, and bibliographies.

National Standard R eference Data Series- Provides quantitative data on the physical and chemical properties of materials, compiled from the world's literature and critically evaluated. Developed under a worldwide program coordinated by NIST under the authority of the National Standard Data A ct (Public Law 90-396). NOTE:The J ournal of Physical and Chemical Reference Data (JPCRD) is published bimonthly for NIST by the A merican Institute of Physics (AIP). Subscription orders and renewals are available from A IP, P.O. B ox 503284, St. Louis, M 063150-3284.

National C onstruction Safety Team Act Reports-This series comprises the reports of investigations carried out under Public L aw 107-231, the technical cause(s) of the building failure investigated; any technical recommendations for changes to or the establishment of evacuation and emergency response procedures; any recommended specific improvements to building standards, codes, and practices; and recomendations for research and other approprate actions to help prevent future building failures.

B uilding Science Series-Disseminates technical information developed at the Institute on building materials, components, systems, and whole structures. The series presents research results, test methods, and performance criteria related to the structural and environmental functions and the durability and safety characteristics of building elements and systems.

Technical Notes - Studies or reports which are complete in themselves but restrictive in their treatment of a subject. A nal ogous to monographs but not so comprehensive in scope or definitive in treatment of the subject area. Often serve as a vehicle for final reports of work performed at NIST under the sponsorship of other government agencies.

Voluntary Product Standards - Developed under procedures published by the Department of Commerce in Part 10, Title 15, of the Code of Federal Regulations. The standards establish nationally recognized requirements for products, and provide all concerned interests with a basis for common understanding of the characteristics of the products. NIST administers this program in support of the efforts of private-sector standardizing organizations.

Order the following NIST publications-FIPS and NISTIRs-from the National Technical Information Service, Springfield, VA 22161.

Federal Information Processing Standards Publications (FIPS PUB)- Publications in this series collectively constitute the Federal Information Processing Standards Register. The Register serves as the official source of information in the Federal Government regarding standards issued by NIST pursuant to the Federal Property and A dministrative Services A ct of 1949 as amended, Public Law 89-306 (79 Stat. 1127), and as implemented by Executive Order 11717 (38 FR 12315, dated M ay 11, 1973) and Part 6 of Title 15 CFR (Code of Federal Regulations).

NIST Interagency or Internal Reports (NISTIR)- The series includes interim or final reports on work performed by NIST for outside sponsors (both government and nongovernment). In general, initial distribution is handled by the sponsor; public distribution is handled by sales through the $N$ ational Technical Information Service, Springfield, VA 22161, in hard copy, electronic media, or microfiche form. NISTIR's may also report results of NIST projects of transitory or limited interest, including those that will be published subsequently in more comprehensive form. 


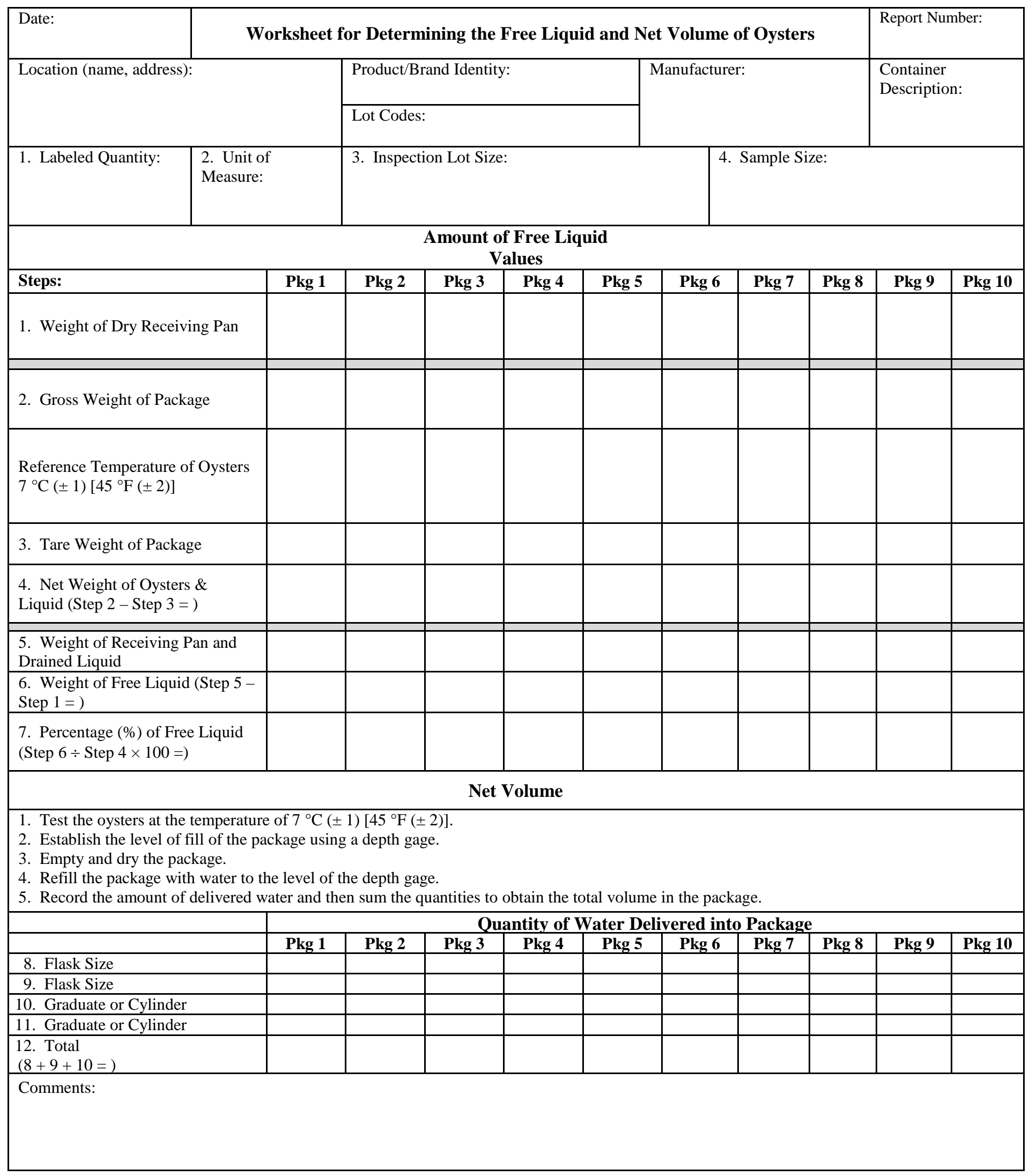




\begin{tabular}{|c|c|c|c|c|c|c|c|c|c|c|c|}
\hline $\begin{array}{l}\text { Date: } \\
\text { December 20, } 2013\end{array}$ & \multicolumn{2}{|c|}{ Worksheet for De } & erminin & the Fre & iquid a & d Net Vo & ume of $\mathrm{C}$ & ysters - 1 & ample & \multicolumn{2}{|c|}{$\begin{array}{c}\text { Report Number: } \\
1 \text { of } 2\end{array}$} \\
\hline \multirow{2}{*}{\multicolumn{3}{|c|}{$\begin{array}{l}\text { Superchain Market } \\
\text { Main Street } \\
\text { Bradenton, FL }\end{array}$}} & \multicolumn{4}{|c|}{$\begin{array}{l}\text { World's Best Oysters - Oyster } \\
\text { Standard }\end{array}$} & \multirow{2}{*}{\multicolumn{3}{|c|}{$\begin{array}{l}\text { Manufacturer: } \\
\text { World's Best Packing } \\
\text { Beach Road, AL }\end{array}$}} & \multirow{2}{*}{\multicolumn{2}{|c|}{$\begin{array}{l}\text { Container } \\
\text { Description: } \\
\text { Clear Plastic Tub } \\
\text { with metal pull top }\end{array}$}} \\
\hline & & & \multicolumn{4}{|c|}{$12 / 26 / 2012$} & & & & & \\
\hline $\begin{array}{l}\text { 1. Labeled Quantity: } \\
12 \mathrm{fl} \text { oz }(355 \mathrm{ml})\end{array}$ & \multicolumn{2}{|c|}{$\begin{array}{l}\text { 2. Unit of Measure: } \\
0.001 \mathrm{lb}\end{array}$} & \multicolumn{5}{|c|}{$\begin{array}{l}\text { 3. Inspection Lot Size: } \\
\qquad 206\end{array}$} & \multicolumn{2}{|c|}{ 4. Sample Size: } & 2 & \\
\hline \multicolumn{12}{|c|}{$\begin{array}{c}\text { Amount of Free Liquid } \\
\text { Values }\end{array}$} \\
\hline Steps: & & Pkg 1 & Pkg 2 & Pkg 3 & Pkg 4 & Pkg 5 & Pkg 6 & Pkg 7 & Pkg 8 & Pkg 9 & Pkg 10 \\
\hline \multicolumn{2}{|c|}{ 1. Weight of Dry Receiving Pan } & 11.841 & 11.841 & 11.841 & 11.841 & 11.841 & & & & & \\
\hline \multicolumn{2}{|c|}{ 2. Gross Weight of Package } & 0.871 & 0.884 & 0.920 & 0.869 & 0.8632 & & & & & \\
\hline \multicolumn{2}{|c|}{$\begin{array}{l}\text { Reference Temperature of } \\
\text { Oysters } \\
7^{\circ} \mathrm{C}( \pm 1)\left[45^{\circ} \mathrm{F}( \pm 2)\right]\end{array}$} & $44^{\circ} \mathrm{F}$ & $46^{\circ} \mathrm{F}$ & $44^{\circ} \mathrm{F}$ & $47^{\circ} \mathrm{F}$ & $45.5^{\circ} \mathrm{F}$ & & & & & \\
\hline \multicolumn{2}{|c|}{ 3. Tare Weight of Package } & 0.060 & 0.060 & 0.060 & 0.059 & 0.060 & & & & & \\
\hline \multicolumn{2}{|c|}{$\begin{array}{l}\text { 4. Net Weight of Oysters \& } \\
\text { Liquid (Step } 2-\text { Step } 3=\text { ) }\end{array}$} & 0.811 & 0.824 & 0.86 & 0.81 & 0.803 & & & & & \\
\hline \multicolumn{2}{|c|}{$\begin{array}{l}\text { 5. Weight of Receiving Pan and } \\
\text { Drained Liquid }\end{array}$} & 12.020 & 12.121 & 12.120 & 12.031 & 12.242 & & & & & \\
\hline \multicolumn{2}{|c|}{$\begin{array}{l}\text { 6. Weight of Free Liquid (Step } 5 \\
\text { - Step } 1=\text { ) }\end{array}$} & 0.179 & 0.28 & 0.279 & 0.19 & 0.401 & & & & & \\
\hline \multicolumn{2}{|c|}{$\begin{array}{l}\text { 7. Percentage (\%) of Free Liquid } \\
\text { (Step } 6 \div \text { Step } 4 \times 100=\text { ) }\end{array}$} & $22 \%$ & $33 \%$ & $32 \%$ & $23 \%$ & $49 \%$ & & & & & \\
\hline \multicolumn{12}{|c|}{ Net Volume } \\
\hline \multicolumn{12}{|c|}{$\begin{array}{l}\text { 1. Test the oysters at the temperature of } 7{ }^{\circ} \mathrm{C}( \pm 1)\left[45^{\circ} \mathrm{F}( \pm 2)\right] \text {. } \\
\text { 2. Establish the level of fill of the package using a depth gage. } \\
\text { 3. Empty and dry the package. } \\
\text { 4. Refill the package with water to the level of the depth gage. } \\
\text { 5. Record the amount of delivered water and then sum the quantit }\end{array}$} \\
\hline & & \multicolumn{10}{|c|}{ Quantity of Water Delivered into Package } \\
\hline & & Pkg 1 & Pkg 2 & Pkg 3 & Pkg 4 & Pkg 5 & Pkg 6 & Pkg 7 & Pkg 8 & Pkg 9 & Pkg 10 \\
\hline \multicolumn{12}{|l|}{ 8. Flask Size } \\
\hline \multicolumn{12}{|l|}{ 9. Flask Size } \\
\hline \multicolumn{12}{|l|}{ 10. Graduate or Cylinder } \\
\hline \multicolumn{12}{|l|}{ 11. Graduate or Cylinder } \\
\hline \multicolumn{2}{|l|}{ 12. Total $(8+9+10=)$} & & & & & & & & & & \\
\hline Comments: & & & & & & & & & & & \\
\hline
\end{tabular}




\title{
Appendix D. AOSA Rules for Testing Seeds
}

\section{AOSA Rules for Testing Seeds - Section 2: Preparation of Working Samples}

\author{
Volume 1. Principles and Procedures \\ (Provided by the Association of Official Seed A nalyst)
}

\section{SECTION 2: PREPARATION OF WORKING SAMPLES}

The laboratory analysis for law enforcement, labeling, and general information as to seed quality, should determine the following for the sample analyzed: (1) the purity composition, (2) the rate of occurrence of noxious-weed seeds per unit weight, and (3) the percentage germination of the pure seed under consideration. A dditional information, such as, seed count, detection of seed treatment, bulk examination for contaminants, tetrazolium viability, detection of fungal endophtyes, and seed moisture content may be determined using approved procedures.

\subsection{Definitions}

(1) Seed unit: the structure usually regarded as a seed in planting practices and in commercial channels. Refer to section 3.2 e for pure seed unit descriptions.

(2) Working samples:

(a) Purity working sample: the sub-sample taken from the submitted sample on which the purity analysis is performed.

\section{$2.2 \quad$ Obtaining the working sample}

The working sample on which the actual analysis is performed shall be taken from the submitted sample in such a manner that it will be representative. A suitable type of mechanical divider (conical, centrifugal, riffle, etc.) should be used. To avoid damage when dividing large-seeded crop kinds such as beans, peas, etc., prevent the seeds from falling great distances onto hard surfaces.

a. Mechanical dividers. - This method is suitable for most kinds of seeds. The apparatus divides a sample into two approximately equal parts. The submitted sample is mixed by passing it through the divider, recombining the two parts and passing the whole sample through a second time and similarly a third time. After mixing, the sample shall be reduced by passing the seed through the divider repeatedly, removing half the sample on each occasion. This process of successive halving is continued until a working sample of approximately, but not less than the minimum weight(s) stated in Table 2A is obtained.

U se of compressed air or a vacuum is highly recommended for cleaning mechanical dividers. 
(1) Centrifugal divider (Gamet type): This divider is suitable for all kinds of seed though it is not recommended for oilseeds (such as rapeseed, canola, mustards, flax) and kinds susceptible to damage (such as peas, soybeans, etc) and the extremely chaffy types.

The divider makes use of centrifugal force to mix and scatter seeds over the dividing surface. The seed flows downward through a hopper onto a shallow rubber cup or spinner. Upon rotation of the spinner by an electric motor the seeds are thrown out by centrifugal force and fall downward. The circle or area where the seeds fall is equally divided into two parts by a stationary baffle so that approximately half the seeds fall in one spout and half in the other spout. The centrifugal divider tends to give variable results when not carefully operated, and therefore the following procedure must be used:

(a) Preparation of the apparatus:

(i) Level the divider using the adjustable feet.

(ii) Check the divider and four containers for cleanliness. Note that seeds can be trapped under the spinner and become a source of contamination.

(b) Sample mixing:

(i) Place a container under each spout.

(ii) Feed the whole sample into the hopper; when filling the hopper, the seed must al ways be poured centrally.

(iii) After the sample has been poured into the hopper, the spinner is operated and the seed passes into the two containers. Turn off spinner.

(iv) Full containers are replaced by empty containers. The contents of the two full containers are fed centrally into the hopper together, the seed being allowed to blend as it flows in. The spinner is operated.

(v) The sample mixing procedure is repeated at least once more.

(c) Sample reduction:

(i) Full containers are replaced by empty containers. The contents of one full container are set aside and the contents of the other container are fed into the hopper. The spinner is operated.

(ii) The successive halving process is continued until the working sample(s) of not less than the minimum weight(s) required stated in Table $2 \mathrm{~A}$ are obtained.

(iii) Ensure that the divider and containers are clean after each mixing operation.

(2) Soil/Riffle divider: This divider is suitable for most kinds of seed. For round-seeded kinds such as Brassica species, the collection containers should be covered to prevent the seeds from bouncing out.

This divider consists of a hopper with attached channels or ducts, a frame to hold the hopper, four collection containers and a pouring pan. Ducts or channels lead from the hopper to the collection containers, alternate ones leading to opposite sides. Riffle dividers are available in different sizes for different sizes of seed. The width and number of channels and spaces are important. The minimum width of the channels must be at least two times the largest diameter of the seed or any possible contaminants being mixed.

This apparatus, similar to the centrifugal divider, divides the sample into approximately equal parts. 
(a) Preparation of the apparatus:

(i) Place the riffle divider on a firm, level clean surface. Ensure the divider is level.

(ii) Ensure that the divider and the four sample collection containers are clean. Check all channels, joints and seams of the divider and collection containers to ensure there are no seeds or other plant matter present before each use.

(iii) Two clean empty collection containers shall be placed under the channels to receive the mixed seed.

(b) Sample mixing:

(i) Pour the whole sample into the divider by running the seed backwards and forwards along the edge of the divider so that all the channels and spaces of the divider receive an equal amount of seed.

(ii) The two full containers shall be replaced with two clean empty containers.

(iii) The contents of one full container shall be poured into the divider by holding the long edge of the pan against the long edge of the riffle hopper and then rotating the bottom up so that the seeds pour across all channels at the same time, followed by the other full container using the same procedure.

(iv) This process of mixing the entire submitted sample shall be repeated at least one more time before successive halving begins.

(c) Sample reduction:

(i) The contents of one full container are set aside. Empty containers are placed under each channel, and the contents of the other container is poured into the hopper by holding the long edge of the pan against the long edge of the riffle hopper and then rotating the bottom up so that the seeds pour across all channels at the same time.

(ii) The successive halving process is continued until the working sample(s) of not less than the minimum weight(s) required stated in Table $2 \mathrm{~A}$ are obtained.

(iii) Ensure that the divider and collection containers are clean after each mixing operation. Check all channels of the divider, the joints and seams.

(3) Boerner divider: This divider is suitable for most kinds of seed, including chaffy species, peas, beans, soybeans, etc.

This divider consists of a hopper, a cone, and a series of baffles which direct the seed into two spouts. The baffles are arranged in a circle at the top and form equal width alternate channels and spaces. The channels lead to one spout, the spaces to the other. The width and number of channels and spaces are important. Five channels and spaces should be regarded as a minimum. The more channels the better but the minimum width of the channels must be at least two times the largest diameter of the seed or any possible contaminants being mixed.

(a) Preparation of the apparatus: Ensure that the divider and the two sample collecting pans are clean.

(b) Sample mixing:

(i) Place a collecting pan under each spout.

(ii) Close the valve at the bottom of the divider.

(iii) Pour the seed centrally into the hopper. 
(iv) Quickly open the valve. Gravity will distribute the seed evenly through the channels and spaces.

(v) To mix the seed, repeat the steps at least twice for free flowing seed and three times for chaffy grasses.

(c) Sample reduction: The contents of one full collection pan are set aside. Repeat steps in 2 "sampling mixing". To improve the randomness of reduction, choose collection pans from alternate sides for the successive halving process. The successive halving process is continued until the working sample(s) of not less than the minimum weight(s) required stated in Table $2 \mathrm{~A}$ are obtained.

\section{b. Non-mechanical methods.}

(2) Hand-halving method: This method can be used when a proper mechanical divider is not available.

Procedure:

(a) Seed is poured evenly onto a clean smooth surface.

(b) The sample shall be thoroughly mixed using a flat-edged spatula and placed into a pile.

(c) The pile shall be divided in half using a straight edge or ruler.

(d) Each half portion is divided in half.

(e) Each of the portions is divided into half again. There are now eight portions.

(f) A rrange the eight portions into two rows of four.

(g) A Iternate portions should be combined to obtain two halves for example, combine the first portion from Row 1 with the second portion from Row 2. Remove the remaining four portions.

(h) Repeat Steps (a) to (g) until sufficient portions of seed are taken to constitute a working sample(s) of not less than the minimum weight(s) required stated in Table $2 \mathrm{~A}$ are obtained.

\subsection{Size of working samples.}

a. Weighing the working sample. - The weight of the working sample shall be determined to the number of decimal places indicated below:

\begin{tabular}{|c|c|}
\hline $\begin{array}{c}\text { Weight of Working Sample in } \\
\text { Grams }\end{array}$ & $\begin{array}{c}\text { Number of } \\
\text { Decimal Places }\end{array}$ \\
\hline \hline Less than 1.000 & 4 \\
\hline 1.000 to 9.999 & 3 \\
\hline 10.00 to 99.99 & 2 \\
\hline 100.0 to 999.9 & 1 \\
\hline 1000 or more & 0 \\
\hline
\end{tabular}




\title{
AOSA Rules for Testing Seeds - Section 12: Mechanical Seed Count
}

\author{
Volume 1. Principles and Procedures
}

(Provided by the Association of Official Seed A nalyst)

\section{SECTION 12: MECHANICAL SEED COUNT}

The following method shall be employed when using a mechanical seed counter to determine the number of seeds contained in a sample of soybean (Glycine max), corn (Zea mays), wheat (Triticum aestivum) and field bean (Phaseolus vulgaris).

\subsection{Samples.}

Samples for testing shall be of at least 500 grams for soybean, corn and field beans and 100 grams for wheat and received in moisture proof containers. Samples shall be retained in moisture proof containers until the weight of the sample prepared for purity analysis is recorded.

\subsection{Seed counter calibration.}

The seed counter shall be calibrated daily prior to use.

(a) Prepare a calibration sample by counting 10 sets of 100 seeds. V isually examine each set to insure that it contains whole seeds. Combine the 10 sets of seeds to make a 1,000 seed calibration sample. The seeds of the calibration sample should be approximately the same size and shape as the seeds in a sample being tested. If the seeds in a sample being tested are noticeably different in size or shape from those in the calibration sample, prepare another calibration sample with seeds of the appropriate size and shape. Periodically re-examine the calibration samples to insure that no seeds have been lost or added.

(b) Carefully pour the 1,000 seed calibration sample into the seed counter. Start the counter and run it until all the seeds have been counted. The seeds should not touch as they run through the counter. Record the number of seeds as displayed on the counter read out. The seed count should not vary more than \pm 2 seeds from 1,000. If the count is not within this tolerance, clean the mirrors, adjust the feed rate and/or reading sensitivity. Rerun the calibration sample until it is within the \pm 2 seed tolerance. If the seed counter continues to fail the calibration procedure and the calibration sample has been checked to ensure that it contains 1,000 seeds, do not use the counter until it has been repaired.

\subsection{Sample preparation.}

Immediately after opening the moisture proof container, mix and divide the submitted sample, in accordance with Section 2.2, to obtain a sample for purity analysis and record the weight of this sample in grams to the appropriate number of decimal places (refer to Section 2.3 a). Conduct the purity analysis to obtain pure seed for the seed count test. 


\subsection{Conducting the test.}

A fter the seed counter has been calibrated, test the pure seed portion from the purity test and record the number of seeds in the sample.

\subsection{Calculation of results.}

Calculate the number of seeds per pound to the nearest whole number using the following formula:

$$
\text { Number of seeds per pound }=\quad \frac{453.6 \mathrm{~g} / \mathrm{lb} \times \text { no. of seeds counted }}{\text { weight }(\mathrm{g}) \text { of sample analyzed for purity }}
$$

\subsection{Tolerances for results from different laboratories.}

M ultiply the labeled seed count or first seed count test result by four percent for soybean samples, two percent for corn (round, flat or plateless) samples, five percent for field bean samples and three percent for wheat samples. Express the tolerance (the number of seeds) to the nearest whole number. Consider the results of two tests in tolerance if the difference, expressed as the number of seeds, is equal to or less than the tolerance.

\section{Example:}

Kind of seed: Corn

Label claim (1st test): $\quad 2275$ seed/lb

Lab Test (2nd test): Purity working weight $=500.3 \mathrm{~g}$

Seed count of pure seed $=2479$ seeds

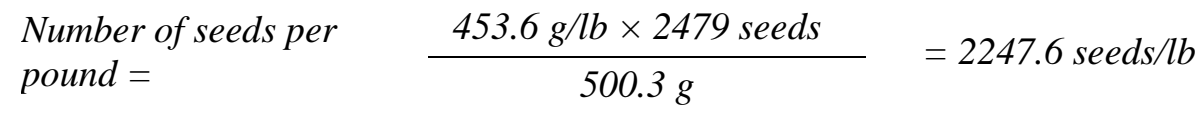

Rounded to the nearest whole number $=2248$ seeds $/ \mathrm{lb}$

Calculate tolerance value for corn:

$$
\begin{gathered}
\text { multiply label claim by } 2 \% \\
2275 \text { seeds } / \text { lb } \times 0.02=45.5 \text { seeds } / l b ; \\
\text { rounded to the nearest whole number }=46 \text { seeds } / \mathrm{lb}
\end{gathered}
$$

Determine the difference between label claim and lab test:

$$
2275 \text { seeds } / l b-2248 \text { seeds } / l b=27 \text { seeds } / l b
$$

The difference between the lab test (2nd test) and the label claim (1st test) is less than the tolerance $(27<46)$; therefore, the two results are in tolerance. 


\section{Appendix E. General Tables of Units of Measurement}

These tables have been prepared for the benefit of those requiring tables of units for occasional ready reference. In Section 4. Tables of U nits of M easurement of this A ppendix, the tables are carried out to a large number of decimal places and exact values are indicated by underlining. In most of the other tables, only a limited number of decimal places are given, therefore making the tables better adapted to the average user.

\section{Section 1. Tables of Metric Units of Measurement}

In the metric system of measurement, designations of multiples and subdivisions of any unit may be arrived at by combining with the name of the unit the prefixes deka, hecto, and kilo meaning, respectively, 10, 100, and 1000, and deci, centi, and milli, meaning, respectively, one-tenth, one-hundredth, and one-thousandth. In some of the following metric tables, some such multiples and subdivisions have not been included for the reason that these have little, if any currency in actual usage.

In certain cases, particularly in scientific usage, it becomes convenient to provide for multiples larger than 1000 and for subdivisions smaller than one-thousandth. Accordingly, the following prefixes have been introduced and these are now generally recognized:

$\begin{array}{llllll}\text { yotta, } & (\mathrm{Y}) & \text { meaning } 10^{24} & \text { deci, } & (\mathrm{d}), & \text { meaning } 10^{-1} \\ \text { zetta, } & (\mathrm{Z}), & \text { meaning } 10^{21} & \text { centi, } & (\mathrm{c}), & \text { meaning } 10^{-2} \\ \text { exa, } & (\mathrm{E}), & \text { meaning } 10^{18} & \text { milli, } & (\mathrm{m}), & \text { meaning } 10^{-3} \\ \text { peta, } & (\mathrm{P}), & \text { meaning } 10^{15} & \text { micro, } & (\mathrm{f}), & \text { meaning } 10^{-6} \\ \text { tera, } & (\mathrm{T}), & \text { meaning } 10^{12} & \text { nano, } & (\mathrm{n}), & \text { meaning } 10^{-9} \\ \text { giga, } & (\mathrm{G}), & \text { meaning } 10^{9} & \text { pico, } & (\mathrm{p}), & \text { meaning } 10^{-12} \\ \text { mega, } & (\mathrm{M}), & \text { meaning } 10^{6} & \text { femto, } & (\mathrm{f}), & \text { meaning } 10^{-15} \\ \text { kilo, } & (\mathrm{k}), & \text { meaning } 10^{3} & \text { atto, } & (\mathrm{a}), & \text { meaning } 10^{-18} \\ \text { hecto, } & (\mathrm{h}), & \text { meaning } 10^{2} & \text { zepto, } & (\mathrm{z}), & \text { meaning } 10^{-21} \\ \text { deka, } & (\mathrm{da}), & \text { meaning } 10^{1} & \text { yocto, } & (\mathrm{y}), & \text { meaning } 10^{-24}\end{array}$

Thus a kilometer is 1000 meters and a millimeter is 0.001 meter.

\section{Units of Length}

10 millimeters $(\mathrm{mm})$

10 centimeters

10 decimeters

10 meters

10 dekameters

10 hectometers
$=1$ centimeter $(\mathrm{cm})$

$=1$ decimeter $(\mathrm{dm})=100$ millimeters

$=1$ meter $(\mathrm{m})=1000$ millimeters

$=1$ dekameter (dam)

$=1$ hectometer $(\mathrm{hm})=100$ meters

$=1$ kilometer $(\mathrm{km})=1000$ meters 


\section{Units of Area}

\author{
100 square millimeters $\left(\mathrm{mm}^{2}\right)$ \\ 100 square centimeters \\ 100 square decimeters \\ 100 square meters \\ 100 square dekameters \\ 100 square hectometers
}

$$
\begin{aligned}
& =1 \text { square centimeter }\left(\mathrm{cm}^{2}\right) \\
& =1 \text { square decimeter }\left(\mathrm{dm}^{2}\right) \\
& =1 \text { square meter }\left(\mathrm{m}^{2}\right) \\
& =1 \text { square dekameter }\left(\mathrm{dam}^{2}\right)=1 \text { are } \\
& =1 \text { square hectometer }\left(\mathrm{hm}^{2}\right)=1 \text { hectare (ha) } \\
& =1 \text { square kilometer }\left(\mathrm{km}^{2}\right)
\end{aligned}
$$

\section{Units of Liquid Volume}

10 milliliters $(\mathrm{mL})$

$=1$ centiliter $(\mathrm{CL})$

10 centiliters

10 deciliters

$=1$ deciliter $(\mathrm{dL})=100$ milliliters

10 liters

$=1$ liter $^{1}=1000$ milliliters

$=1$ dekaliter (daL)

10 dekaliters

$=1$ hectoliter $(\mathrm{hL})=100$ liters

10 hectoliters

$=1$ kiloliter $(\mathrm{kL})=1000$ liters

\section{Units of Volume}

1000 cubic millimeters $\left(\mathrm{mm}^{3}\right)$

$=1$ cubic centimeter $\left(\mathrm{cm}^{3}\right)$

1000 cubic centimeters

$=1$ cubic decimeter $\left(\mathrm{dm}^{3}\right)$

$=1000000$ cubic millimeters

1000 cubic decimeters

$=1$ cubic meter $\left(\mathrm{m}^{3}\right)$

$=1000000$ cubic centimeters

$=1000000000$ cubic millimeters

\section{Units of Mass}

10 milligrams $(\mathrm{mg})$

$$
\begin{aligned}
& =1 \text { centigram }(\mathrm{cg}) \\
& =1 \text { decigram }(\mathrm{dg})=100 \text { milligrams } \\
& =1 \text { gram }(\mathrm{g})=1000 \text { milligrams } \\
& =1 \text { dekagram }(\mathrm{dag})
\end{aligned}
$$

\footnotetext{
${ }^{1}$ By action of the $12^{\text {th }}$ General Conference on W eights and M easures (1964), the liter is a special name for the cubic decimeter.
} 


\section{Units of Mass}

10 dekagrams

10 hectograms

1000 kilograms
$=1$ hectogram $(\mathrm{hg})=100$ grams

$=1$ kilogram $(\mathrm{kg})=1000$ grams

$=1$ megagram $(\mathrm{M} \mathrm{g})$ or 1 metric ton $(\mathrm{t})$

\section{Section 2. Tables of U.S. Units of Measurement ${ }^{2}$}

In these tables where foot or mile is underlined, it is survey foot or U.S. statute mile rather than international foot or mile that is meant.

\section{Units of Length}

12 inches (in)

3 feet

$16^{1 / 2}$ feet

40 rods

8 furlongs

1852 meters (m)
$=1$ foot $(\mathrm{ft})$

$=1$ yard $(\mathrm{yd})$

$=1 \mathrm{rod}(\mathrm{rd})$, pole, or perch

$=1$ furlong (fur) $=660$ feet

$=1$ U.S. statute mile $(\mathrm{mi})=5280$ feet

$=6076.11549$ feet (approximately)

$=1$ international nautical mile

\section{Units of Area $^{3}$}

144 square inches $\left(\mathrm{in}^{2}\right)$

9 square feet

$272^{1 / 4}$ square feet

160 square rods

640 acres

1 mile square

6 miles square
$=1$ square foot $\left(\mathrm{ft}^{2}\right)$

$=1$ square yard $\left(\mathrm{yd}^{2}\right)$

$=1296$ square inches

$=1$ square $\operatorname{rod}\left(\mathrm{rd}^{2}\right)$

$=1$ acre $=43560$ square feet

$=1$ square mile $\left(\mathrm{mi}^{2}\right)$

$=1$ section of land

$=1$ township

$=36$ sections $=36$ square $\underline{\text { miles }}$

\footnotetext{
${ }^{2}$ This section lists units of measurement that have traditionally been used in the U nited States. In keeping with the O mnibus Trade and Competitiveness Act of 1988, the ultimate objective is to make the International System of U nits the primary measurement system used in the U nited States.

${ }^{3}$ Squares and cubes of customary but not of metric units are sometimes expressed by the use of abbreviations rather than symbols. For example, sq ft means square foot, and cu ft means cubic foot.
} 


\section{Units of Volume ${ }^{3}$}

1728 cubic inches $\left(\mathrm{in}^{3}\right)$

$=1$ cubic foot $\left(\mathrm{ft}^{3}\right)$

27 cubic feet

$=1$ cubic yard $\left(\mathrm{yd}^{3}\right)$

\section{Gunter's or Surveyors Chain Units of Measurement}

$\begin{array}{ll}0.66 \text { foot }(\mathrm{ft}) & =1 \text { link }(\mathrm{li}) \\ 100 \text { links } & =1 \text { chain }(\mathrm{ch}) \\ & =4 \text { rods }=66 \underline{\text { feet }} \\ 80 \text { chains } & =1 \text { U.S. statute mile }(\mathrm{mi}) \\ & =320 \text { rods }=5280 \text { feet }\end{array}$

\section{Units of Liquid Volume ${ }^{4}$}

4 gills (gi)

$=1$ pint $(\mathrm{pt})=28.875$ cubic inches $\left(\mathrm{in}^{3}\right)$

2 pints

$=1$ quart $(q t)=57.75$ cubic inches

4 quarts

$=1$ gallon (gal) = 231 cubic inches

$=8$ pints $=32$ gills

\section{Apothecaries Units of Liquid Volume}

$\begin{array}{ll}60 \text { minims } & =1 \text { fluid dram ( } \mathrm{fl} \text { dr or } f 3) \\ & =0.2256 \text { cubic inch }\left(\mathrm{in}^{3}\right) \\ & =1 \text { fluid drams } \\ & =1.8047 \text { cubic inches } \\ 16 \text { fluid ounces } & =1 \text { pint }(\mathrm{pt}) \\ & =28.875 \text { cubic inches } \\ & =128 \text { fluid drams }\end{array}$

\footnotetext{
${ }^{3}$ Squares and cubes of customary but not of metric units are sometimes expressed by the use of abbreviations rather than symbols. For example, sq ft means square foot, and cu ft means cubic foot.

${ }^{4}$ When necessary to distinguish the liquid pint or quart from the dry pint or quart, the word "liquid" or the abbreviation "Iiq" should be used in combination with the name or abbreviation of the liquid unit.
} 


$$
\begin{aligned}
2 \text { pints } & =1 \text { quart }(q t)=57.75 \text { cubic inches } \\
& =32 \text { fluid ounces }=256 \text { fluid drams } \\
& =1 \text { gallon (gal) }=231 \text { cubic inches } \\
& =128 \text { fluid ounces }=1024 \text { fluid drams }
\end{aligned}
$$

\section{Units of Dry Volume ${ }^{5}$}

$\begin{array}{ll}2 \text { pints (pt) } & =1 \text { quart }(\mathrm{qt})=67.2006 \text { cubic inches }\left(\mathrm{in}^{3}\right) \\ 8 \text { quarts } & =1 \text { peck }(\mathrm{pk})=537.605 \text { cubic inches } \\ & =16 \text { pints } \\ & =1 \text { bushel }(\mathrm{bu})=2150.42 \text { cubic inches } \\ & =32 \text { quarts }\end{array}$

\section{Avoirdupois Units of Mass ${ }^{6}$}

(The "grain" is the same in avoirdupois, troy, and apothecaries units of mass.)

$1 \mu \mathrm{lb}$

$27^{11} / 32$ grains (gr)

16 drams

16 ounces

100 pounds

$$
\begin{aligned}
& =0.000001 \text { pound }(\mathrm{lb}) \\
& =1 \mathrm{dram}(\mathrm{dr}) \\
& =1 \text { ounce }(\mathrm{oz}) \\
& =4371 \frac{1}{2} \text { grains } \\
& =1 \text { pound }(\mathrm{lb}) \\
& =256 \text { drams } \\
& =7000 \text { grains } \\
& =1 \text { hundredweight }(\mathrm{cwt})^{7}
\end{aligned}
$$

\footnotetext{
${ }^{5}$ When necessary to distinguish dry pint or quart from the liquid pint or quart, the word "dry" should be used in combination with the name or abbreviation of the dry unit.

${ }^{6}$ When necessary to distinguish the avoirdupois dram from the apothecaries dram, or to distinguish the avoirdupois dram or ounce from the fluid dram or ounce, or to distinguish the avoirdupois ounce or pound from the troy or apothecaries ounce or pound, the word "avoirdupois" or the abbreviation "avdp" should be used in combination with the name or abbreviation of the avoirdupois unit.

7 When the terms "hundredweight" and "ton" are used unmodified, they are commonly understood to mean the 100-pound hundredweight and the 2000-pound ton, respectively; these units may be designated "net" or "short" when necessary to distinguish them from the corresponding units in gross or long measure.
} 


\section{Avoirdupois Units of Mass ${ }^{6}$}

(The "grain" is the same in avoirdupois, troy, and apothecaries units of mass.)

20 hundredweights

$$
=1 \text { ton }(\operatorname{tn})^{8}
$$$$
=2000 \text { pounds }^{7}
$$

In "gross" or "long" measure, the following values are recognized:

$$
\begin{aligned}
112 \text { pounds }(\mathrm{lb}) & =1 \text { gross or long hundredweight }(\mathrm{cwt})^{7} \\
20 \text { gross or long hundredweights } & =1 \text { gross or long ton } \\
& =2240 \text { pounds }^{7}
\end{aligned}
$$

\section{Troy Units of Mass}

(The "grain" is the same in avoirdupois, troy, and apothecaries units of mass.)

24 grains (gr)

20 pennyweights

12 ounces troy

$$
=1 \text { pennyweight }(\mathrm{dwt})
$$$$
=1 \text { ounce troy }(0 z \mathrm{t})=480 \text { grains }
$$$$
=1 \text { pound troy }(\mathrm{lb} \mathrm{t})
$$$$
=240 \text { pennyweights }=5760 \text { grains }
$$

\section{Apothecaries Units of Mass}

(The "grain" is the same in avoirdupois, troy, and apothecaries units of mass.)

$$
\begin{array}{ll}
20 \text { grains (gr) } & =1 \text { scruple (s ap or } \ni) \\
3 \text { scruples } & =1 \text { dram apothecaries (dr ap or } 3 \text { ) } \\
& =60 \text { grains } \\
8 \text { drams apothecaries } & =1 \text { ounce apothecaries ( } 0 z \text { ap or } 3 \text { ) } \\
& =24 \text { scruples }=480 \text { grains }
\end{array}
$$

\footnotetext{
${ }^{6}$ When necessary to distinguish the avoirdupois dram from the apothecaries dram, or to distinguish the avoirdupois dram or ounce from the fluid dram or ounce, or to distinguish the avoirdupois ounce or pound from the troy or apothecaries ounce or pound, the word "avoirdupois" or the abbreviation "avdp" should be used in combination with the name or abbreviation of the avoirdupois unit.

7 When the terms "hundredweight" and "ton" are used unmodified, they are commonly understood to mean the 100-pound hundredweight and the 2000-pound ton, respectively; these units may be designated "net" or "short" when necessary to distinguish them from the corresponding units in gross or long measure.

${ }^{8}$ As of January 1, 2014, "tn" is the required abbreviation for short ton. Devices manufactured between January 1, 2008, and December 31, 2013, may use an abbreviation other than "tn" to specify short ton. This provision is a NIST Handbook 44, "Specifications, Tolerances, and Other Technical Requirements for W eighing and M easuring Devices" in A ppendix C. General Table of U nits of M easurement.
} 


\section{Apothecaries Units of Mass}

(The "grain" is the same in avoirdupois, troy, and apothecaries units of mass.)

12 ounces apothecaries

$$
\begin{aligned}
& =1 \text { pound apothecaries (lb ap) } \\
& =96 \text { drams apothecaries } \\
& =288 \text { scruples }=5760 \text { grains }
\end{aligned}
$$

\section{Section 3. Notes on British Units of Measurement}

In Great B ritain, the yard, the avoirdupois pound, the troy pound, and the apothecaries pound are identical with the units of the same names used in the U nited States. The tables of B ritish linear measure, troy mass, and apothecaries mass are the same as the corresponding U nited States tables, except for the B ritish spelling "drachm" in the table of apothecaries mass. The table of B ritish avoirdupois mass is the same as the U nited States table up to 1 pound; above that point the table reads:

14 pounds

2 stones

4 quarters

20 hundredweight

$$
\begin{aligned}
& =1 \text { stone } \\
& =1 \text { quarter }=28 \text { pounds } \\
& =1 \text { hundredweight }=112 \text { pounds } \\
& =1 \text { ton }=2240 \text { pounds }
\end{aligned}
$$

The present British gallon and bushel - known as the "Imperial gallon" and "Imperial bushel" - are, respectively, about $20 \%$ and $3 \%$ larger than the United States gallon and bushel. The Imperial gallon is defined as the volume of 10 avoirdupois pounds of water under specified conditions, and the Imperial bushel is defined as 8 Imperial gallons. A lso, the subdivision of the Imperial gallon as presented in the table of British apothecaries fluid measure differs in two important respects from the corresponding United States subdivision, in that the Imperial gallon is divided into 160 fluid ounces (whereas the United States gallon is divided into 128 fluid ounces), and a "fluid scruple" is included. The full table of B ritish measures of capacity (which are used alike for liquid and for dry commodities) is as follows:

$\begin{array}{ll}4 \text { gills } & =1 \text { pint } \\ 2 \text { pints } & =1 \text { quart } \\ 4 \text { quarts } & =1 \text { gallon } \\ 2 \text { gallons } & =1 \text { peck } \\ 8 \text { gallons (4 pecks) } & =1 \text { bushel } \\ 8 \text { bushels } & =1 \text { quarter }\end{array}$

The full table of British apothecaries measure is as follows:

$\begin{array}{ll}20 \text { minims } & =1 \text { fluid scruple } \\ 3 \text { fluid scruples } & =1 \text { fluid drachm } \\ & =60 \text { minims }\end{array}$


Handbook 133, Checking the Net Contents of Packaged Goods, (2015)

$\begin{array}{ll}8 \text { fluid drachms } & =1 \text { fluid ounce } \\ 20 \text { fluid ounces } & =1 \text { pint } \\ 8 \text { pints } & =1 \text { gallon (160 fluid ounces) }\end{array}$

Section 4. Tables of Units of Measurement

Units of Length - International Measure ${ }^{9}$

(all underlined figures are exact)

\begin{tabular}{|c|c|c|c|c|c|c|}
\hline Units & Inches & Feet & Yards & Miles & Centimeters & Meters \\
\hline 1 inch & $\underline{1}$ & 0.08333333 & 0.02777778 & 0.00001578283 & $\underline{2.54}$ & $\underline{0.0254}$ \\
\hline 1 foot & $\underline{12}$ & $\underline{1}$ & 0.3333333 & 0.0001893939 & $\underline{30.48}$ & $\underline{0.3048}$ \\
\hline 1 yard & $\underline{36}$ & $\underline{3}$ & $\underline{1}$ & 0.0005681818 & $\underline{91.44}$ & $\underline{0.9144}$ \\
\hline 1 mile & $\underline{63360}$ & $\underline{5280}$ & $\underline{1760}$ & $\underline{1}$ & $\underline{160934.4}$ & $\underline{1609.344}$ \\
\hline 1 centimeter $=$ & 0.3937008 & 0.03280840 & 0.01093613 & 0.000006213712 & $\underline{1}$ & $\underline{0.01}$ \\
\hline 1 meter & 39.37008 & 3.280840 & 1.093613 & 0.0006213712 & $\underline{100}$ & $\underline{1}$ \\
\hline
\end{tabular}

Units of Length - Survey Measure ${ }^{9}$

(all underlined figures are exact)

\begin{tabular}{|c|c|c|c|c|c|c|c|}
\hline \multicolumn{2}{|c|}{ Units } & Links & Feet & Rods & Chains & Miles & Meters \\
\hline 1 link & $=$ & $\underline{1}$ & $\underline{0.66}$ & $\underline{0.04}$ & $\underline{0.01}$ & $\underline{0.000125}$ & 0.2011684 \\
\hline 1 foot & $=$ & 1.515152 & $\underline{1}$ & 0.06060606 & 0.01515152 & 0.0001893939 & 0.3048006 \\
\hline $1 \mathrm{rod}$ & $=$ & $\underline{25}$ & $\underline{16.5}$ & $\underline{1}$ & $\underline{0.25}$ & $\underline{0.003125}$ & 5.029210 \\
\hline 1 chain & $=$ & $\underline{100}$ & $\underline{66}$ & $\underline{4}$ & $\underline{1}$ & $\underline{0.0125}$ & 20.11684 \\
\hline 1 mile & $=$ & 8000 & 5280 & $\underline{320}$ & $\underline{80}$ & $\underline{1}$ & 1609.347 \\
\hline 1 meter & $=$ & 4.970960 & 3.280833 & 0.1988384 & 0.04970960 & 0.0006213699 & $\underline{1}$ \\
\hline
\end{tabular}

\footnotetext{
${ }^{9}$ One international foot

$=0.999998$ survey foot (exactly)

One international mile

$=0.999998$ survey mile (exactly)
} 
Units of Area - International Measure ${ }^{10}$

(all underlined figures are exact)

\begin{tabular}{||lr|r|r|r||}
\hline \multicolumn{1}{|c|}{ Units } & \multicolumn{1}{|c|}{ Square Inches } & Square Feet & \multicolumn{1}{c|}{ Square Yards } \\
\hline \hline 1 square inch & $=$ & $\underline{1}$ & 0.006944444 & 0.000771 \\
1 square foot & $\underline{144}$ & 6049 \\
1 square yard & $=$ & $\underline{1296}$ & $\underline{1}$ \\
1 square mile & $=$ & $\underline{4014489600}$ & $\underline{9}$ & 0.1111111 \\
1 square centimeter & $=$ & 0.1550003 & $\underline{27878400}$ & $\underline{1}$ \\
1 square meter & $=$ & 1550.003 & 0.001076391 & $\underline{3097600}$ \\
\hline
\end{tabular}

Note: 1 survey foot $\quad=\quad={ }^{1200} / 3937$ meter $($ exactly $)$

1 international foot $\quad=12 \times 0.0254$ meter (exactly)

1 international foot $\quad=0.0254 \times 39.37$ survey foot (exactly)

\begin{tabular}{||ll|r|r|r||}
\hline \multicolumn{1}{|c|}{ Units } & \multicolumn{1}{|c|}{ Square Miles } & \multicolumn{1}{c||}{ Square Centimeters } & \multicolumn{1}{c|}{ Square Meters } \\
\hline \hline 1 square inch & $=$ & 0.0000000002490977 & $\underline{6.4516}$ & $\underline{0.00064516}$ \\
1 square foot & 0.00000003587006 & $\underline{929.0304}$ & $\underline{0.09290304}$ \\
1 square yard & $=$ & 0.0000003228306 & $\underline{8361.2736}$ & $\underline{0.83612736}$ \\
1 square mile & $=$ & $\underline{1}$ & $\underline{25899881103.36}$ & $\underline{2589988.110336}$ \\
1 square centimeter & $=$ & 0.00000000003861022 & $\underline{1}$ & $\underline{0.0001}$ \\
1 square meter & $=$ & 0.0000003861022 & $\underline{1000}$ \\
\hline \hline
\end{tabular}

\footnotetext{
${ }^{10}$ One square survey foot $\quad=1.000004$ square international feet

One square survey mile $\quad=1.000004$ square international miles
} 
Units of Area - Survey Measure ${ }^{10}$

(all underlined figures are exact)

\begin{tabular}{||rr|r|r|r|r||}
\hline \multicolumn{1}{|c|}{ Units } & \multicolumn{1}{|c|}{ Square Feet } & Square Rods & \multicolumn{1}{c|}{ Square Chains } & \multicolumn{1}{c|}{ Acres } \\
\hline \hline 1 square foot & $=$ & $\underline{1}$ & 0.003673095 & 0.0002295684 & 0.00002295684 \\
1 square rod & $=$ & $\underline{272.25}$ & $\underline{1}$ & $\underline{0.0625}$ & $\underline{0.00625}$ \\
1 square chain & $=$ & $\underline{4356}$ & $\underline{16}$ & $\underline{1}$ & $\underline{0.1}$ \\
1 acre & $=$ & $\underline{43560}$ & $\underline{160}$ & $\underline{10}$ & $\underline{6400}$ \\
1 square mile & $=$ & $\underline{27878400}$ & $\underline{102400}$ & $\underline{6}$ & $\underline{640}$ \\
1 square meter & $=$ & 10.76387 & 0.03953670 & 0.002471044 & 0.0002471044 \\
1 hectare & $=$ & 107638.7 & 395.3670 & 24.71044 & 2.471044 \\
\hline \hline
\end{tabular}

\begin{tabular}{||ll|r|r|r||}
\hline \multicolumn{1}{|c|}{ Units } & \multicolumn{1}{|c|}{ Square Miles } & \multicolumn{1}{c|}{ Square Meters } & \multicolumn{1}{c|}{ Hectares } \\
\hline \hline 1 square foot & $=$ & 0.00000003587006 & 0.09290341 & 0.000009290341 \\
1 square rod & $=$ & $\underline{0.000009765625}$ & 25.29295 & 0.002529295 \\
1 square chain & $=$ & $\underline{0.00015625}$ & 404.6873 & 0.04046873 \\
1 acre & $\underline{0.0015625}$ & $\underline{1}$ & 2589998 & 0.4046873 \\
1 square mile & $=$ & 0.0000003861006 & $\underline{1}$ & 258.9998 \\
1 square meter & $=$ & 0.003861006 & $\underline{10000}$ & $\underline{0.0001}$ \\
1 hectare & $=$ &
\end{tabular}

\footnotetext{
${ }^{10}$ One square survey foot $\quad=1.000004$ square international feet

One square survey mile $\quad=1.000004$ square international miles
} 
Units of Volume

(all underlined figures are exact)

\begin{tabular}{|c|c|c|c|c|}
\hline Units & & Cubic Inches & Cubic Feet & Cubic Yards \\
\hline 1 cubic inch & $=$ & $\underline{1}$ & 0.0005787037 & 0.00002143347 \\
\hline 1 cubic foot & $=$ & $\underline{1728}$ & $\underline{1}$ & 0.03703704 \\
\hline 1 cubic yard & $=$ & $\underline{46656}$ & $\underline{27}$ & $\underline{1}$ \\
\hline 1 cubic centimeter & $=$ & 0.06102374 & 0.00003531467 & 0.000001307951 \\
\hline 1 cubic decimeter & $=$ & 61.02374 & 0.03531467 & 0.001307951 \\
\hline 1 cubic meter & $=$ & 61023.74 & 35.31467 & 1.307951 \\
\hline
\end{tabular}

\begin{tabular}{||ll|r|r|r||}
\hline \multicolumn{1}{|c|}{ Units } & \multicolumn{1}{|c|}{$\begin{array}{c}\text { Milliliters } \\
\text { (Cubic Centimeters) }\end{array}$} & $\begin{array}{c}\text { Liters } \\
\text { (Cubic Decimeters) }\end{array}$ & \multicolumn{1}{c||}{ Cubic Meters } \\
\hline \hline 1 cubic inch & $=$ & $\underline{16.387064}$ & $\underline{0.016387064}$ & $\underline{0.000016387064}$ \\
1 cubic foot & $\underline{28316.846592}$ & $\underline{28.316846592}$ & $\underline{0.028316846592}$ \\
1 cubic yard & $=$ & $\underline{764554.857984}$ & $\underline{764.554857984}$ & $\underline{0.764554857984}$ \\
1 cubic centimeter & $=$ & $\underline{1}$ & $\underline{0.001}$ & $\underline{0.000001}$ \\
1 cubic decimeter & $=$ & $\underline{1000}$ & $\underline{1000000}$ & $\underline{1000}$ \\
1 cubic meter & $=$ & & & $\underline{0.001}$ \\
\hline
\end{tabular}


Handbook 133, Checking the Net Contents of Packaged Goods, (2015)

Units of Capacity or Volume - Dry Volume Measure

(all underlined figures are exact)

\begin{tabular}{||ll|r|r|r|r||}
\hline \multicolumn{1}{|c|}{ Units } & Dry Pints & Dry Quarts & Pecks & \multicolumn{1}{c||}{ Bushels } \\
\hline \hline 1 dry pint & $=$ & $\underline{1}$ & $\underline{0.5}$ & $\underline{0.0625}$ & $\underline{0.015625}$ \\
1 dry quart & $=$ & $\underline{2}$ & $\underline{1}$ & $\underline{0.125}$ & $\underline{0.03125}$ \\
1 peck & $=$ & $\underline{16}$ & $\underline{8}$ & $\underline{1}$ & $\underline{0.25}$ \\
1 bushel & $=$ & $\underline{64}$ & $\underline{32}$ & $\underline{4}$ \\
1 cubic inch & $=$ & 0.0297616 & 0.0148808 & 0.00186010 & 0.000465025 \\
1 cubic foot & $=$ & 51.42809 & 25.71405 & 3.214256 & 0.80356395 \\
1 liter & $=$ & 1.816166 & 0.9080830 & 0.1135104 & 0.02837759 \\
1 cubic meter & $=$ & 908.0830 & 113.5104 & 28.37759 \\
\hline \hline
\end{tabular}

\begin{tabular}{||ll|r|r|r|r||}
\hline \multicolumn{1}{|c|}{ Units } & \multicolumn{1}{|c|}{ Cubic Inches } & \multicolumn{1}{c|}{ Cubic Feet } & \multicolumn{1}{c|}{ Liters } & \multicolumn{1}{c|}{ Cubic Meters } \\
\hline \hline 1 dry pint & $=$ & $\underline{33.6003125}$ & 0.01944463 & 0.5506105 & 0.0005506105 \\
1 dry quart & $=$ & $\underline{67.200625}$ & 0.03888925 & 1.101221 & 0.001101221 \\
1 peck & $\underline{537.605}$ & 0.311114 & 8.809768 & 0.008809768 \\
1 bushel & $=$ & $\underline{2150.42}$ & 1.244456 & $\underline{35.23907016688}$ & $\underline{0.03523907}$ \\
1 cubic inch & $=$ & $\underline{1}$ & 0.0005787037 & $\underline{0.016387064}$ & $\underline{0.00001638706}$ \\
1 cubic foot & $=$ & $\underline{1728}$ & $\underline{1}$ & $\underline{28.316846592}$ & $\underline{0.0283168}$ \\
1 liter & $=$ & 61.02374 & 0.03531467 & $\underline{1}$ & $\underline{0.001}$ \\
1 cubic meter & $=$ & 35.31467 & $\underline{1000}$ & $\underline{1}$ \\
\hline
\end{tabular}


Units of Capacity or Volume - Liquid Volume Measure

(A II underlined figures are exact)

\begin{tabular}{|c|c|c|c|c|c|}
\hline \multicolumn{2}{|l|}{ Units } & Minims & Fluid Drams & Fluid Ounces & Gills \\
\hline 1 minim & $=$ & $\underline{1}$ & $\underline{0.01666667}$ & $\underline{0.002083333}$ & $\underline{0.0005208333}$ \\
\hline 1 fluid dram & $=$ & $\underline{60}$ & $\underline{1}$ & $\underline{0.125}$ & $\underline{0.03125}$ \\
\hline 1 fluid ounce & $=$ & $\underline{480}$ & $\underline{8}$ & $\underline{1}$ & $\underline{0.25}$ \\
\hline $1 \mathrm{gill}$ & $=$ & $\underline{1920}$ & $\underline{32}$ & $\underline{4}$ & $\underline{1}$ \\
\hline 1 liquid pint & $=$ & $\underline{7680}$ & $\underline{128}$ & $\underline{16}$ & $\underline{4}$ \\
\hline 1 liquid quart & $=$ & $\underline{15360}$ & $\underline{256}$ & $\underline{32}$ & $\underline{8}$ \\
\hline 1 gallon & $=$ & $\underline{61440}$ & $\underline{1024}$ & $\underline{128}$ & $\underline{32}$ \\
\hline 1 cubic inch & $=$ & 265.9740 & 4.432900 & 0.5541126 & 0.1385281 \\
\hline 1 cubic foot & $=$ & 459603.1 & 7660.052 & 957.5065 & 239.3766 \\
\hline 1 milliliter & $=$ & 16.23073 & 0.2705122 & 0.03381402 & 0.008453506 \\
\hline 1 liter & $=$ & 16230.73 & 270.5122 & 33.81402 & 8.453506 \\
\hline
\end{tabular}

\begin{tabular}{||ll|r|r|r|r||}
\hline \multicolumn{1}{|c|}{ Units } & \multicolumn{1}{|c|}{ Liquid Pints } & Liquid Quarts & \multicolumn{1}{c|}{ Gallons } & \multicolumn{1}{c|}{ Cubic Inches } \\
\hline \hline 1 minim & $=$ & 0.0001302083 & 0.00006510417 & 0.00001627604 & 0.003759766 \\
1 fluid dram & $=$ & $\underline{0.0078125}$ & $\underline{0.00390625}$ & $\underline{0.0009765625}$ & $\underline{0.22558594}$ \\
1 fluid ounce & $=$ & $\underline{0.0625}$ & $\underline{0.03125}$ & $\underline{0.0078125}$ & $\underline{1.8046875}$ \\
1 gill & $\underline{0.25}$ & $\underline{0.125}$ & $\underline{0.03125}$ & $\underline{7.21875}$ \\
1 liquid pint & $=$ & $\underline{0.5}$ & $\underline{0.125}$ & $\underline{28.875}$ \\
1 liquid quart & $=$ & $\underline{2}$ & $\underline{1}$ & $\underline{0.25}$ & $\underline{57.75}$ \\
1 gallon & $=$ & $\underline{8}$ & 0.01731602 & $\underline{1}$ & $\underline{231}$ \\
1 cubic inch & $=$ & 0.03463203 & 29.92208 & 7.480519 & 1 \\
1 cubic foot & $=$ & 59.84416 & 0.001056688 & 0.0002641721 & 1728 \\
1 milliliter & $=$ & 0.002113376 & 1.056688 & 0.2641721 & 0.06102374 \\
1 liter & $=$ & 2.113376 & & 61.02374 \\
\hline \hline
\end{tabular}


Handbook 133, Checking the Net Contents of Packaged Goods, (2015)

\begin{tabular}{||ll|r|r|r||}
\hline \multicolumn{1}{|c|}{ Units } & & \multicolumn{1}{c|}{ Cubic Feet } & Milliliters & \multicolumn{1}{|c|}{ Liters } \\
\hline \hline 1 minim & $=$ & 0.000002175790 & 0.06161152 & 0.00006161152 \\
1 fluid dram & $=$ & 0.0001305474 & 3.696691 & 0.003696691 \\
1 fluid ounce & $=$ & 0.001044379 & 29.57353 & 0.02957353 \\
1 gill & $=$ & 0.004177517 & 118.2941 & 0.1182941 \\
1 liquid pint & $=$ & 0.01671007 & 473.1765 & 0.4731765 \\
1 liquid quart & $=$ & 0.03342014 & 946.3529 & 0.9463529 \\
1 gallon & $=$ & 0.1336806 & 3785.411784 & 3.785412 \\
1 cubic inch & $=$ & 0.0005787037 & 16.38706 & 0.01638706 \\
1 cubic foot & $=$ & $\underline{1}$ & 28316.85 & $\underline{1}$ \\
1 milliliter & $=$ & 0.00003531467 & $\underline{1000}$ & $\underline{0.001}$ \\
1 liter & $=$ & 0.03531467 & $\underline{1}$ \\
\hline \hline
\end{tabular}

Units of Mass Not Less Than Avoirdupois Ounces

(all underlined figures are exact)

\begin{tabular}{|c|c|c|c|c|}
\hline Units & $\begin{array}{l}\text { Avoirdupois } \\
\text { Ounces }\end{array}$ & $\begin{array}{l}\text { Avoirdupois } \\
\text { Pounds }\end{array}$ & $\begin{array}{l}\text { Short Hundred- } \\
\text { weights }\end{array}$ & Short Tons \\
\hline 1 avoirdupois ounce $=$ & $\underline{1}$ & $\underline{0.0625}$ & $\underline{0.000625}$ & $\underline{0.00003125}$ \\
\hline 1 avoirdupois pound = & $\underline{16}$ & $\underline{1}$ & $\underline{0.01}$ & $\underline{0.0005}$ \\
\hline 1 short hundredweight= & $\underline{1600}$ & $\underline{100}$ & $\underline{1}$ & $\underline{0.05}$ \\
\hline 1 short ton & $\underline{32000}$ & $\underline{2000}$ & $\underline{20}$ & $\underline{1}$ \\
\hline 1 long ton & $\underline{35840}$ & $\underline{2240}$ & $\underline{22.4}$ & $\underline{1.12}$ \\
\hline 1 kilogram & 35.27396 & 2.204623 & 0.02204623 & 0.001102311 \\
\hline 1 metric ton & 35273.96 & 2204.623 & 22.04623 & 1.102311 \\
\hline
\end{tabular}




\begin{tabular}{||ll|r|r|r||}
\hline \multicolumn{1}{|c|}{ Units } & \multicolumn{1}{|c|}{ Long Tons } & \multicolumn{1}{c|}{ Kilograms } & \multicolumn{1}{c|}{ Metric Tons } \\
\hline \hline 1 avoirdupois ounce & $=$ & 0.00002790179 & $\underline{0.028349523125}$ & $\underline{0.000028349523125}$ \\
1 avoirdupois pound & $=$ & 0.0004464286 & $\underline{0.45359237}$ & $\underline{0.00045359237}$ \\
1 short hundredweight & $=$ & 0.04464286 & $\underline{45.359237}$ & $\underline{0.045359237}$ \\
1 short ton & $=$ & 0.8928571 & $\underline{907.18474}$ & $\underline{0.90718474}$ \\
1 long ton & $=$ & $\underline{1}$ & $\underline{1016.0469088}$ & $\underline{1.0160469088}$ \\
1 kilogram & $=$ & 0.0009842065 & $\underline{1}$ & $\underline{0.001}$ \\
1 metric ton & $=$ & 0.9842065 & $\underline{1000}$ \\
\hline \hline
\end{tabular}

Units of Mass Not Greater Than Pounds and Kilograms

(all underlined figures are exact)

\begin{tabular}{|c|c|c|c|c|c|}
\hline Units & & Grains & $\begin{array}{l}\text { Apothecaries } \\
\text { Scruples }\end{array}$ & Pennyweights & $\begin{array}{l}\text { Avoirdupois } \\
\text { Drams }\end{array}$ \\
\hline 1 grain & $=$ & $\underline{1}$ & $\underline{0.05}$ & 0.04166667 & 0.03657143 \\
\hline 1 apoth. scruple & $=$ & $\underline{20}$ & $\underline{1}$ & 0.8333333 & 0.7314286 \\
\hline 1 pennyweight & $=$ & $\underline{24}$ & $\underline{1.2}$ & $\underline{1}$ & 0.8777143 \\
\hline 1 avdp. dram & $=$ & $\underline{27.34375}$ & $\underline{1.3671875}$ & 1.139323 & $\underline{1}$ \\
\hline 1 apoth. dram & $=$ & $\underline{60}$ & $\underline{3}$ & $\underline{2.5}$ & 2.194286 \\
\hline 1 avdp. ounce & $=$ & 437.5 & $\underline{21.875}$ & 18.22917 & $\underline{16}$ \\
\hline 1 apoth. or troy oz. & $=$ & $\underline{480}$ & $\underline{24}$ & $\underline{20}$ & 17.55429 \\
\hline $\begin{array}{l}1 \text { apoth. or } \\
\text { troy pound }\end{array}$ & $=$ & $\underline{5760}$ & $\underline{288}$ & $\underline{240}$ & 210.6514 \\
\hline 1 avdp. pound & $=$ & $\underline{7000}$ & $\underline{350}$ & 291.6667 & $\underline{256}$ \\
\hline 1 milligram & $=$ & 0.01543236 & 0.0007716179 & 0.0006430149 & 0.0005643834 \\
\hline $1 \mathrm{gram}$ & $=$ & 15.43236 & 0.7716179 & 0.6430149 & 0.5643834 \\
\hline 1 kilogram & $=$ & 15432.36 & 771.6179 & 643.0149 & 564.3834 \\
\hline
\end{tabular}


Handbook 133, Checking the Net Contents of Packaged Goods, (2015)

\begin{tabular}{|c|c|c|c|c|c|}
\hline Units & & $\begin{array}{l}\text { Apothecaries } \\
\text { Drams }\end{array}$ & Avoirdupois Ounces & $\begin{array}{l}\text { Apothecaries or } \\
\text { Troy Ounces }\end{array}$ & $\begin{array}{c}\text { Apothecaries or Troy } \\
\text { Pounds }\end{array}$ \\
\hline 1 grain & $=$ & 0.01666667 & 0.002285714 & 0.002083333 & 0.0001736111 \\
\hline 1 apoth. scruple & $=$ & 0.3333333 & 0.04571429 & 0.04166667 & 0.003472222 \\
\hline 1 pennyweight & $=$ & $\underline{0.4}$ & 0.05485714 & $\underline{0.05}$ & 0.004166667 \\
\hline 1 avdp. dram & $=$ & 0.4557292 & $\underline{0.0625}$ & 0.5696615 & 0.004747179 \\
\hline 1 apoth. dram & $=$ & $\underline{1}$ & 0.1371429 & $\underline{0.125}$ & 0.01041667 \\
\hline 1 avdp. ounce & $=$ & 7.291667 & $\underline{1}$ & 0.9114583 & 0.07595486 \\
\hline $\begin{array}{l}1 \text { apoth. or } \\
\text { troy ounce }\end{array}$ & $=$ & $\underline{8}$ & 1.097143 & $\underline{1}$ & 0.083333333 \\
\hline $\begin{array}{l}1 \text { apoth. or } \\
\text { troy pound }\end{array}$ & $=$ & $\underline{96}$ & 13.16571 & $\underline{12}$ & $\underline{1}$ \\
\hline 1 avdp. pound & $=$ & 116.6667 & $\underline{16}$ & 14.58333 & 1.215278 \\
\hline 1 milligram & $=$ & 0.0002572060 & 0.00003527396 & 0.00003215075 & 0.000002679229 \\
\hline 1 gram & $=$ & 0.2572060 & 0.03527396 & 0.03215075 & 0.002679229 \\
\hline 1 kilogram & $=$ & 257.2060 & 35.27396 & 32.15075 & 2.679229 \\
\hline
\end{tabular}




\begin{tabular}{|c|c|c|c|c|c|}
\hline Units & & $\begin{array}{l}\text { Avoirdupois } \\
\text { Pounds }\end{array}$ & Milligrams & Grams & Kilograms \\
\hline 1 grain & $=$ & 0.0001428571 & $\underline{64.79891}$ & $\underline{0.06479891}$ & $\underline{0.00006479891}$ \\
\hline 1 apoth. scruple & $=$ & 0.002857143 & $\underline{1295.9782}$ & $\underline{1.2959782}$ & $\underline{0.0012959782}$ \\
\hline 1 pennyweight & $=$ & 0.003428571 & $\underline{1555.17384}$ & $\underline{1.55517384}$ & $\underline{0.00155517384}$ \\
\hline 1 avdp. dram & $=$ & 0.00390625 & $\underline{1771.8451953125}$ & $\underline{1.7718451953125}$ & $\underline{0.0017718451953125}$ \\
\hline 1 apoth. dram & $=$ & 0.008571429 & $\underline{3887.9346}$ & $\underline{3.8879346}$ & $\underline{0.0038879346}$ \\
\hline 1 avdp. ounce & $=$ & $\underline{0.0625}$ & $\underline{28349.523125}$ & $\underline{28.349523125}$ & $\underline{0.028349523125}$ \\
\hline $\begin{array}{l}1 \text { apoth. or troy } \\
\text { ounce }\end{array}$ & $=$ & 0.06857143 & $\underline{31103.4768}$ & $\underline{31.1034768}$ & $\underline{0.0311034768}$ \\
\hline $\begin{array}{l}1 \text { apoth. or troy } \\
\text { pound }\end{array}$ & $=$ & 0.8228571 & $\underline{373241.7216}$ & $\underline{373.2417216}$ & $\underline{0.3732417216}$ \\
\hline 1 avdp. pound & $=$ & $\underline{1}$ & $\underline{453592.3737}$ & $\underline{453.59237}$ & $\underline{0.45359237}$ \\
\hline 1 milligram & $=$ & 0.000002204623 & $\underline{1}$ & $\underline{0.001}$ & $\underline{0.000001}$ \\
\hline 1 gram & $=$ & 0.002204623 & $\underline{1000}$ & $\underline{1}$ & $\underline{0.001}$ \\
\hline 1 kilogram & $=$ & 2.204623 & $\underline{1000000}$ & $\underline{1000}$ & $\underline{1}$ \\
\hline
\end{tabular}

\section{Section 5. Tables of Equivalents}

In these tables it is necessary to differentiate between the "international foot" and the "survey foot." Therefore, the survey foot is underlined.

When the name of a unit is enclosed in brackets (thus, [1 hand] . . . ), this indicates (1) that the unit is not in general current use in the United States, or (2) that the unit is believed to be based on "custom and usage" rather than on formal authoritative definition.

Equivalents involving decimals are, in most instances, rounded off to the third decimal place except where they are exact, in which cases these exact equivalents are so designated. The equivalents of the imprecise units "tablespoon" and "teaspoon" are rounded to the nearest milliliter. 


\begin{tabular}{|c|c|}
\hline \multicolumn{2}{|c|}{ Units of Length } \\
\hline angstrom $(\AA)^{11}$ & $\begin{array}{l}0.1 \text { nanometer (exactly) } \\
0.0001 \text { micrometer (exactly) } \\
0.0000001 \text { millimeter (exactly) } \\
0.000000004 \text { inch }\end{array}$ \\
\hline 1 cable's length & $\begin{array}{l}120 \text { fathoms (exactly) } \\
720 \text { feet (exactly) } \\
219 \text { meters }\end{array}$ \\
\hline 1 centimeter $(\mathrm{cm})$ & 0.3937 inch \\
\hline $\begin{array}{l}1 \text { chain (ch) } \\
\text { (Gunter's or surveyors) }\end{array}$ & $\begin{array}{l}66 \text { feet (exactly) } \\
20.1168 \text { meters }\end{array}$ \\
\hline 1 decimeter $(\mathrm{dm})$ & 3.937 inches \\
\hline 1 dekameter (dam) & 32.808 feet \\
\hline 1 fathom & $\begin{array}{l}6 \text { feet (exactly) } \\
1.8288 \text { meters }\end{array}$ \\
\hline $1 \mathrm{foot}(\mathrm{ft})$ & 0.3048 meter (exactly) \\
\hline 1 furlong (fur) & $\begin{array}{l}10 \text { chains (surveyors) (exactly) } \\
660 \text { feet (exactly) } \\
1 / 8 \text { U.S. statute mile (exactly) } \\
201.168 \text { meters }\end{array}$ \\
\hline [1 hand] & 4 inches \\
\hline 1 inch (in) & 2.54 centimeters (exactly) \\
\hline 1 kilometer $(\mathrm{km})$ & 0.621 mile \\
\hline 1 league (land) & $\begin{array}{l}3 \text { U.S. statute miles (exactly) } \\
4.828 \text { kilometers }\end{array}$ \\
\hline 1 link (Ii) (Gunter's or surveyors) & $\begin{array}{l}0.66 \text { foot (exactly) } \\
0.201168 \text { meter }\end{array}$ \\
\hline 1 meter $(\mathrm{m})$ & $\begin{array}{l}39.37 \text { inches } \\
1.094 \text { yards }\end{array}$ \\
\hline 1 micrometer & $\begin{array}{l}0.001 \text { millimeter (exactly) } \\
0.00003937 \text { inch }\end{array}$ \\
\hline $1 \mathrm{mil}$ & $\begin{array}{l}0.001 \text { inch (exactly) } \\
0.0254 \text { millimeter (exactly) }\end{array}$ \\
\hline 1 mile (mi) (U.S. statute) ${ }^{12}$ & $\begin{array}{l}5280 \text { feet survey (exactly) } \\
1.609 \text { kilometers }\end{array}$ \\
\hline 1 mile (mi) (international) & 5280 feet international (exactly) \\
\hline 1 mile (mi) (international nautical) $)^{13}$ & 1.852 kilometers (exactly) \\
\hline
\end{tabular}

${ }^{11}$ The angstrom is basically defined as $10^{-10}$ meter.

${ }^{12}$ The term "statute mile" originated with Q ueen Elizabeth I who changed the definition of the mile from the Roman mile of 5000 feet to the statute mile of 5280 feet. The international mile and the U.S. statute mile differ by about three millimeters although both are defined as being equal to 5280 feet. The international mile is based on the international foot ( 0.3048 meter) whereas the U.S. statute mile is based on the survey foot (1200/3937 meter). 


\begin{tabular}{|l|l||}
\hline \multicolumn{2}{|c|}{ Units of Length } \\
\hline \hline \multirow{2}{*}{1 millimeter $(\mathrm{mm})$} & 1.151 survey miles \\
\hline 1 nanometer $(\mathrm{nm})$ & 0.03937 inch \\
& 0.001 meter (exactly) \\
\hline \multirow{3}{*}{1 Point (typography) } & 0.00000003937 inch \\
& 0.013837 inch (exactly) \\
\hline \multirow{2}{*}{ rod $(\mathrm{rd})$, pole, or perch } & $1 / 72$ inch (approximately) \\
& 0.351 millimeter \\
\hline 1 yard $(\mathrm{yd})$ & $161 / 2$ feet (exactly) \\
\hline
\end{tabular}

\begin{tabular}{|l|l||}
\hline \multicolumn{2}{|c|}{ Units of Area } \\
\hline \hline 1 acre ${ }^{14}$ & $\begin{array}{l}43560 \text { square feet (exactly) } \\
0.405 \text { hectare }\end{array}$ \\
\hline 1 are & $\begin{array}{l}119.599 \text { square yards } \\
0.025 \text { acre }\end{array}$ \\
\hline 1 hectare & 2.471 acres \\
\hline 1 square $($ building $)]$ & 100 square feet \\
\hline 1 square centimeter $\left(\mathrm{cm}^{2}\right)$ & 0.155 square inch \\
\hline 1 square decimeter $\left(\mathrm{dm}^{2}\right)$ & 15.500 square inches \\
\hline 1 square foot $\left(\mathrm{ft}^{2}\right)$ & 929.030 square centimeters \\
\hline 1 square inch $\left(\mathrm{in}^{2}\right)$ & 6.4516 square centimeters (exactly) \\
\hline 1 square kilometer $\left(\mathrm{km}^{2}\right)$ & 247.104 acres \\
\hline 1 square meter $\left(\mathrm{m}^{2}\right)$ & 0.386 square mile \\
\hline 1 square mile $\left(\mathrm{mi}^{2}\right)$ & 1.196 square yards \\
\hline 1 square millimeter $\left(\mathrm{mm}^{2}\right)$ & 10.764 square feet \\
\hline 1 square rod $\left(\mathrm{rd}^{2}\right), \mathrm{sq} \mathrm{pole}$ or sq perch & 258.999 hectares \\
\hline 1 square yard $\left(\mathrm{yd}^{2}\right)$ & 0.002 square inch \\
\hline
\end{tabular}

\footnotetext{
${ }^{13}$ The international nautical mile of 1852 meters (6076.115 49 feet) was adopted effective July 1, 1954, for use in the U nited States. The value formerly used in the U nited States was 6080.20 feet $=1$ nautical (geographical or sea) mile.

${ }^{14}$ The question is often asked as to the length of a side of an acre of ground. A $n$ acre is a unit of area containing 43560 square feet. It is not necessarily square, or even rectangular. B ut, if it is square, then the length of a side is equal to $\sqrt{43560 \mathrm{ft}^{2}}=208.710 \mathrm{ft}$ (not exact).
} 


\begin{tabular}{|c|c|}
\hline \multicolumn{2}{|c|}{ Units of Capacity or Volume } \\
\hline 1 barrel (bbl), liquid & 31 to 42 gallons $^{15}$ \\
\hline $\begin{array}{l}1 \text { barrel }(\mathrm{bbl}) \text {, standard for fruits, } \\
\text { vegetables, and other dry } \\
\text { commodities, except cranberries }\end{array}$ & $\begin{array}{l}7056 \text { cubic inches } \\
105 \text { dry quarts } \\
3.281 \text { bushels, struck measure }\end{array}$ \\
\hline 1 barrel (bbl), standard, cranberry & $\begin{array}{l}5826 \text { cubic inches } \\
86^{45} / 64 \text { dry quarts } \\
2.709 \text { bushels, struck measure }\end{array}$ \\
\hline 1 bushel (bu) (U.S.) struck measure & $\begin{array}{l}2150.42 \text { cubic inches (exactly) } \\
35.238 \text { liters }\end{array}$ \\
\hline [1 bushel, heaped (U.S.)] & $\begin{array}{l}2747.715 \text { cubic inches } \\
1.278 \text { bushels, struck measure }{ }^{16}\end{array}$ \\
\hline $\begin{array}{l}\text { [1 bushel (bu) (B ritish Imperial) } \\
\text { (struck measure)] }\end{array}$ & $\begin{array}{l}\text { 1.032 U.S. bushels, struck measure } \\
2219.36 \text { cubic inches }\end{array}$ \\
\hline 1 cord (cd) (firewood) & 128 cubic feet (exactly) \\
\hline 1 cubic centimeter $\left(\mathrm{cm}^{3}\right)$ & 0.061 cubic inch \\
\hline 1 cubic decimeter $\left(\mathrm{dm}^{3}\right)$ & 61.024 cubic inches \\
\hline 1 cubic foot $\left(\mathrm{ft}^{3}\right)$ & $\begin{array}{l}7.481 \text { gallons } \\
28.316 \text { cubic decimeters }\end{array}$ \\
\hline 1 cubic inch $\left(\mathrm{in}^{3}\right)$ & $\begin{array}{l}0.554 \text { fluid ounce } \\
4.433 \text { fluid drams } \\
16.387 \text { cubic centimeters }\end{array}$ \\
\hline 1 cubic meter $\left(\mathrm{m}^{3}\right)$ & 1.308 cubic yards \\
\hline 1 cubic yard $\left(\mathrm{yd}^{3}\right)$ & 0.765 cubic meter \\
\hline 1 cup, measuring & $\begin{array}{l}8 \text { fluid ounces (exactly) } \\
237 \text { milliliters } \\
1 / 2 \text { liquid pint (exactly) }\end{array}$ \\
\hline 1 dekaliter (daL) & $\begin{array}{l}2.642 \text { gallons } \\
1.135 \text { pecks }\end{array}$ \\
\hline $\begin{array}{l}1 \text { dram, fluid (or liquid) (fl dr) } \\
\text { or } f 3 \text { (U.S.) }\end{array}$ & $\begin{array}{l}1 / 8 \text { fluid ounce (exactly) } \\
0.226 \text { cubic inch } \\
3.697 \text { milliliters } \\
1.041 \text { B ritish fluid drachms }\end{array}$ \\
\hline [1 drachm, fluid (fl dr) (B ritish)] & $\begin{array}{l}0.961 \text { U.S. fluid dram } \\
0.217 \text { cubic inch } \\
3.552 \text { milliliters }\end{array}$ \\
\hline 1 gallon (gal) (U.S.) & $\begin{array}{l}231 \text { cubic inches (exactly) } \\
3.785 \text { liters }\end{array}$ \\
\hline
\end{tabular}

${ }^{15}$ There are a variety of "barrels" established by law or usage. For example, federal taxes on fermented liquors are based on a barrel of 31 gallons; many state laws fix the "barrel for liquids" as $31 \frac{1}{2}$ gallons; one state fixes a 36-gallon barrel for cistern measurement; federal law recognizes a 40-gallon barrel for "proof spirits;" by custom, 42 gallons comprise a barrel of crude oil or petroleum products for statistical purposes, and this equivalent is recognized "for liquids" by four states.

${ }^{16}$ Frequently recognized as $1 \frac{1 / 4}{4}$ bushels, struck measure. 


\begin{tabular}{|c|c|}
\hline \multicolumn{2}{|c|}{ Units of Capacity or Volume } \\
\hline & $\begin{array}{l}0.833 \text { B ritish gallon } \\
128 \text { U.S. fluid ounces (exactly) }\end{array}$ \\
\hline [1 gallon (gal) (B ritish Imperial)] & $\begin{array}{l}277.42 \text { cubic inches } \\
1.201 \text { U.S. gallons } \\
4.546 \text { liters } \\
160 \text { B ritish fluid ounces (exactly) }\end{array}$ \\
\hline 1 gill (gi) & $\begin{array}{l}7.219 \text { cubic inches } \\
4 \text { fluid ounces (exactly) } \\
0.118 \text { liter }\end{array}$ \\
\hline 1 hectoliter $(\mathrm{hL})$ & $\begin{array}{l}26.418 \text { gallons } \\
2.838 \text { bushels }\end{array}$ \\
\hline 1 liter ( 1 cubic decimeter exactly) & $\begin{array}{l}1.057 \text { liquid quarts } \\
0.908 \text { dry quart } \\
61.025 \text { cubic inches }\end{array}$ \\
\hline 1 milliliter (mL) & $\begin{array}{l}0.271 \text { fluid dram } \\
16.231 \text { minims } \\
0.061 \text { cubic inch }\end{array}$ \\
\hline $\begin{array}{l}1 \text { ounce, fluid (or liquid) (fl oz) } \\
\text { or } f \xi \text { ) (U.S.) }\end{array}$ & $\begin{array}{l}1.805 \text { cubic inches } \\
29.573 \text { milliliters } \\
1.041 \text { B ritish fluid ounces }\end{array}$ \\
\hline [1 ounce, fluid (floz) (B ritish)] & $\begin{array}{l}0.961 \text { U.S. fluid ounce } \\
1.734 \text { cubic inches } \\
28.412 \text { milliliters }\end{array}$ \\
\hline 1 peck (pk) & 8.810 liters \\
\hline 1 pint (pt), dry & $\begin{array}{l}33.600 \text { cubic inches } \\
0.551 \text { liter }\end{array}$ \\
\hline 1 pint (pt), liquid & $\begin{array}{l}28.875 \text { cubic inches (exactly } \\
0.473 \text { liter }\end{array}$ \\
\hline 1 quart (qt), dry (U.S.) & $\begin{array}{l}67.201 \text { cubic inches } \\
1.101 \text { liters } \\
0.969 \text { B ritish quart }\end{array}$ \\
\hline 1 quart (qt), liquid (U.S.) & $\begin{array}{l}57.75 \text { cubic inches (exactly) } \\
0.946 \text { liter } \\
0.833 \text { B ritish quart }\end{array}$ \\
\hline [1 quart (qt) (B ritish)] & $\begin{array}{l}69.354 \text { cubic inches } \\
1.032 \text { U.S. dry quarts } \\
1.201 \text { U.S. liquid quarts }\end{array}$ \\
\hline 1 tablespoon, measuring & $\begin{array}{l}3 \text { teaspoons (exactly) } \\
15 \text { milliliters } \\
4 \text { fluid drams } \\
1 / 2 \text { fluid ounce (exactly) }\end{array}$ \\
\hline
\end{tabular}




\begin{tabular}{|l|l|}
\hline \multicolumn{2}{|c|}{ Units of Capacity or Volume } \\
\hline \hline \multirow{3}{*}{1 teaspoon, measuring } & $1 / 3$ tablespoon (exactly) \\
& 5 milliliters \\
& $1 \frac{1}{3}$ fluid drams ${ }^{17}$ \\
\hline 1 water ton (E nglish) & 270.91 U.S. gallons \\
& 224 B ritish Imperial gallons (exactly) \\
\hline
\end{tabular}

\begin{tabular}{||l|l|}
\hline \multicolumn{2}{|c|}{ Units of Mass } \\
\hline \hline 1 assay ton ${ }^{18}$ (AT) & 29.167 grams \\
\hline 1 carat (c) & $\begin{array}{l}200 \text { milligrams (exactly) } \\
3.086 \text { grains }\end{array}$ \\
\hline 1 dram apothecaries (dr ap or 3$)$ & 60 grains (exactly) \\
& 3.888 grams \\
\hline 1 dram avoirdupois (dr avdp) & $27^{11} / 32$ (=27.344) grains \\
& 1.772 grams \\
\hline 1 gamma $(\gamma)$ & 1 microgram (exactly) \\
\hline 1 grain & 64.798 91 milligrams (exactly) \\
\hline 1 gram (g) & 15.432 grains \\
& 0.035 ounce, avoirdupois \\
\hline 1 hundredweight, gross or long ${ }^{19}$ & 112 pounds (exactly) \\
(gross cwt) & 50.802 kilograms \\
\hline 1 hundredweight, gross or short & 100 pounds (exactly) \\
\hline (cwt or net cwt) & 45.359 kilograms \\
\hline 1 kilogram (kg) & 2.205 pounds \\
\hline 1 microgram ( $\mu g$ ) [the G reek letter mu & 0.000 o01 gram (exactly) \\
\hline in combination with the letter g] & \\
\hline 1 milligram (mg) & 0.015 grain \\
\hline 1 ounce, avoirdupois (oz avdp) & 437.5 grains (exactly) \\
& 0.911 troy or apothecaries ounce \\
28.350 grams \\
\hline
\end{tabular}

\footnotetext{
${ }^{17}$ The equivalent " 1 teaspoon $=1 \frac{1}{3}$ fluid drams" has been found by the Bureau to correspond more closely with the actual capacities of "measuring" and silver teaspoons than the equivalent " 1 teaspoon $=1$ fluid dram," which is given by a number of dictionaries.

${ }^{18} \mathrm{U}$ sed in assaying. The assay ton bears the same relation to the milligram that a ton of 2000 pounds avoirdupois bears to the ounce troy; hence the mass in milligrams of precious metal obtained from one assay ton of ore gives directly the number of troy ounces to the net ton.

${ }^{19}$ The gross or long ton and hundredweight are used commercially in the U nited States to only a very limited extent, usually in restricted industrial fields. The units are the same as the B ritish "ton" and "hundredweight."
} 


\begin{tabular}{||l|l||}
\hline \multicolumn{2}{|c||}{ Units of Mass } \\
\hline \hline 1 ounce, troy or apothecaries & 480 grains (exactly) \\
(oz t or oz ap or 3 ) & 1.097 avoirdupois ounces \\
\hline 1 pennyweight (dwt) & 31.103 grams \\
\hline 1 point & 1.555 grams \\
\hline \multirow{3}{*}{1 pound, avoirdupois (lb avdp) } & 0.01 carat \\
& 2 milligrams \\
\hline \multirow{2}{*}{1 pound, troy or apothecaries } & 7000 grains (exactly) \\
(Ib t or lb ap) & 1.215 troy or apothecaries pounds \\
\hline \multirow{2}{*}{1 scruple (s ap or $\ni)$} & 453.592 37 grams (exactly) \\
\hline \multirow{3}{*}{1 ton, gross or long ${ }^{20}$} & 5760 grains (exactly) \\
& 0.823 avoirdupois pound \\
\hline \multirow{2}{*}{1 ton, metric (t) } & 373.242 grams \\
\hline \multirow{2}{*}{1 ton, net or short (tn) ${ }^{21}$} & 20 grains (exactly) \\
& 1.296 grams \\
\hline \hline
\end{tabular}

${ }^{20}$ The gross or long ton and hundredweight are used commercially in the U nited States to a limited extent only, usually in restricted industrial fields. These units are the same as the B ritish "ton" and "hundredweight."

${ }^{21}$ As of J anuary 1, 2014, "tn" is the required abbreviation for a short ton. Devices manufactured between January 1, 2008, and December 31, 2013, may use an abbreviation other than "tn" to specify short ton. This provision is a NIST Handbook 44, "Specifications, Tolerances, and Other Technical Requirements for Weighing and M easuring Devices" in A ppendix C. General Table of U nits of M easurement. 
Handbook 133, Checking the Net Contents of Packaged Goods, (2015)

THIS PAGE INTENTIONALLY LEFT BLANK 


\section{Appendix F. Glossary}

\section{A}

allowable difference. The amount, by which the actual quantity in the package may differ from the declared quantity. Pressed and blown tumblers and stemware labeled by count and capacity are assigned an allowable difference in capacity. This is also called a tolerance.

audit testing. Preliminary tests designed to quickly identify potential noncompliance units.

average. The sum of a number of individual measurement values divided by the number of values. For example, the sum of the individual weights of 12 packages divided by 12 would be the average weight of those packages.

average error. The sum of the individual "package errors" (defined) (considering their arithmetic sign) divided by the number of packages comprising the sample.

average requirement. A requirement that the average net quantity of contents of packages in a "Iot" equals the net quantity of contents printed on the label.

average tare. The sum of the weights of individual package containers (or wrappers, etc.) divided by the number of containers or wrappers weighed.

\section{B}

berry baskets and boxes. Disposable containers in capacities of 1 dry quart or less for berries and small fruits. See Section 4.46. in NIST Handbook 44.

\section{C}

Category A (Category B). A set of sampling plans provided in this handbook to use in checking packages that must (except when exempted) meet the "average requirement" (defined).

chamois. A natural leat

her made from skins of sheep and lambs that have been oil-tanned.

combination quantity declarations. A package label that contains the count of items in the package as well as one or more of the following: weight, measure, or size.

compliance testing. Determining package conformance using specified legal requirements.

\section{D}

decision criteria. The rules for deciding whether or not a lot conforms to package requirements based on the results of checking the packages in the sample.

delivery. A quantity of identically labeled product received at one time by a buyer. 
dimensionless units. The integers in terms of which the official records package errors. The dimensionless units must be multiplied by the "unit of measure" to obtain package errors in terms of weight, length, etc.

division, value of (d). The value of the scale division, expressed in units of mass, is the smallest subdivision of the scale for analog indication or the difference between two consecutively indicated or printed values for digital indication or printing. See NIST Handbook 44.

drained weight. The weight of solid or semisolid product representing the contents of a package obtained after a prescribed method for removal of the liquid has been employed.

dry measure. Rigid containers designed for general and repeated use in the volume measurement of particulate solids. See Section 4.45. D ry M easures in NIST Handbook 44.

dry pet food. All extruded dog and cat foods and baked treats packaged in K raft paper bags and cardboard boxes that have a moisture content of $13 \%$ or less at the time of packaging.

dry tare. See UNUSED DRY TARE.

$\mathbf{E}$

error. See PACKAGE ERROR.

G

gravimetric test procedure. A n analytical procedure that involves measurement by mass or weight.

gross weight. The weight of the package including contents, packing material, labels.

$\mathbf{H}$

headspace. The container volume not occupied by product.

I

U.S. customary units. Units based upon the yard, gallon, and the pound commonly used in the United States of A merica. Some of these units have the same name as similar units in the United Kingdom (B ritish, English, or Imperial units), but they are not necessarily equal to them.

initial tare sample. The first packages (either two or five) selected from the sample to be opened for tare determination in the tare procedure. Depending upon the variability of these individual tare weights as compared with the variability of the net contents, this initial tare sample may be sufficient or more packages may be needed to determine the tare.

inspection lot. The collection of identically labeled (random packages, in some cases, are exempt from identity and labeled quantity when determining the inspection lot) packages available for inspection at one time. This collection will pass or fail as a whole based on the results of tests on a sample drawn from this collection. 


\section{$\mathbf{L}$}

label. A ny written, printed, or graphic matter affixed to, applied to, attached to, blown into, formed, molded into, embossed on, or appearing upon or adjacent to a consumer commodity or a package containing any consumer commodity, for purposes of branding, identifying, or giving any information with respect to the commodity or to the contents of the package, except that an inspector's tag or other non-promotional matter affixed to or appearing upon a consumer commodity is not a label. See Section 2.5 in the U niform Packaging and Labeling Regulation in NIST Handbook 130.

linear measures. Rulers and Tape M easures.

location of test. The place where the package will be examined. This is broadly defined as one of three general locations: (1) where the commodity was packaged, (2) a warehouse or storage location, or (3) a retail outlet.

\section{lot. See INSPECTION LOT.}

lot code. A series of identifying numbers and/or letters on the outside of a package designed to provide information such as the date and location of packaging or the expiration date.

lot size. The number of packages in the "inspection lot".

\section{M}

\section{MAV. See MAXIMUM ALLOWABLE VARIATION}

maximum allowable variation (MAV). A deficiency in the weight, measure, or count of an individual package beyond which the deficiency is considered to be an "unreasonable error". The number of packages with deficiencies that are greater than the M AV is controlled by the sampling procedure.

measure containers. Containers whose capacities are used to determine quantity. They are of two basic types: (a) retail and (b) prepackaged. Retail containers are packaged at the time of retail sale, and prepackaged containers are packaged in advance of sale. An example of a prepackaged measure container is an ice cream package.

metric or SI units. U nits of the International System of U nits as established in 1960 by the General Conference on W eights and M easures and interpreted or modified for the U nited States by the Secretary of Commerce. (See NIST Special Publication (SP) 811, "Guide for the U se of the International System of U nits (SI)" [http://www.nist.gov/pml/pubs/sp811/index.cfm] and SP 330, The International System of U nits (SI)" [http://www.nist.gov/pml/pubs/sp330/index.cfm].)

minus or plus errors. N egative or positive deviations from the labeled quantity of the actual package quantities as measured. See PACKAGE ERROR.

moisture allowance. That variation in weight of a packaged product permitted in order to account for loss of weight due to loss of moisture during good package distribution practices. For packaged goods subject to moisture loss, when the average net weight of a sample is found between the labeled weight and the boundary of the moisture allowance, the lot is said to be in a no-decision area. Further information is required to determine lot compliance or noncompliance. 
mulch. A ny product or material other than peat or peat moss for sale, or sold for primary use as a horticultural, above-ground dressing for decoration, moisture control, weed control, erosion control, temperature control, or other similar purposes.

\section{$\mathbf{N}$}

net quantity or net contents. That quantity of packaged product remaining after all necessary deductions for tare (defined) have been made.

nominal. A designated or theoretical size that may vary from the actual.

nominal gross weight. The sum of the nominal tare weight (defined) plus the declared or labeled weight (or other labeled quantity converted to a weight basis).

\section{$\mathbf{P}$}

package error. The difference between the actual net contents of an individual package as measured and the declared net contents on the package label; minus (-) for less than the label and plus (+) for more than the label.

packaged goods. Product or commodity put up in any manner in advance of sale suitable for either wholesale or retail sale.

petroleum products. Gasoline, diesel fuel, kerosene, or any product (whether or not such a product is actually derived from naturally occurring hydro-carbon mixtures known as "petroleum") commonly used in powering, lubricating, or idling engines or other devices, or labeled as fuel to power camping stoves or lights. Sewing machine lubricant, camping fuels, and synthetic motor oil are "petroleum products" for the purposes of this regulation. The following products are not "petroleum products": brake fluid, copier machine dispersant, antifreeze, cleaning solvents, and alcohol.

\section{plus errors. See MINUS OR PLUS ERRORS}

principal display panel or panels. Part(s) of a label that are designed to be displayed, presented, shown, or examined under normal and customary conditions of display and purchase. Wherever a principal display panel appears more than once on a package, all requirements pertaining to the "principal display panel" shall pertain to all such "principal display panels." See Section 2.7 in the U niform Packaging and L abeling Regulation in NIST Handbook 130.

production lot. The total collection of packages defined by the packager, usually consisting of those packages produced within a given unit of time and coded identically.

pycnometer. A container of known volume used to contain material for weighing so that the weight of a known volume may be determined for the material. If it is constructed, it is called a density cup. 


\section{$\mathbf{R}$}

random pack. The term "random package" shall be construed to mean a package that is one of a lot, shipment, or delivery of packages of the same consumer commodity with varying weights which means, packages of the same consumer commodity with no fixed pattern of weight.

random sampling. The process of selecting sample packages such that all packages under consideration have the same probability of being selected. A $n$ acceptable method of random selection is to use a table of random numbers.

range. The difference between the largest and the smallest of a set of measured values.

reasonable variation. An amount by which individual package net contents are allowed to vary from the labeled net contents. This term is found in most federal and state laws and regulations governing packaged goods. Reasonable variations from the labeled declaration are recognized for (1) unavoidable deviations in good manufacturing practice, and (2) loss or gain of moisture in good distribution practice.

rounding. The process of omitting some of the end digits of a numerical value and adjusting the last retained digit so that the resulting number is as near as possible to the original number.

\section{$\mathbf{S}$}

sample. A group of packages taken from a larger collection of packages and providing information that can be used to make a decision concerning the larger collection of packages or of the package production process. A sample provides a valid basis for decision only when it is a random sample (defined).

sample correction factor. The factor as computed is the ratio of the $97.5^{\text {th }}$ quantile of the student's t-distribution with ( $n-1)$ degrees of freedom and the square root of $n$ where $n$ is the sample size.

sample error limit (SEL). A statistical value computed by multiplying the sample standard deviation times the sample correction factor from Column 3 of Table 2-1. Category A - Sampling Plans for the appropriate sample size. The SEL value allows for the uncertainty between the average error of the sample and the average error of the inspection lot with an approximately $97.5 \%$ level of confidence.

sample size (n). The number of packages in a sample.

sampling plan. A specific plan that states the number of packages to be checked and the associated decision criteria.

scale tolerance. The official value fixing the limit of allowable error for weighing equipment as defined in NIST Handbook 44.

seat. (as in "seat diameter" or "seated capacity"). The projection or shoulder near the upper rim of a cup or container that is designed to serve as the support for a lid or cover.

seated capacity. The capacity of a cup, container, or bottle, as defined by the volume contained by them when the lid or a flat disc is inserted into the lid groove that is located inside and near the upper rim of the cup, container, or bottle.

SEL. See SAM PLE ERROR LIMIT. 
shipment. A quantity of identically labeled product (except for lot code) sent at one time to a single location.

slicker plate. A flat plate, usually of glass or clear plastic composition, used to determine the "level full" condition of a capacity (volumetric) measure.

standard deviation. A measure to describe the scatter of the individual package contents around the mean contents.

standard pack. That type of package in which a commodity is put up with identical labels and only in certain specific quantity sizes. Examples of goods so packed are canned, boxed, bottled and bagged foods, and over-the-counter drugs.

supplementary quantity declarations. The required quantity declaration may be supplemented by one or more declarations of weight, measure, or count, such declaration appearing other than on a principal display panel. Such supplemental statement of quantity of contents shall not include any terms qual ifying a unit of weight, measure, or count that tends to exaggerate the amount of commodity contained in the package (e.g., "giant" quart, "full" gallon, "when packed," "minimum," or words of similar import). See Section 6.12 in the Uniform Packaging and Labeling Regulation in NIST Handbook 130.

\section{$\mathbf{T}$}

tare sample. The packages or packaging material used to determine the average tare weight.

tare sample size. The number of packages or packaging material units used to determine the average tare weight.

tare weight. The weight of a container, wrapper, or other material that is deducted from the gross weight to obtain the net weight.

tolerance. A value fixing the limit of allowed departure from the labeled contents; usually presented as a plus (+) and minus (-) value.

\section{$\mathbf{U}$}

unit of measure. An increment of weight, length, or volume so that an inspector may record package errors in terms of small integers. (The package errors are actually the integers multiplied by the unit of measure.)

unreasonable errors. M inus package errors that exceed the MAV (defined). The number of unreasonable errors permitted in a sample is specified by the sampling plan.

unused dry tare. All unused packaging materials (including glue, labels, ties, etc.) that contain or enclose a product. It includes prizes, gifts, coupons, or decorations that are not part of the product.

used dry tare. Used tare material that has been air dried, or dried in some manner to simulate the unused tare weight. It includes all packaging materials that can be separated from the packaged product, either readily (e.g., by shaking) or by washing, scraping, ambient air drying, or other techniques involving more than "normal" household recovery procedures, but not including laboratory procedures like oven drying. L abels, wire closures, staples, prizes, decorations, and such are considered tare. It is not the same as "wet tare." See also "wet tare." 


\section{V}

volumetric measures. Standard measuring flasks, graduates, cylinders, for use in measuring volumes of liquids.

W

wet tare. U sed packaging materials when no effort is made to reconstruct unused tare weight by drying out the absorbent portion (if any) of the tare. 
Handbook 133, Checking the Net Contents of Packaged Goods (2015)

THIS PAGE INTENTIONALLY LEFT BLANK 


\section{Index}

A

Aerosol Containers .19

Allowable Difference ..........................................159

Assistance in Testing Operations ...........................6 Association of Official Seed Analyst (AOSA)...129, 133

Audit Testing. 159

Audits

Packages $L$ abeled by Count ....................................... 71

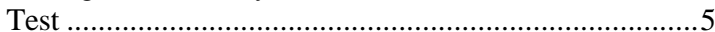

Average..................................................................159

Average Error ........................................................159

Average Requirement................... 159, See Package Requirement

Average Tare. .159

\section{B}

Baler Twine ..........................................................882

Berry Baskets and Boxes.....................................159

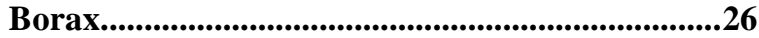

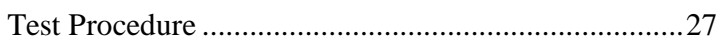

\section{C}

Category A (Category B). .159

Caulking Compounds. .49

Certification Requirements for Standards and Test Equipment . .7

Chamois $84,85,159$

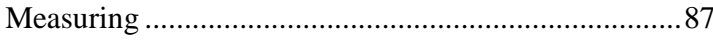

Sample Conditioning …................................................ 87

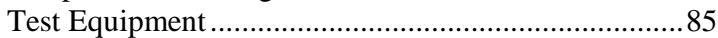

Test M ethods......................................................... 85

Test Procedure ................................................ 85, 87

Combination Quantity Declarations ...................159

Compliance Testing ..........................................159

Compressed Gas

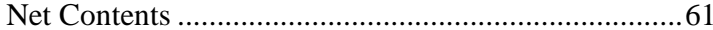

Test Equipment ..................................................... 62

Count $69,70,71,73$

Decision Criteria .159

Decreasing-Load Test.............................................12

Defoaming agent ..............................................35, 38

Delivery...

.159

Deviations Caused by Moisture Loss or Gain ... See Package Requirements
Dimensionless Units...... 16, 18, 21, 73, 82, 119, 120, 121, 122, 160

Division, value of (d) ..............................................160

Drained Weight................................................28, 160

Encased-in-Ice, I ce Glazed, or Frozen F oods .............. 29

Test Equipment ........................................................... 28

Test Procedure .................................................... 29

Dry Measure.......................................................160

Dry Pet Food ............................................................160

Dry Tare ..........................................................See Tare

\section{$\mathbf{E}$}

Error ..................................... See Packages, Error

Evaluating Results 32, 38, 41, 42, 49, 53, 55, 59, 61, 64, 67, 75, 79, 80, 82, 84, 87, 89

Compliance. 21

Fair Packaging and Labeling Act (FPLA).............6 Federal Agencies

B ureau of Alcohol and Tobacco Tax and Trade Bureau

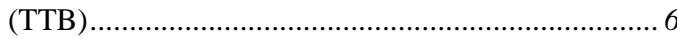
Environmental Protection A gency (EPA) ....................6 6

Federal Trade Commission (FTC) .............................. 6

Food and Drug A dministration (FDA ) ......................... 5

U.S. Department of A griculture (USDA) ..................... 5

U.S. Department of the Treasury ............................... 6

Federal Alcohol Administration Act .......................6

Firewood.............................................65, 66, 67

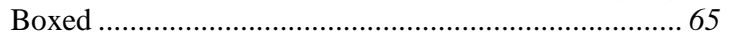

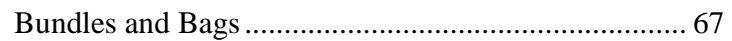

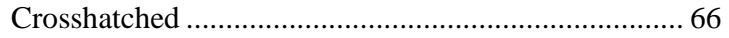

Evaulation of Results................................................ 67

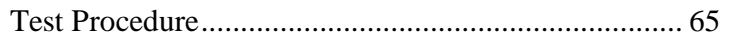

Flour .........................................................................4

Food, Drug, and Cosmetic Act (FDCA).................6

Forms ..............................................................117

Ice Glazed Package Report..................................... 125

Ice Glazed Package Report - Example...................... 126

Ice-Glazed Package W orksheet ............................... 123

Ice-Glazed Package W orksheet - Example ............... 124

Random Package Report ....................................... 119

Random Package R eport - Example ....................... 120

Standard Package Report....................................... 121

Standard Package Report - Example....................... 122

W orksheet for Determining the Free Liquid and $N$ et V olume of Oysters..................................... 127, 128

Frozen Foods ......................................................29

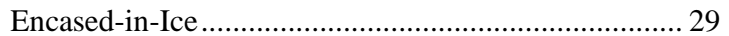

Ice Glazed..................................................... 29

Ice Glazed Package Report.................................... 125

Ice Glazed Package Report - Example..................... 126

Ice-Glazed Package W orksheet ............................... 123 
Ice-Glazed Package W orksheet - Example

124

\section{G}

General Tables of Units of Measurement 135

Glass Tumblers See Glassware

\section{Glassware}

Allowable Differences ................................................. 42

Blown GlasS ...................................................... 42

Pressed Glass ......................................................... 42

Stemware ............................................................... 42

Glossary ............................................................159

allowable difference...............................................159

audit testing.............................................................. 159

average

average error .......................................................... 159

average requirement..................................................159

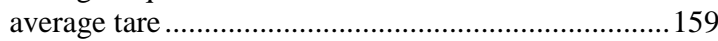

berry baskets and boxes ............................................159

Category A (Category B) ...........................................159

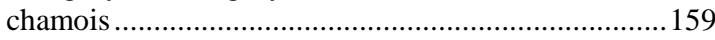

combination quantity declarations ..............................159

compliance testing ……............................................159

decision criteria.........................................................

delivery ............................................................. 159

dimensionless units .................................................160

division, value of (d) .........................................160

drained weight......................................................160

dry measure..........................................................160

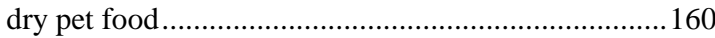

dry tare difference....................................................160

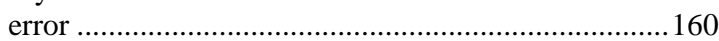

gravimetric test procedure ......................................160

gross weight......................................................... 160

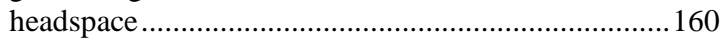

initial tare sample

inspection lot............................................................ 160

label ..............................................................161

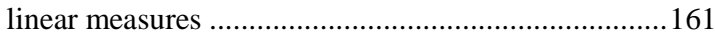

location of test..........................................................

lot 161

lot code ……........................................................

lot size..............................................................

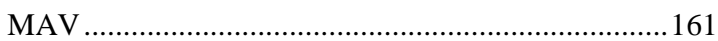

maximum allowable variation (M A V ) ........................161

measure containers.......................................................161

metric or SI units.....................................................

minus or plus errors ................................................... 161

moisture allowance ......................................................161

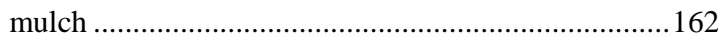

net quantity or net contents .......................................162

nominal ......................................................................162

nominal gross weight ............................................162

package error.........................................................162

packaged goods...........................................................162

petroleum products......................................................162

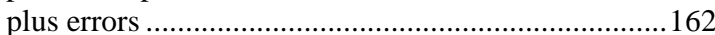

principal display panel or panels...............................162

production lot..........................................................162

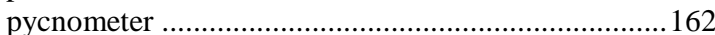

random pack............................................................ 163 random sampling ....................................................... 163

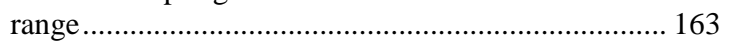

reasonable variation .................................................. 163

rounding .................................................................... 163

sample .......................................................... 163

sample correction factor ............................................ 163

sample error limit (SEL) .......................................... 163

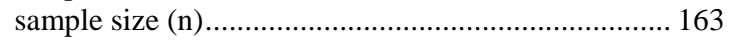

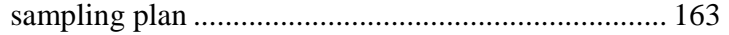

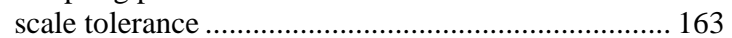

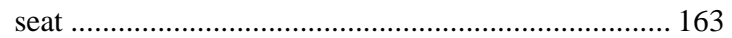

seated capacity...................................................... 163

SEL …................................................................ 163

shipment............................................................. 164

slicker plate ............................................................ 164

standard deviation........................................................... 164

standard pack ........................................................ 164

supplementary quantity declarations ......................... 164

tare sample ............................................................... 164

tare sample size ................................................. 164

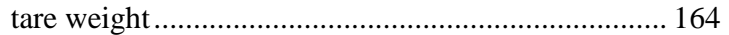

tolerance .................................................................... 164

U.S. customary units ............................................. 160

unit of measure ................................................. 164

unreasonable errors................................................. 164

unused dry tare ...................................................... 164

used dry tare .......................................................... 164

volumetric measures ............................................... 165

wet tare.......................................................... 165

Good Measurement Practices............................6, 10

Goods Labeled by Capacity ....................................41

Gravimetric Test Procedure ...................................160

B asic Test Procedure .................................................... 13

Checking the Net Contents of Packaged Goods ............ 9

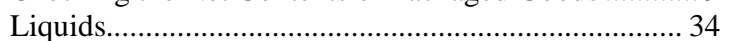

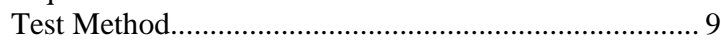

Gross Weight.................................................................160

\section{H}

Headspace............................................................160

Health and Safety........................................................6

I

\section{Ice Cream}

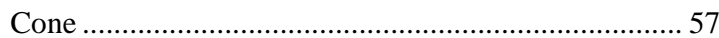

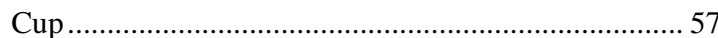

Displacement $V$ essel ...................................................... 56

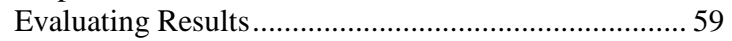

Ice Pop ..................................................... 57

Novelties ........................................................... 55, 57

Sandwich ............................................................. 57

Test Equipment ….................................................... 56

Test Procedure.............................................................. 57

Increasing-Load Test...............................................12

Individual Package Requirement .........See Package

Requirements

Initial Tare Sample ...................................................160

Inspection lot ............................................................161 
Inspection Lot ..14, 160, See Package Requirement

$\mathbf{L}$

Label . .161

Lacquers .43

Linear Measure, Area, Thickness, and Combinations of Quantities .69

Linear Measures .161

Location of Test 161

Lot See Inspection Lot

Lot Code .161

Lot Size . .161

\section{M}

MAV See Maximum Allowable Variation

Maximum Allowable Variation . .161 Maximum Allowable Variation (MAV) 3, 9, 14, 21, 24, 55, 67, 70, 71, 98, 100, See Package Requirements

Measure Containers .161

Measurement Standards and Test Equipment.6, 9, $28,34,43,49,56,59,62,70,76,80,82$

Metric Units ..........................................................161

Milk

Minus or Plus Errors .161

Model Inspection Forms See Forms

Moisture Allowance .161

A pplying ...4

Wet Tare

Moisture Allowances 22, 23

Moisture Loss or Gain. See Package Requirements

Mulch . .162

Mulch and Soils. . .53 Specifications. . .54

\section{$\mathbf{N}$}

Net Content 162 Compressed Gas Cylinders

Net Quantity. .162

Net Weight

Frozen Foods

29,31

Nominal 162

Nominal Gross Weight15, 20, 28, 37, 49, 59, 72, 73, 82,162

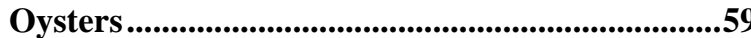

Evaluation of Results .................................................61

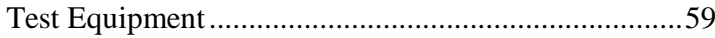

Test Procedure ...............................................................60

W orksheet for D etermining the F ree Liquid and N et V olume of Oysters
W orksheet for D etermining the F ree Liquid and $\mathrm{N}$ et V olume of Oysters-Example.....

\section{$\mathbf{P}$}

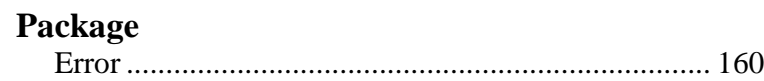

Package Checking Procedures....................................1

Point-of-pack ........................................................ 1

Retail ................................................................ 1

Wholesale

Package Requirements ................................................2

A verage Requirement............................................... 3

Deviations Caused by M oisture L oss or Gain ............... 3

Exceptions to the A verage........................................... 3

Exceptions to the Individual ...................................... 3

Individual Package R equirement................................... 3

Inspection Lot........................................................ 2

M aximum Allowable $\mathrm{V}$ ariation (M A V ) ........................ 3

M oisture L OSS or Gain ................................................... 3

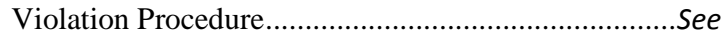

Packaged Goods.......................................................162

Packages

A erosol Containers ................................................ 19

Errors..................................20, 21, 22, 28, 55, 75, 162

Ice Glazed Package Report.................................. 125

Ice Glazed Package Report - Example...................... 126

Ice-Glazed Package W orksheet................................. 123

Ice-Glazed Package W orksheet - Example ................ 124

Labeled by Count ........................................................ 69

L abeled by Count of 50 Items or Fewer ....................... 69

$L$ abeled by Count of $M$ ore than 50 Items.............. 69, 70

L abeled by L inear or Square (A rea) M easure.............. 80

L abeled by V olume ..................................................... 33

L abeled with 50 Items or Fewer ................................ 69

M easure $\mathrm{N}$ et Contents ................................................ 17

Package R equirements................................................. 2

Random Package R eport ....................................... 119

Random Package Report - Example ....................... 120

Random Sample Selection......................................... 16

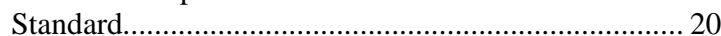

Standard Package Report....................................... 121

Standard Package R eport - Example.......................... 122

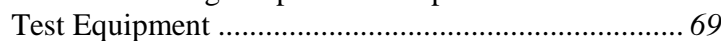

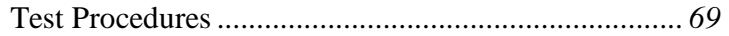

Uncompressed V olume .......................................... 51

V iolation Procedure .................................................. 72

Paint ...................................................43, 44, 46, 47, 49

Paper Plates and Sanitary Paper Products ........See Paper Products

Paper Products

Evaluation of Results................................................... 75

Paper Plates ............................................................ 74

Sanitary Paper Products............................................... 74

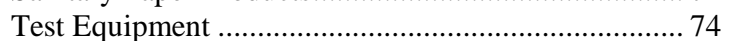

Test Procedure ......................................................... 74

Pasta Products ................................................23, 24

Peat Moss............................................................51

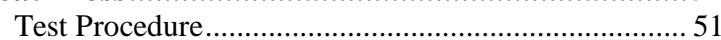

Pet Food...................................................4, 23, 160 
Petroleum Products .162

Plus Errors ........................See Minus or Plus Errors Point-of-pack1, See Package Checking Procedures

Point-of-sale.

Polyethylene Sheeting............................................75

A verage Thickness.................................................. 80

Individual Thickness ................................................... 80

Test Equipment......................................................... 76

Test Procedure .............................................................76

Pressed and Blown Glass Tumblers and Stemware

Pressed Glass..........................................See Glassware

Principal Display Panel or Panels ........................162

Product Testing................................................................2

Production Lot ..........................................................162

Pycnometer....................................................................162

\section{$\mathbf{R}$}

Random Number Tables ..........................................17

Random Pack. ..........................................................163

Random Sample Selection..........................................16

Random Sampling ..................................................163

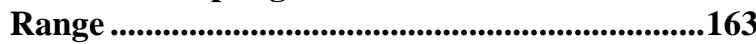

Reasonable variation ......................................................3

Reasonable Variation ...............................................163

Recordkeeping ............................................................15

Recording Data ........................................................ 15

Regulatory Agencies Responsible for Package

Regulations and Applicable Requirements ........5

Retail.................See Package Checking Procedures

Return to Zero

. .13

Rounding ......

.163

\section{S}

Safety ...................................... See Health and Safety

Sample 163

Correction Factor ................................................... 163

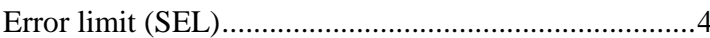

Error Limit (SEL). .................................................. 163

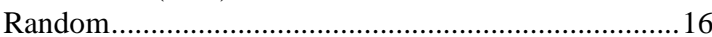

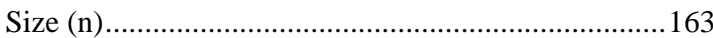

Tare ..................................................................

Sampling Plan......

$5,14,15,18,22,163$

Audit Test.

...5

Scale Tolerance

.163

Scales

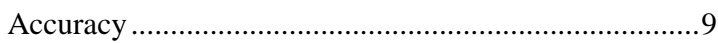

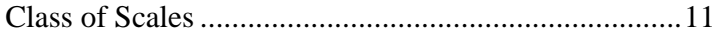

Decreasing-Load Test ................................................12

Gravimetric Test M ethod ............................................

Increasing-L oad Test ……......................................12

Return to Zero ........................................................ 13

Shift Test...............................................................12

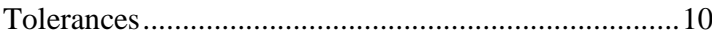

V erification .......................................................... 12

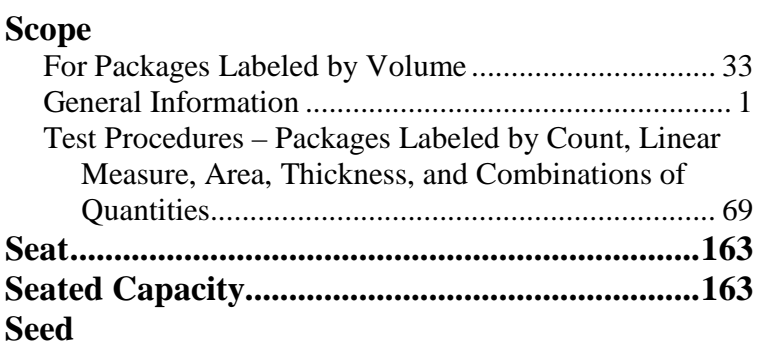

A OSA Rules for Testing Seeds - Section 12

M echanical Seed Count...................................... 133

A OSA Rules for Testing Seeds - Section 2

Preparation of W orking Samples........................ 129

A ssociation of Official Seed A nalyst (A OSA) .. 129, 133

Labeled by Count ......................................................... 88

SEL

See Sample:Error Limit (SEL)

Shift Test........................................................................12

Shipment......................................................................164

SI Units ........................................................................161

Slicker Plate .............................................................164

Special Test Requirements for Packages Labeled

by Linear or Square Measure (Area) ................75

Standard Deviation................................................164

Standard Pack...........................................................164

Stemware ................................................. See Glassware

Supplementary Quantity Declarations 164

\section{$\mathbf{T}$}

Tare

Determination of ................................................. 19

Dry Tare .................................................................. 160

Initial Tare Sample ................................................. 160

Procedure

A erosol Containers .................................................... 19

Determination of ............................................ 17, 18

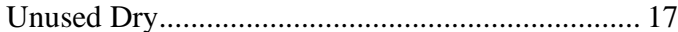

Used Dry.............................................................. 17

V acuum Packed C offee ......................................... 20

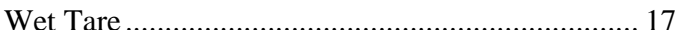

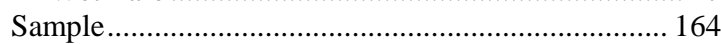

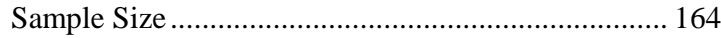

Unused Dry ................................................. 19, 164

Used Dry ..................................................... 18, 164

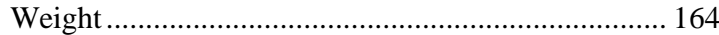

Wet

Test Equipment

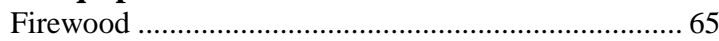

Linear or Square (area) M easure ............................... 80

Test Procedure

Baler Twine ...................................................................... 82

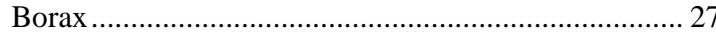

Chamois........................................................ 85

Cylinders L abeled by V olume............................................ 64

Cylinders L abeled By W eight .................................... 63

Drained Weight ........................................................ 29

Encased-in-Ice Product................................................ 30

Field (Retail) A uditing ............................................ 44

Goods Labeled by Capacity

V olumetric Test Procedure....................................... 41 
Gravimetric Test/Liquids ...................................... 34

Headspace Test ............................................................. 41

Ice Cream .............................................................. 57

Ice-Glazed Product................................................... 31

$M$ ayonnaise, Salad Dressing, and W ater Immiscible

Products with no Smooth Level Surface ..................40 40

Oils, Syrups, and other V iscous Liquids with a Smooth and Level Surface........................................................ 39

Packages $L$ abeled by V olume..................................... 33

Paint, L acquers, V arnish ......................................... 44

Polyethylene Sheeting............................................. 76

Pressed and B lown Glass Tumblers and Stemware......42

V olumetric Test

.. 38

Testing Viscous Materials

Caulking Compounds and Pastes................................49 49

Tolerance .........................................................164

Traceability ............................................................6

\section{U}

U.S. customary units.

.160

Uncompressed Volume Packages ..........................52

Evaluation of Results......

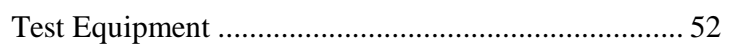

Test Procedure ............................................................... 52

Unit of Measure ...........................................42, 164

Unreasonable Errors .........................................164

V

Varnish ............................................................43

Volumetric measures ..........................................165

Volumetric Measures

Ice Cream ............................................................... 56

Volumetric Test Procedure

Goods L abeled by Capacity .................................... 41

Liquids............................................................. 33, 37

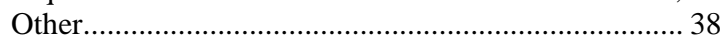

Packaged Firewood ............................................ 65

W

Wet Tare...........................................................165

Wholesale....... 1, See Package Checking Procedures 
Handbook 133, Checking the Net Contents of Packaged Goods (2015)

THIS PAGE INTENTIONALL LEFT BLANK 


\section{References}

2010 A OSA Rules for Testing Seeds, V olume 1 Section 2 and Section 12. A ssociation of Official Seed A nalyst (AOSA), Inc. 653 Constitution Avenue, NW, Washington, DC. Available at http://www.aosaseed.com

C. B rickenkamp, S. Hasko, and M. G. Natrella, Third Edition of NIST Handbook 133 - Checking the Net Contents of Packaged Goods, 1988.

L. Crown, D. Sefcik, and L. Warfield, Fourth Edition NIST Handbook 133 - Checking the Net Contents of Packaged Goods, 2014. A vailable at http://www.nist.gov/pml/wmd

T. B utcher, L. Crown, R. Harshman, and J. Williams, Specifications, Tolerances, and Other Technical Requirements for Weighing and Measuring Devices, National Institute of Standards and Technology Handbook 44, 2014. A vailable at http://www.nist.gov/pml/wmd.

L. Crown, D. Sefcik and L. W arfield, Uniform Laws and Regulations in the A reas of Legal M etrology and Engine Fuel Quality, National Institute of Standards and Technology Handbook 130, 2014. A vailable at http://www.nist.gov/pml/wmd

Compressed Gas A ssociation, Fourth Edition - Handbook of Compressed Gases, 1999. Compressed Gas Association, 14501 George Carter Way, Suite 103, Chantilly, Virginia 20151. A vailable at http://www.cganet.com

Compressed Gas Association - pamphlet P-1, "Safe Handling of Compressed Gases in Containers, Compressed Gas A ssociation, 4221 W al ney Road, $5^{\text {th }}$ Floor, Chantilly, V irginia 20151-2923.

A vailable at http://www.cganet.com

P. Cunniff, ed., Official Methods of A nalysis of the Association of Official A nalytical Chemists International, Nineteenth Edition, A ssociation of Official A nalytical Chemists, 481 North Frederick A venue, Suite 500, Gaithersburg, M aryland 20877, 2012. A vailable at http://www.aoac.org

Federal Test M ethod Standard 311 "Leather, M ethods of Sampling and Testing." (J anuary 15, 1969). U.S. General Services A dministration.

G. L. Harris, Specifications and Tolerances for Reference Standards and Field Standard Weights and M easures, 1. Specifications and Tolerances for Field Standard W eights ( $N$ ational Institute of Standards and Technology Class F), National Institute of Standards and Technology Handbook 105-1, 1990. A vailable at http://www.nist.gov/pml/wmd

G. L. Harris, Specifications and Tolerances for Reference Standards and Field Standard Weights and M easures; 2. Specifications and Tolerances for Field Standard M easuring Flasks, National Institute of Standards and Technology Handbook 105-2, U.S. Government Printing Office, W ashington, D.C., 1996. A vailable at http://www.nist.gov/pml/wmd 
G. L. Harris, Specifications and Tolerances for Reference Standards and Field Standard Weights and Measures, 5. Specifications and Tolerances for Field Standard Stopwatches, National Institute of Standards and Technology Handbook 105-5, 1997. A vailable at http://www.nist.gov/pml/wmd

G. L. Harris, Specifications and Tolerances for Reference Standards and Field Standard Weights and M easures, 6. Specifications and Tolerances for Thermometers, National Institute of Standards and Technology $\mathrm{H}$ andbook 105-6, 1997. A vailable at http://www.nist.gov/pml/wmd

M. W. J ensen and R. W. Smith, The Examination of W eighing Equipment, National Institute of Standards and Technology Handbook 94, U.S. Government Printing Office, W ashington, D.C., 1965.

G. D. L ee, Examination Procedure Outlines for Commercial Weighing and M easuring Devices, $N$ ational Institute of Standards and Technology Handbook 112, 2002.

Rand Corporation. A M illion Random Digits with 100,000 Normal Deviates, Glencoe, IL: The Free Press, 1955. The Rand Corporation, 1776 Main Street, P.O. Box 2138, Santa M onica, California 90401-3208. A vailable at http://www.rand.org/publications/classics/randomdigits

Standard M ethod of Test for Density of Plastics by the Density Gradient Technique, A STM D1505-10, 2010. A vailable at http://www.astm.org

Standard M ethod of Test for V olume of Processed Peat M aterials, ASTM D2978-03, 2010. A vailable at http://www.astm.org

Standard M ethod of Test for Y arn Number by the Skein M ethod, ASTM D1907-12, 2012. A vailable at http://www.astm.org

Standard Practice for Calibration of Laboratory V olumetric A pparatus, ASTM E542-01, 2012. A vailable at http://www.astm.org

Standard Specification for Glass Volumetric (Transfer) Pipets, ASTM E969-02, 2012. A vailable at http://www.astm.org

Standard Specification for Laboratory Glass Graduated Burets, ASTM E287-02, 2012. A vailable at http://www.astm.org

Standard Specification for Polyethylene Film and Sheeting, ASTM D2103-03, 2010. Available at http://www.astm.org

Standard Specification for Polyethylene Sheeting for Construction, Industrial, and Agricultural Applications, ASTM D 4397-10. A vailable at http://www.astm.org

U.S. Department of Defense M ilitary Standard, Sampling Procedures and Tables for Inspection by Attributes (M IL -STD-105 D), U.S. Government Printing Office, W ashington, DC, 1963.

B. Y ounglove and N. Olien. NBS Technical Note 1079 - Tables of Industrial Gas Container Contents and D ensity for Oxygen, Argon, Nitrogen, Helium, and Hydrogen, 1985. A vailable at http://www.nist.gov/pml/wmd 